DEMETRIO JACKSON DOS SANTOS

CARACTERIZAÇÃO DA RELAXAÇÃO POR COMPRESSÃO DE BORRACHA ACRÍLICA IRRADIADA

\author{
Tese apresentada à Escola \\ Politécnica da Universidade de \\ São Paulo para a obtenção do \\ Título de Doutor em Engenharia Mecânica
}

São Paulo 
DEMETRIO JACKSON DOS SANTOS

\title{
CARACTERIZAÇÃO DA RELAXAÇÃO POR COMPRESSÃO DE BORRACHA ACRÍLICA IRRADIADA
}

\author{
Tese apresentada à Escola \\ Politécnica da Universidade de \\ São Paulo para a obtenção do \\ Título de Doutor em Engenharia Mecânica
}
Área de concentração:
Engenharia Mecânica de Projeto de
Fabricação

Professor Orientador:

Prof. Dr. Gilmar Ferreira Batalha

\section{São Paulo}


Este exemplar foi revisado e alterado em relação à versão original, sob responsabilidade única do autor e com a anuência de seu orientador.

São Paulo, de março de 2011.

Assinatura do autor

Assinatura do orientador

FICHA CATALOGRÁFICA

Santos, Demetrio Jackson

Caracterização da relaxação por compressão de borracha acrílica irradiada / D.J. Santos. -- ed.rev. -- São Paulo, 2011. $158 \mathrm{p}$.

Tese (Doutorado) - Escola Politécnica da Universidade de São Paulo. Departamento de Engenharia Mecatrônica e de Sistemas Mecânicos.

1. Radiação ionizante 2. Resistência dos materiais 3. Bor racha I. Universidade de São Paulo. Escola Politécnica. Departamento de Engenharia Mecatrônica e de Sistemas Mecânicos II. t. 


\section{AGRADECIMENTOS}

Ao amigo e orientador Prof. Dr. Gilmar Ferreira Batalha, pelo constante apoio, compreensão e incentivo nesta jornada, feita por ele possível.

A minha esposa e filhas, Edileide de Carvalho dos Santos, Nicole de Carvalho dos Santos e Alanis Carvalho dos Santos pela compreensão, intenso apoio nos momentos em que estive ausente e incentivo nos momentos em que cogitei desistir.

À minha mãe e irmã, Deolinda Doce dos Santos e Débora Doce dos Santos por tudo o que sempre me ensinaram.

À Hermínia Hesse pelos ensinamentos e pela coragem de viver o exemplo não como a melhor forma de ensinar, mas sim a única.

Ao amigo Guilherme Andrade pelo confiança, oportunidade e direcionamento.

Ao Sr. Luiz Augusto Moreira, pelo suporte incondicional e confiança.

Aos laboratórios que disponibilizaram seus recursos para a realização deste trabalho: Centro de Tecnologia de Radiações (IPEN), Laboratório de Polímeros da FEI, Laboratórios Henkel em Itapevi, Jundiaí, Detroit e Munique.

A todos que cooperaram direta ou indiretamente na realização deste trabalho. 
A vida de todo ser humano é um caminho em direção a si mesmo, a tentativa de um caminho, o seguir de um simples rastro.

(...) Quem quiser nascer tem que destruir um mundo. Busque sua própria razão de existir. Ser é ousar ser. 


\section{RESUMO}

Este trabalho tem como objetivo investigar a redução da relaxação por compressão de borracha acrílica modificada (ACM) irradiada por feixe de elétrons, através da caracterização de seu comportamento mecânico e de sua estrutura molecular. O material, nas condições original e irradiado, foi inicialmente submetido a ensaios uniaxiais de tração e espectroscopia por infravermelho com o objetivo de verificar a influência da irradiação EB em seu comportamento, eliminando a possibilidade de degradação do material, permitindo a continuidade dos estudos. Definidas as doses, novos corpos de prova foram irradiados e submetidos a ensaios uniaxiais, equibiaxiais de tensão e cisalhamento puro, gerando resultados que foram aplicados na simulação pelo método de elementos finitos, utilizando o modelo de comportamento elástico não-linear de Ogden, para predizer o comportamento do material em condições de compressão. Confirmado o aumento da tensão por compressão para mesmas deformações, com o aumento da dose de radiação, análises termogravimétricas e dinâmicas mecânicas foram realizadas para possibilitar o entendimento do fenômeno. $\mathrm{Na}$ fase final do trabalho ensaios de relaxação por compressão foram realizados, em diferentes níveis de deformação e temperatura, apresentando a redução da relaxação por compressão gerada pela radiação EB e quantificando tal influência combinada com outros fatores, através da aplicação dos resultados no método de Planejamento Fatorial $2^{k}$.

Palavras-chaves: Borracha acrílica. ACM. Radiação EB. Relaxação por tensão de compressão, Planejamento fatorial. 


\begin{abstract}
The aim of this work is to investigate the compression stress relaxation (CSR) decrease of modified acrylic rubber, irradiated by electron beam, through its mechanical behavior and molecular structure characterization. Uniaxial tensile test and infrared spectroscopy were carried out, on original and irradiated material conditions, to verify the influence of EB irradiation on ACM, and to eliminate the possibility of degradation caused by EB radiation. After to define the radiation doses, new ACM specimens were irradiated. Uniaxial, equibiaxial and planar shear tests generated experimental data, which were applied to simulate the non linear elastic behavior of the material, through finite elements method, using the Ogden Model. Confirmed the compression stress increase at same deformation level, caused by increasing of radiation dose, thermogravimetric and dynamic mechanical analysis were carried out in order to make possible to understand the behavior changes. In the final part of this work, compression stress relaxation experiments were carried out, at two deformation and temperature levels, with the purpose to validate the compression stress relaxation decrease caused by EB radiation, and to quantify such influence combined with other factors. The CSR decrease combined with other influence variables were studied through use of factorial design.
\end{abstract}

Keywords: Acrylic rubber. ACM. EB radiation. Compression stress relaxation. Factorial design. 


\section{LISTA DE ABREVIATURAS}

$\begin{array}{ll}\text { ACM } & \text { Borracha Acrílica Modificada ou Poliacrilato } \\ \text { ASTM } & \text { American Society for Testing Materials } \\ \text { ATR } & \text { Attenuated Total Reflectance } \\ \text { CEAL } & \text { Centro de Engenharia de Adesivos Loctite } \\ \text { DMA } & \text { Análise Dinâmico Mecânica } \\ \text { DSC } & \text { Differential Scanning Calorimetry } \\ \text { EB } & \text { Electron Beam } \\ \text { FIPG } & \text { Formed in Place Gasket } \\ \text { IR } & \text { Infrared } \\ \text { PA } & \text { Poliamida } \\ \text { PC } & \text { Policarbonato } \\ \text { PE } & \text { Polietileno } \\ \text { PMMA } & \text { Polimetacrilato de Metila } \\ \text { PP } & \text { Polipropileno } \\ \text { PS } & \text { Poliestireno } \\ \text { PU } & \text { Poliuretano } \\ \text { MIPG } & \text { Molded in Place Gasket } \\ T_{c} & \text { Temperatura de Cristalinização } \\ T_{g} & \text { Temperatura de Transição Vítrea } \\ \text { TGA } & \text { Análise Termogravimétrica } \\ T_{m} & \text { Temperatura de Amolecimento } \\ \text { UV } & \text { Ultravioleta }\end{array}$




\section{SUMÁRIO}

1 INTRODUÇÃO

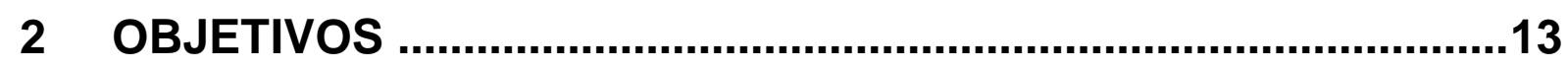

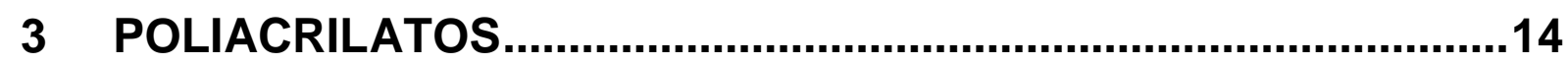

3.1 ESTRUTURAS E PROPRIEDADES ……….................................15

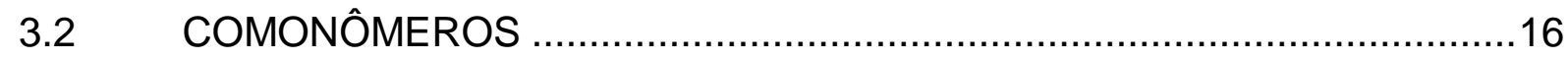

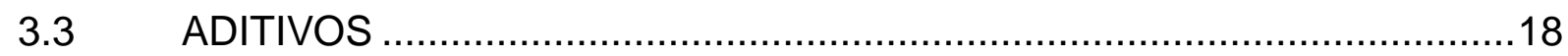

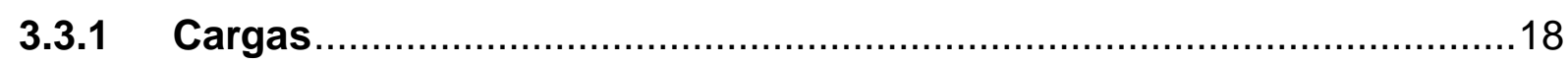

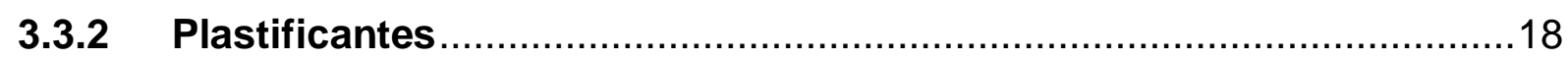

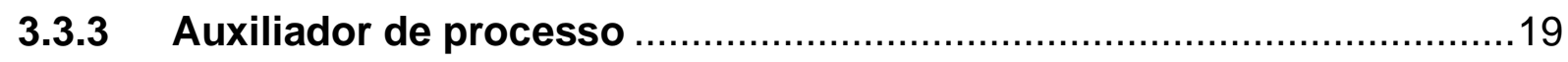

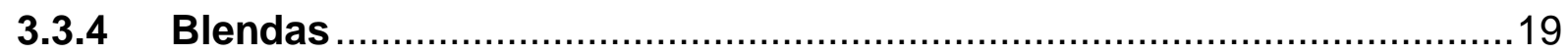

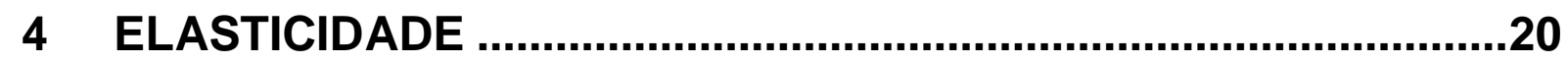

4.1 PROPRIEDADES ELÁSTICAS EM PEQUENAS DEFORMAÇÕES ...........21

4.2 PROPRIEDADES ELÁSTICAS EM LARGAS DEFORMAÇÕES ................22

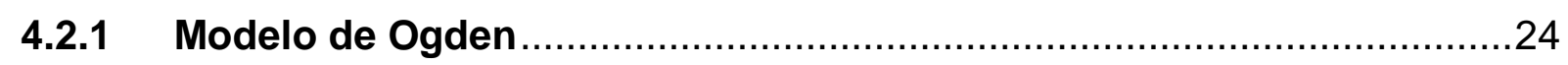

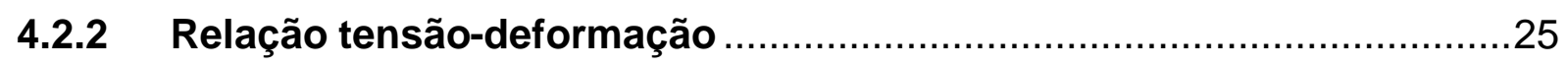

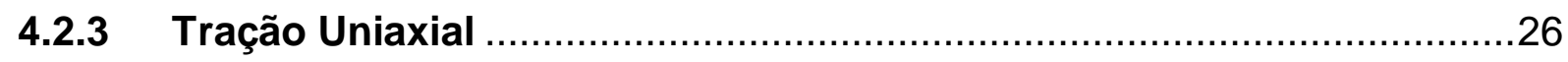

4.2.4 Cisalhamento puro ou Planar Shear ……......................................27

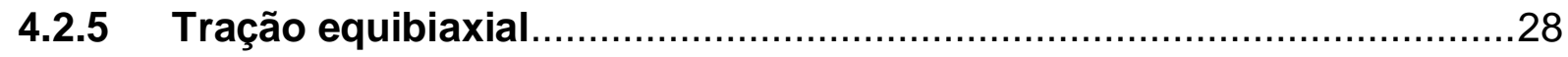

5 TECNOLOGIA DE RADIAÇÕES ...............................................29

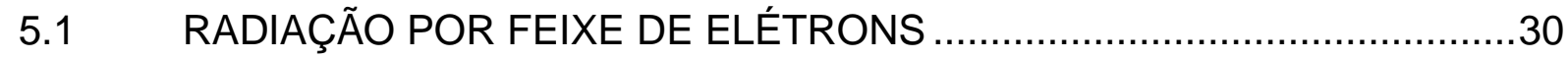

5.1.1 Fontes de radiação por elétrons ...........................................................

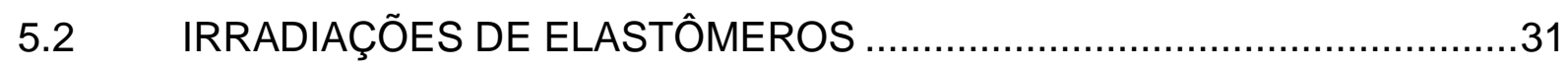

5.2.1 Radiação por elétrons aplicada como agente de vulcanização..............31

5.2.2 Radiação por elétrons aplicada em elastômeros vulcanizados ............32

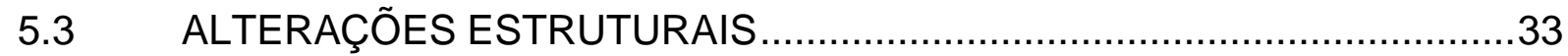

5.3.1 Alterações estruturais nas cadeias poliméricas ……............................33

5.3.2 Alterações estruturais em poliacrilatos (ACM) ……...........................35 


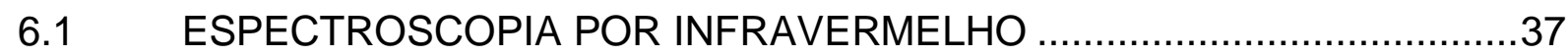

6.1.1 Reflectância Total Atenuada (ATR) ……..........................................

6.2 CALORIMETRIA DIFERENCIAL DE VARREDURA …...........................38

6.2.1 Determinação da temperatura de transição vítrea $\left(\mathrm{T}_{\mathrm{g}}\right)$ por DSC............39

6.3 ANÁLISE TERMODINÂMICO-MECÂNICA (DMTA)..................................41

6.3.1 Determinação da temperatura de transição vítrea $\left(T_{g}\right)$ por DMTA .........43

6.4 ANÁLISE TERMOGRAVIMÉTRICA...................................................44

7 VISCOELASTICIDADE LINEAR ..............................................

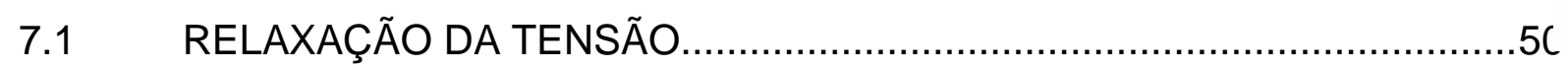

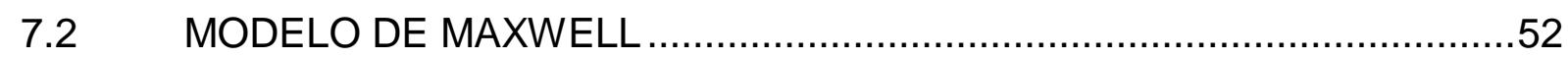

8 MATERIAIS E MÉTODOS …...................................................55

8.1 TESTES PRELIMINARES - VERIFICAÇÃO DA INFLUÊNCIA DO EB ......55

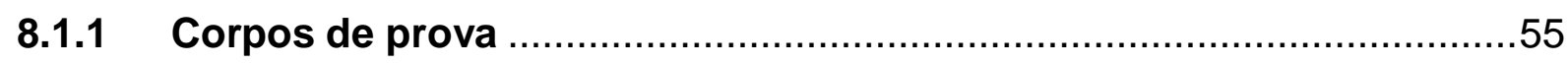

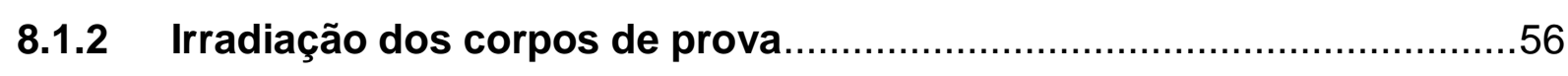

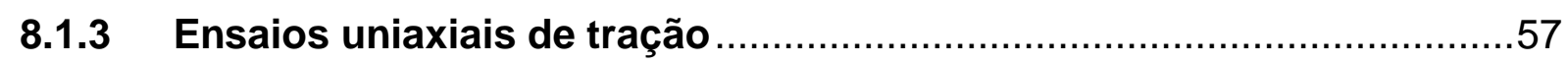

8.1.4 Espectroscopia por infravermelho - Testes preliminares …...............58

8.2 CARACTERIZAÇÃO DA RESPOSTA ELÁSTICA ..................................60

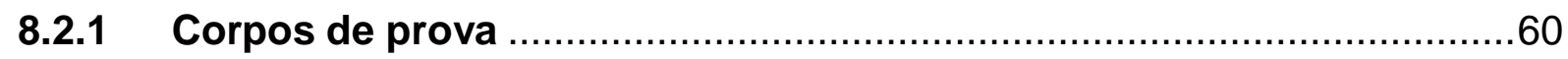

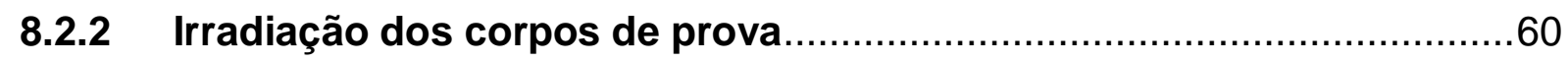

8.2.3 Ensaios mecânicos para caracterização do comportamento elástico..61

8.2.4 Análise termodinâmico-mecânica (DMTA) .........................................66

8.2.5 Análise de decomposição térmica por termogravimetria (TGA) ..........67

8.2.6 Espectroscopia por infravermelho - Segunda fase ............................68

8.3 VERIFICAÇÃO DO RELAXAMENTO DA TENSÃO POR COMPRESSÃO 69

8.3.1 Ensaio para análise da relaxação da tensão por compressão ..............69

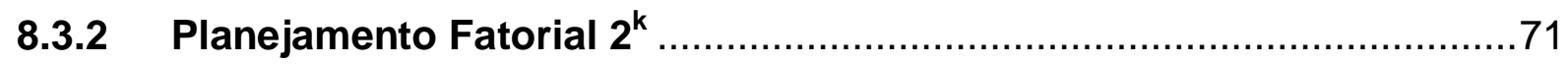

9 RESULTADOS E DISCUSSÃO ..................................................72

9.1 VERIFICAÇÃO DA INFLUÊNCIA DE RADIAÇÃO EB ............................72

9.1.1 Resultados dos ensaios uniaxiais - Testes preliminares .....................72

9.1.2 Resultados da espectroscopia por IR - Testes preliminares ...............77 


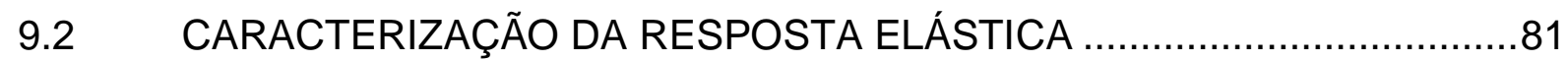

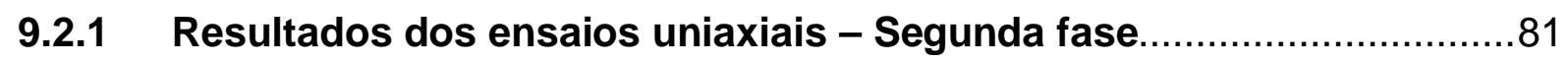

9.2.2 Resultados dos ensaios equibiaxiais - Segunda fase …....................

9.2.3 Resultados dos ensaios de cisalhamento puro - Segunda fase ...........91

9.2.4 Resultados da análise termodinâmico-mecânica - Segunda fase .........95

9.2.5 Resultado da análise de decomposição térmica - Segunda fase .........98

9.2.6 Resultados da espectroscopia por IR - Segunda fase ......................100

9.2.7 Resultados da simulação por elementos finitos - Segunda fase .........103

9.3 VERIFICAÇÃO DA RELAXAÇÃO DA TENSÃO POR COMPRESSÃO ....106

9.3.1 Resultados do ensaio da relaxação da tensão por compressão ..........106

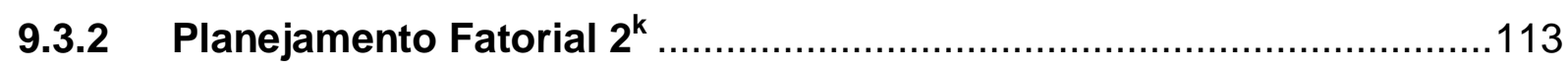

10 CONCLUSÕES......................................................................121

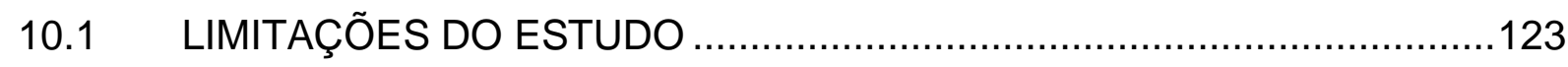

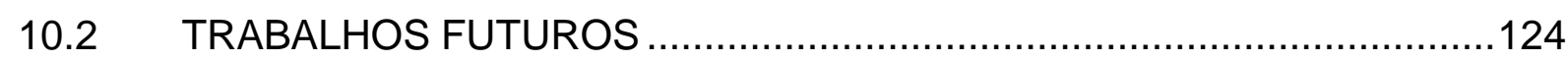

11 REFERÊNCIAS BIBLIOGRÁFICAS.......................................125

APÊNDICE A - RESULTADOS EXPERIMENTAIS DE TRAÇÃO ......129

APÊNDICE B - RESULTADOS EXPERIMENTAIS DE CSR ..............156 


\section{INTRODUÇÃO}

Elastômeros são materiais largamente utilizados em aplicações industriais, como componentes para absorção de vibrações, compensação de variações de dimensões ou como elementos de vedação. Determinadas características destes materiais, como relaxação da tensão e fluência, limitam a utilização dos elastômeros em aplicações estruturais onde são submetidos a altos esforços por prolongados períodos de tempo. Cada elastômero responde de maneira particular a estes tipos de fenômenos, alguns com maior outros com menor suscetibilidade à relaxação da tensão e fluência.

Particularmente as aplicações de elastômeros em vedação de componentes automotivos, como juntas sólidas, exigem que o material apresente uma combinação de propriedades como resistência à alta temperatura, resistência ao contato permanente com óleo de motor de combustão interna e baixa relaxação da tensão por compressão. O elastômero denominado poliacrilato (ACM), ou borracha acrílica, atende à maioria das exigências deste tipo de aplicação, por isso é largamente utilizada na fabricação de juntas sólidas para vedação de componentes automotivos. O poliacrilato apresenta como limitação um complexo processo de obtenção, ou vulcanização. Uma nova tecnologia de poliacrilato está sendo desenvolvida, a qual permite a aplicação de dois mecanismos de cura, sendo uma versão curável por radiação de luz ultravioleta (UV) e a segunda curável pela umidade presente no ar. A versão deste material com cura UV permite a obtenção de juntas sólidas através da injeção em moldes com posterior cura por radiação ultravioleta. Tal versão ainda se encontra em fase de desenvolvimento, não disponível comercialmente e foi cedido por uma multinacional alemã do ramo químico para estudo neste trabalho. O segundo mecanismo de cura possibilita a utilização do poliacrilato em aplicações onde se requer a tecnologia de juntas líquidas e as propriedades dos materiais atualmente disponíveis, como silicone, não atendam os requerimentos técnicos.

A cura do poliacrilato por UV supera a limitação deste material referente ao complexo processo de vulcanização, porém não altera seu comportamento quanto à relaxação da tensão por compressão. Tal relaxação é resultado da estrutura macromolecular dos elastômeros e de fenômenos como cisão das cadeias, 
dissociação de ligações físicas e deslizamento de cadeias, fatores que resultam no comportamento viscoelástico dos Elastômeros.

Esta tese propõe a utilização de radiação ionizante por feixe de elétrons, como agente de alteração da estrutura molecular do poliacrilato, conseqüente alteração do comportamento mecânico deste elastômero e redução da relaxação da tensão por compressão em condições de aplicação como elemento de vedação.

Amostras de poliacrilato, corpos de prova, curadas por radiação ultravioleta foram submetidas à irradiação por feixe de elétrons (EB), sob diferentes doses desta radiação. Após a irradiação, foram realizados ensaios uniaxiais de tração, para se verificar possíveis alterações em propriedades como: alongamento, tensão na ruptura e módulo de cisalhamento. A caracterização por infravermelho foi utilizada para investigar alterações nos tipos de grupos químicos após a irradiação, comparando com valores obtidos antes da irradiação. Tal procedimento permitiu verificar, de maneira resumida, a influência das diferentes doses de radiação EB na estrutura e comportamento mecânico deste material.

Verificada a influência da radiação EB no poliacrilato e descartada a possibilidade de degradação do material, ou seja da fragmentação de sua estrutura molecular, foram selecionadas doses específicas a serem aplicadas no estudo da redução da relaxação da tensão deste material. Na segunda fase desta tese, novos corpos de prova foram preparados e ensaiados em condições uniaxiais de tração, equibiaxiais de tração e de cisalhamento puro, com o objetivo de aplicar os resultados em um modelo de comportamento elástico não linear, denominado Modelo de Ogden. Este modelo representa o comportamento elástico do material considerando como variável de saída sua densidade de energia de deformação, aplicável em largas deformações e comportamento elástico não linear, condições onde os conceitos da elasticidade clássica não são suficientes. A resposta elástica do poliacrilato, obtida através deste método, gerou dados aplicáveis ao método de elementos finitos, para predição do comportamento de elastômeros sob compressão, além de caracterizar com alta precisão a diferença causada pela radiação na resposta elástica do poliacrilato, dados que permitiram verificar o aumento da tensão para o mesmo nível de deformação por compressão do material estudado. Análise termogravimétrica e análise dinâmico mecânicas do ACM permitiram verificar, de maneira resumida, a influência das diferentes doses de radiação EB na estrutura e comportamento térmico e dinâmico deste material, através da variação de propriedades como 
temperatura de transição vítrea, temperatura de degradação, capacidade de armazenar energia elástica e dissipação de energia viscosa do material em função do aumento de temperatura.

A parte final visou à realização de ensaios de relaxação da tensão por compressão, gerando os dados necessários para confirmação da tese proposta de redução da relaxação, através da aplicação de radiação ionizante por feixe de elétrons. Os ensaios de relaxação por compressão mostraram que a radiação por feixe de elétrons aumentou a capacidade de vedação do material, através do aumento da força por compressão, ou força de vedação, retida após 5.000 min de ensaio.

A redução do relaxamento da tensão por compressão do poliacrilato, associada à inovação da cura por radiação UV, aproxima este material da condição ideal de comportamento, requerido em aplicações de vedação por juntas sólidas em componentes automotivos como transmissões, coletores e bombas. 


\section{OBJETIVOS}

O objetivo final deste trabalho é investigar a eficiência da aplicação de radiação ionizante por feixe de elétrons, como agente de pós cura, na redução da relaxação da tensão por compressão em poliacrilatos curados por radiação ultravioleta, através de análise absoluta e percentual da força retida, além de quantificar e analisar estatisticamente tal influência em dois níveis de deformação e temperatura. Atingir este objetivo foi possível através da realização de diversos ensaios mecânicos e análises físico químicas.

Na primeira fase deste trabalho como objetivo específico foi verificada a influência da radiação por feixe de elétrons em poliacrilatos, através de ensaios mecânicos uniaxiais e análise dos grupos químicos por infravermelho, descartando a hipótese de degradação.

A fase seguinte objetivou caracterizar a resposta elástica através da realização de ensaios mecânicos uniaxiais, equibiaxiais e de cisalhamento puro, com aplicação dos resultados em modelo de comportamento elástico não linear, Modelo de Ogden e simulação em elementos finitos do comportamento do material em compressão.

Atingir o objetivo geral foi possível através da realização de ensaios de relaxação da tensão por compressão em diferentes níveis de temperatura e deformação. Análises térmicas e dinâmicas auxiliaram na explicação dos fenômenos nas condições de deformação e temperatura estudadas. 


\section{POLIACRILATOS}

A partir da copolimerização de ésteres acrílicos com outros monômeros, os quais possibilitam subseqüente reticulação, dá-se origem a polímeros termorígidos, saturados, de estrutura amorfa e bastante polar, denominados poliacrilatos (HOFMANN, 1996). Os primeiros poliacrilatos (ACM), também chamados de elastômeros de base acrílica, foram desenvolvidos por Goodrich nos Estados Unidos e produzidos com finalidade comercial desde meados de 1947. Atualmente os poliacrilatos são amplamente utilizados na fabricação de elementos de vedação na indústria automotiva, devido sua alta resistência à temperatura, alta resistência a óleos automotivos e à retenção de sua flexibilidade mesmo em baixas temperaturas. Segundo Harper (2002) os elastômeros de base acrílica são principalmente obtidos por processos de polimerização por emulsão ou por suspensão, sendo o processo por emulsão o mais utilizado dentre estes. Tratam-se de processos complexos e com diversas variáveis a serem controladas. Com o objetivo de ampliar as formas de cura do ACM e consequentemente gerar novas aplicações para este elastômero, recentemente novos poliacrilatos foram desenvolvidos, tendo como inovação sua forma de cura. Duas novas variações de poliacrilatos foram disponibilizadas, sendo uma delas curável por radiação UV (ultravioleta) e a segunda pelo reação com a umidade presente no ar.

Tais inovações permitiram utilizar o ACM como adesivo selante em aplicações denominadas formed in place gasket (FIPG), juntas formadas no local ou molded in place gasket (MIPG), juntas moldadas no local. Estas novas tecnologias de cura permitem aplicar o material na forma líquida, na região onde acontecerá a vedação, com posterior polimerização. Assim o elemento vedante realizará sua função não apenas pela compressão exercida sobre o material, como nos métodos de vedação tradicionais com ACM, mas também por adesão do elastômero com a região a ser vedada. O ACM curável por UV ou por umidade une os benefícios de tecnologias FIPG, como anaeróbicos e silicones, às ótimas propriedades já oferecidas por este material em suas formas tradicionais de cura. A redução do custo de obtenção do ACM, proporcionado pelas novas formas de cura, tornam este elastômero ainda mais atrativo para as aplicações deste elastômero como elementos vedantes na indústria automotiva. 


\subsection{ESTRUTURAS E PROPRIEDADES}

Segundo Bernardi et al. (1999) o primeiro poliacrilato desenvolvido foi feito de homopolímeros de acrilato de etila. Como estes polímeros eram saturados e difíceis de curar, optou-se por realizar a copolimerização destes ésteres acrílicos com outros monômeros, denominados comonômeros de cura, os quais facilitaram o processo de cura e a formação das ligações cruzadas ou reticulações. Outros ésteres acrílicos, como acrilato de butila, também são atualmente utilizados na obtenção de poliacrilatos, a Figura 1 apresenta as estruturas do grupos reativo citados.

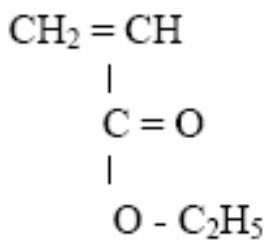

Etil Acrilato

$$
\begin{aligned}
& \mathrm{CH}_{2}=\mathrm{CH} \\
& \text { l } \\
& \mathrm{C}=\mathrm{O} \\
& \text { I } \\
& \mathrm{O}-\mathrm{C}_{2} \mathrm{H}_{4}-\mathrm{O}-\mathrm{CH}_{3}
\end{aligned}
$$

\section{2 - Metoxil Etil Acrilato}

Figura 1 - Estruturas de ésteres acrílicos comumente utilizados na obtenção de poliacrilatos (Bernardi et al., 1999).

A escolha do éster acrílico utilizado determina propriedades de resistência química, térmica e de comportamento mecânico destes elastômeros. Vanderbilt (1990) complementa afirmando que ao variar grupo $R$ de $C_{1}$ (metila) para $C_{8}$ (octila) a temperatura de mudança de comportamento rígido para viscoelástico pode variar em até $60^{\circ} \mathrm{C}$, sendo que a resistência a óleo é inversamente proporcional, diminui com o aumento de $\mathrm{CH}_{2}$ do grupo $\mathrm{R}$.

Um homopolímero de acrilato de etila, por exemplo, apresenta excelente resistência a óleo e às altas temperaturas, porém, perde propriedades em baixas temperaturas, devido sua relativamente alta, para um elastômero, temperatura de transição vítrea $\left(\mathrm{T}_{\mathrm{g}}\right)$ de $-18^{\circ} \mathrm{C}$. Ao se adicionar acrilato de butila, o qual possui grupo $\mathrm{R}$ com maior número de $\mathrm{CH}_{2}$, o elastômero perde em resistência a óleo, porém tem um acréscimo 
em suas propriedades em baixas temperaturas, isto se dá devido à $T_{g}$ de $-55^{\circ} \mathrm{C}$ do acrilato de butila. A blenda entre acrilato de metila e acrilato de butila apresenta $T_{g}$ de $-40^{\circ} \mathrm{C}$. Na Figura 2 é ilustrada a variação das propriedades do elastômero obtido em função da alteração do grupo R utilizado, apresentando também a influência do metoxietil acrilato, o qual oferece melhor relação entre as propriedades de resistência a óleo e de comportamento em baixas temperaturas, porém apresenta redução na resistência à temperatura. Os dados de resistência a óleo apresentados na Figura 2 foram obtidos através de ensaios de acordo com a norma IRM 903, segundo a qual o elastômero é imerso em óleo por $70 \mathrm{~h}$ a $150^{\circ} \mathrm{C}$.

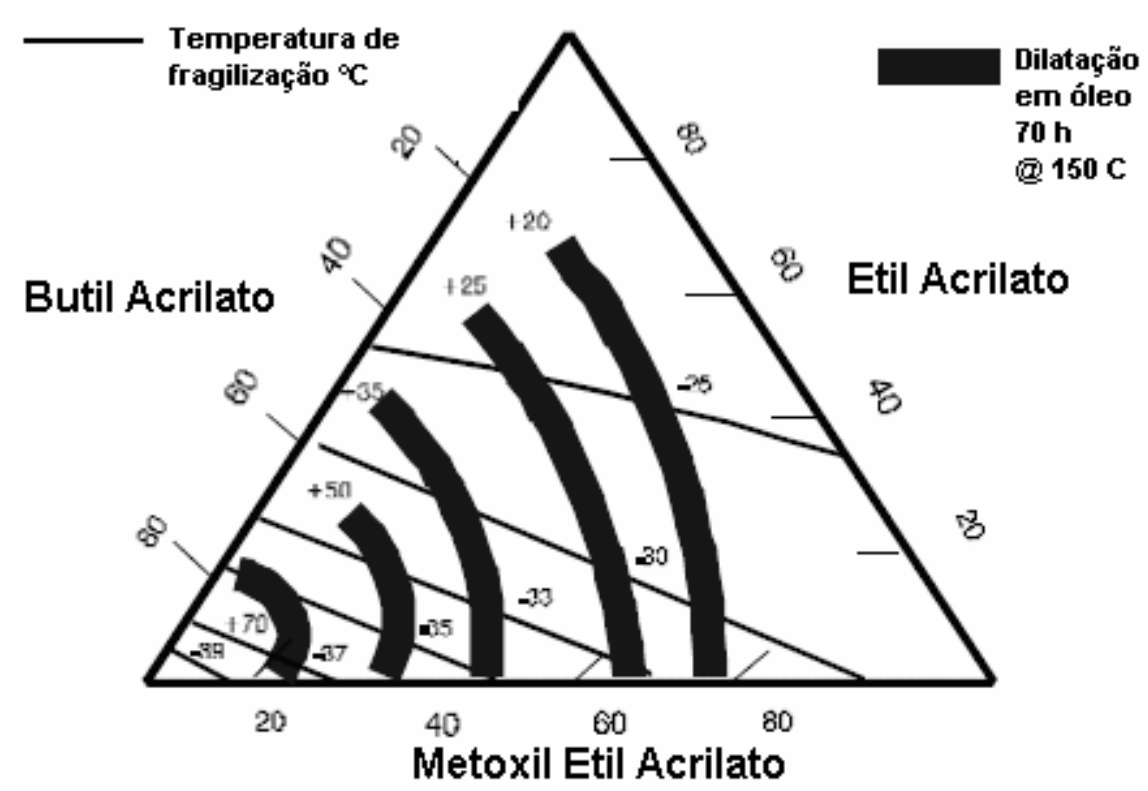

Figura 2 - Relação entre óleo swell e comportamento em baixas temperaturas dos diferentes monômeros (Bernardi et al., 1999).

\subsection{COMONÔMEROS}

Hofmann (1996) afirma que a escolha do comonômero tem pouca influência em propriedades do elastômero obtida como resistência a óleo e flexibilidade em baixas temperaturas, porém determina, ao invés disso, o comportamento de cura e as propriedades físicas do vulcanizado. Os primeiros comonômeros utilizados na polimerização e reticulação de poliacrilatos foram os éteres de cloreto de vinila, que ofereciam baixa reatividade e consequentemente uma polimerização e reticulação 
pobres e insatisfatórias. Níveis satisfatórios de polimerização só foram obtidos com o desenvolvimento de um nova geração, ou grau, de poliacrilatos, os quais necessitaram de novos comonômeros para polimerização e reticulação, esta segunda geração utilizava cloroacetato de vinila como comonômero. Atualmente duas classes de comonômeros são bastantes utilizados, os clorados e os epoxídeos. Os epoxídeos proporcionam ao poliacrilato benefícios como menor relaxação de tensão por compressão, menor oxidação e tornam dispensável a utilização de um método de pós cura. A Figura 3 mostra quatro estruturas de comonômeros bastante utilizados na polimerização de poliacrilatos, dentre eles os clorados e os epoxídeos.

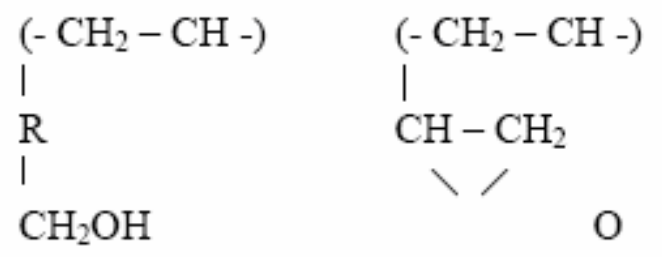

\section{Hidroxil}

\section{Epoxídeo}

Figura 3 - Estruturas de comonômeros comumente utilizados na obtenção de poliacrilatos (Bernardi et al., 1999).

Alguns poliacrilatos necessitam de um processo de pós cura, que de acordo com Bernardi et al. (1999) a pós cura pode proporcionar aumento das propriedades físicas e redução da relaxação por tensão de compressão. Este mesmo autor sugere a utilização de fornos com alta temperatura e intensa ventilação, sem a sobreposição de peças, indicando como parâmetros os valores de $177^{\circ} \mathrm{C}$ por 4 horas.

Nesta revisão de literatura nenhum dado foi encontrado sobre a possibilidade de utilização de outras formas de pós cura, ou aumentando da reticulação, por irradiação de nêutrons ou elétrons. Estes métodos de irradiação são atualmente utilizados para aumentar propriedades de polímeros, por exemplo, utilizados em aplicações automotivas em altas temperaturas.

A Tabela 1 apresenta propriedades básicas obtidas de duas diferentes fontes. Os valores apresentados são genéricos, sem citação de produto específico, por isso as variações obtidas entre as duas fontes. 
Tabela 1 - Propriedades básicas de poliacrilatos.

\begin{tabular}{ccc}
\hline Propriedades & Bernardi et al. (1999) & Vanderbilt (1990) \\
\hline Resistência Máxima à Tração (MPa) & $7-14$ & 16 \\
Alongamento Máximo (\%) & $100-250$ & 400 \\
Dureza, Shore A & $45-90$ & 67 \\
Densidade Relativa & 1,30 & $1,1-1,15$ \\
\hline
\end{tabular}

\subsection{ADITIVOS}

Elastômeros sem aditivos, como cargas de reforçamento, plastificantes, estabilizantes ou anti-oxidantes comumente não apresentam boas propriedades mecânicas. Porém para se obter a resistência desejada é necessário selecionar de maneira correta os materiais a serem adicionados.

\subsubsection{Cargas}

Vanderbilt (1990) propõem que em comum com outros elastômeros amorfos, as borrachas acrílicas requerem cargas de reforçamento. Segundo Bernardi et al. (1999) negro de fumo é o material mais utilizado, porém em níveis moderados de aplicação, melhorando a resistência à tração e a processabilidade do poliacrilato. Os três tipos de negro de fumo mais utilizados são: N650, N550 para uso geral e N326 para alta resistência e alto alongamento. Hofmann (1996) recomenda também a aplicação de sílicas combinadas com Al-silicatos.

\subsubsection{Plastificantes}

Em geral, grandes quantidades de plastificantes não são utilizadas na formulação de poliacrilatos. Existe uma tendência de volatilização dos plastificantes em aplicações em altas temperaturas, além de incompatibilidade com alguns tipos de óleos. Alguns 
plastificantes utilizados em silicones, por exemplo, geram uma espécie de espuma ao entrar em contato com óleos aplicados em transmissões automáticas.

As pequenas quantidades aplicadas em poliacrilatos geram um aumento do alongamento do elastômeros em baixas temperaturas. Quanto menor o peso molecular do plastificante utilizado, maior será sua eficiência, porém mais fácil será liberado quando em altas temperaturas. Monômeros de éster são comumente aplicados como plastificantes.

\subsubsection{Auxiliador de processo}

Devido à alta complexidade no processamento de poliacrilatos, o auxiliador de processo é citado como crítico por diversos autores. De acordo Vanderbilt (1990) a escolha incorreta pode interferir na taxa de cura ou promover rápido aquecimento. Bernardi et al. (1999) sugere a utilização de auxiliador de processo como Struktol WB222, WS280 e pasta TE80.

\subsubsection{Blendas}

A natureza polar do poliacrilato não permite sua utilização na formação de blendas com diversos tipos de elastômeros. Normalmente os poliacrilatos são utilizados na formação de blendas com outros poliacrilatos que utilizam o mesmo processo de cura. Por exemplo, um poliacrilato com alta resistência a óleo, pode ser aplicado em formação de blenda com outro poliacrilato, com alta flexibilidade em baixa temperatura, visando atingir o equilíbrio entre as propriedades ótimas de cada poliacrilato. 


\section{ELASTICIDADE}

A capacidade de um corpo sólido se deformar, quando submetido a algum carregamento, retornando ao seu formato e dimensões originais, quando esse carregamento é retirado, é denominada elasticidade. Para que tal fenômeno seja possível, o processo de deformação causado por este carregamento, ou sistema de forças, deve ser isotérmico e toda a energia aplicada e utilizada nesta deformação deve ser armazenada.

A teoria clássica da elasticidade assume que ao se tomar dois pontos vizinhos de qualquer corpo sólido, em sua região de comportamento elástico, a separação destes pontos causada por um carregamento é pequena, ou negligenciável, quando comparada com a distância inicial entre tais pontos. Existe porém uma grande gama de materiais cujo comportamento não atende a esta condição requerida pela teoria clássica da elasticidade, ou seja, estes materiais apresentam elevada deformação quando submetidos a um determinado carregamento, dentro de sua região de comportamento elástico, tais como os elastômeros.

Segundo Gent (1992) a típica alta capacidade dos elastômeros, de se deformarem, retornando à condição inicial ao se retirar o carregamento, se deve à sua estrutura molecular. Como suas moléculas lineares são longas e flexíveis, elas assumem uma configuração aleatória em determinadas condições térmicas. Quando a força aplicada é retirada, as moléculas retornam à sua configuração inicial, tão rapidamente quando a condição térmica permita. Gent compara as moléculas dos elastômeros às serpentes agitadas.

O comportamento dos elastômeros pode ser abordado de duas maneiras diferentes, de acordo com a magnitude da deformação considerada. Em caso de aplicações onde a deformação do elastômero é mínima, pode-se realizar uma análise elástica convencional, tratando o comportamento elástico do material como linear, ou seja, a deformação causada é linearmente proporcional à força aplicada (GENT, 1992). Para altas deformações, condições onde a distância entre dois pontos vizinhos, separados por um carregamento aplicado dentro da região elástica do material, não pode ser considerada mínima ou negligenciada, Rivlin (1956) propôs um modelo de comportamento possível, assumindo que os materiais em questão são incompressíveis e isotrópicos. 


\subsection{PROPRIEDADES ELÁSTICAS EM PEQUENAS DEFORMAÇÕES}

Grande parte das aplicações de elastômeros ocorre em condições de deformação inferiores a $25 \%$ em extensão ou compressão e inferiores a $75 \%$ em cisalhamento puro. Nas condições acima ainda é possível utilizar, com boa aproximação, uma análise elástica convencional.

Gent (1992) afirma que o comportamento de materiais elásticos isotrópicos, em seu estado não deformado, pode ser descrito através de duas constantes elásticas fundamentais. A primeira constante trata da resistência à compressão em volume sob pressão hidrostática, denominada módulo de compressão (K). A Equação 1 relaciona a variação de volume $(\Delta \mathrm{V})$, comparado ao volume inicial $\left(\mathrm{V}_{0}\right)$, em função da pressão hidrostática $(P)$ aplicada.

$$
P=K\left(\frac{\Delta V}{V_{0}}\right)
$$

A segunda constante se relaciona com a resistência à tensão de cisalhamento simples $(\tau)$. Esta constante é denominada módulo de cisalhamento $(G)$, definida pela relação proposta na Equação 2. Onde o módulo de cisalhamento é obtido pela divisão da tensão de cisalhamento $(\tau)$ pela tangente $(\gamma)$, ilustrada na Figura 4.

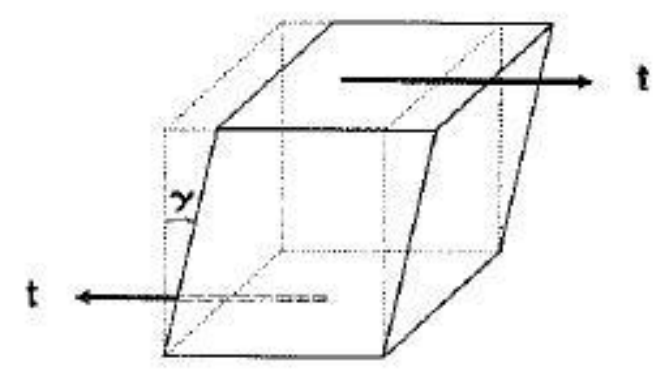

Figura 4 - Cubo unitário para exemplificação das variações determinantes do Módulo de Cisalhamento G (Gent., 1992).

$$
G=\frac{\tau}{\gamma}
$$


Outras constantes podem ser derivadas destas duas primeiras, como módulo de elasticidade (E), apresentado na Equação 3 e o coeficiente de Poison, apresentado na Equação 4, este coeficiente normalmente aproxima-se do valor 0,5 para elastômeros.

$$
\begin{gathered}
E=\frac{9 K G}{3 K+G} \\
v=\frac{1}{2} \frac{3 K-2 G}{3 K+2 G}
\end{gathered}
$$

\subsection{PROPRIEDADES ELÁSTICAS EM LARGAS DEFORMAÇÕES}

$\mathrm{Na}$ literatura relacionada com largas deformações elásticas de materiais elastoméricos isotrópicos, é costumeiro expressar deformações em termos das três principais deformações. Sendo a deformação principal obtida pela relação entre o comprimento final e o comprimento inicial, na direção correspondente ao eixo de deformação principal. Tais deformações principais normalmente são representadas por $\lambda_{1}, \lambda_{2}$ e $\lambda_{3}$ (HAINES; WILSON,1979).

Rivlin (1956) desenvolveu as seguintes equações para os invariantes de deformação $\left(I_{1}, I_{2}\right.$ e $\left.I_{3}\right)$ em termos das deformações, ou extensões, principais.

$$
\begin{aligned}
& I_{1}=\lambda_{1}^{2}+\lambda_{2}^{2}+\lambda_{3}^{2} \\
& I_{2}=\lambda_{1}^{2} \lambda_{2}^{2}+\lambda_{2}^{2} \lambda_{3}^{2}+\lambda_{3}^{2} \lambda_{1}^{2} \\
& I_{3}=\lambda_{1}^{2} \lambda_{2}^{2} \lambda_{3}^{2}
\end{aligned}
$$

As invariantes de deformação são de extrema importância no estudo de largas deformações. Segundo Gent (2005) Rivlin apresentou no década de 40 o primeiro modelo de comportamento elástico baseado em densidade de energia de deformação $(W)$, relacionando o módulo de cisalhamento $G$ do material com uma medição escalar de deformação baseada nas extensões principais. 
A Equação 6 mostra o modelo proposto por Rivlin, o qual apresentava boa aplicabilidade em pequenas deformações, este modelo foi definido por Rivlin como Neo-Hookeano, devido à sua simplicidade e aplicabilidade às pequenas deformações.

$$
W=\frac{G}{2} J_{1}
$$

Onde:

$$
J_{1}=\lambda_{1}^{2}+\lambda_{2}^{2}+\lambda_{3}^{2}-3
$$

Rivlin (1956) apresenta na Equação 8 o modelo denominado Mooney-Rivlin desenvolvido para materiais considerados isotrópicos e incompressíveis. De acordo com Rivlin em caso de materiais incompressíveis isotrópicos elásticos, é visto que a função de energia de deformação (W) pode ser escrita em termos de $I_{1}$ e $I_{2}$ somente, já que a condição de incompressibilidade exige $I_{3}=1$. A função de energia de deformação pode ser expressa com boa aproximação e bom nível de precisão por uma série de potência em $\mathrm{I}_{1}-3$ e $\mathrm{I}_{2}-3$, para deformações de magnitude limitada.

O primeiro termo da Equação 8 corresponde à relação obtida da teoria molecular da elasticidade de borracha, a qual sugere que a constante $\mathrm{C}_{1 \text { é }}$ proporcional ou nível de reticulações das cadeias poliméricas por unidade de volume e $\mathrm{C}_{2}$ reflete outras restrições físicas presentes na estrutura molecular e sua importância diminui com o aumento do nível de deformação.

$$
W=\sum_{i j=0}^{\infty} C_{1}\left(I_{1}-3\right)^{i}+C_{2}\left(I_{2}-3\right)^{j}
$$

Segundo Boulenouar e Mazari (2008) o Modelo de Mooney e Rivlin é bem adaptado para representar o comportamento de materiais com deformações de até $200 \%$ em ensaios uniaxiais de tração. Enquanto ABAQUS REGIONAL USERS GROUP MEETING (2003) sugere que este modelo não seja utilizado para deformações superiores a $100 \%$. Outros modelos foram desenvolvidos para largas deformações até $600 \%$. 
O tipo de função de energia de deformação proposta por Ogden demonstrou a habilidade de representar os dados experimentais, com bastante precisão, para condições de tração uniaxial, equibiaxial, planar shear e leves compressões (HAINES; WILSON, 1979).

ABAQUS REGIONAL USERS GROUP MEETING (2003) afirma que poucos modelos trabalham bem com múltiplos tipos de testes, os quais são essenciais para representar o comportamento de elastômeros. O Modelo de Ogden é indicado para aplicação em métodos de elementos finitos com boa precisão.

Boulenouar e Mazari (2008) cita que o Modelo de Ogden com seis constantes apresenta uma precisão muito boa para reproduzir os dados de Treloar, levando em consideração deformações de 0 até $600 \%$.

As diversões citações e positivas referências ao Modelo de Ogden, levaram à escolha do mesmo para tratamento dos dados obtidos experimentalmente neste trabalho.

\subsubsection{Modelo de Ogden}

Ogden (1997) apresenta um modelo de função de energia de deformação, desenvolvida a partir da função de Mooney-Rivlin, onde segundo o autor, desde que $\lambda_{1}^{2} \lambda_{2}^{2} \lambda_{3}^{2}=1$ não há a necessidade de restrição do expoente $\alpha$, apresentado em seu modelo, à número inteiro. A Equação 9 é um caso do modelo de Ogden para materiais incompressíveis e isotrópicos.

$$
W\left(\lambda_{1}, \lambda_{2}, \lambda_{3}\right)=\sum_{p=1}^{N \infty} \frac{\mu_{p}}{\alpha_{p}}\left(\lambda_{1}^{\alpha_{p}}+\lambda_{2}^{\alpha_{p}}+\lambda_{3}^{\alpha_{p}}-3\right)
$$

Onde $\alpha_{\mathrm{p}}(p=1, \ldots, \mathrm{N})$ é um número real e $\mathrm{N}$ é um número inteiro positivo, que pode ser adotado de acordo com a necessidade. ABAQUS REGIONAL USERS GROUP MEETING (2003) sugere a seleção do fator $N$ de acordo com a faixa de extensão do material estudado:

$N=1$ para condições onde $0,8 \geq \lambda \geq 1,2$;

$\mathrm{N}=2$ para condições onde $\lambda>>1,2$. 


\subsubsection{Relação tensão-deformação}

De acordo com Ogden (1997) ao se estudar um material tratado como incompressível, pode-se operar somente com dois valores de extensão, já que:

$$
\lambda_{3}=\frac{1}{\lambda_{1} \lambda_{2}}
$$

A isotropia do material exige que a função de energia de deformação deva ser simétrica, logo:

$$
W\left(\lambda_{1}, \lambda_{2}, \lambda_{3}\right)=W\left(\lambda_{1}, \lambda_{3}, \lambda_{2}\right)=W\left(\lambda_{3}, \lambda_{1}, \lambda_{2}\right)
$$

Ogden (1997) apresenta a tensão principal de Cauchy dada por:

$$
t_{i}=\lambda_{i} \frac{\partial \tilde{W}}{\partial \lambda_{i}}-p
$$

Onde:

p: pressão;

$\mathrm{I}=1,2,3$.

Devido à Equação 10 é possível eliminar $\lambda_{3}$ e introduzir a notação a seguir:

$$
\tilde{W}\left(\lambda_{1}, \lambda_{2}\right)=\tilde{W}\left(\lambda_{2}, \lambda_{1}\right)=W\left(\lambda_{1}, \lambda_{2}, \lambda_{1}^{-1}, \lambda_{2}^{-1}\right)
$$

Sendo possível deduzir através da Equação 12:

$$
t_{1}-t_{3}=\lambda_{1} \frac{\partial \tilde{W}}{\partial \lambda_{1}}
$$




$$
t_{2}-t_{3}=\lambda_{2} \frac{\partial \tilde{W}}{\partial \lambda_{2}}
$$

As duas relações de tensão deformação apresentadas na Equação 14 dão condições de relacionar esta teoria base com resultados experimentais. Em solicitações onde $t_{3}=0$, como tração uniaxial, equibiaxial ou planar shear, a Equação 14 é reduzida a:

$$
\begin{aligned}
& t_{1}=\lambda_{1} \frac{\partial \tilde{W}}{\partial \lambda_{1}} \\
& t_{2}=\lambda_{2} \frac{\partial \tilde{W}}{\partial \lambda_{2}}
\end{aligned}
$$

\subsubsection{Tração Uniaxial}

Em condição de tração simples, ou uniaxial, $t_{2}=t_{3}=0$, sendo possível escrever $t_{1}=t$ e $\lambda_{1}=\lambda$. Por simetria $\lambda_{2}=\lambda_{3}=\lambda^{-1 / 2}$ sendo a relação tensão-deformação dada pela Equação 16. A Figura 5 ilustra a relação entre as extensões ou deformações principais do material.

$$
t=\lambda \frac{\partial \hat{W}}{\partial \lambda}
$$

Onde:

$$
\hat{W}(\lambda)=\tilde{W}\left(\lambda, \lambda^{-1 / 2}\right)
$$




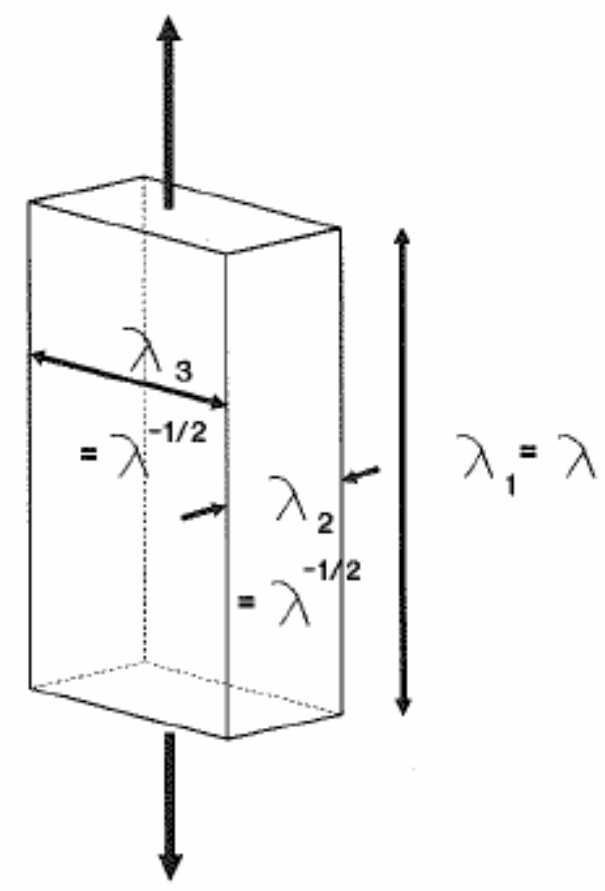

Figura 5 - Extensões principais em tração uniaxial (Gent., 1992).

\subsubsection{Cisalhamento puro ou Planar Shear}

Gent (1992) apresenta como cisalhamento puro o esforço aplicado em um determinado corpo, de maneira que um dos principais eixos não seja alterado, ou seja, $\lambda_{1}, \lambda_{2}$ ou $\lambda_{3}=1$. A Figura 6 toma $\lambda_{2}=1$, definindo assim $\lambda_{1}=\lambda, \lambda_{3}=\lambda^{-1}$ com t $_{1}=t$ e $\mathrm{t}_{2}=0$. $A$ relação tensão-deformação é dada pela Equação 18 .

$$
t=\lambda \frac{\partial \hat{W}}{\partial \lambda}
$$

Onde:

$$
\hat{W}(\lambda)=\tilde{W}\left(\lambda, \lambda^{-1}\right)
$$


A Figura 6 ilustra a relação entre as extensões principais em condição de cisalhamento puro, tornando mais simples a visualização das relações entre as taxas.

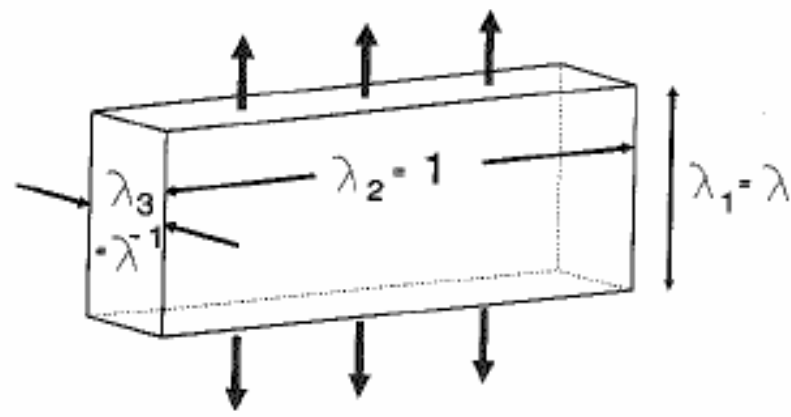

Figura 6 - Extensões principais em cisalhamento puro (Gent., 1992).

\subsubsection{Tração equibiaxial}

Em tração equibiaxial $t_{1}=t_{2}=t$ e $t_{3}=0$, associado com $\lambda_{1}=\lambda_{2}=\lambda$, têm-se:

$$
t=\frac{1}{2} \lambda \frac{\partial W}{\partial \lambda}
$$

Onde:

$$
\hat{W}(\lambda)=\tilde{W}(\lambda, \lambda)
$$

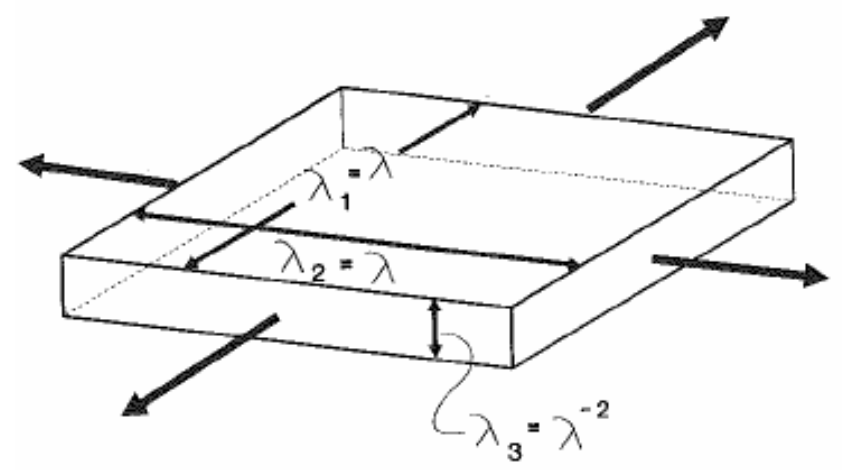

Figura 7 - Extensões principais em tração equibiaxial (Gent., 1992). 


\section{TECNOLOGIA DE RADIAÇÕES}

Zagórski (2004) cita que a primeira observação de reticulação de polímeros, através da absorção de radiação ionizante, provavelmente se deu em reatores nucleares. Devido ao escasso nível de informações sobre o assunto na década de 1940, assumiu-se a possibilidade de que a absorção de radiação ionizante não intencional, pelos revestimentos de polietileno (PE) dos cabos elétricos dos reatores nucleares, pudessem ocasionar deterioração, fogo ou até mesmo explosão, originada nos revestimentos de PE. A aceitação desta possibilidade ocorreu devido à similaridade entre as moléculas de $\mathrm{PE}\left(\mathrm{CH}_{3}-\left[\mathrm{CH}_{\mathrm{p}}\right]-\mathrm{CH}_{3}\right)$ e de combustíveis utilizados em motores de combustão interna $\left(\mathrm{CH}_{3}-\left[\mathrm{CH}_{\mathrm{f}}\right]-\mathrm{CH}_{3}\right)$, onde $\mathrm{p}>>\mathrm{f}$. Ao se analisar os revestimentos de PE destes cabos, teve-se uma grata surpresa, ao contrário do que se esperava, os revestimentos de PE deixaram os campos de radiações com melhores propriedades mecânicas e térmicas.

Diversos trabalhos foram apresentados considerando a aplicação de radiações ionizantes, por raios gamma ou por elétrons, para alteração da estrutura e consequentemente de propriedades mecânicas e térmicas de diversos polímeros. A literatura mostra diversos trabalhos com polietileno (PE) (MISHRA et al., 2008), polipropileno (PP) (MANAS et al., 2008), poliamida (PA) (SENGUPTA et al., 2005), policarbonato (PC) (CHEN et al., 2005) entre outros. Além da aplicação em polímeros, como aumento da resistência térmica de revestimentos de cabos, a tecnologia de radiação ionizante é largamente aplicada para prolongamento da vida útil de determinados alimentos e esterilização de materiais médicos.

Charlesby apud Zagórski (2004) apresentou em 1954 uma explicação para as alterações no comportamento de PE irradiado, segundo o autor ocorreu a formação de crosslinking (reticulação) entre cadeias poliméricas vizinhas. Posteriormente Chalerby e Pinner apud Zagórski (2004) formularam juntos relações quantitativas entre as radiação aplicada e as alterações obtidas, tais equações ainda hoje são largamente utilizadas e são conhecidas como Equação de Charlesby e Pinner.

Os principais tipos de radiação ionizante citadas na literatura, nas aplicações mencionadas acima, são radiação Gamma e radiação por feixe de elétrons. Sendo a radiação por feixe de elétrons apresentada com maior freqüência em relação à radiação por raios gamma. 


\subsection{RADIAÇÃO POR FEIXE DE ELÉTRONS}

Zagórski (2004) cita o trabalho de Lawton et al. (1953) como fundamental para a área de química de radiação de polímeros, pois neste trabalho foi utilizado pela primeira vez uma fonte elétrica de $800 \mathrm{keV}$ para a irradiação de polímeros. Anteriormente à este trabalho eram utilizadas fontes de radioisótopos de alta atividade, como reatores nucleares, classificados como canais inconvenientes para obtenção de material para estudo. A literatura mostra que nas últimas décadas as duas principais fontes de radiação utilizadas foram: irradiação por raios gamma, emitidas por Cobalto-60 e irradiação por feixe de elétrons, emitida por fontes elétricas, tendo esta segunda maior aplicação industrial.

\subsubsection{Fontes de radiação por elétrons}

Segundo Manas et al. (2008) para obtenção do feixe de elétrons é utilizado um acelerador, o qual opera segundo o princípio de Braun, onde um cátodo é aquecido em vácuo até uma determinada temperatura onde elétrons são liberados deste cátodo. Simultaneamente, alta tensão é gerada em um vaso de pressão ocupado com gás isolante. Os elétrons liberados do cátodo são acelerados e direcionados neste vaso através de um campo magnético, dando origem à um feixe de elétrons. $O$ feixe é externalizado através de uma janela de titânio sobre o material a ser irradiado. O processo citado por Manas et al. (2008) é definido por Rosário (2008) como processo de obtenção indireta de feixe de elétrons.

Rosário (2006) cita como benefícios da utilização de radiação por elétrons o baixo custo e a alta segurança de operação desta fonte, quando comparados com os mesmos parâmetros de fontes de radioisótopos. A alta energia obtida com feixes de elétrons possibilita sua aplicação em filmes ou cabos em processos de alta velocidade. A Figura 8 compara a capacidade de penetração de radiação por feixe de elétrons de 4,5 MeV com radiação por raios gamma, obtidas por Cobalto 60 . 


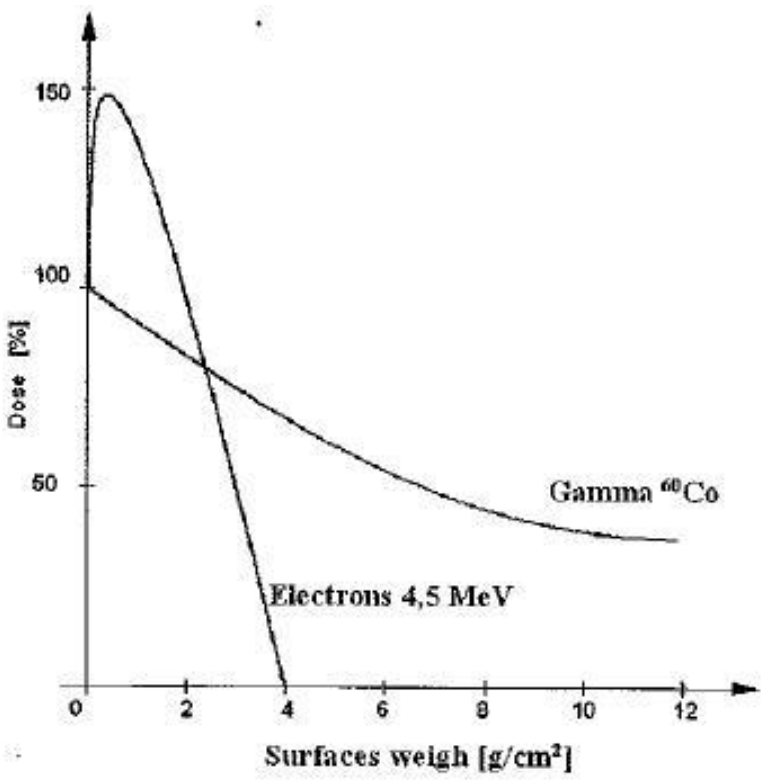

Figura 8 - Capacidade de penetração de radiação por elétrons- $\beta$ e gamma-y (Manas et al., 2008).

Além dos diversos trabalhos já citados onde o feixe de elétrons foi aplicado para alterar propriedades de polímeros, como PE, PP, PA e PC, alguns trabalhos apresentam a irradiação por elétrons como método alternativo para reticulação (crosslinking) ou vulcanização de elastômeros. Sendo que mais recentemente trabalhos foram publicados utilizando radiação ionizante como método de alteração de propriedades de elastômeros já vulcanizados.

\subsection{IRRADIAÇÕES DE ELASTÔMEROS}

\subsubsection{Radiação por elétrons aplicada como agente de vulcanização}

A reticulação ou vulcanização de elastômeros por processos químicos e térmicos apresenta uma história de sucesso nos últimos cem anos, criando desta forma uma resistência à introdução de outros processos em escala industrial, diferente do polietileno que apresenta larga aplicação em escala industrial.

De acordo com Bik et al. (2003) a reticulação induzida por radiação é proposta como uma alternativa para os métodos convencionais de reticulação. Diversos trabalhos foram publicados apresentando e em alguns casos comparando o comportamento 
de elastômeros curados por radiação ionizante com elastômeros vulcanizados pelos métodos convencionais. Bik et al. (2003) estudou o comportamento de borracha butadieno acrilonitrila hidrogenada (HNBR) irradiadas, Salgueiro (2007) estudou as alterações causadas pela radiação em borracha natural (NR) e borracha de butadieno estireno (SBR) e Vijayabaskar (2006) analisou a estrutura e propriedades de borrachas nitrílicas.

Apesar de ser apresentada como uma forma de vulcanização alternativa, a radiação ionizante é aplicada em elastômeros em escala bastante modesta. Zagórski (2004) cita como as principais aplicações industriais de irradiação de elastômeros a vulcanização parcial de borrachas "verdes", ou ecológicas, e a vulcanização de pneus em plantas pilotos.

Vijayabaskar (2006) afirma que a vulcanização por radiação tem vantagens como ser mais rápida, mais versátil, gerar uma vulcanização mais uniforme, consumir menos energia e requerer pouco espaço físico para implantação do processo. Além de não gerar resíduos químicos como alguns processos convencionais de vulcanização.

\subsubsection{Radiação por elétrons aplicada em elastômeros vulcanizados}

Embora a utilização de vulcanização por EB não tenha encontrado um segmento específico, o qual justifique sua aplicação em escala industrial, sua utilização na melhoria de propriedades de elastômeros especiais, pode ser uma boa oportunidade para justificar essa aplicação. Este trabalho, por exemplo, objetiva apresentar modelo de comportamento e proposta para redução de relaxação por compressão de borracha acrílica curada por radiação UV, propriedade que aumenta a capacidade de vedação de juntas sólidas.

Vijayabaskar (2004) define a irradiação de elastômeros por EB como uma solução verde, ocupando uma posição importante no caminho da concepção de um mundo livre de poluição, classifica o processo como limpo, requerendo pouco energia e permitindo alta velocidade de processo em temperatura ambiente.

Muitos trabalhos foram feitos sobre a irradiação de elastômeros não vulcanizados, tratando a tecnologia como processo alternativo de vulcanização, porém trabalhos 
sobre a utilização de radiação ionizante para alteração de propriedades de elastômeros já vulcanizados são poucos. Banik (2000) estudou os efeitos da radiação por EB em borracha natural (NR), borracha butadieno acrilonitrila (NBR) e borracha fluorada $(F K M)$. A radiação por feixe de elétrons alterou propriedades mecânicas dos materiais testados, aumentando o módulo de elasticidade e o alongamento da ruptura em todos os casos. Sendo que a variação da resistência à tração destes elastômeros, depois de irradiados, apresentou comportamentos distintos variando de acordo com material e dose aplicada.

Vijayabaskar (2004) estudou os efeitos da irradiação de borracha acrílica (ACM) vulcanizada em alta temperatura, misturados com diversos monômeros polifuncionais, identificando alterações em propriedades mecânicas e estruturais do ACM. Nenhum artigo foi encontrado sobre borrachas acrílicas, ou poliacrilatos, curados por radiação ultravioleta e posteriormente irradiados por EB, material de estudo deste desta tese.

\subsection{ALTERAÇÕES ESTRUTURAIS}

\subsubsection{Alterações estruturais nas cadeias poliméricas}

A radiação aplicada sobre os polímeros, incluindo os elastômeros, transfere energia ao material, interagindo com as suas moléculas e causando a ionização das mesmas. Essa ionização comumente ocorre devido à quebra de ligações de carbono, ou de ligações carbono hidrogênio, existentes ao longo da cadeia polimérica.

Rosário (2006) define dois efeitos principais causados pela irradiação de polímeros: Cisão da cadeia principal, onde há o rompimento da cadeia, reduzindo a massa molar do polímero e causando perda de propriedades mecânicas.

Reticulação que resulta na formação de várias ligações cruzadas, aumento da massa molar do polímero, podendo ocasionar melhorias nas propriedades físicas, químicas e mecânicas. 
Zagórski (2004) explica de outra maneira os efeitos da radiação ionizante em polímeros. Segundo este autor, os efeitos químicos da radiação em polímeros reticuláveis apresentam as seguintes conseqüências:

- A radiação ionizante interage estatisticamente com elétrons da camada de valência, não importando à qual componente do sistema ele pertence.

- A maior parte da energia aplicada, cerca de $80 \%$, gera a ionização simples da cadeia, que ao reagirem formam ligações do tipo $\mathrm{X}$, aumentam a reticulação do polímero irradiado. Os outros $20 \%$ geram ionização múltipla, responsáveis pelas cisões das cadeias e parcial degradação dos polímeros. Zagórski (2004) afirma que mesmo no caso de cisão das cadeias, em polímeros reticuláveis como PP e HNBR, o fragmento de cadeia pode se rearranjar com outra macromolécula próxima, dando origem à uma ligação de tipo Y. Desta forma, mesmo que $20 \%$ da energia aplicada gere ionização múltipla, somente de 6 a $9 \%$ terminam em degradação.

Bik et al. (2003) explica que a ionização múltipla é formada quando uma determinada quantidade de energia é depositada em uma região concentrada do polímero, com elétrons alcançando o final da degradação de sua energia. Isto ocasiona a cisão da cadeia, separando uma parte da cadeia da cadeia principal, devido a baixa mobilidade da parte desprendida, ela poderá reagir com a macromolécula mais próxima, gerando uma ligação do tipo $\mathrm{Y}$ ou por outro mecanismo de reação, como a oxidação, se estabilizar e reduzir o peso molecular do polímero.

A formação de ligações do tipo X é explicada por Zagórski (2004) pela reação entre dois pontos de ionização simples, os quais se mantêm distantes até o momento em que se encontram, devido à mobilidade das cadeias, e reagem quimicamente através da liberação de $\mathrm{H}_{2}$, conforme representado na Figura 9. Esta explicação implica na necessidade do encontro entre os pontos ionizados para que ocorra a reação, sendo assim este efeito deve ser menor em polímeros semicristalinos e maior em polímeros amorfos, como a maioria dos elastômeros. 


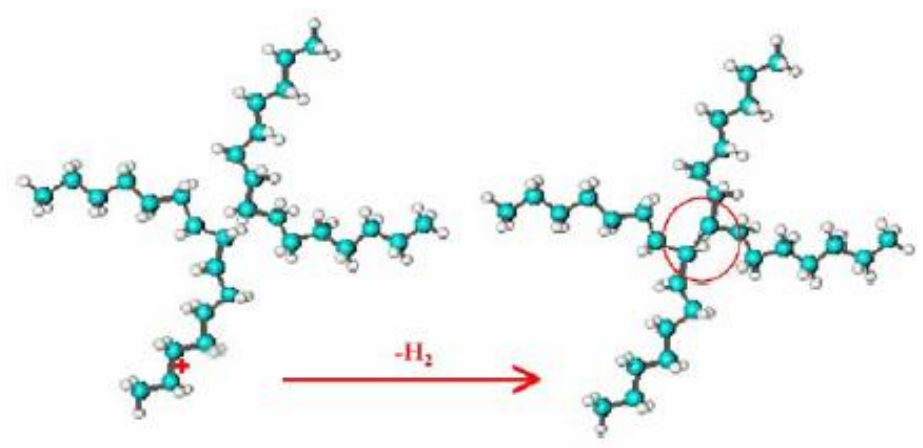

Figura 9 - Reticulação tipo X em polietileno por ionização simples (Zagórski, 2004).

\subsubsection{Alterações estruturais em poliacrilatos (ACM)}

Vijayabaskar (2004) apresenta algumas possíveis reações causadas pela radiação EB em borrachas acrílicas curadas por processo térmico. O aumento da reticulação, já apresentado anteriormente, e segundo Zagórski (2004) conseqüência de ligações tipo X é esquematizado e apresentado por Vijayabaskar (2004) na Figura 10, devese atender para o ponto de ionização gerado no átomo de carbono e conseqüente formação de um macroradical.

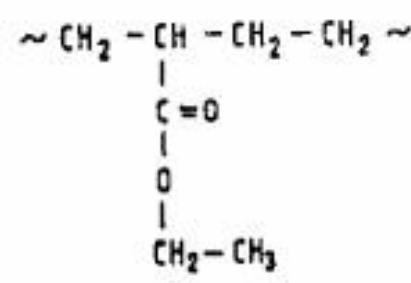

E B

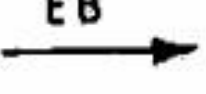

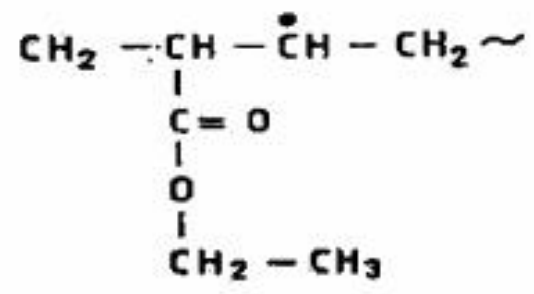

Macroradical

Figura 10 - Geração de macroradical e conseqüente ligação tipo X em ACM (Vijayabaskar, 2004).

Outra reação proveniente da formação de macroradicais é a oxidação, onde o macroradical gerado por EB reage com oxigênio presente no ambiente, dando origem à uma ligação $\mathrm{C}=\mathrm{O}$, conforme ilustrado na Figura 11 . 


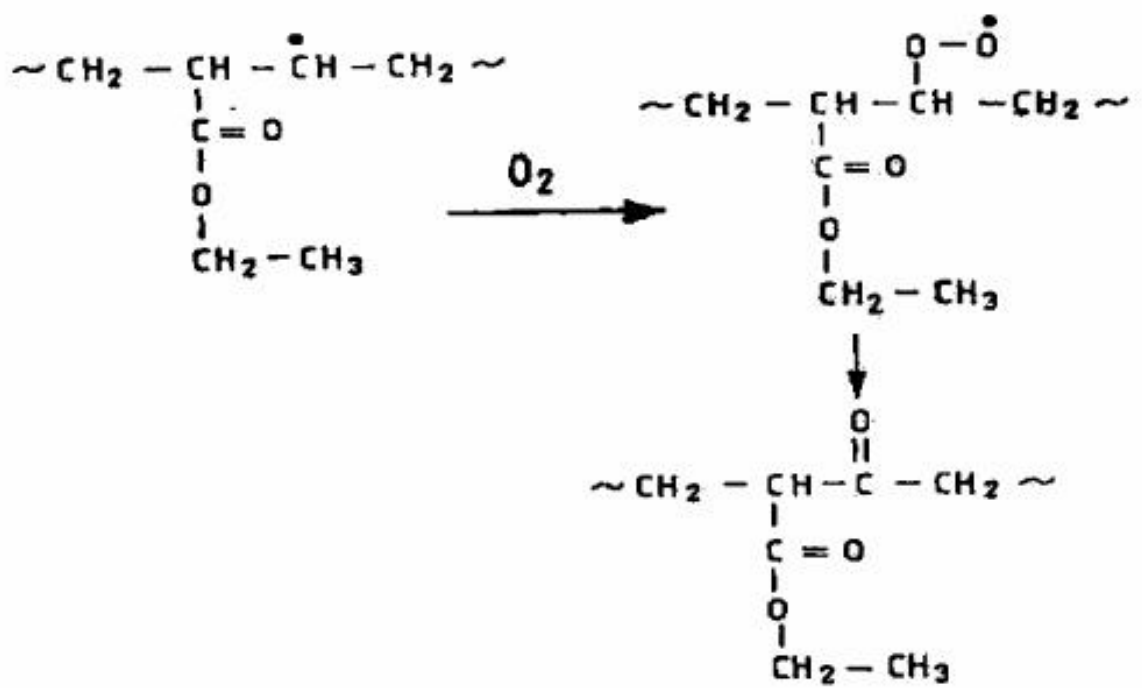

Figura 11 - Reação de oxidação em ACM (Vijayabaskar, 2004).

A Figura 12 representa outra reação possível causada pela irradiação de $A C M$, curado por processo térmico, onde inicialmente ocorre a cisão da cadeia através da quebra de uma ligação simples de carbono, um dos radicais formados reage com oxigênio e posteriormente com hidrogênio. O resultado final da reação é a recombinação das duas partes da cadeia, inicialmente separadas, sendo estas porém interligadas por um átomo de oxigênio, dando origem à uma ligação C-O-C.

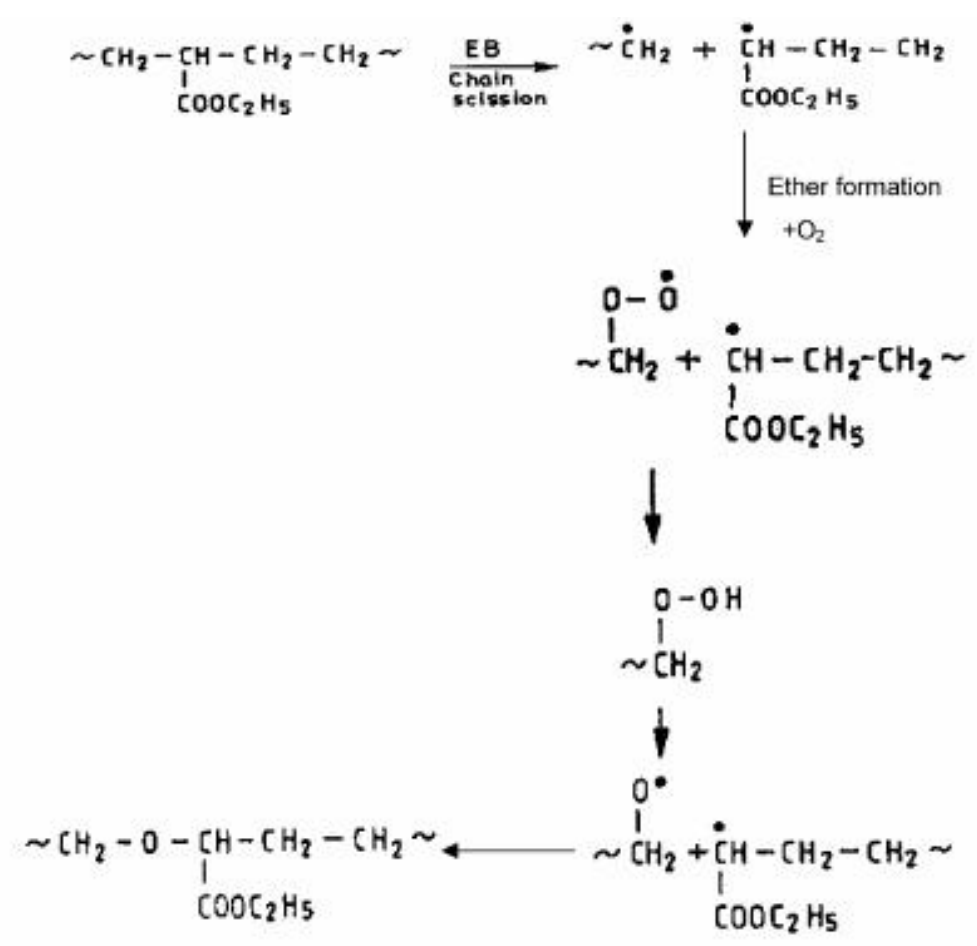

Figura 12 - Formação de ligação tipo C-O-C em ACM (Vijayabaskar, 2004). 


\section{CARACTERIZAÇÃO DE POLÍMEROS}

\subsection{ESPECTROSCOPIA POR INFRAVERMELHO}

A espectroscopia por infravermelho é uma técnica não destrutiva de caracterização, aplicável à uma vasta quantidade de materiais, que permite identificação das ligações químicas dos materiais, com pouca ou nenhuma preparação dos corpos de prova. Um espectro infravermelho resulta de interações dos movimentos de vibrações de um material com radiação eletromagnética. Estas interações vibracionais podem ser descritas por um modelo oscilatório harmônico simples (KOENIG, 1997).

Diversos técnicas de espectroscopia por infravermelho são encontradas na literatura, Vijayabaskar (2004) utilizou o método de reflectância total atenuada (ATR) para comparar as ligações químicas do elastômero acrílico (ACM) com e sem a aplicação de radiação. Segundo Koenig (1997) este método é indicado para análise de materiais líquidos ou poliméricos, condições onde um contato óptico não apresenta problemas.

\subsubsection{Reflectância Total Atenuada (ATR)}

O método de refletância total atenuada (ATR), também conhecido como espectroscopia de reflexão interna (IRS) é uma técnica para a obtenção de espectro de absorbância de materiais opacos. O material a ser analisado entra em contato óptico com um elemento de reflexão interna do equipamento, formando uma interface através da qual um campo evanescente não propagante penetra no material a ser analisado em profundidades da ordem do comprimento de onda da radiação. Quando um material absorbante de radiação infravermelha está em contato com o elemento de reflexão, a onda evanescente interage com o material, causando uma atenuação na propagação da radiação infravermelha dentro do elemento. Desta forma, na saída deste elemento, é possível o espectro verificando 
qual foi a absorbância gerada pela material analisado, em diversas faixas do espectro infravermelho.

Cada tipo de ligação química apresenta maior absorbância em determinados comprimentos de onda do espectro infravermelho. O pico do espectro de absorbância têm relação linear direta com a quantidade de ligações químicas existentes no material, segundo a lei de Lambert-Beer. Por exemplo, em elastômero acrílico (ACM) quando maior o pico de absorbância apresentado para o comprimento de onda de $1740 \mathrm{~cm}^{-1}$, maior a quantidade de ligações tipo $>\mathrm{C}=\mathrm{O}$ existe no material. Vijayabaskar (2004) relaciona os comprimentos de onda específicos para identificar alguns tipos de ligações, grupos funcionais, em borracha acrílica, apresentados na Tabela 2.

Tabela 2 - Pico de absorbância do espectro IR para borracha ACM (Vijayabaskar, 2004).

\begin{tabular}{ll}
\hline Comprimento de onda $\left(\mathrm{cm}^{-1}\right)$ & Grupo funcional \\
\hline 1740 & $>\mathrm{C}=\mathrm{O}$ \\
1632 & $>\mathrm{C}=\mathrm{C}<$ \\
1160 & C $-\mathrm{O}-\mathrm{C}$ \\
\hline
\end{tabular}

\subsection{CALORIMETRIA DIFERENCIAL DE VARREDURA}

Os elastômeros aplicados em vedações, principalmente de componentes de motores e transmissões automotivos, normalmente trabalham em temperaturas em torno de $90^{\circ} \mathrm{C}$ até $150^{\circ} \mathrm{C}$. Desta forma, o estudo do comportamento destes materiais em altas temperaturas merece especial atenção.

Os polímeros apresentam variação das propriedades térmicas de acordo com sua estrutura, os termoplásticos, por exemplo, apresentam determinadas faixas de temperatura através das quais seus comportamentos podem ser caracterizados, como: temperatura de transição vítrea e temperatura de fusão. Os polímeros termofixos, como os elastômeros, não apresentam temperatura de fusão devido sua estrutura reticulada e amorfa, a temperatura de fusão é uma característica dos termoplásticos. Porém apresentam temperatura de transição vítrea, como os termoplásticos, e temperatura de degradação, ou fragmentação da estrutura molecular, fatores importantes na especificação de suas aplicações. Tais 
temperaturas podem ser determinadas através de diversas técnicas, dentre estas a chamada calorimetria diferencial de varredura (DSC), segundo Shah (1984) trata-se de uma técnica de medições calorimétricas pelo verificação e integração da diferença de temperatura ou pela verificação da energia necessária para estabelecer a diferença de temperatura zero entre o material analisado e uma referência.

Basicamente o equipamento de DSC opera dois compartimentos, monitorando a temperatura e a energia fornecida para dois materiais diferentes por filamentos individuais de platina, que trabalham como termômetros resistivos e aquecedores de para dois materiais. Trata-se de um material a ser analisado e de outro utilizado como referência, este segundo tem seu comportamento térmico conhecido.

Com taxa constante, calor é fornecido aos materiais com o objetivo de elevar suas temperaturas e de mantê-las idênticas. Durante qualquer processo físico ou químico que ocorra na amostra, faz-se necessário alterar a quantidade de calor fornecida para re-equillibrar as temperaturas. A determinação do material que receberá maior quantidade de calor dependerá se o processo ocorrido na amostra é exotérmico ou endotérmico. A temperatura onde se inicia o aumento da taxa de energia fornecida, caracteriza o ponto onde se dá início do processo químico ou físico, bem como o ponto onde as taxas de energia e as temperaturas voltam a ser idênticas, encontrase a temperatura final deste processo. A diferença da quantidade das energias fornecidas, quantifica a energia necessária para realização do mesmo.

\subsubsection{Determinação da temperatura de transição vítrea $\left(\mathrm{T}_{\mathrm{g}}\right)$ por DSC}

Uma das mais importantes características dos polímeros em estado amorfo é o comportamento destes durante a transição do estado sólido para líquido. Se o polímero amorfo no estado vítreo é aquecido, a energia cinética das moléculas aumenta, sendo esta movimentação restrita à vibrações e rotações. Aumentando a temperatura do polímero atinge-se um ponto onde ocorrem alterações em seu comportamento, o polímero perde propriedades de materiais rígidos e assume propriedades similares as dos elastômeros (CARNEVAROLO, 2002). 
A temperatura onde ocorrem essas modificações é chamada Temperatura de Transição Vítrea $\left(T_{g}\right)$. Com menor freqüência alguns polímeros possuem uma Temperatura de Transição Vítrea de Segunda Ordem. Caso o polímero continue a ser aquecido, provavelmente este perderá suas propriedades de elastômeros e se tornará líquido, afirmação válida para termoplásticos. No caso de termofixos,os polímeros degradam em caso de superaquecimento.

A $T_{g}$ é uma das características fundamentais do polímero e relata suas propriedades e processabilidade. A partir da $T_{g}$ ocorre um aumento da liberdade rotacional e conseqüentemente maior movimentação das cadeias. $O$ aumento da liberdade de movimentação ocasiona maior distância entre os átomos, aumentando desta forma o volume especifico do polímero. O monitoramento da variação do volume especifico é uma forma de determinação da temperatura de transição vítrea.

A temperatura de transição vítrea é identificada através de uma variação brusca no calor específico do material, sem alteração da entalpia do mesmo (LUCAS; SOARES \& MONTEIRO, 2001). A Figura 13 apresenta uma curva típica obtida por DSC, onde podem ser identificados processos endotérmicos, exotérmicos e a temperatura de transição vítrea. A temperatura de cristalização $\left(T_{c}\right)$ é um processo exotérmico, já a temperatura de fusão $\left(T_{m}\right)$ trata-se de um processo endotérmico, onde ocorre a separação das cadeias cristalinas. A área abaixo da curva da $T_{c}$ representa a quantidade de energia envolvida no processo.

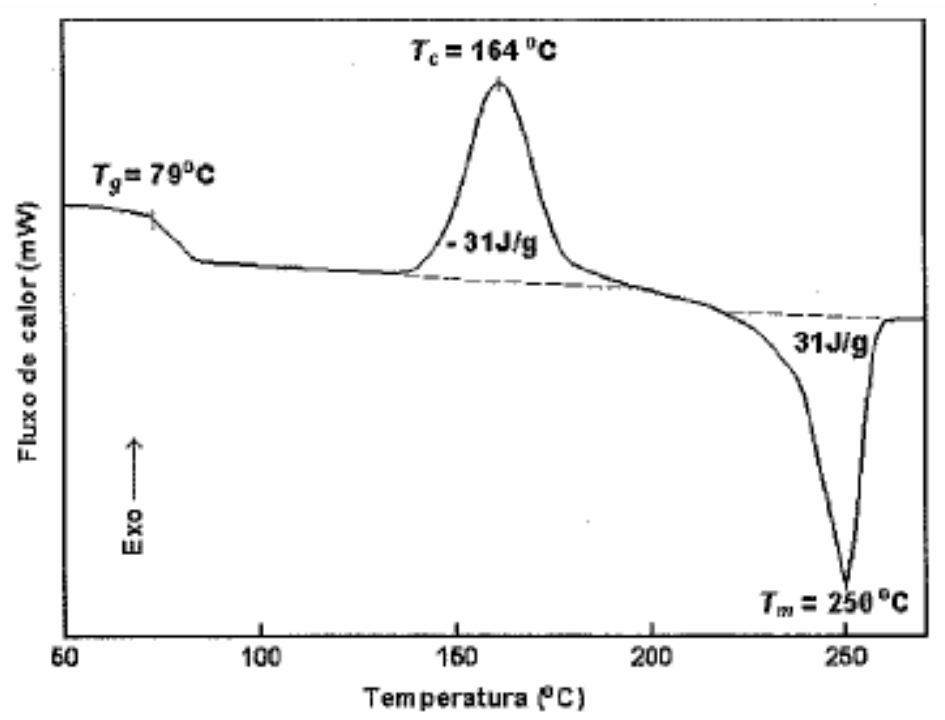

Figura 13 - Curva de DSC de PET, registrada a $20^{\circ} \mathrm{C} / \mathrm{min}$ (Lucas; Soares e Monteiro, 2001). 
Lucas, Soares e Monteiro (2001) apresentam três possibilidade de determinação da temperatura de transição vítrea através de curvas de DSC. Figura 14: (a) no início da transição, $T_{1}$; (b) na meia altura dos prolongamentos, $T_{2}$; e (c) no ponto de inflexão da curva, $T_{3}$. $O$ início da transição é tomado pela interseção dos prolongamentos da descontinuidade. A meia altura dos prolongamentos diz respeito aos prolongamentos das linhas tangentes à curva, antes e após a transição, traçando-se uma perpendicular à estes prolongamentos, a qual é cortada ao meio pela DSC.

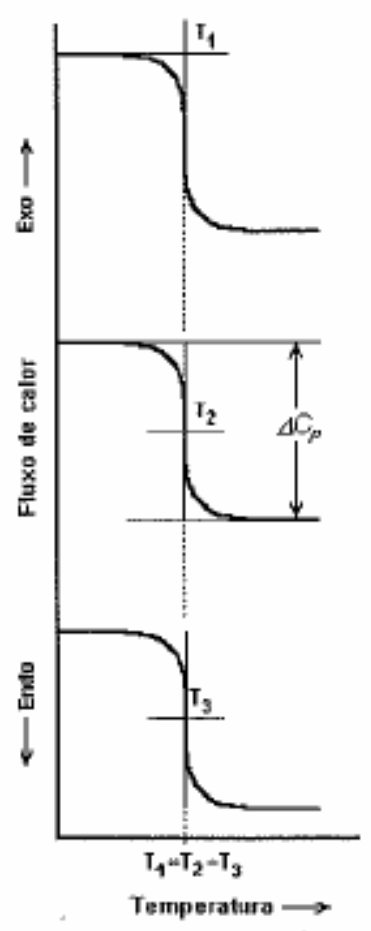

(a)

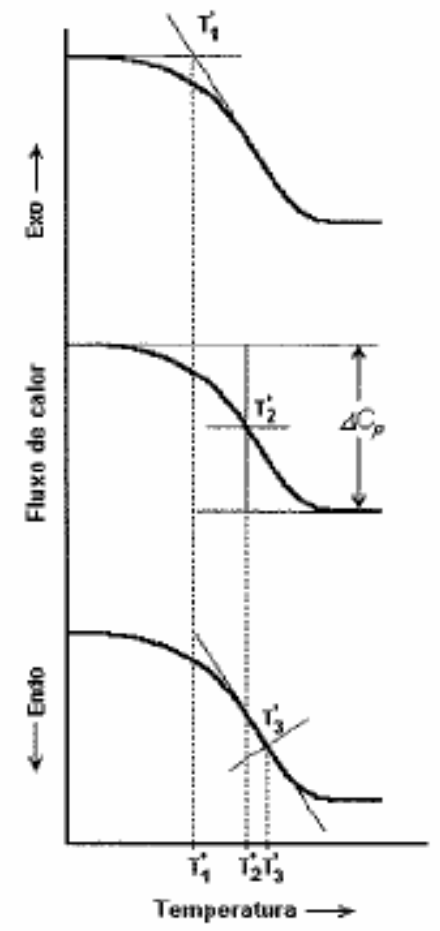

Figura 14 - Métodos de determinação de Tg em curvas de DSC (Lucas; Soares e Monteiro, 2001).

\subsection{ANÁLISE TERMODINÂMICO-MECÂNICA (DMTA)}

Este método possibilita o estudo do comportamento viscoelástico de materiais através da análise de dois tipos de contribuições, a elástica e a viscosa. Neste tipo de ensaio o material é tracionado ciclicamente, com deformação senoidal do tipo $\gamma=\gamma_{0} \operatorname{sen}(\omega t)$ de amplitude máxima $\gamma_{0}$ e freqüência angular $\omega(=2 \pi f)$, ao longo de uma faixa pré-determinada de temperatura, resultando em uma variação da tensão senoidal em função da variação da temperatura. Tal variação da tensão, aplicada a 
um modelo matemático, permite identificar a variação da contribuições elástica e viscosa do material ao longo da faixa de temperatura citada.

Ao considerar o comportamento de um material como elástico ideal e submetê-lo a uma deformação senoidal do tipo:

$$
\gamma=\gamma_{0} \operatorname{sen}(\omega t)
$$

A resposta tensão também será senoidal e estará em fase com a deformação, considerando o módulo de elasticidade como a razão entre a amplitude máxima de tensão e a amplitude máxima de deformação, com algumas manipulações algébricas simples pode-se descrever a resposta tensão de um material elástico ideal através da Equação 23:

$$
\sigma=E \gamma_{0} \operatorname{sen}(\omega t)
$$

Para um material de comportamento viscoso ideal a resposta tensão também será do tipo senoidal, porém defasada de $90^{\circ}$ em relação a deformação. Para materiais de comportamento viscoso a tensão e a taxa de deformação estão relacionadas entre si pela viscosidade ( $\eta$ ), conforme Equação 24:

$$
\eta=\frac{\sigma}{\dot{\gamma}}
$$

Como a deformação aplicada é tipo senoidal, descrita na Equação 22 e a taxa de deformação é dada pela derivada da deformação em função do tempo, resposta tensão para um material elástico ideal é dada pela Equação 25:

$$
\sigma=\eta \omega \gamma_{0} \cos (\omega t)
$$

O comportamento de elastômeros normalmente é considerado como viscoelástico, apresentando contribuições tanto elástica como viscosa em um mesmo material, desta forma a tensão resposta de um material viscoelástico deve ser do tipo senoidal, defasada por um ângulo $\delta(0 \leq \delta \leq \pi / 2)$ dada pela Equação 26 : 


$$
\sigma=\sigma_{0} \operatorname{sen}(\omega t+\delta)
$$

Aplicando a regra de $\operatorname{sen}(A+B)=\operatorname{sen} A \cos B+\operatorname{sen} B \cos A$ torna-se possível resolver a Equação 27 em duas componentes, uma em fase com a deformação, relacionada com a energia elástica armazenada e representada pelo primeiro termo da Equação 27, a outra defasada em $90^{\circ}$ da deformação, relacionada com a energia viscosa dissipada e representada pelo segundo termo da Equação 26.

$$
\sigma=\sigma_{0} \operatorname{sen}(\omega t) \cos \delta+\sigma_{0} \cos (\omega t) \operatorname{sen} \delta
$$

Ao dividir cada uma das componentes pela deformação senoidal aplicada, obtém-se dois módulos. O módulo de armazenamento de energia elástica E', representado pela Equação 27 e o módulo de perda de energia viscosa representado pela Equação 28.

$$
\begin{aligned}
& E^{\prime}=\frac{\sigma_{0} \operatorname{sen}(\omega t)}{\gamma_{0} \operatorname{sen}(\omega t)} \cos \delta \\
& E^{\prime \prime}=\frac{\sigma_{0} \cos (\omega t)}{\gamma_{0} \operatorname{sen}(\omega t)} \operatorname{sen} \delta
\end{aligned}
$$

A análise de DMTA permite estudar a variação das contribuições das parcelas elástica e viscosa de um material, bem como determinar a temperatura de transição vítrea $\left(T_{g}\right)$ do mesmo.

\subsubsection{Determinação da temperatura de transição vítrea $\left(T_{g}\right)$ por DMTA}

Além da análise das contribuições elástica e viscosa do material, o DMTA permite determinar de maneira precisa a temperatura de transição vítrea de polímeros. De acordo com Costa (2008) a DMTA apresenta maior precisão na determinação da $T_{g}$, 
sendo capaz de identificar movimentações moleculares de menor intensidade e com maior sensibilidade, quando comparado ao método de DSC.

$A T_{g}$ é determinada na DMTA através da análise da relação entre o módulo de perda de energia viscosa e o módulo de armazenamento de energia elástica, tal relação, denominada tangente de perda (tan $\delta)$, é apresentada na Equação 30:

$$
\tan \delta=\frac{E^{\prime \prime}}{E^{\prime}}
$$

Conforme apresentado neste trabalho, a $\mathrm{T}_{\mathrm{g}}$ é determinada pela alteração do comportamento do material, região onde o comportamento passa de uma predominância elástica para uma maior contribuição viscosa, assumindo a partir deste ponto o comportamento viscoelástico. A tangente de perda é a relação destas contribuições, a redução da contribuição elástica, ou da capacidade de armazenamento de energia elástica (E') e o aumento da dissipação de energia viscosa, causada pelo aumento da contribuição viscoso do material, gera um pico na curva da tangente de perda em função do aumento da temperatura, através do qual a $T_{g}$ é determinada, ou seja, temperatura a partir da qual a parcela viscosa é superior a parcela de contribuição elástica no comportamento do material.

A DMTA permite identificar a imiscibilidade entre possíveis fases de um polímero, através do número de picos da curva da tangente de perda. Este trabalho utilizou o método de DMTA na determinação da $T_{g}$ e na análise das contribuições elástica e viscoso do ACM.

\subsection{ANÁLISE TERMOGRAVIMÉTRICA}

A análise termogravimétrica (TGA) é definida como um processo contínuo que envolve a medição da variação de massa de uma amostra em função da temperatura (varredura de temperatura), ou do tempo a uma temperatura constante (modo isotérmico) (LUCAS; SOARES \& MONTEIRO, 2001). 
Este processo de análise consiste basicamente do aquecimento de uma amostra a uma taxa constante, normalmente de $10^{\circ} \mathrm{C} / \mathrm{min}$, com o monitoramento da perda de massa causada por este aumento de temperatura, medidas por uma balança. As principais causas de perda de massa são volatilização ou degradação.

De acordo com Shah (1984), a análise termogravimétrica é muito utilizada na caracterização de polímeros contendo diferentes níveis de aditivos pela medição dos graus de perdas de massa. Cada aditivo volatiliza a uma determinada temperatura, sendo possível determinar tal temperatura de volatilização de cada aditivo, através do gráfico gerado pelo ensaios de TGA. A Figura 15 mostra a curva de TGA de um homopolímero sem aditivos, comparativamente com a curva do mesmo polímero com aditivo, ilustrando a variação na perda percentual da massa.

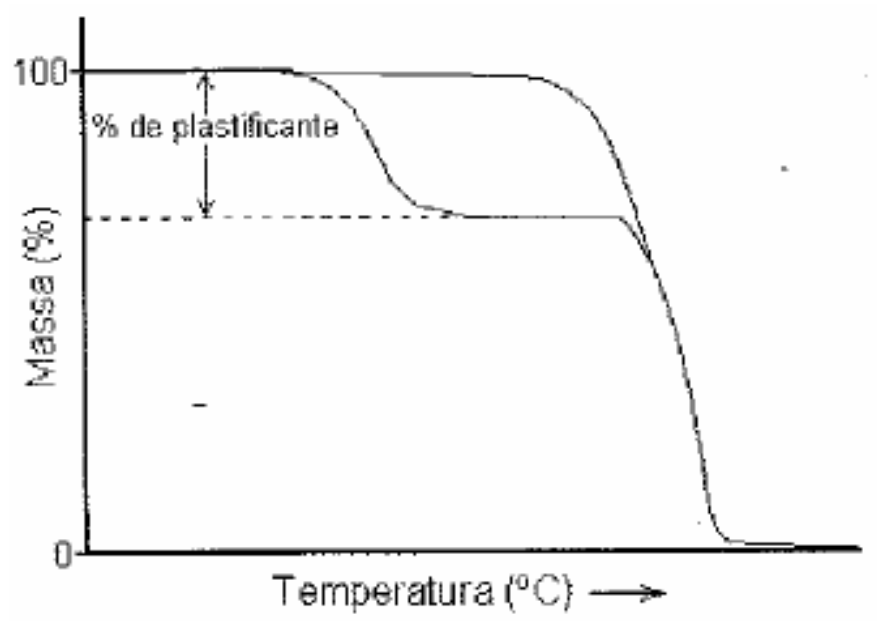

Figura 15 - Curvas de TGA de: (a) polímero A + plastificante e (b) polímero A puro (Lucas; Soares e Monteiro, 2001).

Comumente os gráficos são expressos em percentual de perda de massa em função do aumento de temperatura, podendo também ser possível encontrar gráficos descritos por massa (abscissa) em função da variação da temperatura. Além de identificar a temperatura de volatilização de cada componente do polímero, esta análise permite identificar as temperaturas de início e fim de degradação do material, a Figura 16 ilustra os pontos de determinação de tais temperaturas. 


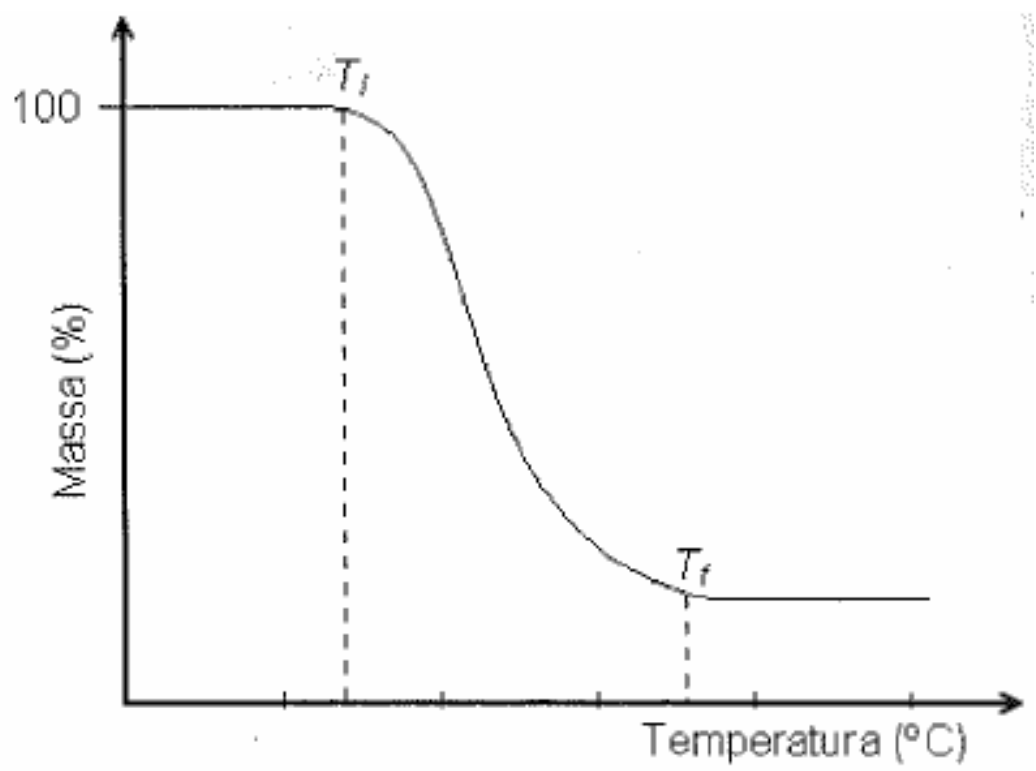

Figura 16 - Curva de decomposição térmica de um material (Lucas; Soares e Monteiro, 2001).

Diversos fatores influenciam nos resultados obtidos por TGA, como forma da amostra, atmosfera da câmara, velocidade de aquecimento e sonda de medição de massa. A amostra ensaiada pode apresentar-se na forma de pó, grânulos ou flocos, resultando em curvas diferentes mesmo se tratando do mesmo material. Quanto a velocidade de aquecimento, quanto maior a taxa de aquecimento maiores são as temperaturas de início e fim de degradação. $O$ fator de maior influência é o gás de arraste ou atmosfera da câmara, o ambiente onde ocorre o aquecimento influencia de maneira acentuada no resultado, com o objetivo de minimizar tal influência normalmente se utiliza nitrogênio $\left(\mathrm{N}_{2}\right)$ com gás de arraste do material volatilizado ou degradado.

Os fenômenos de volatilização e degradação, ou fragmentação da estrutura, são melhores esclarecidos pelos processos definidos por Lucas, Soares e Monteiro (2001) como despolimerização, clivagem aleatória e casual de cadeia, e reações intra e intermoleculares.

A despolimerização se baseia na clivagem das cadeias seguida pelo processo exatamente oposto ao da polimerização, ou seja, a geração de radicais livres que se recombinam gerando uma grande quantidade de monômero, tal processo é caracterizado por um único estágio verificado na curva. Como exemplo de polímeros que despolimerizam pode-se citar o poli(metacrilato de metila) (PMMA), conforme apresentado na Figura 17. 
A clivagem aleatória e casual das cadeias, ou degradação de polímeros que não despolimerizam, normalmente é apresentada pelas poliolefinas. O processo inicial de degradação se dá pela clivagem aleatória seguida pelo rompimento casual de ligações simples de carbono $\mathrm{R}-\mathrm{C}-\mathrm{C}-\mathrm{R}$, principalmente de ramificações ou ligações fracas geradas durante o processo de polimerização.

Os polímeros que sofrem reações intra- e intermoleculares inicial sua degradação por uma reação química intramolecular, seguida por uma reação de reticulação e clivagem aleatória da cadeia com alta geração de voláteis, conforme o poli(metacrilato de t-butila) cuja curva de perda de massa está apresentada na Figura 17.

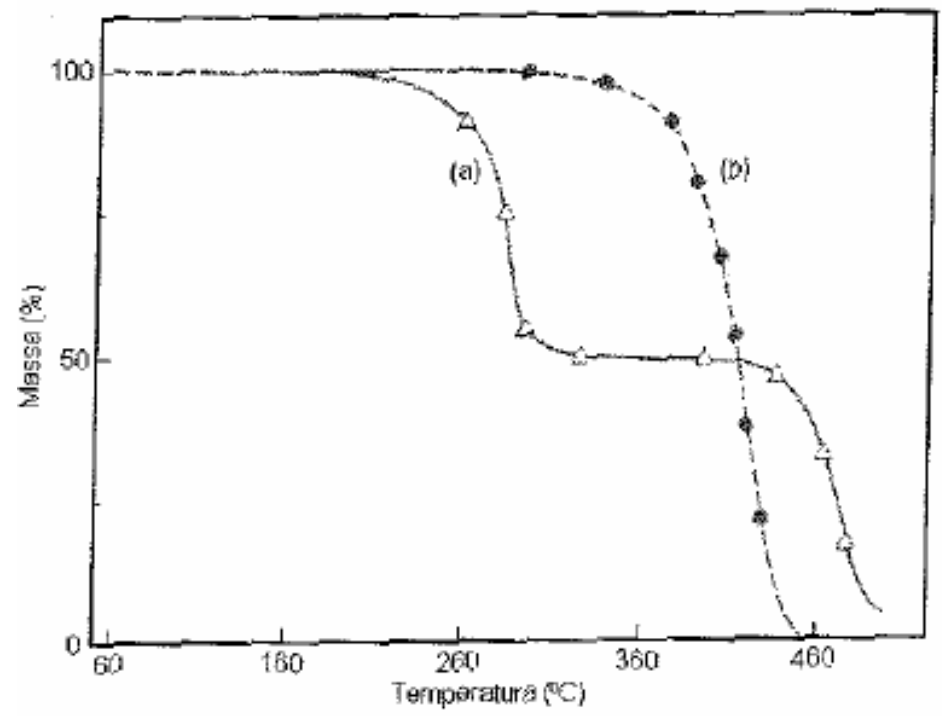

Figura 17 - Curvas de TGA de homopolímeros: (a) poli(metacrilato de t-butila) e (b) poli(metacrilato de metila) (Lucas; Soares e Monteiro, 2001).

A estabilidade térmica de materiais poliméricos pode variar em função do nível de reticulação, ou massa molar. Em alguns casos foi verificada variação de $20^{\circ} \mathrm{C}$ na temperatura de degradação de um determinado polímero ao variar sua massa molar. Porém, após uma determinação do nível de reticulação esta variação deixa de ocorrer, devido a redução dos terminais de cadeia conseqüentes do alto nível de reticulação. Desta forma, a partir de um determinado nível de reticulação, ou massa molar, a temperatura de degradação do polímero deixa de aumentar. 


\section{VISCOELASTICIDADE LINEAR}

O comportamento de alguns sistemas poliméricos usualmente são representados pela combinação de dois tipos particulares de materiais ideais: o sólido elástico e o líquido viscoso. O sólido elástico tem a capacidade de se deformar e retornar à sua forma inicial, quando as forças externas que causam a deformação são retiradas. $O$ líquido, em contraste ao sólido, não tem uma forma definitiva e se deforma de maneira irreversível sob a ação de forças externas (WARD; SWEENEY, 2004).

A combinação do comportamento destes dois materiais ideais resulta em um fenômeno chamado viscoelasticidade. Segundo Navarro (1997) a viscoelasticidade é um fenômeno dependente do tempo. Carreau; De Kee e Chhabra (1997) citam polímeros termoplásticos e elastômeros como materiais que apresentam comportamento viscoelástico e afirmam que a natureza viscoelástico destes polímeros não pode ser negligenciada.

A associação de elementos mecânicos simples, molas e amortecedores, é utilizada para fundamentar modelos de comportamento do fenômeno da viscoelasticidade, sendo que a mola representa a parcela elástica do material e o amortecedor a parcela viscosa.

O modelo mais simples e conhecido para representar o comportamento viscoelástico dos materiais é o Modelo de Maxwell, onde uma mola e um amortecedor são colocados em série, conforme Figura 18 , se submetendo à tensões idênticas, causadas por uma força externa e dividindo a deformação em parcelas definidas pelas propriedades de cada elemento, mola ou amortecedor. O segundo modelo mais utilizado e também bastante simples é o Modelo de Kelvin, onde os elementos mola e amortecedor são dispostos em configuração paralela e devido à isto, ao contrário do ocorrido com os elementos de Maxwell, a tensão causada pela força externa se divide entre os elementos de acordo com suas propriedades e a deformação é igual nos dois elementos, conforme Figura 18. 

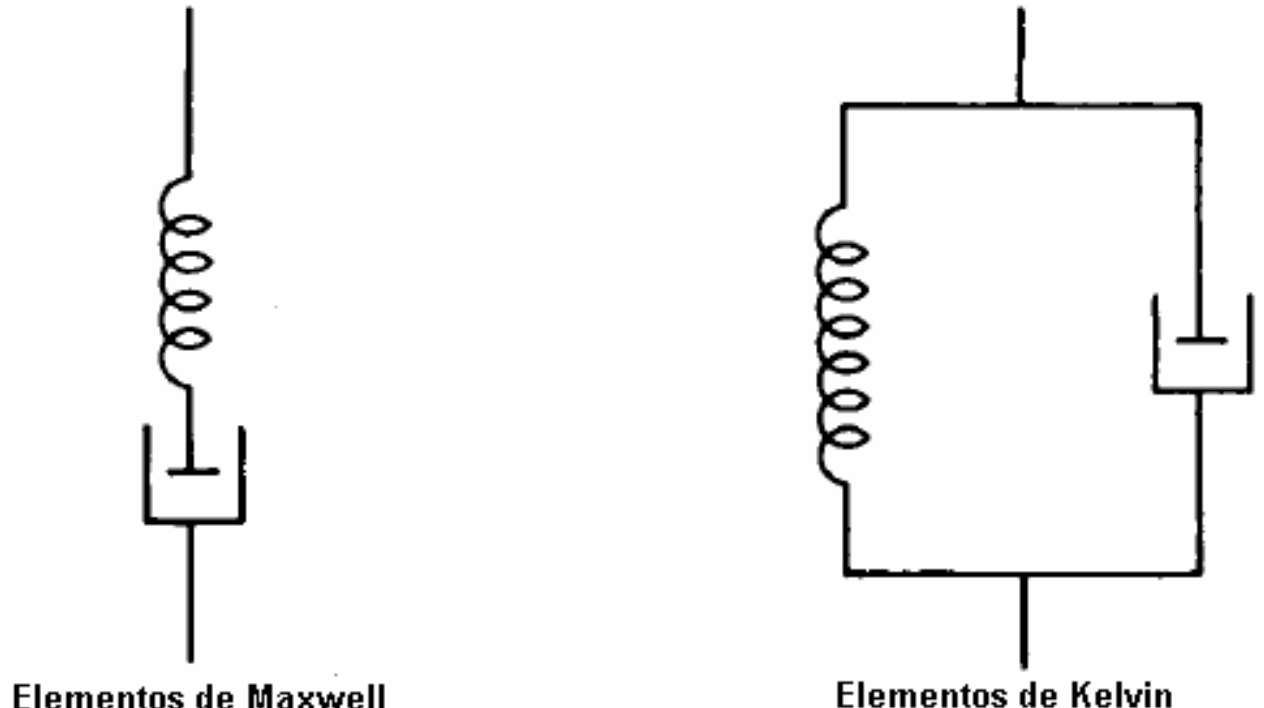

Elementos de Kelvin

Figura 18 - Elementos de Maxwell e Kelvin (Sperling, 2006).

Este dois modelos citados tratam da viscoelasticidade linear, que segundo Carreau; De Kee e Chhabra (1997) é o campo da reologia responsável pelo estudo de materiais viscoelásticos sob pequenas deformações ou deslocamentos. A deformação deve ser suficientemente pequena, de maneira que a estrutura do material, por exemplo a conformação das macromoléculas, não seja perturbada. De acordo com estes autores, deformações de até 0,5 são aceitáveis para tratamento por modelos viscoelásticos lineares.

O fenômeno da viscoelasticidade linear pode ser aplicado para modelar os comportamentos de fluência (creep) e relaxação da tensão apresentados por elastômeros ao longo do tempo. Mostafa (2009) atribui à fluência e a relaxação de tensão, apresentados pelos elastômeros, a limitação da aplicação destes materiais em solicitações estruturais. A relaxação da tensão pode comprometer aplicações de elastômeros como elementos de vedação, na forma de anéis ou juntas sólidas. Ao serem comprimidos estes elementos oferecem uma resistência, ou tensão, contrária ao sentido de compressão. Com o passar do tempo esta tensão é reduzida devido a relaxação do material, comprometendo a função do elemento de vedação. Placek; Kohout e Bartonicek (2009) estudaram a relaxação da tensão de anéis de vedação em componentes de reatores nucleares, submetidos à irradiação espontânea. 


\subsection{RELAXAÇÃO DA TENSÃO}

Quando uma deformação instantânea é aplicada à um sólido elástico ideal uma tensão finita e constante será gerada no material. Para um sólido viscoelástico submetido à uma deformação nominal instantânea a tensão inicial será proporcional à deformação aplicada, decaindo com o tempo à uma taxa caracterizada pelo tempo de relaxação, enquanto a deformação é mantida constante, situação apresentada na Figura 19 (WARD; SWEENEY, 2004).

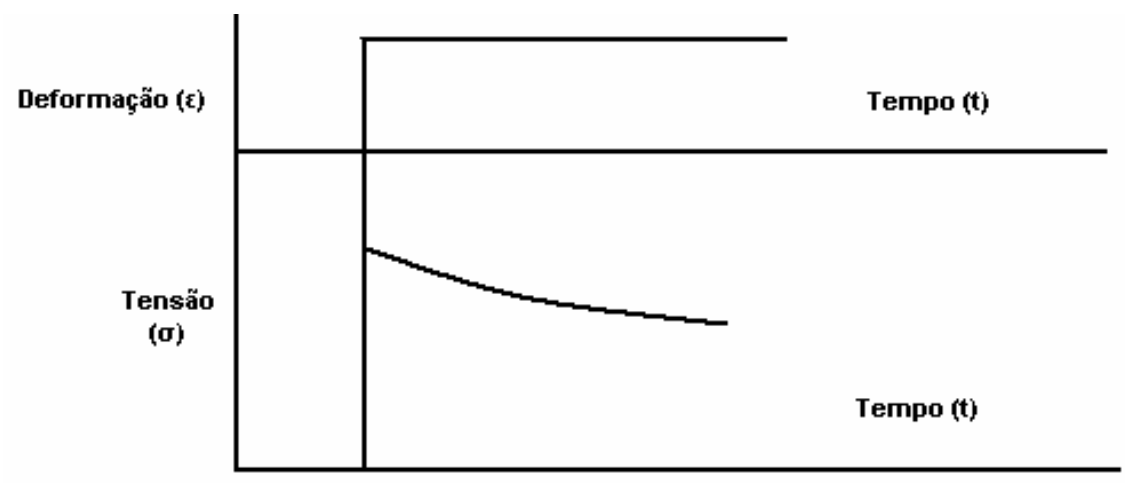

Figura 19 - Relaxamento da tensão (Ward; Sweeney, 2004).

Sperling (2006) apresenta algumas prováveis causas, baseadas nas estruturas moleculares, para a relaxação da tensão:

Cisão da cadeia: Fragmentação por oxidação e hidrólises são as causas primárias. A redução na resistência causada pela cisão da cadeia durante o relaxamento da tensão pode ser ilustrada por um modelo, conforme Figura 20, onde três cadeias estão suportando um carregamento e uma delas é cisionada.
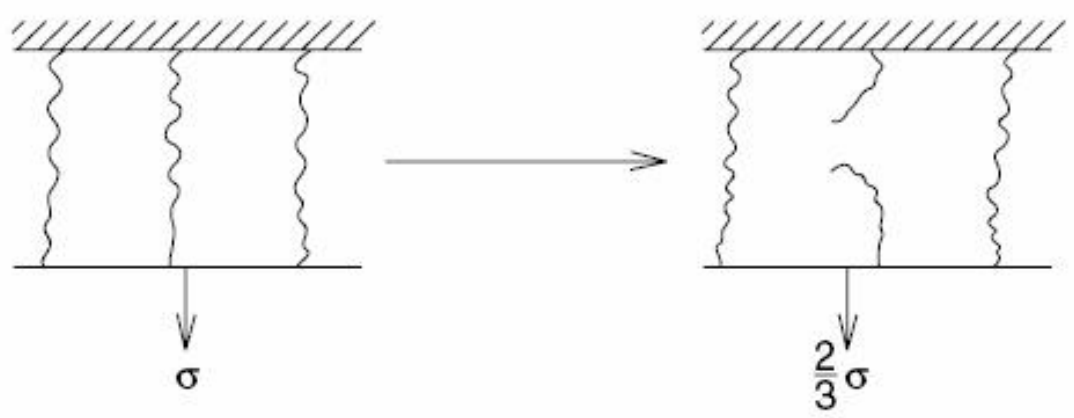

Figura 20 - Oxidação e cisão de uma das cadeias (Sperling, 2006). 
Intercâmbio e dissociação de ligações físicas: Porções da cadeia trocam os parceiros com os quais interagem fisicamente, causando uma relaxação da tensão. O intercâmbio de ligações não está condicionado à tensões geradas pela aplicação de uma força externa, ou seja, pode acontecer com o material em repouso, porém em escala inferior de quantidades. Em alguns casos os parceiros apenas se dissociam temporariamente, gerando uma relaxação reversível após a retirada da tensão, comportamento denominado como dissociação de ligações físicas, esta por sua vez depende de uma tensão gerada por força externa e segundo Sperling (2006) é responsável por aproximadamente $5 \%$ da relaxação do material. Monteiro e Fonseca (1998) ilustram o fenômeno da dissociação de ligações físicas na Figura 21. Estas duas causas não são consideradas degradação do material, por não reduzirem seu peso molecular.
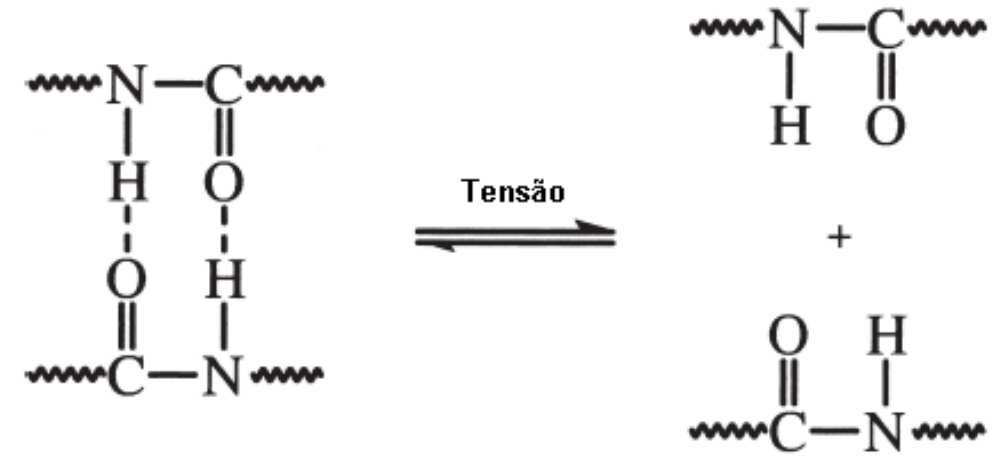

Figura 21 - Dissociação de ligações de ponte de hidrogênio (Monteiro e Fonseca, 1998).

Fluxo viscoso: Causado pelo escorregamento linear das cadeias através de outras cadeias.

Relaxação molecular próximo à temperatura de transição vítrea: Em experimentos de relaxação da tensão as cadeias relaxam ao se aproximarem da temperatura de transição vítrea, tendendo a liberar à tensão do material através da movimentação das cadeias.

É necessário enfatizar que mais de um modo de relaxação citado acima influencia simultaneamente no fenômeno da relaxação da tensão. 


\subsection{MODELO DE MAXWELL}

O Modelo de Maxwell é classificado por Navarro (1997) como a mais simples analogia mecânica para representar a viscoelasticidade, obtida pela associação de uma mola de módulo $E_{m}$ com um amortecedor que contém um fluido de viscosidade $\eta_{a}$, apresentado na Figura 18. Este modelo é comumente utilizado para predição do comportamento de relaxação da tensão, pelo fato da associação em série resultar em tensões iguais nos dois elementos, mola e amortecedor, enquanto a deformação, ou alongamento total, é a soma das deformações nos dois elementos.

A Equação 31 apresenta a relação tensão deformação na mola, enquanto a Equação 32 relaciona a tensão no amortecedor $\sigma_{a}$ com a deformação no amortecedor $\mathrm{e}_{\mathrm{a}}$.

$$
\sigma_{m}=E_{m} e_{m}
$$

Onde:

$\sigma_{\mathrm{m}}$ : tensão na mola;

$\mathrm{E}_{\mathrm{m}}$ : módulo da mola;

$\mathrm{e}_{\mathrm{m}}$ : deformação da mola;

$\eta_{a}$ : viscosidade do fluido no amortecedor;

$\mathrm{e}_{\mathrm{a}}$ : deformação do amortecedor.

$$
\sigma_{a}=\eta_{a} \frac{d e_{a}}{d t}
$$

A Equação 33, ou seja, a equação do movimento deste modelo é dada pela associação da derivada da Lei de Hooke em relação ao tempo com a Lei de Newton para escoamentos viscosos, considerando que devido à associação em série, temse $\sigma_{\mathrm{m}}=\sigma_{\mathrm{a}}=\sigma_{\text {total }}$ e e $e_{\text {total }}=\mathrm{e}_{\mathrm{m}}+\mathrm{e}_{\mathrm{a}}$. 


$$
\frac{d e_{\text {total }}}{d t}=\frac{1}{E_{m}} \frac{d \sigma_{\text {total }}}{d t}+\frac{\sigma}{\eta_{a}}
$$

Em experimentos de relaxação da tensão, a deformação aplicada é mantida constante, enquanto a tensão decai em função do tempo, em virtude das causas apresentadas no subcapítulo anterior. Tal comportamento gera a possibilidade de formular uma caso particular do Modelo de Maxwell para a relaxação da tensão, apresentado na Equação 35, já que:

$$
\begin{gathered}
\frac{d e_{\text {total }}}{d t}=0 \quad \text { e } \frac{1}{E_{m}} \frac{d \sigma_{\text {total }}}{d t}=-\frac{\sigma}{\eta_{a}} \\
\frac{d \sigma_{\text {total }}}{\sigma}=-\frac{E_{m}}{\eta_{a}} d t
\end{gathered}
$$

No tempo $t=0$, considerando $\sigma=\sigma_{0}$ na tensão inicial e integrando em função do tempo, tem-se:

$$
\sigma_{\text {total }}=\sigma_{0} \exp \left(-\frac{E_{m}}{\eta_{a}}\right) t
$$

A Equação 35 apresenta o comportamento de um material viscoelástico em condição de relaxação da tensão, com redução exponencial da tensão ao longo do tempo, mantendo-se a deformação constante.

Por se tratar de um modelo extremamente simples, o Modelo de Maxwell apresenta limitações em suas aplicações em representar o fenômeno da viscoelasticidade, Ward e Sweeney (2004) citam duas dessas limitações: i. Em condições de fluência, tem-se que a variação da tensão em função do tempo é nula, desta forma a equação final demonstraria o comportamento de um fluido Newtoniano, o que não é real em materiais viscoelásticos. ii. O comportamento de relaxação da tensão não pode ser representado por um decaimento exponencial simples, já que a tensão não decairá necessariamente até zero no infinito.

Diversos outros modelos foram desenvolvidos, os quais utilizam os elementos mola e amortecedor como base, porém outras configurações foram propostas com 
diversas molas e amortecedores em série ou paralelo, ou até mesmo com a combinação dos elementos em série e paralelo. 


\section{MATERIAIS E MÉTODOS}

Para atingir o objetivo final, este trabalho foi dividido em fases, onde experimentos específicos foram utilizados para atingir o objetivo de cada uma destas partes.

\subsection{TESTES PRELIMINARES - VERIFICAÇÃO DA INFLUÊNCIA DO EB}

O objetivo inicial foi investigar as alterações causadas pela radiação EB na estrutura molecular e no comportamento mecânico do poliacrilato curado por radiação UV, para descartar a hipótese de degradação do polímero pela radiação EB.

\subsubsection{Corpos de prova}

O material utilizado nesta fase inicial foi obtido através da polimerização de poliacrilato curável por UV. O produto, ainda líquido, foi aplicado manualmente em moldes de vidro, revestidos com filme de polietileno e curados de acordo com método desenvolvido pelo fabricante do material, segundo o qual se deve utilizar uma fonte UV de pressão média de mercúrio capaz de manter uma intensidade de $100 \mathrm{~mW} / \mathrm{cm} 2$ medida a $365 \mathrm{~nm}$ com dosímetro abaixo dos moldes de vidro. Destes moldes foram extraídos folhas de poliacrilato com dimensões de $150 \mathrm{~mm} \times 150 \mathrm{~mm}$ x $2 \mathrm{~mm}$, das quais foram cortados corpos de prova com dimensões de acordo com a norma ASTM 412 - 6 a Die C, conforme Figura 22. Todo este procedimento, cura e corte dos corpos de prova, foi realizado pelo fabricante do material em Detroit nos Estados Unidos. Embora o método de obtenção dos corpos de prova requeira diversos cuidados para eliminar bolhas de ar, como aguardar 10 minutos entre a aplicação do material e cura, em molde de geometria especifica para eliminação de possíveis bolhas, pequenas bolhas de ar foram encontradas nos corpos de prova, as quais influenciam no resposta elástica do material e nas informações geradas nos ensaios uniaxiais de tração. 


\subsubsection{Irradiação dos corpos de prova}

Os corpos de prova obtidos de acordo com a norma ASTM 412 - 6 a Die C foram irradiados com feixe por acelerador de elétrons modelo DC 1500 / 25 / 4 - job 188, da Radiation Dynamics, Inc. no Centro de Tecnologia de Radiações (CTR) pelo Instituto de Pesquisas Energéticas e Nucleares (IPEN). As doses de radiação utilizadas foram de $20 \mathrm{kGy}, 50 \mathrm{kGy}$ e $100 \mathrm{kGy}$, especificadas com base em trabalho científico referente à aplicação de radiação EB em poliacrilato vulcanizado através de processo termoquímico. Abaixo se encontram dados do equipamento e processo de radiação:

Energia: mínima de 0,50 MeV e máxima de 1,5 MeV;

Corrente do feixe: mínima de 0,3 mA e máxima de 25,0 mA;

Varredura: mínima de $60 \mathrm{~cm}$ e máxima de $120 \mathrm{~cm}$;

Potência: $150 \mathrm{~kW}$.

Condições de Irradiação das amostras:

Energia: 1,013 MeV;

Varredura: $100 \mathrm{~cm}$;

Corrente do feixe: 4,54 mA;

Taxa de dose: 22,42 kGy / s;

Sistema: Esteira;

Velocidade da esteira: $6,72 \mathrm{~m} / \mathrm{min}$;

Dose por ciclo sob o feixe: $5 \mathrm{kGy}$.

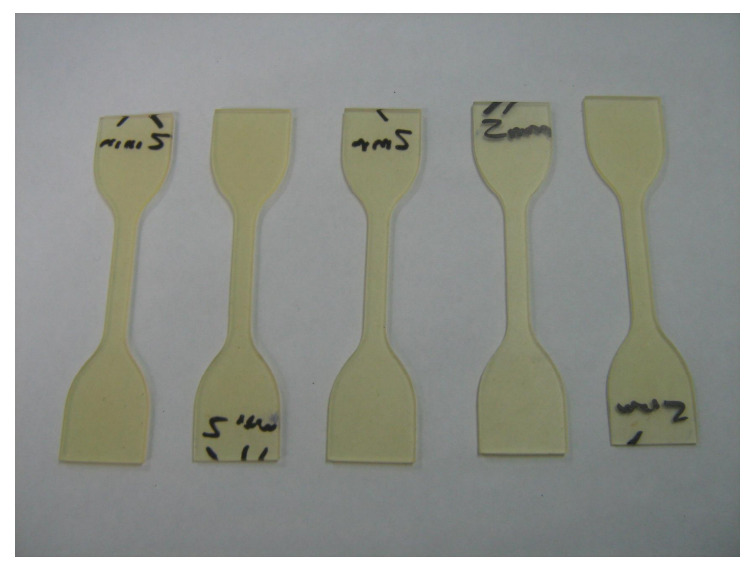

Figura 22 - Corpos de prova de ACM de acordo com ASTM 412 - 6 a Die C. 


\subsubsection{Ensaios uniaxiais de tração}

O resultado da irradiação por feixe de elétrons nos corpos de prova era desconhecido, o poliacrilato curado por UV poderia apresentar degradação de sua estrutura e conseqüente perda de propriedades mecânicas, como poderia apresentar aumento do peso molecular ocasionado por um aumento do nível de reticulação do polímero e conseqüente ganhos no comportamento mecânico. Ensaios uniaxiais de tração foram utilizados para investigar a influência da radiação EB no comportamento mecânico do poliacrilato. Embora este tipo de ensaio não gere dados suficientes para caracterização do comportamento elástico não linear de elastômeros, o ensaio uniaxial de tração fornece parâmetros como tensão máxima na ruptura, alongamento e módulo de cisalhamento. A variação destes parâmetros permite uma análise inicial da ação da radiação $E B$, além de descartar a possibilidade de degradação da estrutura e sinalizar quais as doses de radiação com maior influência.

Foram ensaiados corpos de prova sem irradiação EB, além de corpos de prova submetidos às doses de 20 kGy, 50 kGy e 100 kGy. Três réplicas de cada condição foram ensaiadas com o objetivo de verificar a variação na tensão máxima na ruptura, no alongamento e no módulo de cisalhamento do material. Os ensaios de tração foram realizados no Centro de Engenharia de Adesivos Loctite em Itapevi, em equipamento EMIC DL5000, com célula de carga de $5 \mathrm{kN}$, conforme Figura 23. Os parâmetros de ensaio, assim como a configuração geométrica, foram baseados na ASTM 412 - 6a, bem como a velocidade de tracionamento utilizada $500 \mathrm{~mm} / \mathrm{min}$, sendo o comprimento de fixação das corpos de prova nas garras de $20 \mathrm{~mm}$. Nesta fase do trabalho não se utilizou extensômetro para medição da deformação do material, desta foram o alongamento medido se refere ao deslocamento do cabeçote do equipamento. 


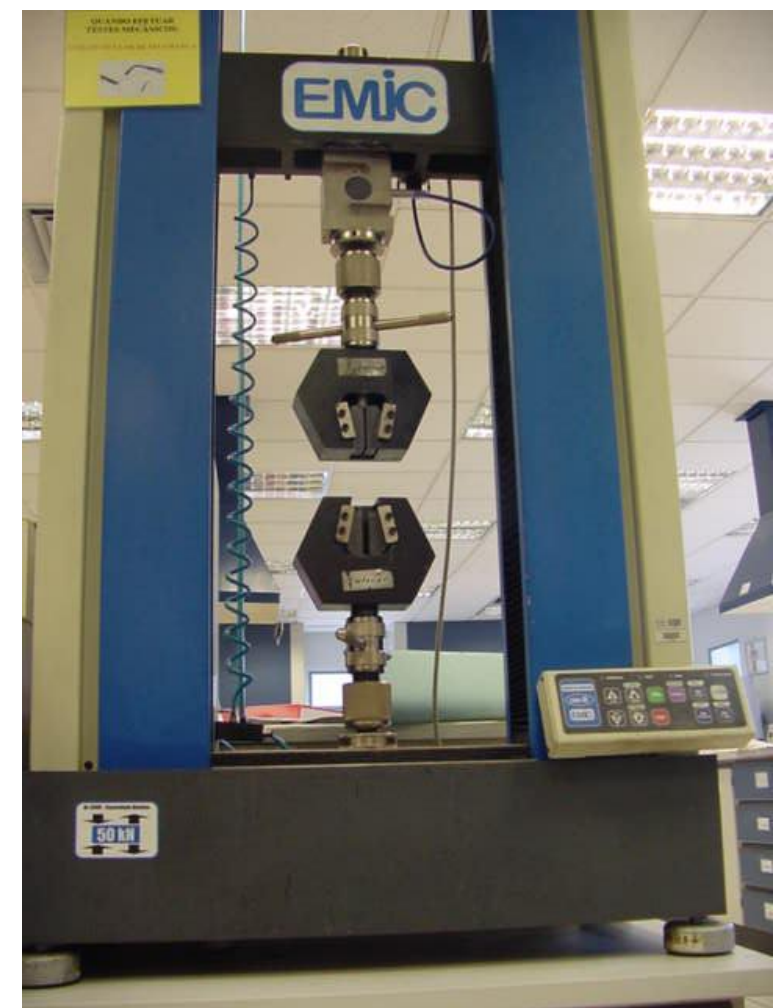

Figura 23 - Equipamento EMIC DL5000 com célula de carga de 5kN.

\subsubsection{Espectroscopia por infravermelho - Testes preliminares}

Com o objetivo de identificar as alterações causadas pelas diferentes doses de irradiação EB nos grupos químicos presentes no poliacrilato curado, foi realizada espectroscopia por infravermelho do material em estudo. A altura dos picos do espectro obtidos por absorbância são diretamente proporcionais à quantidade de grupos químicos presentes no material, segundo a Lei de Lambert-Berr. Comprimentos de onda específicos se relacionam com grupos químicos específicos, conforme apresentado na Tabela 2.

As análises por infravermelho foram realizadas pelo Laboratório da Qualidade da empresa Henkel em Jacareí, utilizando um equipamento Spectrum One FT-IR da Perkin Elmer e técnica de refletância total atenuada (ATR), Figura 24. 


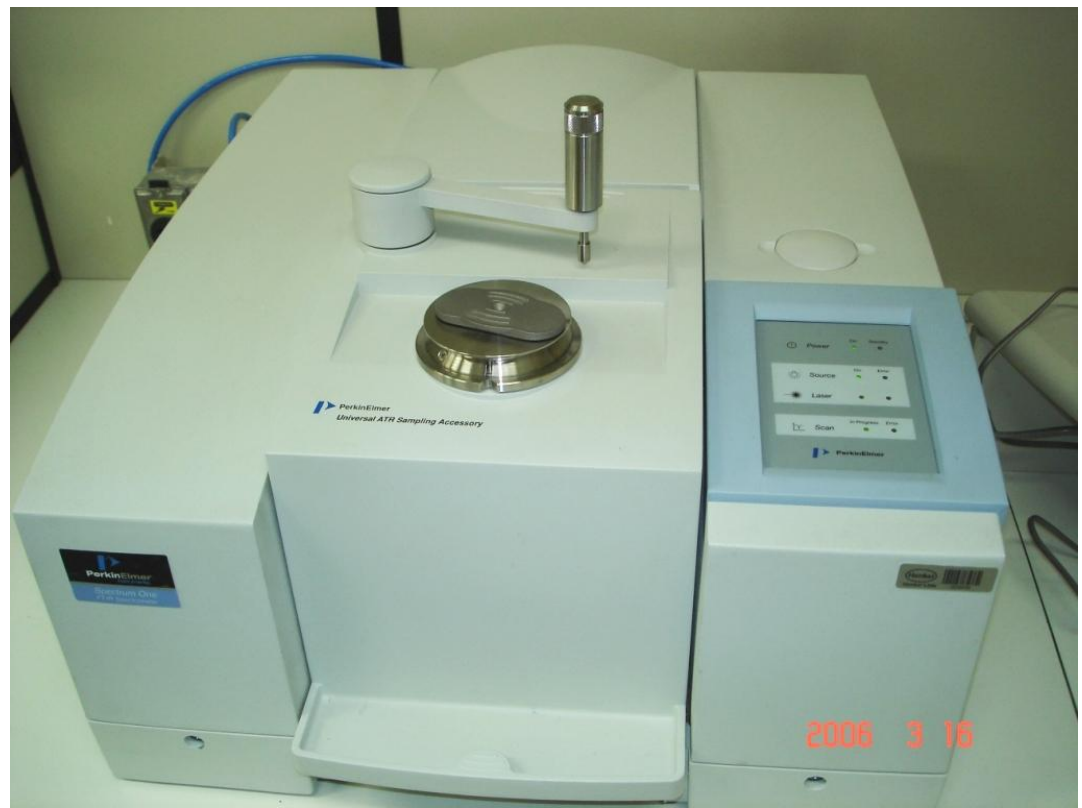

Figura 24 - Equipamento Perkin Elmer utilizado na análise por infravermelho.

O processo de cura na região superficial ocorre de maneira diferente do processo de cura na região central do material, devido ao contato com vidro e possível presença de ar. Durante a irradiação EB a área em contato com ar está suscetível à reação das cadeias cisionadas com oxigênio, resultando no processo de oxidação do material e diferenciando as estruturas obtidas na região central e superficial do material, por isso os corpos de prova foram analisados nas duas regiões em questão, a região superficial e a central.

Três leituras em pontos aleatórios ao longo das amostras foram realizadas. A análise dos picos foi realizada no espectro obtido pela média aritmética dos espectros resultantes dessas três leituras, o software do equipamento também forneceu os valores de absorbância corrigidos, salientando que quanto maiores os picos, linearmente maiores são as quantidades do grupo químico representado por este pico. Foram obtidos os espectros de $930 \mathrm{~cm}^{-1}$ até $2000 \mathrm{~cm}^{-1}$, das regiões central e superficial, com destaque para os comprimentos de onda de $1740 \mathrm{~cm}^{-1}, 1632 \mathrm{~cm}^{-1} \mathrm{e}$ $1160 \mathrm{~cm}^{-1}$, respectivamente referentes aos grupos químicos $>\mathrm{C}=\mathrm{O},>\mathrm{C}=\mathrm{C}<\mathrm{e} \mathrm{C}-\mathrm{O}-\mathrm{C}$. 


\subsection{CARACTERIZAÇÃO DA RESPOSTA ELÁSTICA}

Esta segunda fase tem como objetivo caracterizar o comportamento elástico do ACM, bem como as alterações causadas neste comportamento pelas diferentes doses de irradiação. Alterações na estrutura molecular do ACM foram estudadas através da análise do comportamento de propriedades de elastômeros como temperatura de transição vítrea, temperatura de degradação e da repetição da espectroscopia por infravermelho.

\subsubsection{Corpos de prova}

A obtenção dos corpos de prova, para os ensaios referentes a segunda fase, foi feita de maneira automatizada. Ao invés de aplicar manualmente o poliacrilato em moldes de vidro, foi utilizado um processo de injeção do material em moldes de silicones, os quais possuem a geometria desejada das folhas de ACM, ou seja, $150 \mathrm{~mm} \times 150$ $\mathrm{mm} \times 2 \mathrm{~mm}$. A injeção foi realizada por equipamento para injeção em baixas pressões da empresa Henkel em Detroit nos Estados Unidos, equipamento utilizado no desenvolvimento de novo conceito de elementos de vedação denominado "Molded in Place Gasket". A partir da folhas de ACM foram obtidos corpos de prova para cada ensaio em questão neste método.

\subsubsection{Irradiação dos corpos de prova}

Foram utilizados o mesmo método e o mesmo equipamento já apresentados no capítulo 8.1.2. As doses porém foram alteradas para 100 kGy e 250 kGy devido aos resultados obtidos nos ensaios descritos como testes preliminares. 


\subsubsection{Ensaios mecânicos para caracterização do comportamento elástico}

A caracterização do comportamento, ou resposta elástica do ACM foi possível através da realização de ensaios uni e equibiaxiais de tração, ensaios de cisalhamento puro e da aplicação dos resultados obtidos nestes ensaios no Modelo de Ogden.

\subsubsection{Ensaios Uniaxiais de Tração}

O obtenção de pares de dados de tensão - deformação, para a caracterização dos comportamento elástico de elastômeros, exige a utilização de extensômetro na medição da deformação do material, por se tratarem dos valores a serem utilizados na obtenção dos parâmetros do Modelo de Ogden.

Para tal foi utilizado equipamento de ensaios mecânicos modelo Instron 5567 do departamento de Materiais Poliméricos da FEI em São Bernardo do Campo, o qual estava equipado com célula de carga de 5 kN e extensômetro, conforme Figura 25.

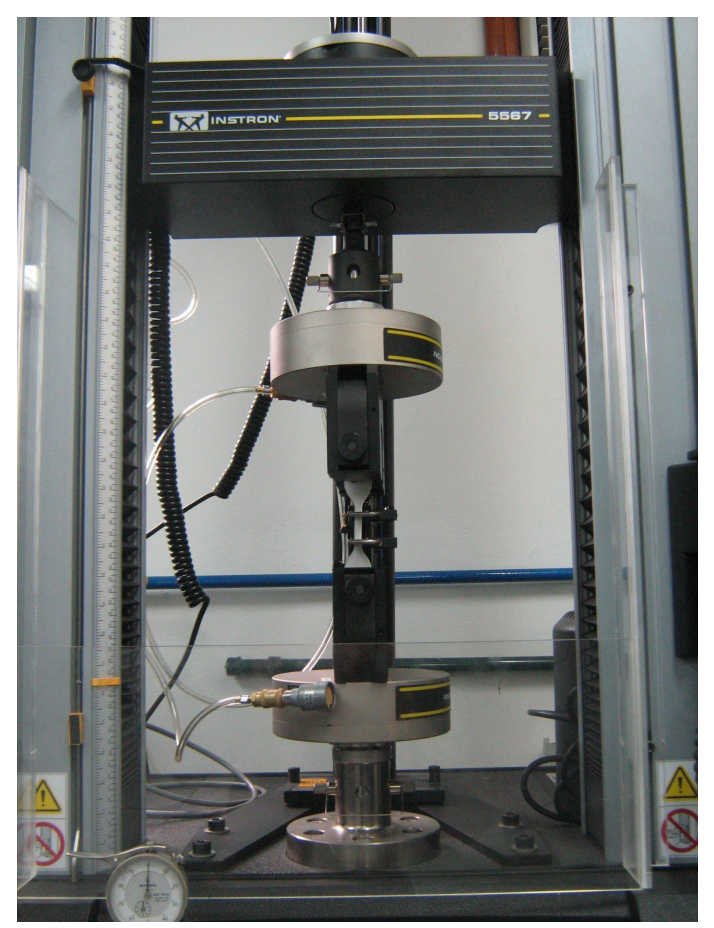

Figura 25 - Equipamento Instron com célula de carga de $5 \mathrm{kN}$ e extensômetro. 
Foram ensaiadas três réplicas de cada condição, ou seja, sem pós cura, com 100 kGy e com 250 kGy de radiação como pós cura. Os corpos de prova foram obtidos e os ensaios realizados de acordo com ASTM 412 - 6a, com geometria Die C e taxa de deslocamento de $500 \mathrm{~mm} / \mathrm{min}$. O comprimento de fixação dos corpos de prova nas garras do equipamento Instron foi de $20 \mathrm{~mm}$ e a distância inicial entre as garras do extensômetro de $25 \mathrm{~mm}$.

Este procedimento de ensaio forneceu dezenas de pares tensão / deformação do material, além de dados de saída como: força na ruptura $(N)$, tensão na ruptura (MPa), alongamento (\%) e módulo de elasticidade a 100\% de deformação (MPa).

\subsubsection{Ensaios Equibiaxiais}

Devido ao grande número de variáveis envolvidas na determinação dos parâmetros do Modelo de Ogden, faz-se necessário a utilização de diferentes equações que relacionam tensão e deformação. Os ensaios equibiaxiais geram dados para que seja possível solucionar o sistema de equações e consequentemente determinar os parâmetros do modelo.

De acordo com Day e Miller (2000) normalmente dois tipos de ensaios equibiaxiais são utilizados, sendo um deles possível ao se inflar com ar comprimido uma fina membrana do elastômero a ser estudado, analisando a região central da membrana onde supostamente se forma uma condição equibiaxial de tração. A dificuldade neste método se encontra em medir as deformações nesta região.

O segundo método de ensaio equibiaxial, o qual foi utilizado neste trabalho, consiste em tracionar um corpo de prova circular, através de 16 grampos distribuídos em seu perímetro, gerando uma condição de tração equibiaxial na região central do corpo de prova, conforme simulação apresentada na Figura 26. 


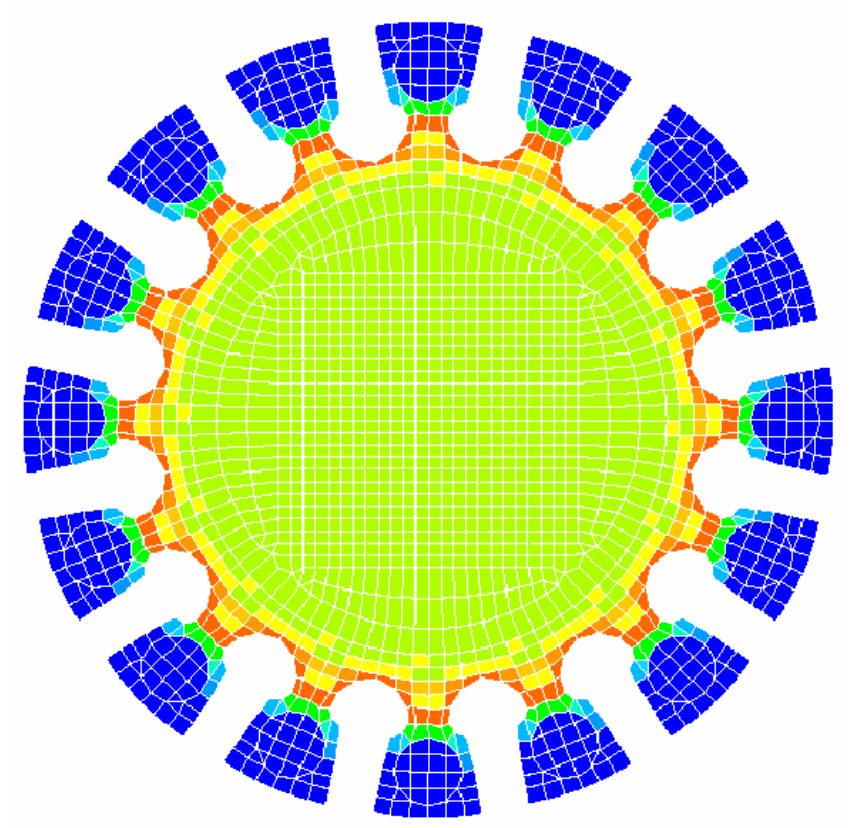

Figura 26 - Simulação de corpo prova submetido a ensaio equibiaxial.

O corpo de prova foi fixado aos grampos através de um dispositivo com mola. Os grampos por sua vez são unidos à disco de carga através de cabos de aço que passam por roldanas. Ao se deslocar o disco de carga, todos os grampos são deslocados uniformemente gerando na região central do corpo de prova condição equibiaxial de tensão. Neste método a deformação foi medida por um extensômetro laser sem contato e a tensão através do disco de carga. A Figura 27 ilustra o equipamento utilizado e a geometria do corpo e prova, é importante salientar que circunferências foram cortadas na região de encontro das tiras de fixação dos grampos, para evitar o corte do corpo de prova nesta região.

Devido a indisponibilidade deste tipo de equipamento no Brasil, os corpos de prova foram cortados, das folhas de ACM apresentadas em 8.2.1, e os ensaios realizados pelo Laboratório Axel Physical Testing Services em Michigan nos Estados Unidos, com equipamento apresentado na Figura 27 e especialmente desenvolvido para este tipo de teste pelo laboratório. Os ensaios foram realizados de acordo com a norma GMN 6814, norma interna General Motors para caracterização de elastômeros, baseada em normas ASTM, com velocidade de tracionamento de 30 $\mathrm{mm} / \mathrm{min}$. Esta norma foi desenvolvida com base e usa como referência os equipamentos e parâmetros de processo do laboratório que realizou os ensaios. Como variáveis de saída foram obtidos dezenas de pares tensão / deformação por réplica ensaiada, alongamento e tensão na ruptura. 


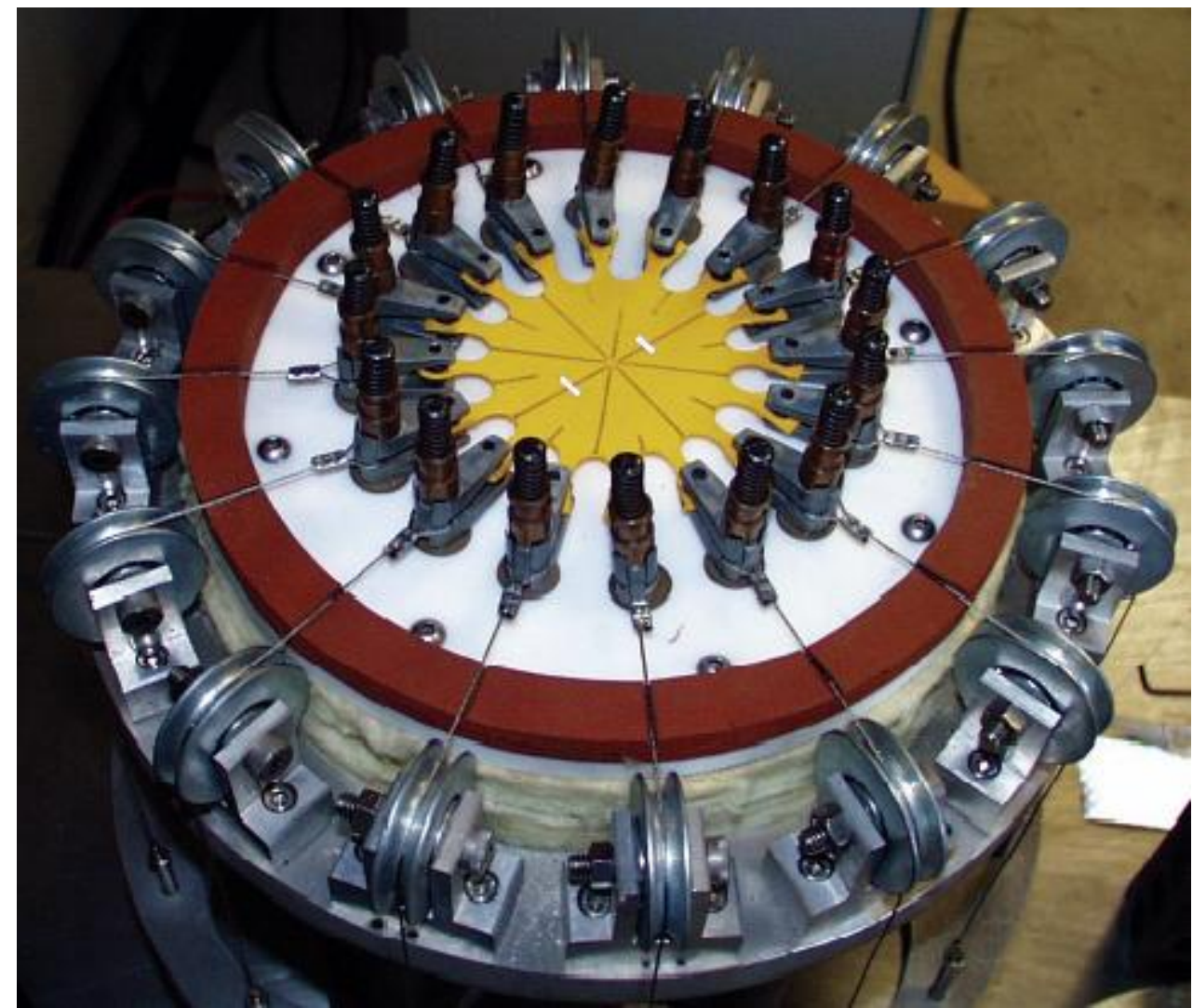

Figura 27 - Equipamento utilizado na realização dos ensaios equibiaxiais.

\subsubsection{Ensaios de Cisalhamento Puro}

Para finalizar a obtenção de dados necessários na aplicação do Modelo de Ogden e definição dos parâmetros deste modelo, foram realizados ensaios mecânicos, denominados de cisalhamento puro. A denominação cisalhamento puro é utilizada devido a condição de esforço gerada, onde devido a elevada relação entre a largura do corpo de prova e a altura do mesmo, a variação no comprimento , a extensão principal $\lambda_{2}$, pode ser negligenciada e considerada igual a 1 , enquanto $\lambda_{3}=\left(\lambda_{1}\right)^{-1}$.

Os ensaios foram realizados de acordo com a norma GMN 6814, com velocidade de tracionamento de $5 \mathrm{~mm} / \mathrm{min}$. Os corpos de prova foram obtidos a partir das folhas de ACM, sendo posteriormente aderidos ao dispositivo de fixação do equipamento de tração, a distância inicial entre as garras de fixação foi de $10 \mathrm{~mm}$, o distância inicial entre pontos medido pelo extensômetro laser sem contato foi de $3,35 \mathrm{~mm}$. 
Foram ensaiados três corpos de prova para cada condição de material. Os experimentos foram realizados pelo laboratório do Centro de Engenharia da empresa Henkel em Munique na Alemanha. O laboratório não informou os modelos do equipamento de tração e do extensômetro utilizados, a Figura 28 ilustra o equipamento utilizado.

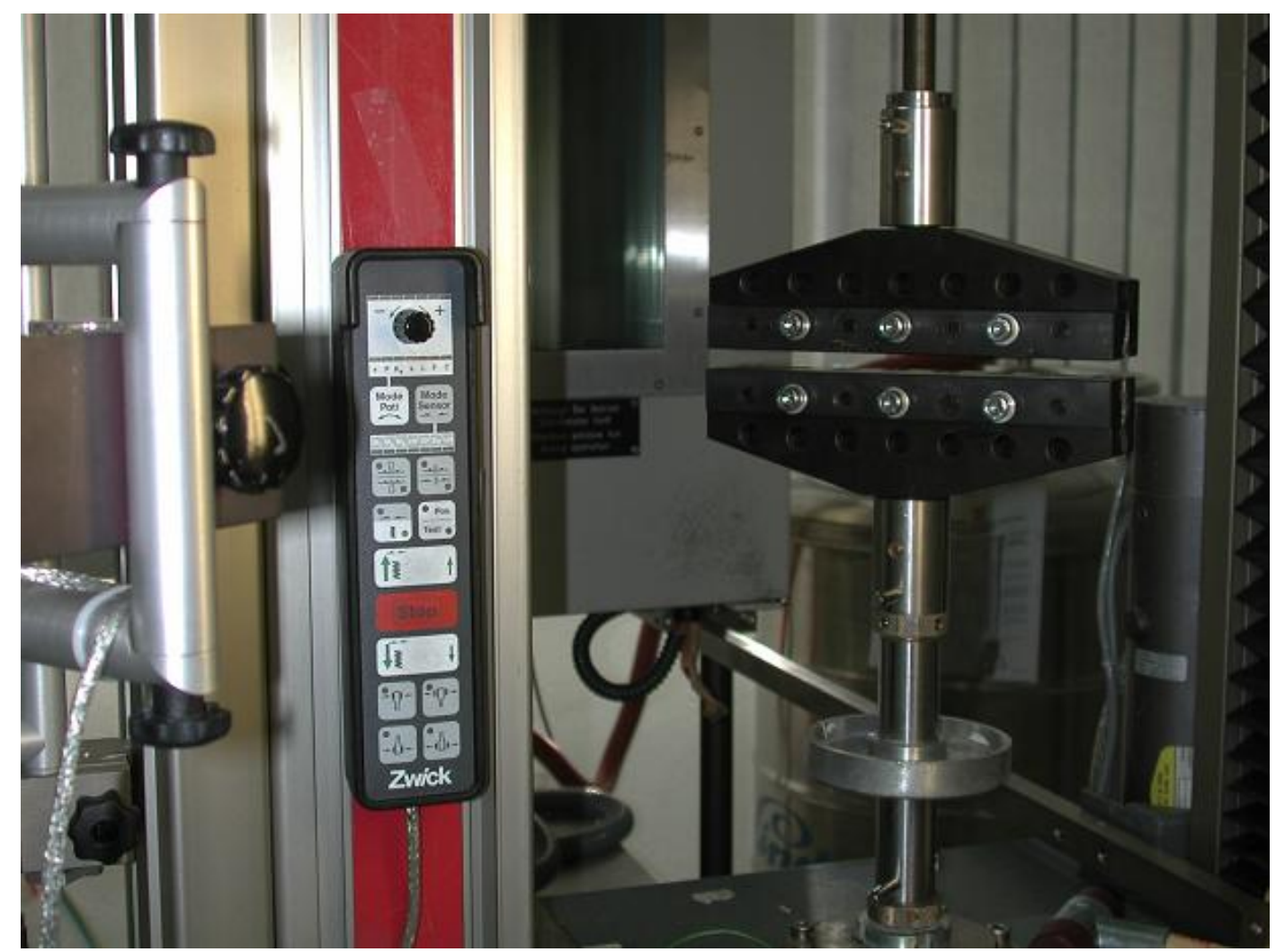

Figura 28 - Equipamento utilizado na realização dos ensaios de cisalhamento puro.

Como variáveis de saída foram obtidos dezenas de pares tensão - deformação por réplica ensaiada, alongamento e tensão na ruptura.

\subsubsection{Simulação do comportamento do ACM sob compressão}

Com o objetivo de verificar de maneira prévia o comportamento do ACM sob compressão, sem a necessidade de realização de testes de ensaios de compressão, foram realizadas simulações do comportamento do material sob compressão com a utilização do software ANSYS. Através destas simulações foi possível verificar se a 
irradiação causaria o aumento da resistência mecânica, verificada em outras condições como tensão uniaxial e equibiaxial, também quando submetidas ao esforço de compressão. Auxiliando na escolha da dose de radiação a ser utilizada nos ensaios finais de relaxação por compressão e justificando a realização de tais ensaios.

A simulação foi realizada considerando corpos de prova de ACM com diâmetros de $13 \mathrm{~mm}$ e altura de $6,5 \mathrm{~mm}$. Os parâmetros necessários para realização das simulações, referentes as propriedades mecânicas do ACM, foram obtidas através dos resultados experimentais do segundo método, ou seja, ensaios de tração uniaxial, equibiaxial e cisalhamento puro, considerando as condições de ACM não irradiado, irradiados com 100 kGy e 250 kGy. Tais resultados foram também utilizados na determinação dos parâmetros do Modelo de Ogden, utilizado no software para descrição do comportamento não linear deste material.

O contato entre as superfícies foi considerado seco, ou seja, não lubrificado. Devido a ausência de dados sobre o coeficiente de atrito deste material na literatura, uma simulação inicial foi realizada, com o objetivo de identificar uma faixa de valores para o coeficiente de atrita, dentro da qual não ocorreria variação do comportamento do material na simulação definitiva. Foram geradas curvas de força em função de deformação para os coeficientes de atrito $\mu=0,05, \mu=0,5$ e $\mu=0,8$, considerando o modelo de Ogden de $2^{\circ}$ ordem. A simulação final gerou dados de comportamento do material sob compressão considerando o modelo de Ogden de $2^{\circ}$ e $3^{\circ}$ ordens.

\subsubsection{Análise termodinâmico-mecânica (DMTA)}

Os comportamentos elástico e viscoso do material foram analisados através da técnica de DMTA. Os ensaios foram realizados pelo laboratório da empresa Henkel em Jundiaí, através da utilização de equipamento modelo Pyris Diamond da marca Perkin Elmer. Os ensaios foram realizados de acordo com norma interna da empresa. Inicialmente o corpo de prova foi resfriado até $-60^{\circ} \mathrm{C}$ com taxa de redução de temperatura de $10^{\circ} \mathrm{C} / \mathrm{min}$, após 3 minutos de espera, deu-se início a rampa de aquecimento de $-60^{\circ} \mathrm{C}$ até $100^{\circ} \mathrm{C}$, com taxa de aquecimento de $2^{\circ} \mathrm{C} / \mathrm{min}$, faixa de temperatura na qual foram realizados os ensaios de DMTA. Os corpos de prova 
foram fixados por garras ao equipamento e deformados ciclicamente com freqüência de $1 \mathrm{~Hz}$.

As aplicação da técnica de DMTA resultou na determinação da temperatura de transição vítrea das três condições de ACM testadas, sem pós-cura, 100 kGy e 250 kGy, através da análise das curvas de tangente de perda obtidas. Além das curvas de tangente de perda em função da temperatura, este técnica permitiu obter gráficos da variação da parcela de contribuição elástica, ou módulo de armazenamento de energia elástica e do módulo de dissipação de energia viscoso em função da temperatura, conforme citado, para as três condições de pós-cura estudadas. Somente um corpo de prova de cada condição foi ensaiado, com geometria definida pela norma interna do laboratório citado.

\subsubsection{Análise de decomposição térmica por termogravimetria (TGA)}

Análises termogravimétricas do poliacrilato foram realizadas pelo mesmo laboratório que realizou os experimentos de TGA, através da utilização de equipamento modelo Pyris 1 TGA da marca Perkin Elmer, conforme Figura 29.

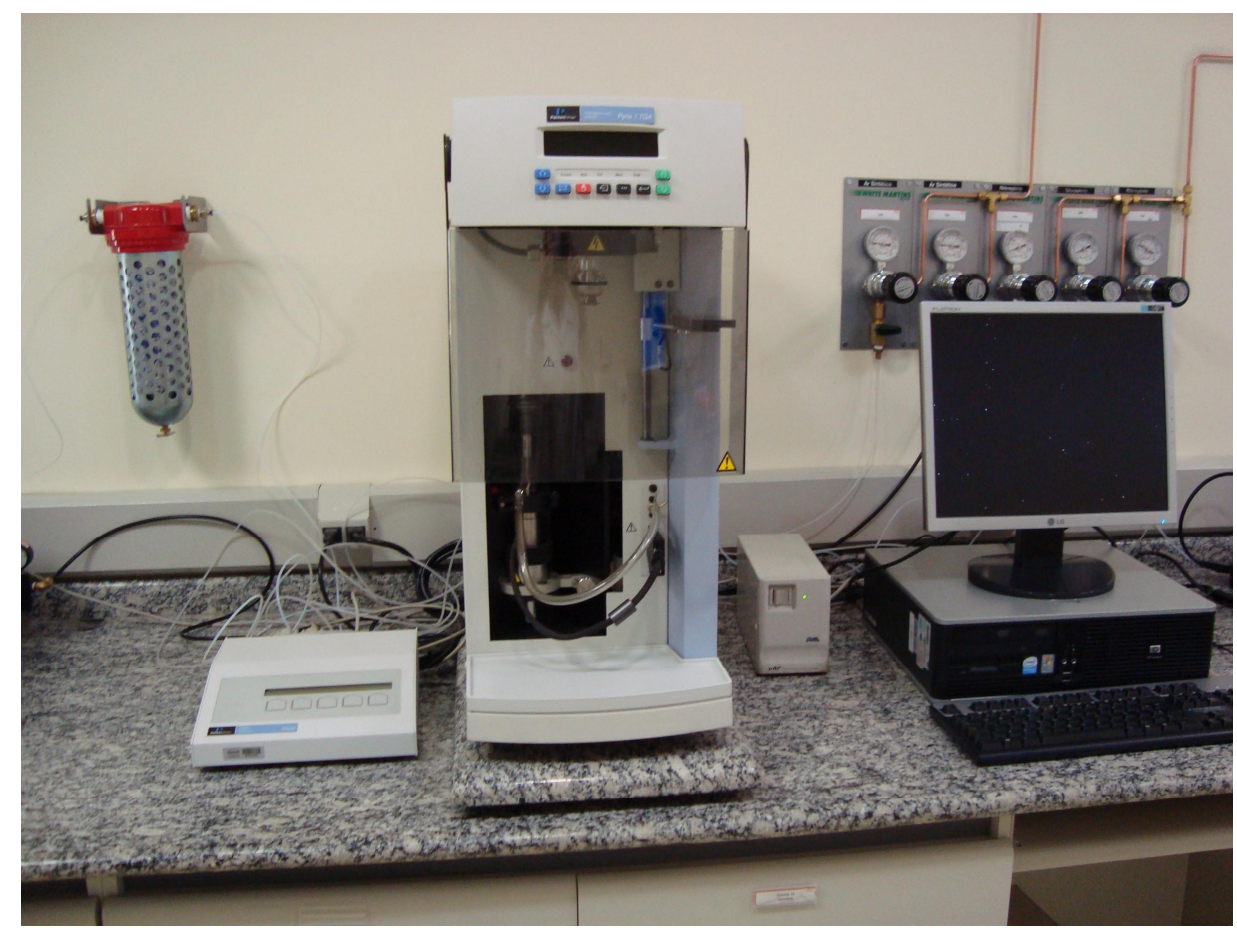

Figura 29 - Equipamento Pyris 1 TGA utilizado na realização da análise termogravimétrica. 
Os ensaios foram realizados de acordo com norma interna da empresa, com taxa de aquecimento de $10^{\circ} \mathrm{C} / \mathrm{min}$ e varredura na faixa de $20^{\circ} \mathrm{C}$ a $800^{\circ} \mathrm{C}$. O equipamento utilizado forneceu as curvas de percentual de perda de massa em função do aumento de temperatura para cada condição de material, as curva da derivada do percentual de perda de massa em função da temperatura, bem como o ponto de perda máxima de massa, as temperaturas inicial e final de degradação e o percentual residual de massa de cada amostra. Somente uma amostra de cada condição foi testada.

\subsubsection{Espectroscopia por infravermelho - Segunda fase}

Nesta segunda fase, após a definição das doses a serem aplicadas e de precisa medição dos pares tensão / deformação de acordo com diferentes métodos de ensaios, fez-se necessário reavaliar as variações estruturais causadas pela radiação na estrutura molecular através da espectroscopia por infravermelho.

O mesmo modelo de equipamento, Spectrum One FT-IR da Perkin Elmer e técnica de refletância total atenuada (ATR) empregados no primeiro método foram repetidos neste segundo método, este porém foi realizado no mesmo laboratório onde foram realizados os ensaios de DMTA e TGA.

As regiões central e superficial foram analisadas, desta vez porém na faixa espectral de $4000 \mathrm{~cm}^{-1}$ a $400 \mathrm{~cm}^{-1}$. Devido a norma interna do laboratório não foram geradas as tabelas de picos máximos e picos corrigidos, sendo possível realizar apenas uma análise qualitativa das variações das quantidades de grupos químicos geradas pela radiação.

Foram gerados espectros referentes a superfície do material, comparando as três doses aplicadas, e referentes a região central dos corpos de prova, também de maneira comparativa entre as doses. Posteriormente, os espectros focados nos grupos químicos $>\mathrm{C}=\mathrm{O},>\mathrm{C}=\mathrm{C}<\mathrm{e}$ C-O- $\mathrm{C}$, referentes aos comprimentos de onda de $1740 \mathrm{~cm}^{-1}, 1632 \mathrm{~cm}^{-1}$ e $1160 \mathrm{~cm}^{-1}$, presentes na superfície e centro foram comparados em gráficos exclusivos. 


\subsection{VERIFICAÇÃO DO RELAXAMENTO DA TENSÃO POR COMPRESSÃO}

Esta fase final, tem como objetivo verificar o comportamento da borracha acrílica irradiada, com a dose de maior influência verificada pelos métodos anteriores, referente ao comportamento de relaxação por compressão. Foram realizados ensaios para análise da relaxação por compressão, com posterior análise estatística dos dados, por planejamento fatorial $2^{k}$.

\subsubsection{Ensaio para análise da relaxação da tensão por compressão}

Utilizando equipamento de injeção a baixa pressão, ACM foi injetado em moldes de silicone, permitindo obter corpos de prova cilíndricos e curados de acordo com especificação do fabricante do material. Os corpos de prova foram obtidos utilizando equipamento específico, em laboratório do fabricante do ACM em Detroit nos Estados Unidos.

Respeitando os requerimentos do equipamento utilizado para realização dos testes de relaxação por compressão, os corpos de prova cilíndricos apresentavam diâmetro de $13 \mathrm{~mm}$ e altura de 6,3 $\mathrm{mm}$. Com base nos resultados do segundo método, a dose de $250 \mathrm{kGy}$ foi selecionada para irradiar os corpos de prova submetidos aos ensaios de relaxação, processo realizado pelo Instituto de Pesquisas Energéticas e Nucleares (IPEN) em São Paulo, permitindo comparar o comportamento das condições de ACM não irradiado com ACM irradiado com dose de 250 kGy.

Devido a vasta utilização de ACM na fabricação de juntas sólidas para componentes automotivos, sendo este também o segmento foco da empresa que desenvolveu o material, optou-se por realizar testes de relaxação em temperatura de ambiente e em temperatura de $90^{\circ} \mathrm{C}$, condição usual de aplicações em motores veiculares.

Dois níveis de deformação foram selecionados para análise, 10\% e 15\% de deformação, percentual referente a relação entre a altura após compressão e a altura inicial do corpo de prova. Os ensaios foram realizados em laboratório especializado em Munique, na Alemanha, em laboratório do fabricante, com uso de equipamento Elastocon, modelo EB 02, conforme Figura 30. 


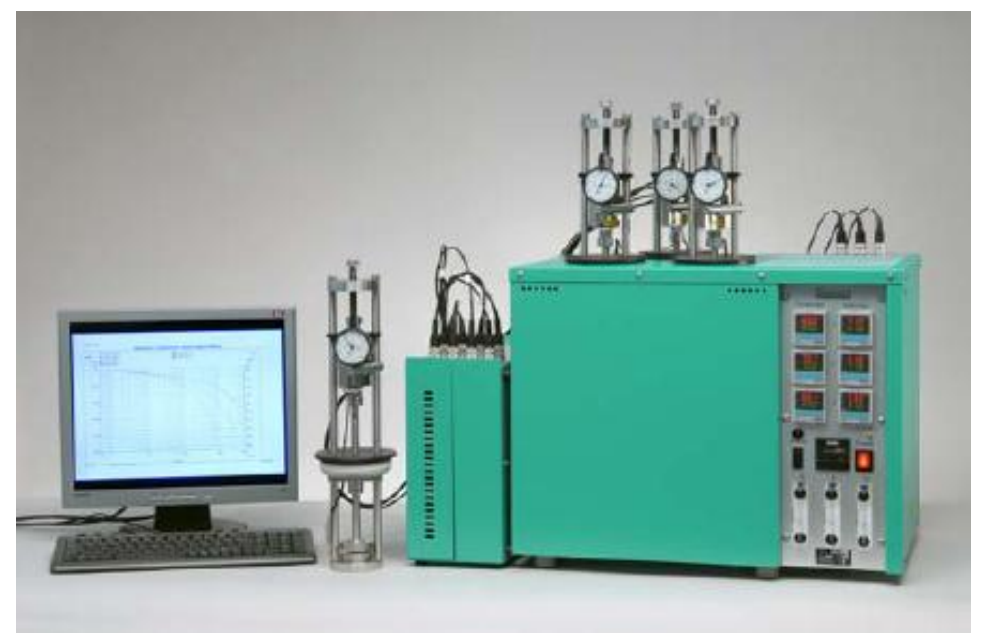

Figura 30 - Equipamento Elastocon Modelo EB02, utilizado nos ensaios CSR.

Este equipamento tem capacidade para realizar testes com três corpos de prova ao mesmo tempo, desde que em mesma temperatura de teste. Foram ensaiadas três réplicas para cada condição, sendo que a mesma condição não se repetiu durante o mesmo período, ou seja, os três dispositivos do equipamento não ensaiaram de maneira simultânea a mesma condição de deformação ou radiação. A altura inicial de cada corpo de prova foi medida com micrômetro específico, após cálculo para determinar a altura final, para se obter as deformações de 10\% e 15\%, a redução de altura necessária foi medida com micrômetro do equipamento Elastocon.

Estabilizada e mantida constante a deformação, uma célula de carga coletava os dados de força de compressão oferecida pelo corpo de prova a cada 20 segundos e tornava possível plotar a curva de relaxação da compressão, sob deformação constante. A temperatura de $90{ }^{\circ} \mathrm{C}$ foi obtida em compartimento específico deste equipamento, capaz de armazenar os três dispositivos, mantendo a temperatura de teste constante na câmara de prova e mantendo a temperatura da célula de carga em $23^{\circ} \mathrm{C}$, para evitar variações em relação a condição testada em $23^{\circ} \mathrm{C}$.

A força de compressão foi medida para cada condição e respectivo número de réplicas por $5.000 \mathrm{~min}$, permitindo gerar curvas de tensão de compressão em função do tempo e conseqüente variação da mesma. O equipamento utilizado apresenta resolução de $0,1 \mathrm{~N}$ em compressão e precisão de $0,1 \%$ em toda a faixa de medição especificada. 


\subsubsection{Planejamento Fatorial $2^{k}$}

Visando utilizar o menor número possível de réplicas, bem como permitir uma análise estatística dos resultados e verificar a influência de cada variável na relaxação por compressão, foi utilizado planejamento fatorial $2^{k}$ na determinação dos experimentos e análise dos resultados experimentais.

O planejamento fatorial $2^{k}$ controla fatores críticos e investiga seus efeitos em dois ou mais níveis. No Planejamento Fatorial $2^{k}$ fatores são selecionados e ajustados em dois níveis, sendo seu nível inferior indicado por $\quad(-1)$ e o nível superior por $(+1)$.

Os fatores a serem analisados são combinados e a influência causada pela variação de seus níveis é quantificada de forma individual, efeitos principais, ou de forma combinada, efeitos de interação. As três variáveis, temperatura, deformação e radiação, foram analisadas em dois níveis, $23^{\circ} \mathrm{C}$ e $90^{\circ} \mathrm{C}, 10 \%$ e $15 \%, 0$ kGy e 250 kGy, respectivamente. A combinação destas variações geraram oito condições de ensaios, apresentadas na Tabela 3. A impossibilidade de análise de todos os dados de tensão de compressão gerados, criou a necessidade de seleção de pontos específicos ao longo da escala de tempo. Foram analisados os resultados nos tempos de 500, 1000, 1500, 2000, 2500, 3000, 3500, 4000 e 5000 minutos.

Tabela 3- Condições ensaiadas em CSR.

\begin{tabular}{cccc}
\hline Condição & ${\text { Temperatura }\left({ }^{\circ} \mathbf{C}\right)}$ & Deformação (\%) & Radiação (kGy) \\
\hline 1 & 23 & 10 & 0 \\
2 & 23 & 10 & 250 \\
3 & 23 & 15 & 0 \\
4 & 23 & 15 & 250 \\
5 & 90 & 10 & 0 \\
6 & 90 & 10 & 250 \\
7 & 90 & 15 & 0 \\
8 & 90 & 15 & 250 \\
\hline
\end{tabular}




\section{RESULTADOS E DISCUSSÃO}

\subsection{VERIFICAÇÃO DA INFLUÊNCIA DE RADIAÇÃO EB}

\subsubsection{Resultados dos ensaios uniaxiais - Testes preliminares}

Os corpos de prova foram submetidos aos ensaios destrutivos sob deformação uniaxial por tração, as 3 réplicas de cada condição foram testadas sequencialmente em ambiente com temperatura e umidade controladas. A Tabela 4 apresenta os resultados de tensão na ruptura, média e desvio padrão para cada condição de radiação.

Tabela 4 - Tensões na ruptura em ensaio uniaxial de tração

\begin{tabular}{cccccc}
\hline Condição & \multicolumn{3}{c}{ Tensão na Ruptura (MPa) } & Média & Desvio (MPa) \\
\hline 0 kGy & 4,11 & 4,28 & 4,00 & 4,13 & 0,15 \\
20 kGy & 4,22 & 4,32 & 4,19 & 4,24 & 0,07 \\
50 kGy & 4,17 & 4,30 & 4,24 & 4,24 & 0,06 \\
100 kGy & 4,86 & 4,78 & 4,64 & 4,76 & 0,11 \\
\hline
\end{tabular}

A Figura 31 mostra as curvas de tensão deformação das três réplicas ensaiadas.

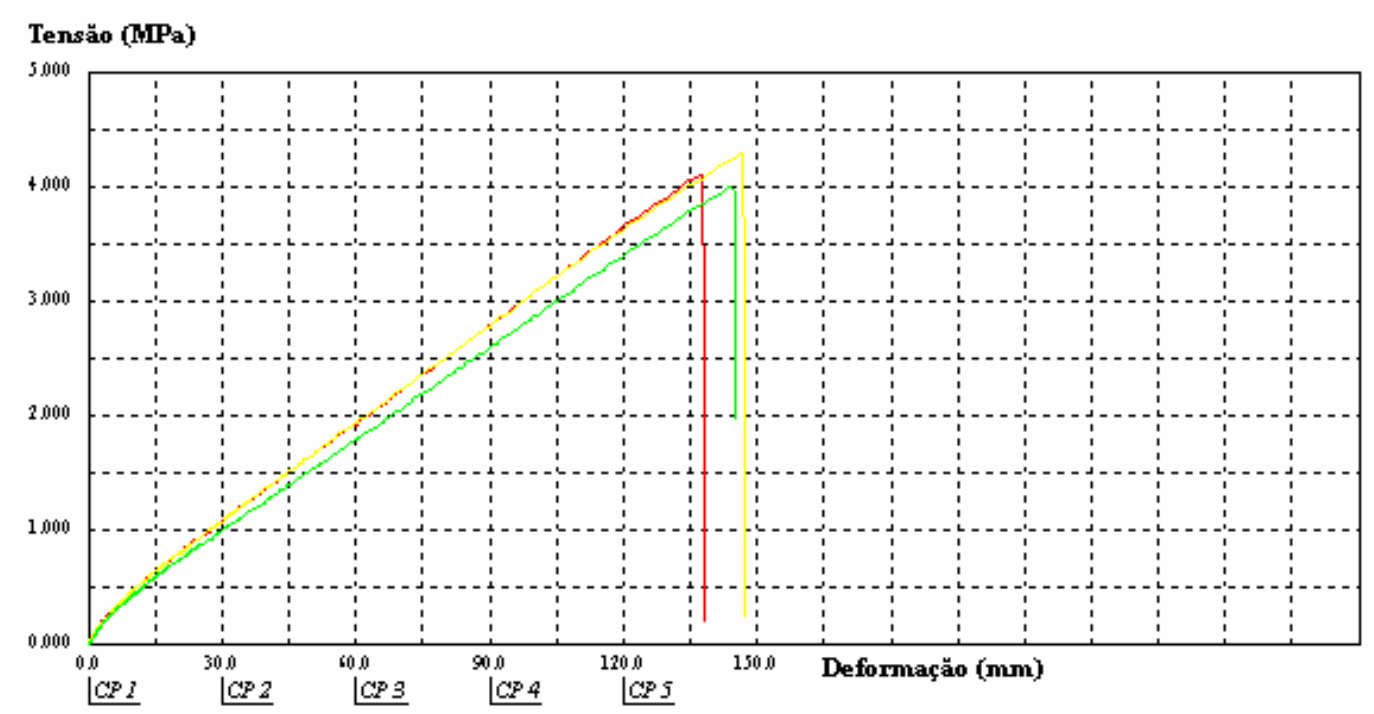

Figura 31 - Curva tensão / deformação das réplicas ensaiadas sem pós cura (0 kGy). 
As Figuras 32, 33 e 34 apresentam respectivamente os resultados obtidos nos ensaios dos corpos de prova com 20 kGy, 50 kGy e 100 kGy.

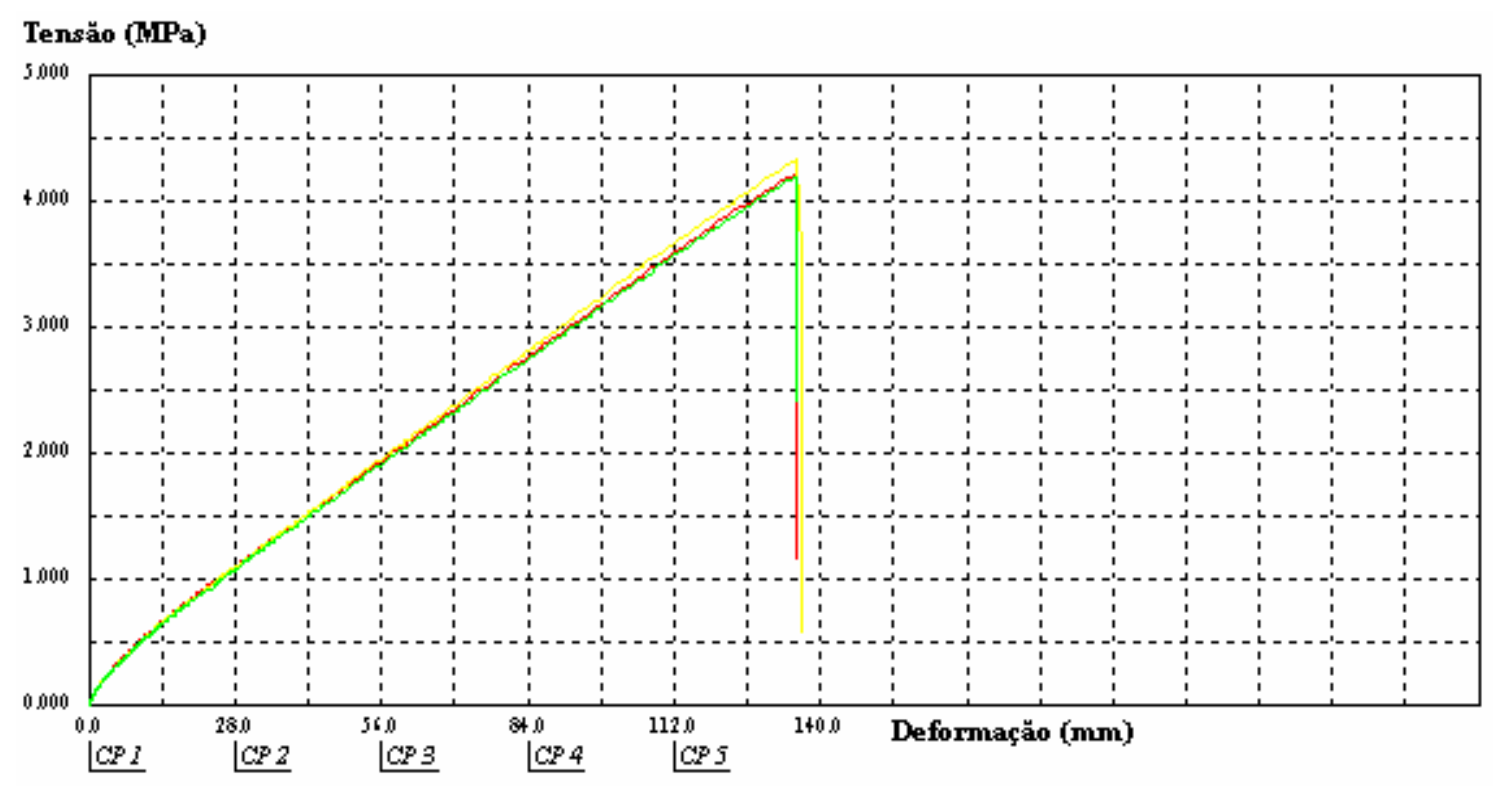

Figura 32 - Curva tensão / deformação das réplicas ensaiadas após 20 kGy de pós cura.

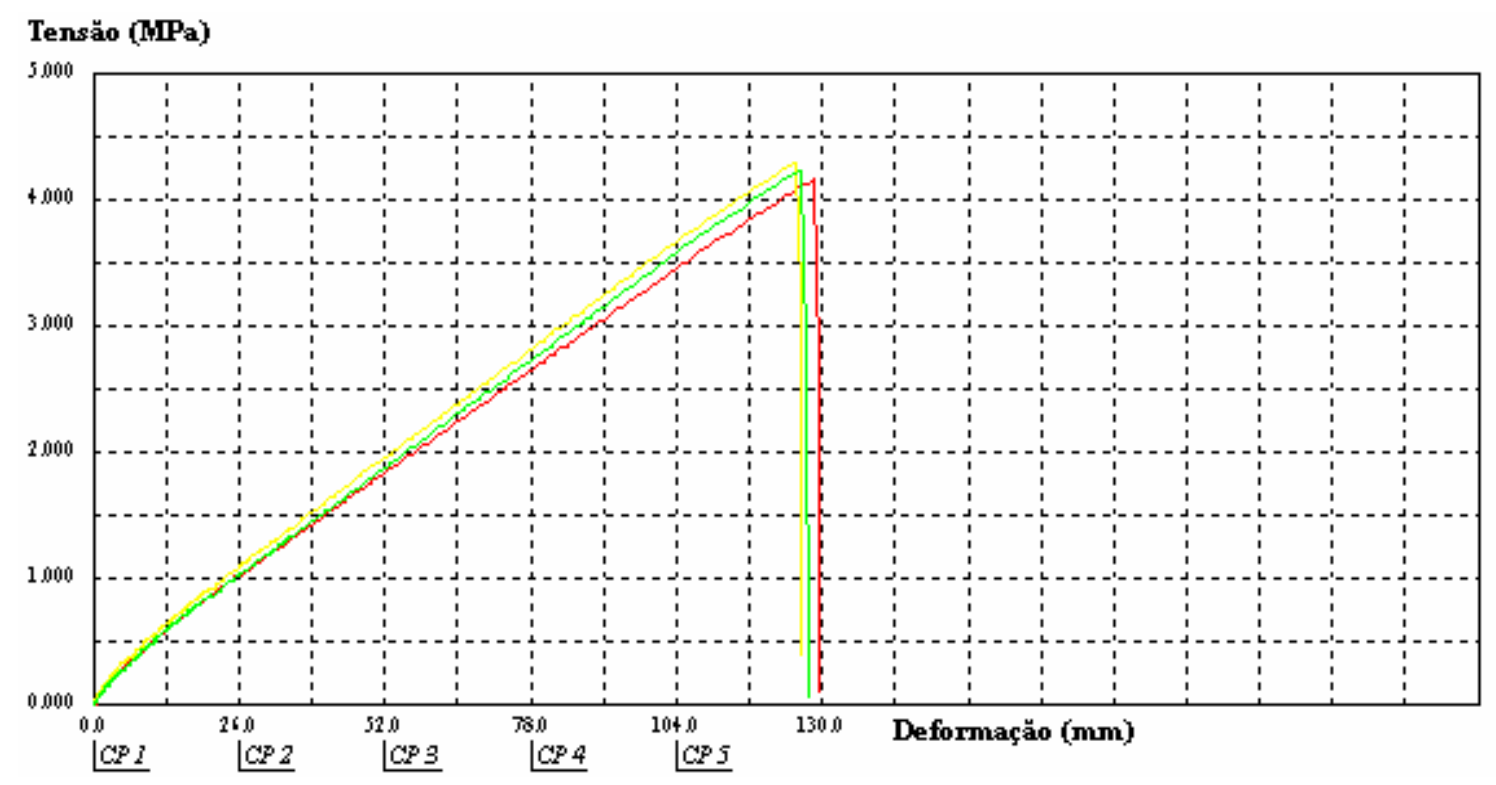

Figura 33 - Curva tensão / deformação das réplicas ensaiadas após 50 kGy de pós cura. 


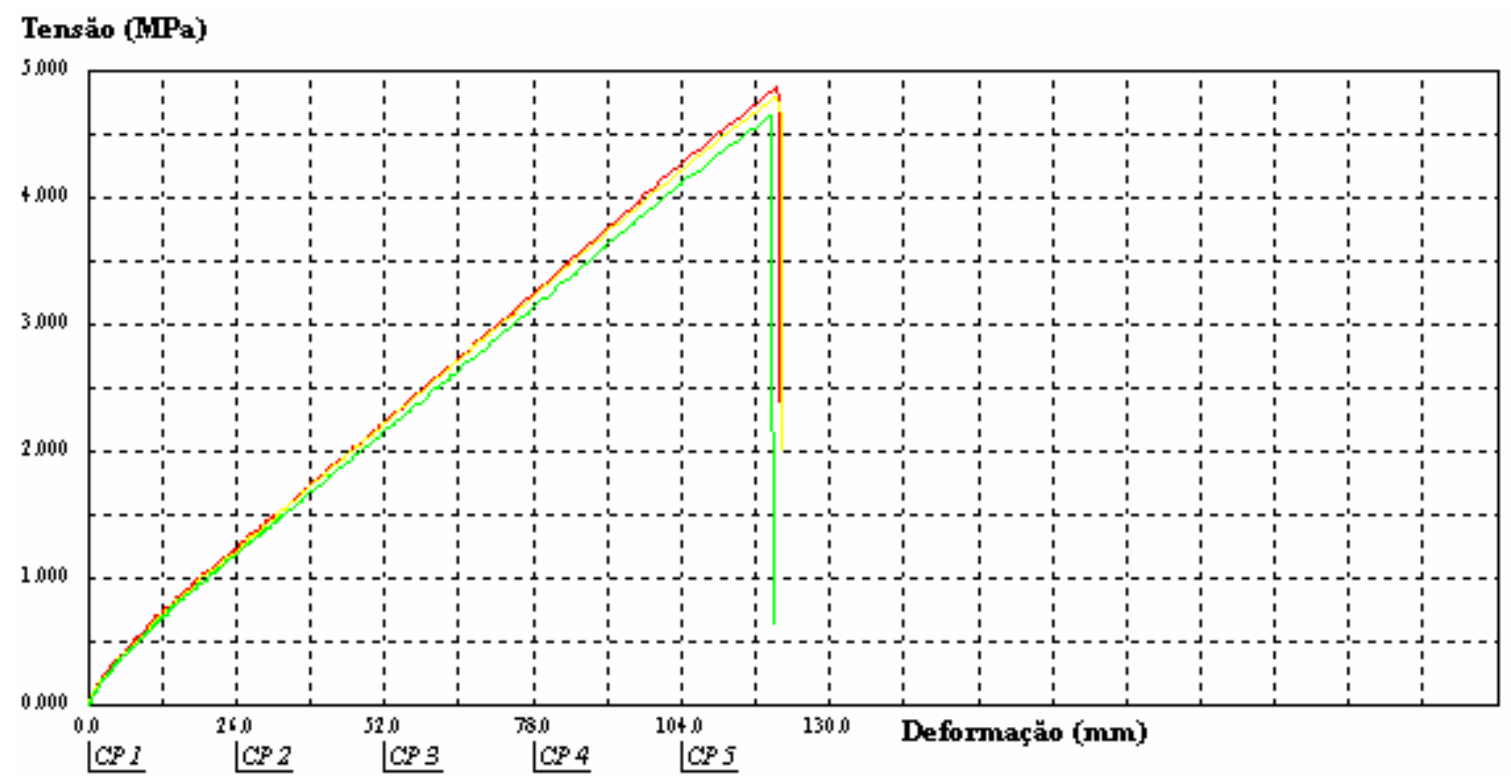

Figura 34 - Curva tensão / deformação das réplicas ensaiadas após 100 kGy de pós cura.

Para melhor visualização das alterações causadas pela radiação na tensão de ruptura, alongamento e respectivamente módulo do material, a Figura 35 apresenta a curva média de cada uma das condições ensaiadas.

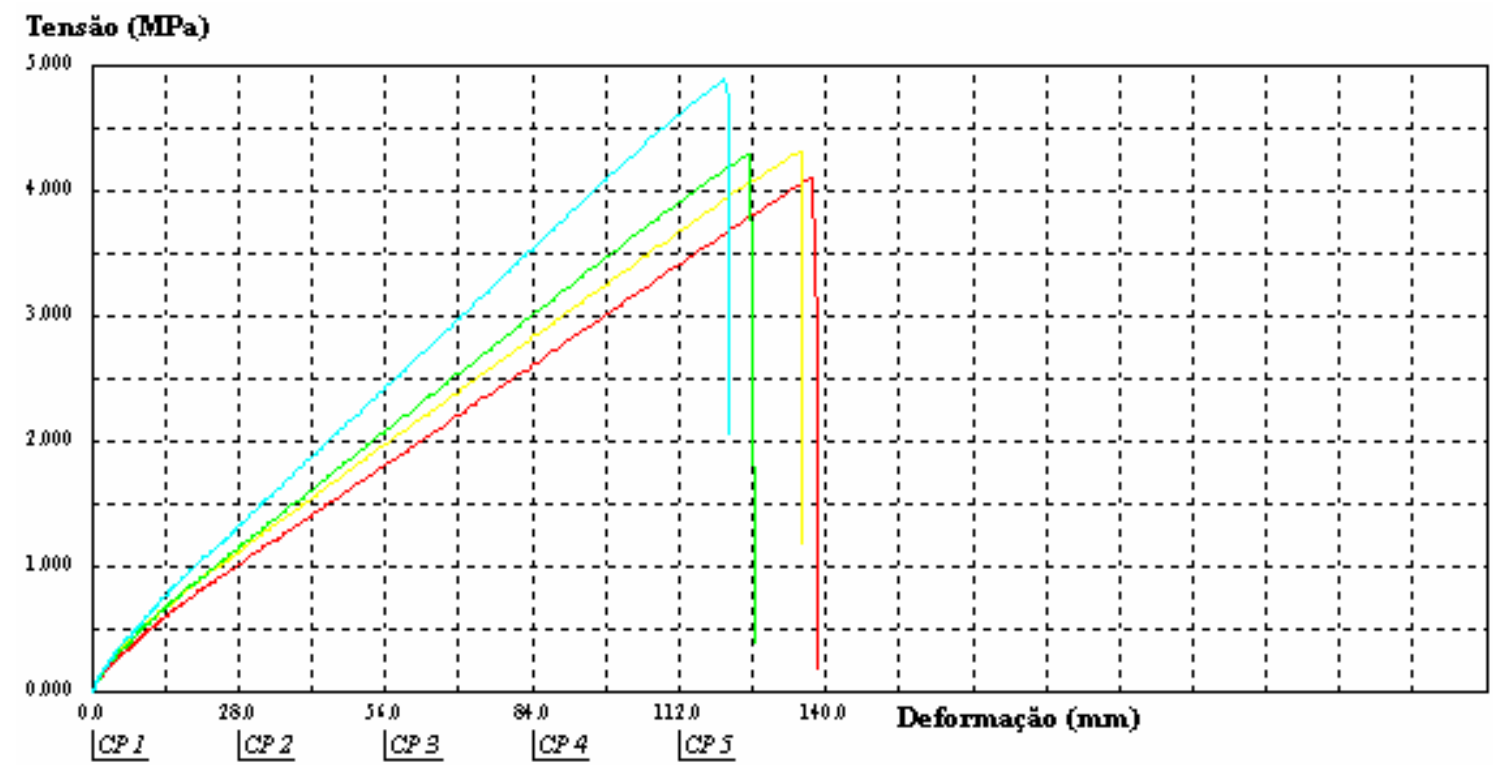

Figura 35 - Curva média de cada condição ensaiada 0 kGy (vermelha), 20 kGy (amarela), 50 kGy (verde) e 100 kGy (azul). 


\subsubsection{Discussão dos Resultados}

As Figuras 32, 33 e 34 mostram que as réplicas repetiram um padrão de comportamento para cada condição ensaiada, as curvas seguiram um perfil com pouca variação entre cada réplica. Os resultados de tensão na ruptura obtidos com os corpos de prova não irradiados apresentaram um desvio padrão de $0,15 \mathrm{MPa}$, equivalente à um percentual de variação de $3,54 \%$. Os desvios padrão para as condições de 20 kGy e 50 kGy ficaram respectivamente em 0,07 MPa e 0,06 MPa, equivalentes à 1,60 \% e 1,55 \%. Finalizando os ensaios mecânicos iniciais com um desvio padrão de $0,11 \mathrm{MPa}$ e 2,34 \% para os corpos de prova irradiados com 100 kGy.

A análise da Tabela 4 associada a Figura 35 mostra um aumento de 2,66 \% da média da tensão na ruptura com a aplicação de 20 kGy de pós cura, em relação aos ensaios realizados com corpos de prova sem radiação. As curvas da Figura 35 mostram, de maneira não quantitativa, uma redução no alongamento do material com a aplicação da radiação.

Não houve diferença na média da tensão na ruptura entre os corpos de prova irradiados com 20 kGy e 50 kGy, o alongamento do material apresentou redução nas condição de 50 kGy, em comparação com a condição de 20 kGy. A condição de 100 kGy apresentou as maiores variações da média da tensão na ruptura, o aumento desta média foi de 15,25 \% em relação a condição não irradiada e de 12,26 \% em relação as condições de 20 kGy e 50 kGy de radiação.

O aumento da tensão na ruptura, associado a redução no alongamento, indica um aumento do módulo de elasticidade do material proporcional ao aumento da dose de radiação. Mesmo entre as condições de $20 \mathrm{kGy}$ e $50 \mathrm{kGy}$, onde as tensões se mostraram idênticas, a redução no alongamento direciona para um aumento do módulo entre estas condições. O aumento do módulo de elasticidade é proporcional ao nível de reticulação, ligações químicas cruzadas, do material. Desta forma os resultados mostram que o aumento da dose de radiação até $100 \mathrm{kGy}$ aumenta o módulo de elasticidade e consequentemente o nível de reticulação do ACM.

$O$ aumento do nível de reticulação sugere que o nível de recombinação entre as moléculas do ACM é superior ao nível de cadeias cisionadas. Zagórski (2004) sugere uma relação de 80 \% de recombinação e 20 \% de cisão molecular quando 
elastômeros são irradiados. A recombinação, consequentemente aumento da reticulação, se dá através do encontro de duas macromoléculas, geradas pelo feixe de elétrons. Denominada como ligação $X$, neste tipo de ligação a união das moléculas é feita por átomos de carbono, sendo que $\mathrm{H}_{2}$ é liberado. Outro tipo de recombinação pode ser formada pela, combinação de macromoléculas, onde ligações do tipo C-O-C são geradas.

Estes ensaios não provam a formação das ligações específicas apresentadas, apenas mostram o aumento do nível da reticulação e alteração do comportamento mecânico do material. Porém atinge seu objetivo mais importante, ao mostrar que a radiação por feixe de elétrons não causa degradação do ACM curado por UV, mas o aumento de algumas propriedades mecânicas importantes para a aplicação deste elastômero.

A ausência de um extensômetro nestes ensaios, desqualificam os resultados para aplicação em modelo de comportamento não linear, como o Modelo de Ogden, por não representarem a deformação do material em uma determinada região, mas o deslocamento dos cabeçotes do equipamento de tração, gerando a necessidade da repetição dos ensaios.

Tal necessidade gerou a possibilidade de reavaliar as doses aplicadas no estudo e devido a pequena variação das propriedades analisadas, entre as condições sem radiação, 20 kGy e 50 kGy, optou-se por utilizar somente a dose de 100 kGy na repetição dos ensaios e estender a dose máxima para 250 kGy, comparando os resultados com a condição sem radiação. Sendo assim possível estender o estudo do comportamento mecânico do material para condições de irradiação de 250 kGy e verificar se há degradação com esta dose.

A opção de abandonar a análise dos efeitos das doses de 20 kGy e 50 kGy se deu devido ao baixo aumento da tensão na ruptura, em relação a condição não irradiada, e devido a não alteração da mesma variável entre as doses. 


\subsubsection{Resultados da espectroscopia por IR - Testes preliminares}

A análise por infravermelho realizada nos corpos de prova gerou espectros na faixa de $930 \mathrm{~cm}^{-1}$ até $2000 \mathrm{~cm}^{-1}$ das duas regiões estudadas, a altura dos picos é proporcional à quantidade de ligações presentes no material. As Tabelas 5 e 6 apresentam os picos máximos $\left(H_{\text {máx }}\right)$ encontrados em cada comprimento de onda nas regiões, obtida pela media aritmética das três medições, bem como as alturas corrigidas destes picos $\left(\mathrm{H}_{\text {corr }}\right)$, ambos os parâmetros foram fornecidos pelo software do equipamento utilizado. A discussão dos resultados será realizada com base na altura corrigida.

Tabela 5 - Alturas máximas e médias dos picos encontrados na região superficial.

\begin{tabular}{|c|c|c|c|c|}
\hline \multicolumn{2}{|c|}{ Condição } & \multirow{2}{*}{$\begin{array}{c}1740 \mathbf{~ c m}^{-1} \\
0,3734\end{array}$} & \multirow{2}{*}{$\begin{array}{c}1632 \mathbf{~ c m}^{-1} \\
0,0658\end{array}$} & \multirow{2}{*}{$\begin{array}{r}1160 \mathbf{~ m}^{-1} \\
0,3460\end{array}$} \\
\hline 0 kGy & $\mathrm{H}_{\text {máx }}$ & & & \\
\hline & $\mathrm{H}_{\text {corr }}$ & 0,3607 & 0,0531 & 0,1534 \\
\hline \multirow[t]{2}{*}{20 kGy } & $\mathrm{H}_{\text {máx }}$ & 0,3686 & 0,0698 & 0,3460 \\
\hline & $\mathrm{H}_{\text {corr }}$ & 0,3547 & 0,0557 & 0,1481 \\
\hline \multirow[t]{2}{*}{50 kGy } & $\mathrm{H}_{\text {máx }}$ & 0,3514 & 0,0754 & 0,3362 \\
\hline & $\mathrm{H}_{\text {corr }}$ & 0,3396 & 0,0582 & 0,1348 \\
\hline \multirow[t]{2}{*}{$100 \mathrm{kGy}$} & $\mathrm{H}_{\text {máx }}$ & 0,3567 & 0,0578 & 0,3365 \\
\hline & $\mathrm{H}_{\text {corr }}$ & 0,3426 & 0,0429 & 0,1441 \\
\hline
\end{tabular}

Tabela 6 - Alturas máximas e médias dos picos encontrados na região central do material.

\begin{tabular}{clccc}
\hline \multicolumn{2}{c}{ Condição } & $\mathbf{1 7 4 0} \mathbf{~ c m}^{-1}$ & $\mathbf{1 6 3 2} \mathbf{~ m}^{-1}$ & $\mathbf{1 1 6 0 \mathbf { ~ c m } ^ { - 1 }}$ \\
\hline \multirow{2}{*}{0 kGy } & $\mathrm{H}_{\text {máx }}$ & 0,2819 & 0,1140 & 0,2874 \\
& $\mathrm{H}_{\text {corr }}$ & 0,2638 & 0,0989 & 0,1057 \\
\multirow{3}{*}{$50 \mathrm{kGy}$} & $\mathrm{H}_{\text {máx }}$ & 0,3116 & 0,1133 & 0,3158 \\
& $\mathrm{H}_{\text {corr }}$ & 0,3002 & 0,1054 & 0,1193 \\
& $\mathrm{H}_{\text {máx }}$ & 0,3055 & 0,1120 & 0,3081 \\
& $\mathrm{H}_{\text {corr }}$ & 0,2942 & 0,1041 & 0,1168 \\
& $\mathrm{H}_{\text {máx }}$ & 0,3197 & 0,1169 & 0,3225 \\
& $\mathrm{H}_{\text {corr }}$ & 0,3068 & 0,1072 & 0,1198 \\
\hline
\end{tabular}




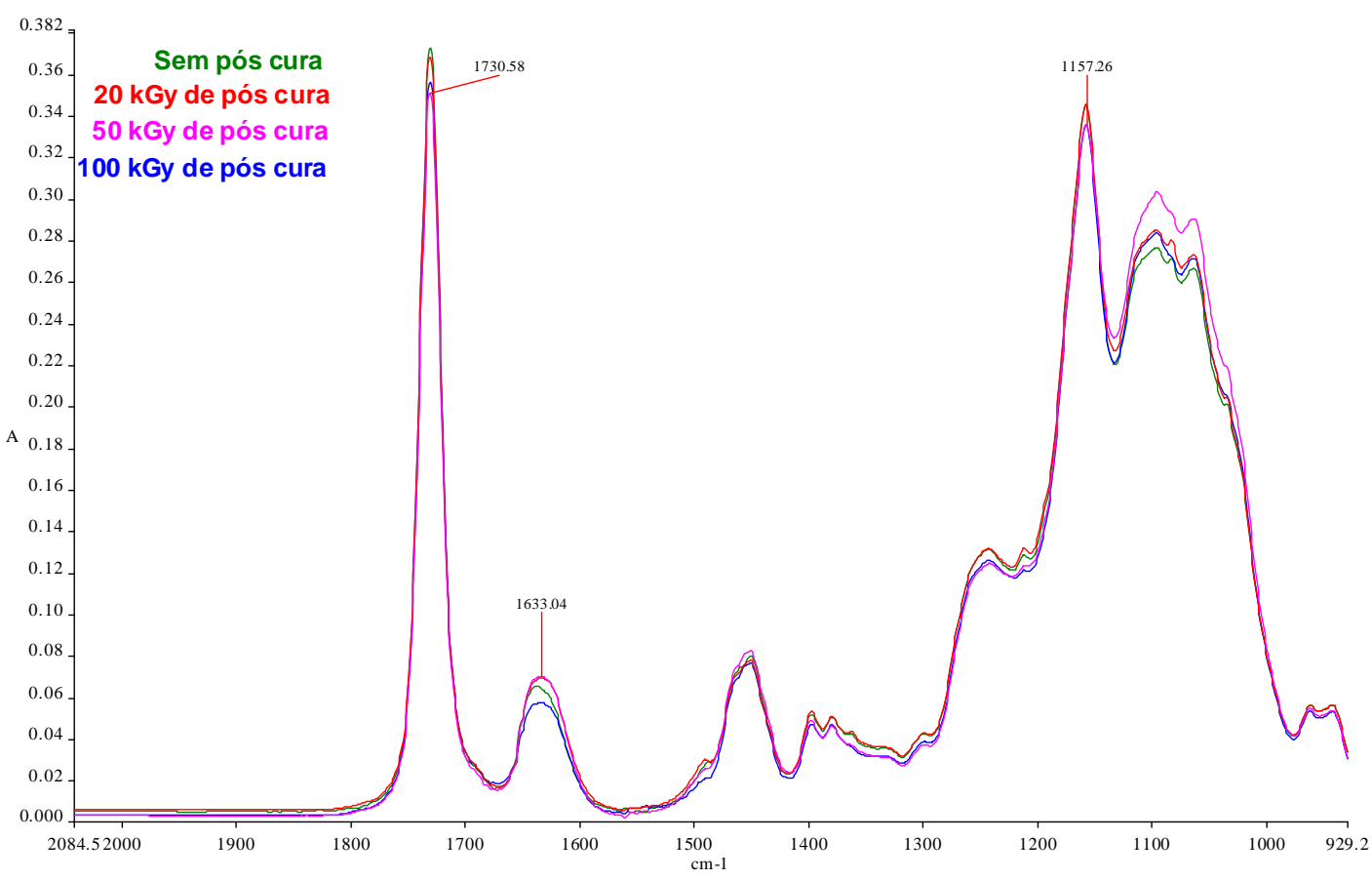

Figura 36 - Espectro de absorbância de $930 \mathrm{~cm}-1$ até $2000 \mathrm{~cm}-1$ na superfície do ACM.

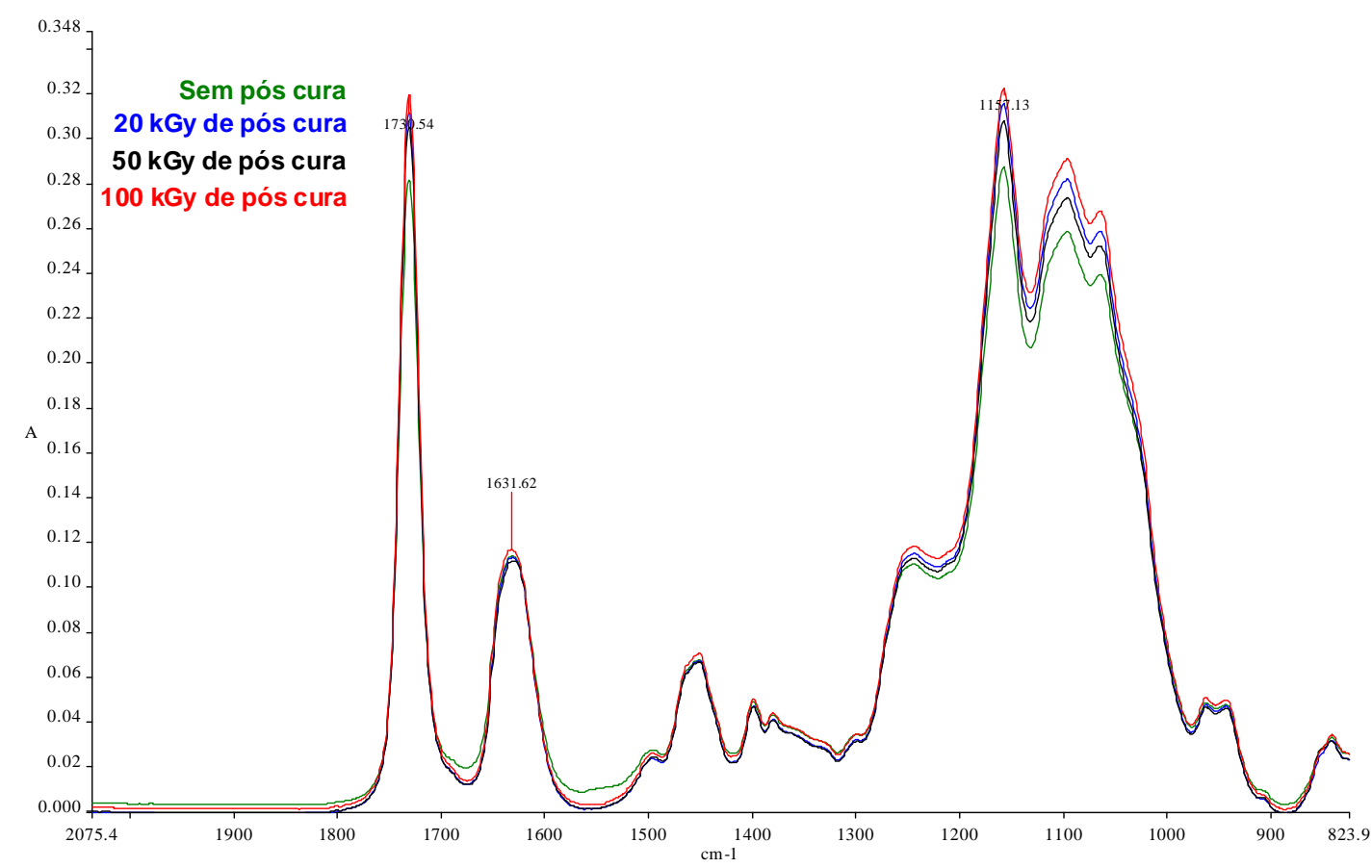

Figura 37 - Espectro de absorbância de 930 cm-1 até 2000 cm-1 na região central do ACM. 


\subsubsection{Discussão dos Resultados}

A análise do espectro de absorbância, no comprimento de onda de $1740 \mathrm{~cm}^{-1}$, referente a quantidade de ligações tipo $>\mathrm{C}=\mathrm{O}$, mostrou uma redução na quantidade deste grupo químico na região superficial do ACM com o aumento da dose de radiação. As três doses aplicadas elevaram a quantidade de ligações $>\mathrm{C}=\mathrm{O}$ na superfície, a dose de 50 kGy porém, mostrou uma redução em relação a quantidade gerada com 20 kGy, mostrando uma irregularidade no comportamento deste aumento, confirmando a afirmação de Zagórski (2004) de que cada dose atua de maneira diferente no material, gerando reações diferentes.

Ao comparar o nível de ligações tipo $>\mathrm{C}=\mathrm{O}$ existentes na superfície do material com a quantidade da região central, nota-se uma maior quantidade deste tipo de ligação na região superficial. Isto se deve ao fato da superfície do material estar em contato com $\mathrm{O}_{2}$ durante o processo de cura por UV, gerando uma maior oxidação da superfície. Outro fator responsável por esta maior quantidade deste tipo de ligação é a necessidade de comprimento de onda específico para curar o material superficialmente.

A aplicação do feixe de elétrons na superfície pode ter gerado a quebra destas ligações químicas, devido a alta quantidade de energia do feixe e quantidade de ligações disponíveis, as quais se agruparam com outros radicais livres disponíveis, causando a redução citada de $>\mathrm{C}=\mathrm{O}$ na superfície, com o aumento da dose de radiação.

$\mathrm{Na}$ região interna, ou central, devido a ausência de contato com $\circ \mathrm{O}_{2}$ durante a cura, a quantidade de $>\mathrm{C}=\mathrm{O}$ na amostra não irradiada é inferior a quantidade na superfície. Esta quantidade porém, diferente da dinâmica ocorrida na superfície, apresenta um aumento com o aumento da dose de radiação.

O comportamento das quantidades de C-O-C, referentes ao comprimento de onda de $1160 \mathrm{~cm}^{-1}$, na superfície e na região central, apresentou dinâmica qualitativa semelhante ao ocorrido com o grupo $>\mathrm{C}=\mathrm{O}$. Na superfície houve uma redução da quantidade deste grupo com o aumento da dose aplicada, todas as doses apresentaram tal redução quando comparado com o ACM não irradiado, porém a dose de 100 kGy apresentou maior quantidade de C-O-C em relação a dose de 50 
kGy. Mais uma vez mostrando a variação do efeito causado de acordo com a dose aplicada.

$\mathrm{Na}$ região central, repetindo o aumento apresentado com os grupos $>\mathrm{C}=\mathrm{O}$, a quantidade de grupos C-O-C também aumentou com o aumento da dose de radiação. A Figura 12 apresenta uma possível dinâmica de reação para explicar este aumento de C-O-C.

Nos dois grupos e regiões estudados até o momento, $>\mathrm{C}=\mathrm{O}$, C-O-C, superfície e região central, ambos envolvendo átomos de oxigênio, sempre que ocorreu um aumento da quantidade de um dos grupos na superfície, houve aumento do mesmo grupo na região central. Tal comportamento pode indicar um deslocamento de átomos de oxigênio da superfície para o centro, com a aplicação da radiação, ou a reação destes átomos com outros grupos existentes no material. Porém como o objetivo deste trabalho não é caracterizar a dinâmica de polimerização ou de pós cura do ACM, mas verificar as alterações estruturais causadas pela radiação EB, não será aprofundada a investigação de possíveis causas e comprovação destes fenômenos.

A análise da absorbância em $1632 \mathrm{~cm}^{-1}$, referente ao grupo químico $>\mathrm{C}=\mathrm{C}<$, mostra que no material não irradiado a quantidade deste grupo químico é superior na região central, devido à uma possível limitação de cura por profundidade deste material. Porém, mesmo com o aumento do nível de reticulação, mostrado pelo aumento do módulo de cisalhamento causado pela radiação, não houve redução da quantidade de $>\mathrm{C}=\mathrm{C}<$ na região central do material com o aumento da dose. Diferente do esperado, a quantidade de grupos $>\mathrm{C}=\mathrm{C}<$ reduziu com o aumento da dose de EB na região central, mesmo com o aumento do módulo cisalhamento e reticulação, esta por sua vez deve-se outro tipo de reação química e não a redução da quantidade deste grupo, que não ocorreu. Na superfície, a quantidade de ligações $>\mathrm{C}=\mathrm{C}<$ aumentou com o aumento da dose de radiação até 50 kGy e reduziu consideravelmente com a aplicação de 100 kGy.

A formulação exata do poliacrilato em estudo não foi informada pelo fabricante, por se tratar de um material ainda em desenvolvimento, sendo assim a influência do comonômero de cura presente no material e desconhecido pelo autor, pode explicar de maneira mais clara as modificações moleculares geradas pela radiação.

Mais uma vez as alterações causadas pelas doses de 20 kGy e 50 kGy apresentaram variações pequenas e não regulares, ou seja, não proporcionais a 
dose. As alterações causadas pela dose de $100 \mathrm{kGy}$ foram mais intensas e definidas, acentuando a decisão de não dar continuidade ao estudo dos efeitos das doses de 20 kGy e 50 kGy, mantendo apenas a análise da influência da dose de 100 kGy e abrindo a possibilidade de estudar os efeitos de uma nova dose, $250 \mathrm{kGy}$.

Embora as reações exatas causadas pela radiação não foram caracterizadas, o que se deve reforçar não é o objetivo deste trabalho, o objetivo deste ensaio foi atingido ao mostrar que houve variação da estrutura molecular em função da aplicação de radiação EB. Não foi possível relacionar diretamente as variações estruturais moleculares apresentadas com as alterações de comportamento mecânico geradas.

\subsection{CARACTERIZAÇÃO DA RESPOSTA ELÁSTICA}

\subsubsection{Resultados dos ensaios uniaxiais - Segunda fase}

Os resultados obtidos nos ensaios uniaxiais do primeiro método indicaram um aumento significativo da tensão de ruptura e do módulo com a dose de $100 \mathrm{kGy}$, o que levou a repetição dos ensaios, com maior precisão, para as condições sem cura, pós curado a 100 kGy e um aumento da dose máxima aplicada para 250 kGy, com o objetivo de verificar se o aumento da dose para 250 kGy, continuaria a alterar o comportamento mecânico do material.

A utilização do extensômetro possibilitou maior precisão nos dados de deformação e obtenção de dados como módulo de elasticidade a 100\% de deformação e alongamento na ruptura, dados apresentados na Tabela 7 para as três condições testadas, com informações sobre as três réplicas de cada condição. Os ensaios com ACM pós curados com doses de 20 kGy e 50 kGy não foram repetidos, devido a proximidade dos resultados de alongamento e tensão na ruptura no primeiro método.

Tabela 7 - Tensões na ruptura em ensaio uniaxial de tração do segundo método.

\begin{tabular}{cccccc}
\hline Condição & \multicolumn{3}{c}{ Tensão na Ruptura (MPa) } & Média (MPa) & Desvio (MPa) \\
\hline 0 kGy & 4,76 & 4,84 & 4,81 & 4,80 & 0,04 \\
100 kGy & 4,79 & 4,77 & 5,19 & 4,93 & 0,22 \\
250 kGy & 5,22 & 5,00 & 5,05 & 5,09 & 0,11 \\
\hline
\end{tabular}


Tabela 8 - Alongamento na ruptura em ensaio uniaxial de tração do segundo método.

\begin{tabular}{cccccc}
\hline Condição & \multicolumn{3}{c}{ Alongamento na Ruptura (\%) } & Média (\%) & Desvio (\%) \\
\hline 0 kGy & 188,60 & 190,00 & 196,29 & 191,63 & 4,09 \\
100 kGy & 152,37 & 158,46 & 158,55 & 156,46 & 3,54 \\
250 kGy & 118,14 & 118,83 & 123,20 & 120,06 & 2,74 \\
\hline
\end{tabular}

Tabela 9 - Módulo @ 100\% na ruptura em ensaio uniaxial de tração do segundo método.

\begin{tabular}{cccccc}
\hline Condição & \multicolumn{3}{c}{ Módulo @ 100\% (MPa) } & Média (MPa) & Desvio (MPa) \\
\hline 0 kGy & 2,59 & 2,64 & 2,46 & 2,56 & 0,09 \\
100 kGy & 3,10 & 2,91 & 3,36 & 3,12 & 0,22 \\
250 kGy & 4,54 & 4,26 & 4,09 & 4,30 & 0,23 \\
\hline
\end{tabular}

A Tabela 10 apresenta comparativamente os resultados de tensão na ruptura, dos ensaios uniaxiais de tração, apresentados de acordo com o primeiro e segundo métodos, em mesma condições de material e dose de irradiação. Os resultados obtidos com corpos de prova curados com 250 kGy estão descritos na última linha da tabela, embora esta condição tenha sido testada no primeiro método, disponibilizar os resultados permite comparar os resultados com as outras condições de ambos os métodos.

Tabela 10 - Tabela comparativa entre os resultados, de mesma dose, em ensaios de tração uniaxial no primeiro ${ }^{(1)}$ e segundo ${ }^{(2)}$ métodos.

\begin{tabular}{cccccc}
\hline Condição & \multicolumn{3}{c}{ Tensão na Ruptura (MPa) } & Média (MPa) & Desvio (MPa) \\
\hline $0 \mathrm{kGy}^{(2)}$ & 4,76 & 4,84 & 4,81 & 4,80 & 0,04 \\
$0 \mathrm{kGy}^{(1)}$ & 4,11 & 4,28 & 4,00 & 4,13 & 0,15 \\
$100 \mathrm{kGy}^{(2)}$ & 4,79 & 4,77 & 5,19 & 4,93 & 0,22 \\
$100 \mathrm{kGy}^{(1)}$ & 4,86 & 4,78 & 4,64 & 4,76 & 0,11 \\
$250 \mathrm{kGy}^{(2)}$ & 5,22 & 5,00 & 5,05 & 5,09 & 0,11 \\
\hline
\end{tabular}

As Figuras 38, 39 e 40 apresentam as curvas de tensão / deformação apresentadas respectivamente pelos réplicas nas condições sem cura, com 100 kGy e 250 kGy de radiação. 


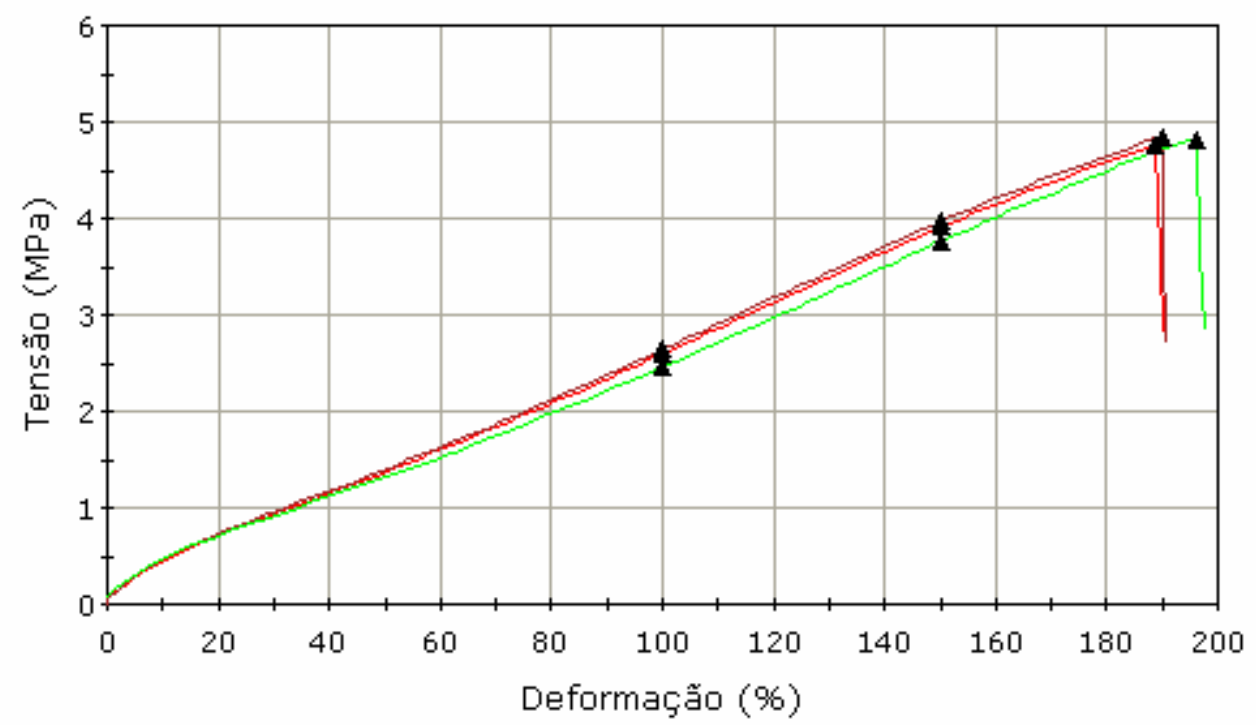

Figura 38 - Curva tensão / deformação das réplicas ensaiadas sem pós cura - ensaio uniaxial do segundo método.

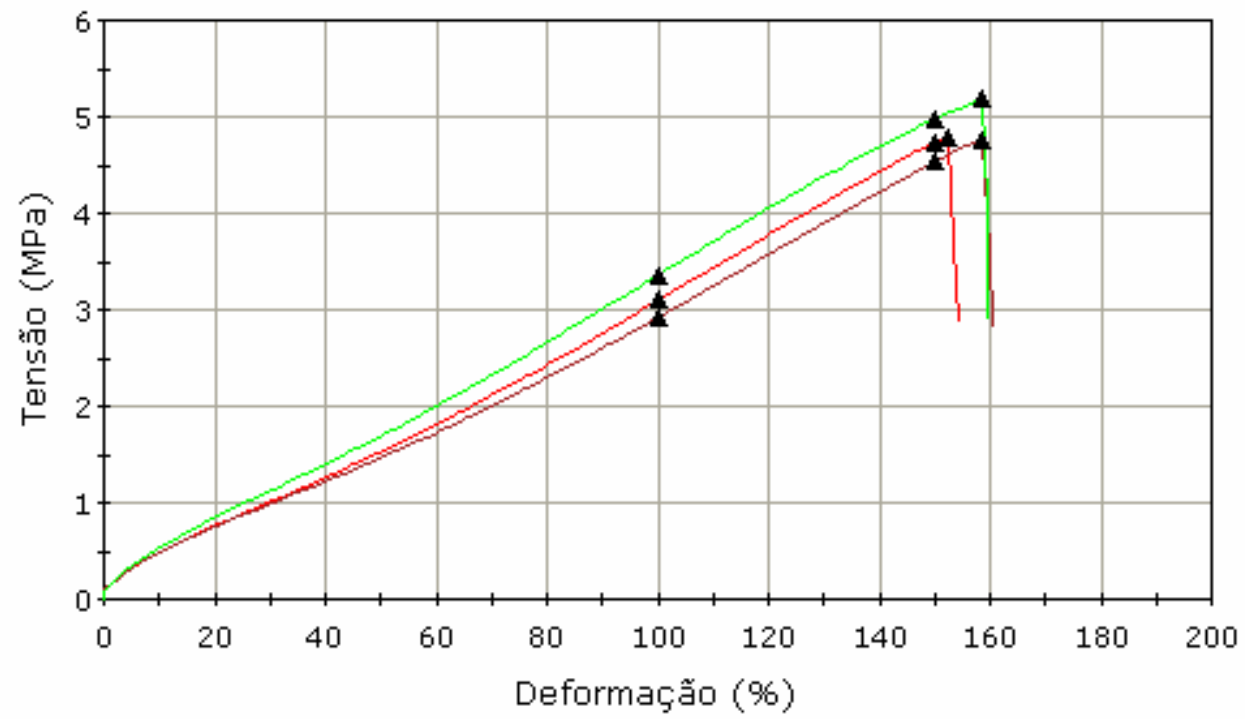

Figura 39 - Curva tensão / deformação das réplicas ensaiadas após 100 kGy de pós cura - ensaio uniaxial do segundo método. 


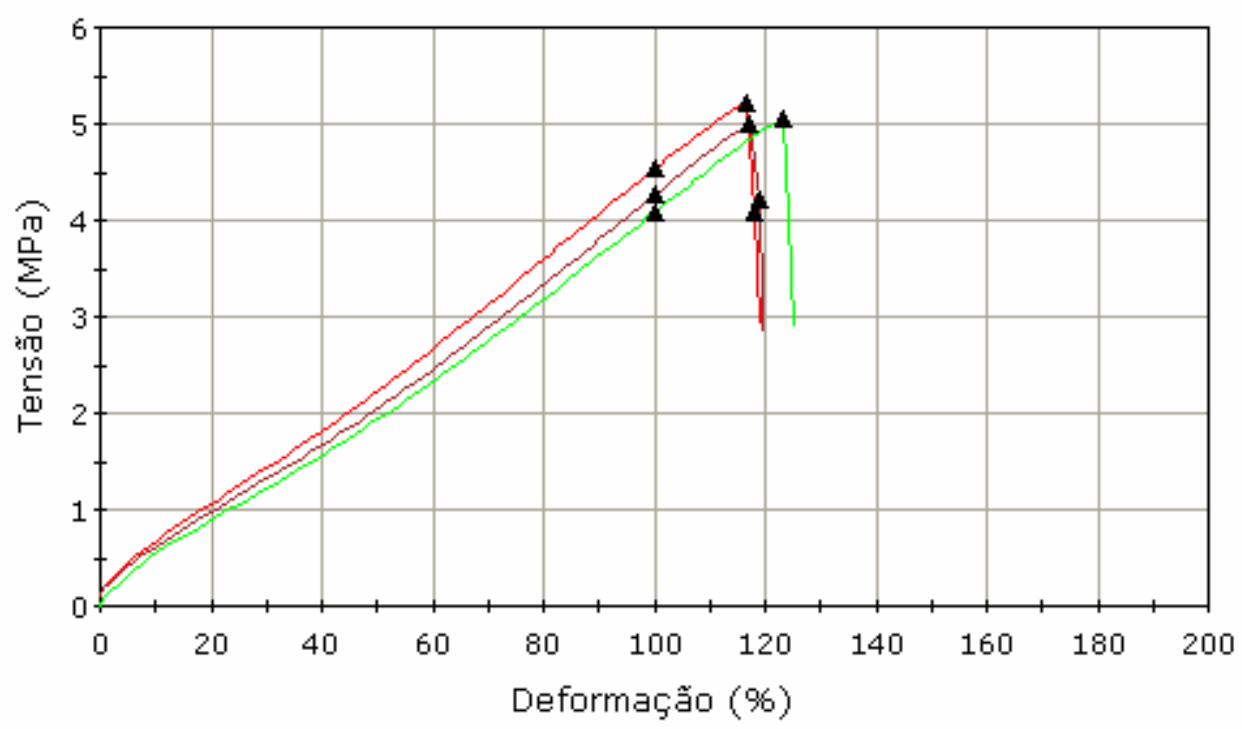

Figura 40 - Curva tensão / deformação das réplicas ensaiadas após 250 kGy de pós cura - ensaio uniaxial do segundo método.

\subsubsection{Discussão dos Resultados}

Os resultados experimentais mostraram mais uma vez que as curvas obtidas nas condições testadas apresentaram boa repetibilidade, no que se referem as réplicas testadas nas mesmas condições. Indicando desta forma método de ensaio e condição de materiais adequados. Os desvios padrão de 0,04 MPa, 0,22 Mpa e 0,11 $\mathrm{MPa}$, para médias de 4,80 MPa, 4,93 MPa e 5,09 MPa, respectivamente referente as condições sem radiação, pós curada com 100 kGy e 250 kGy.

O aumento da média da tensão na ruptura alcançada neste segundo método, ao se comparar os corpos de prova não irradiados com os irradiados com 100 kGy, foi de $2,7 \%$, valor bastante inferior ao encontrado no primeiro método, que apresentou variação de 15,25 \% na mesma condição. Esta diferença provavelmente se deve aos diferentes processos de obtenção dos corpos de prova e dos diferentes equipamentos utilizados nos dois métodos. Os corpos de prova utilizados no primeiro método apresentaram pequenas bolhas de ar, devido ao processo manual utilizado, enquanto os corpos de prova do segundo método eram homogêneos, sem presença de bolhas. A dose de 250 kGy por sua vez, ocasionou um aumento da média da tensão na ruptura de 6,04 \% em relação a condição não irradiada e de 
3,24 \% em relação aos corpos de prova pós curados com 100 kGy. Mostrando que mesmo com doses maiores que 100 kGy, a radiação EB continua causando aumento da tensão na ruptura do material.

Este segundo método possibilitou a medição do alongamento dos corpos de prova na ruptura, fornecendo dados quantitativos sobre este parâmetro. A aplicação e aumento da dose de radiação mostrou grande redução na capacidade de alongamento do material. Os corpos de prova não radiados apresentaram uma média no alongamento de $191,63 \%$, reduzindo esta média para $156,46 \%$ ao se irradiar os corpos de prova com 100 kGy, o que corresponde a uma redução de $18,35 \%$ na média do alongamento na ruptura. O ACM irradiado com 250 kGy apresentou uma média do alongamento na ruptura de 120,06\%, ou seja, uma redução de 37,35 \% em relação a condição não irradiada e de 23,26 \% em relação ao ACM irradiado com $100 \mathrm{kGy}$. Diferente das tímidas variações ocorridas na média da tensão na ruptura, as variações ocorridas no alongamento do material foram bastantes significativas, salientando que os resultados individuais dentre de cada condição testada apresentaram boa repetibilidade, com desvios padrão de 4,09\%, $3,54 \%$ e $2,74 \%$ proporcionalmente aos resultados de média do alongamento na ruptura causados pela dose de radiação aplicada.

O aumento da tensão na ruptura associado a redução do alongamento ocasionaram um aumento do módulo de elasticidade do material a $100 \%$ de alongamento, proporcionalmente crescente a dose de radiação aplicada. O aumento do módulo é um indicativo do aumento do peso molecular do material, ou seja, do nível de ligações químicas cruzadas presentes na estrutura molecular deste elastômero termofixo e conseqüente enrijecimento do material.

Enquanto o material não irradiado apresentou uma média do módulo a $100 \%$ de alongamento de 2,56 MPa, a irradiação com $100 \mathrm{kGy}$ aumentou este módulo em 21,87 \% elevando-o para o nível de 3,12 MPa. A dose de 250 kGy ocasionou outro aumento deste módulo, desta vez de 67,97 \% em relação ao material não irradiado e de 37,82 \% em relação ao resultado obtido com 100 kGy, o valor do módulo medido a $100 \%$ de alongamento para o ACM pós curado com 250 kGy de radiação EB foi de 4,30 MPa.

As três propriedades medidas apresentaram variação e se mostraram influenciadas pela aplicação e dose de radiação $\mathrm{EB}$, porém o resultado mais significativo demonstrado por estes resultados, foi a variação do módulo de cisalhamento do 
material, por apresentarem os maiores níveis de variação e estarem diretamente relacionados com o nível de reticulação do material, mecanismo através do qual se pretende reduzir a relaxação da tensão deste material, causado por esforços de compressão.

Dezenas de pares tensão / deformação medidos para todas as réplicas ensaiadas estão relacionados no Apêndice A deste trabalho. Estes pares serão aplicados no sistema de séries gerados pelo Modelo de Ogden, com a finalidade de se obter os parâmetros deste modelo, possibilitando a aplicação do Modelo de Ogden em métodos de elementos finitos permitindo similar de maneira precisa 0 comportamento elástico deste material, inclusive nas condições irradiadas.

\subsubsection{Resultados dos ensaios equibiaxiais - Segunda fase}

$\mathrm{Na}$ Tabela 11 estão contidos os resultados de tensão na ruptura dos ensaios equibiaxiais realizados com corpos de prova nas condições propostas, assim como as médias destas tensões para cada condição e os desvios padrão. Na seqüência as Figuras 41, 42 e 43 apresentam as curvas obtidas, divididas em condição de ensaio, com três réplicas por condição. No Apêndice A estão relacionados os pares tensão / deformação medidos em cada réplica ensaiada.

Tabela 11 - Tensões na ruptura em ensaio equibiaxial de tração do segundo método.

\begin{tabular}{cccccc}
\hline Condição & \multicolumn{3}{c}{ Tensão na Ruptura (MPa) } & Média (MPa) & Desvio (MPa) \\
\hline 0 kGy & 1,04 & 1,02 & 1,09 & 1,05 & 0,04 \\
100 kGy & 1,08 & 1,23 & 1,11 & 1,14 & 0,08 \\
250 kGy & 1,25 & 1,20 & 1,45 & 1,30 & 0,13 \\
\hline
\end{tabular}

Tabela 12 - Alongamento na ruptura em ensaio equibiaxial de tração do segundo método.

\begin{tabular}{cccccc}
\hline Condição & \multicolumn{3}{c}{ Alongamento na Ruptura (\%) } & Média (\%) & Desvio (\%) \\
\hline 0 kGy & 48,44 & 46,90 & 49,54 & 48,29 & 1,33 \\
100 kGy & 36,40 & 40,65 & 36,57 & 37,87 & 2,41 \\
250 kGy & 30,82 & 28,87 & 28,06 & 29,25 & 1,42 \\
\hline
\end{tabular}


Tabela 13 - Tensão a 20\% de alongamento.

\begin{tabular}{|c|c|c|c|c|c|}
\hline Condição & \multicolumn{3}{|c|}{ Tensão a 20\% de Alongamento (MPa) } & Média (MPa) & Desvio (MPa) \\
\hline 0 kGy & 0,603 & 0,593 & 0,613 & 0,603 & 0,01 \\
\hline 100 kGy & 0,732 & 0,773 & 0,745 & 0,75 & 0,02 \\
\hline 250 kGy & 0,931 & 0,944 & 1,163 & 1,01 & 0,13 \\
\hline
\end{tabular}

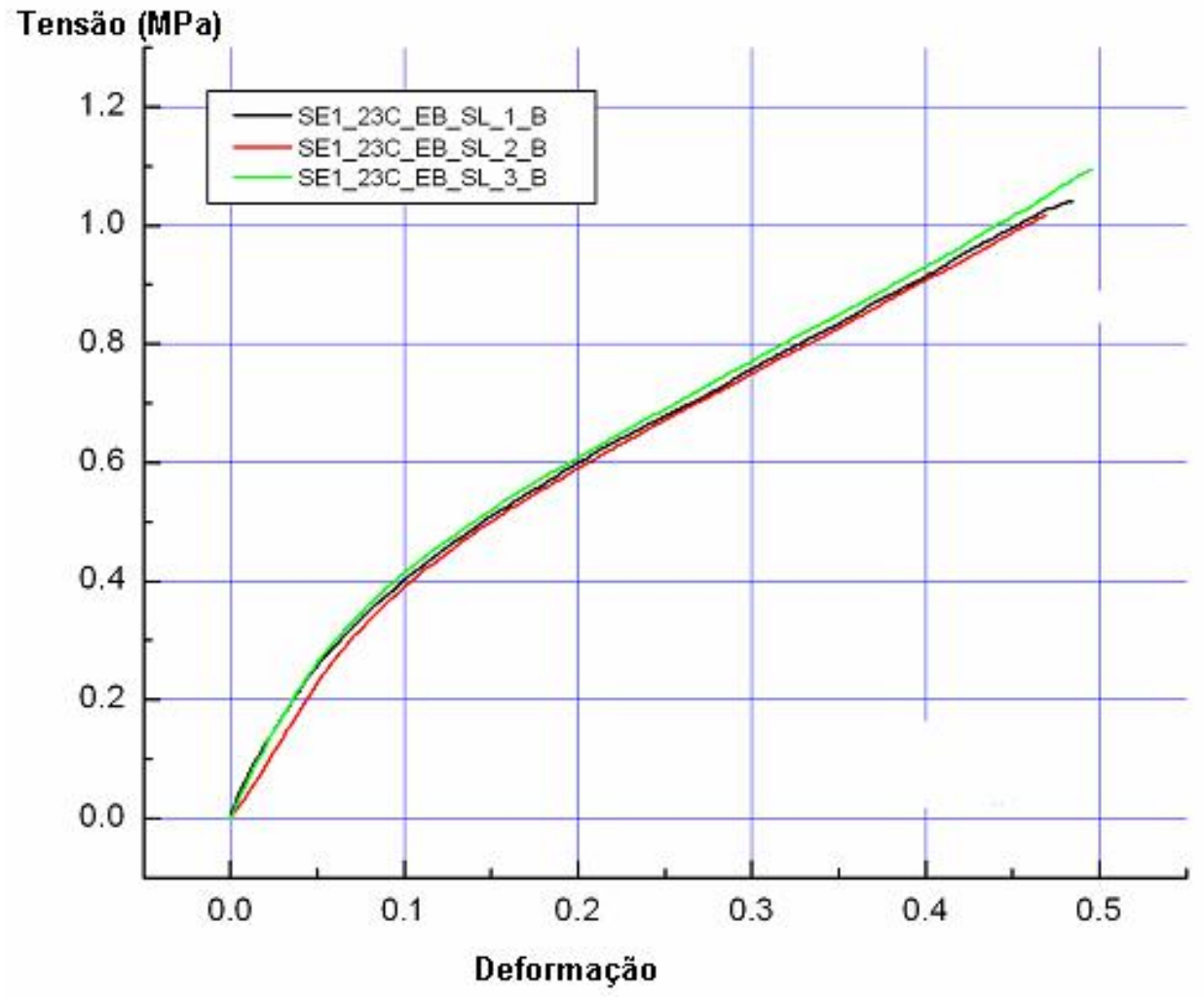

Figura 41 - Curva tensão / deformação das réplicas ensaiadas sem pós cura - ensaio equibiaxial do segundo método. 


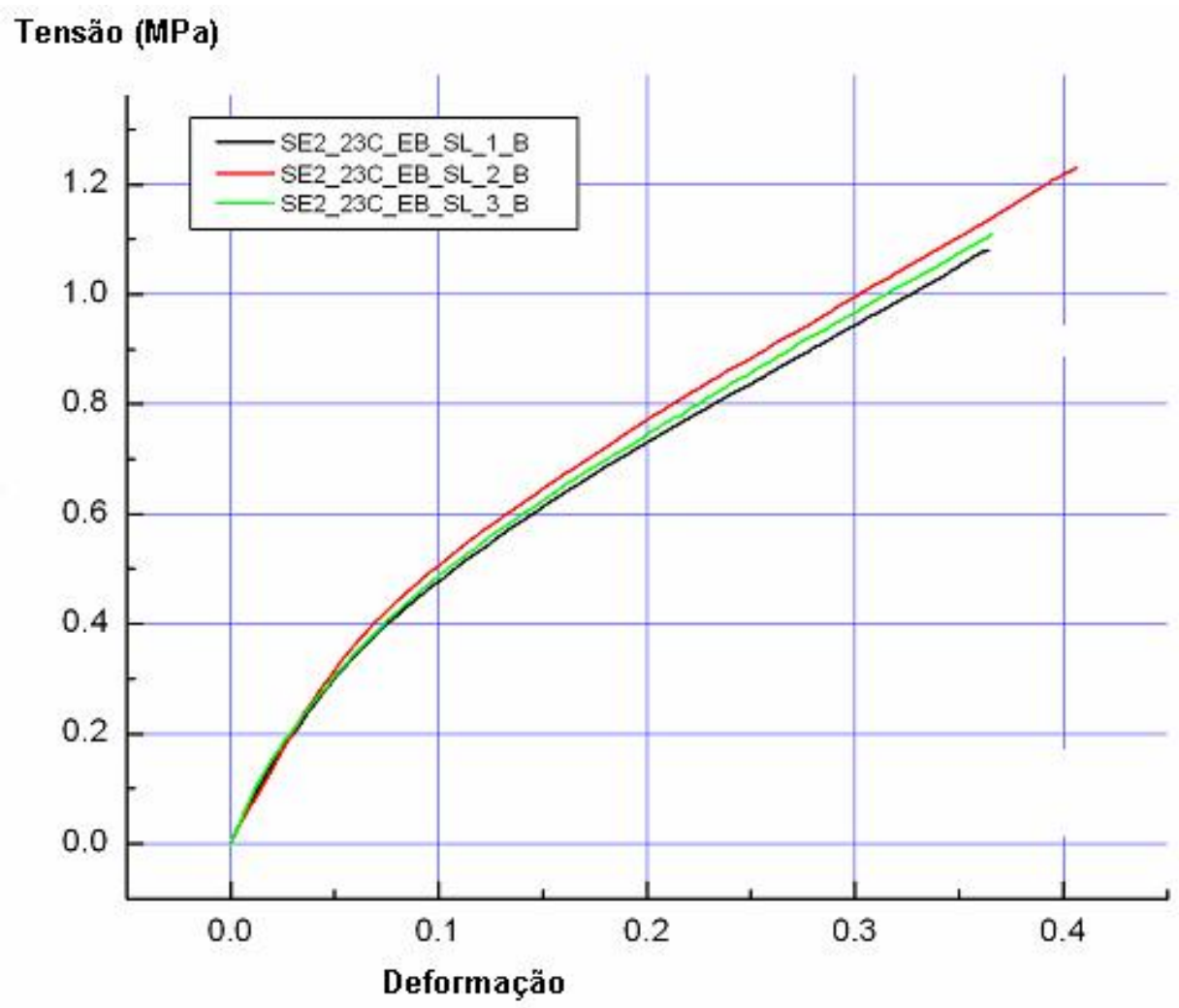

Figura 42 - Curva tensão / deformação das réplicas ensaiadas após 100 kGy de pós cura - ensaio equibiaxial do segundo método.

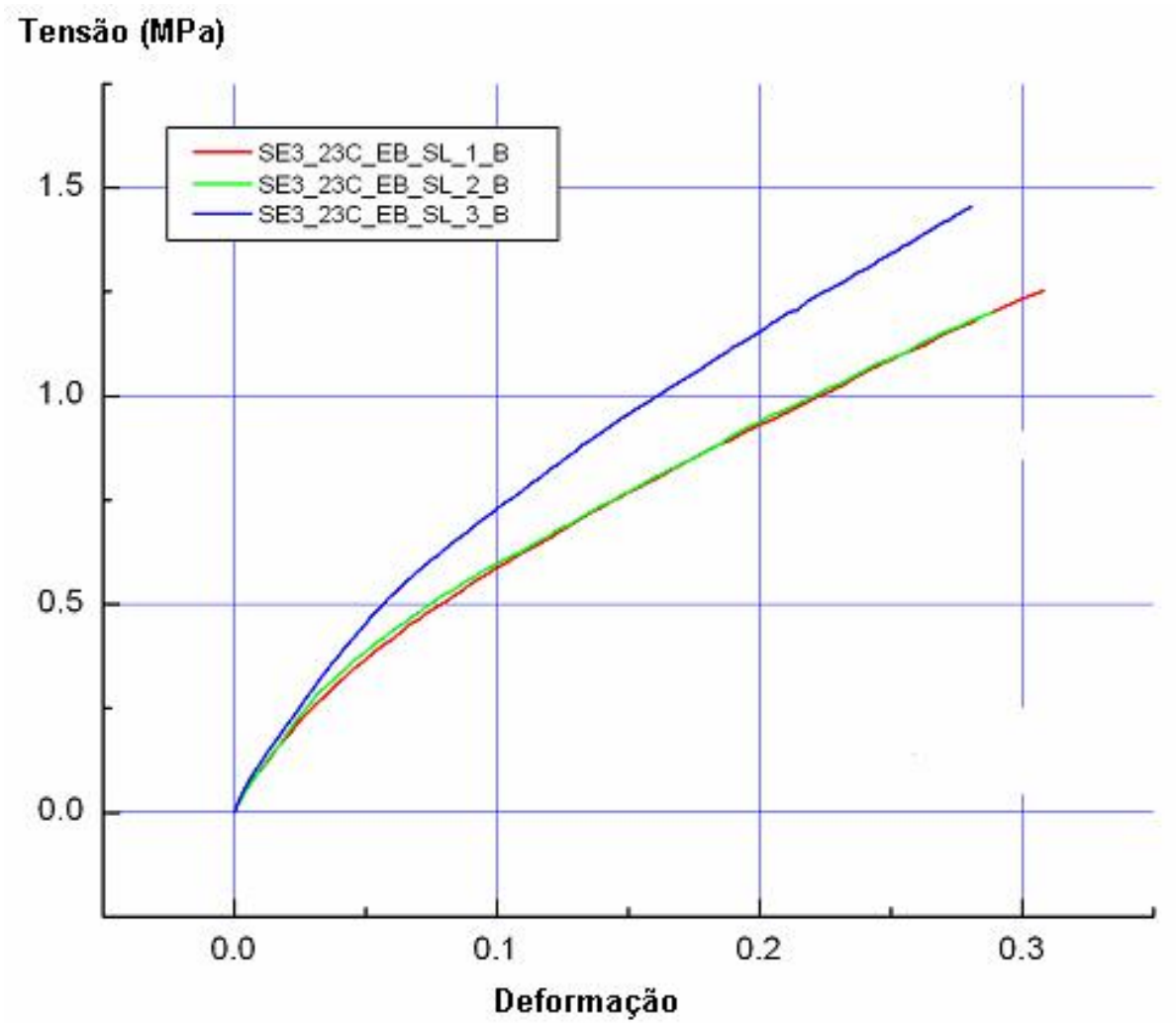

Figura 43 - Curva tensão / deformação das réplicas ensaiadas após 250 kGy de pós cura - ensaio equibiaxial do segundo método. 


\subsubsection{Discussão dos Resultados}

As médias da tensão de ruptura apresentada nos ensaios equibiaxiais mostraram uma variação positiva com a aplicação e com o aumento da dose de radiação $E B$. $O$ elastômero ACM não irradiado, rompeu ao ser submetido a uma tensão média de 1,05 MPa, aplicada de maneira a gerar deformações positivas idênticas nas extensões $\lambda_{1}$ e $\lambda_{2}$, consequentemente reduzindo $\lambda_{3}$ na proporção de $1 /\left(\lambda_{1}\right)^{2}$, exatamente por se tratar de um esforço equibiaxial. A aplicação de 100 kGy elevou a média da tensão na ruptura do material nesta condição de esforço para 1,14 MPa, equivalente a um aumento de 8,57 \% em relação ao material não irradiado. A dose de 250 kGy gerou um acréscimo de 23,81 \% na média da tensão na ruptura em relação ao material não irradiado e 14,03 \% em relação ao material pós curado com 100 kGy. Repetindo o padrão já apresentado nos ensaios uniaxiais as curvas obtidas com as réplicas em cada condição foram bastante próximas, o maior distanciamento de um suposto padrão, foi verificado pelo réplica três da condição irradiada com 250 kGy, que apresentou maior tensão na ruptura em relação as outras duas réplicas, elevando o desvio padrão da média neste condição para 0,13 MPa.

No que se refere ao alongamento na ruptura, os valores apresentados nesta condição foram significativamente inferiores ao valores de alongamento apresentados nos ensaios uniaxiais, isto se deve ao fato da deformação ser induzida em duas direções neste tipo de ensaio. A radiação EB por sua vez causou uma redução na capacidade de alongamento do $A C M$, enquanto o material não irradiado apresentou uma média de alongamento na ruptura de 48,29 \%, a irradiação com 100 kGy baixou a média do alongamento na ruptura para $37,87 \%$, o equivalente a uma redução de 21,58 \% dos percentuais apresentados. O aumento da dose para 250 kGy obedeceu a tendência de queda do alongamento na ruptura, apresentado a ruptura ao ser aplicado uma deformação média de 29,25 \% nos corpos de prova, tal capacidade de alongamento foi reduzida em 39,43 \% em relação ao material não irradiado e 22,76 \% em relação ao material irradiado com 100 kGy.

Por se tratar de um tipo de ensaio específico para caracterização de elastômeros, não foi encontrado na literatura nenhum método para a determinação do módulo de cisalhamento com base nestes ensaios equibiaxiais, a norma GMN 6814, que 
descreve os parâmetros e equipamentos para este tipo de ensaio, não faz referência a obtenção do módulo de cisalhamento do material através deste tipo de experimento.

A tensão na ruptura medida e informada pelo equipamentos, nos ensaios realizados neste trabalho, não consideram a redução da área do corpo de prova durante os procedimentos experimentais. Tal redução da área, associada a força aplicada no momento da ruptura do substrato, geram uma tensão real maior que a tensão informada pelo equipamento. Para tornar possível trabalhar e comparar de maneira eficaz tais dados, utiliza-se como principal referência o módulo de cisalhamento, normalmente medido a $100 \%$ de alongamento, como nos ensaios uniaxiais. Devido ao fato da ausência de uma metodologia para obtenção do módulo em ensaios equibiaxiais, foram utilizados valores de tensão na ruptura a $20 \%$ de alongamento, valor próximo a metade da capacidade média de alongamento apresentada pelo material neste tipo de ensaio. Desta forma se tornou possível verificar a tensão nesta condição de alongamento, e comparar os dados de variação da resistência para uma específica condição de deformação do material, sem a influência da variação não considerada pela equipamento. Os pares tensão / deformação utilizados nesta comparação foram retirados do dados relacionados no Apêndice $A$ deste trabalho.

$\mathrm{Na}$ condição não irradiada o material apresentou uma média de tensão de 0,603 MPa $20 \%$ de alongamento, passando para $0,75 \mathrm{MPa}$ na condição pós curada a 100 kGy e 1,01 MPa na condição pós curada a $250 \mathrm{kGy}$. Desta forma o aumento da média da tensão a $20 \%$ de alongamento ao irradiar o ACM com 100 kGy foi de $24,38 \%$ e de $67,94 \%$ ao irradiar com 250 kGy de radiação EB, ao comparar o aumento ocasionado pelas duas doses verifica-se um aumento de 35,02 \% na tensão medida nesta condição de alongamento.

De maneira geral, os resultados apresentaram as mesmas tendências obtidas nos ensaios uniaxiais, aumentando a tensão na ruptura, reduzindo o alongamento e consequentemente aumentando o "módulo" do material (nível de reticulação) com a aplicação de radiação e aumento da dose nos corpos de prova. As curvas mostram uma maior não linearidade no comportamento mecânico do material em condições de alongamento inferiores a $10 \%$, acima deste patamar a variação se aproxima de um comportamento linear, situação visualmente apresentada nos gráficos relacionadas nos ensaios uni e equibiaxiais. 


\subsubsection{Resultados dos ensaios de cisalhamento puro - Segunda fase}

Os ensaios de cisalhamento puro geraram dados referentes ao comportamento do material, quando submetidos a ensaios de tração, de modo a considerar que a deformação causada na largura fosse negligenciada quando comparada com o valor inicial da mesma, causando um estado de deformação bidirecional com $\lambda_{1}=\lambda_{2}$ (taxa de extensão na direção do esforço aplicado), $\lambda_{2}=1$ e $\lambda_{3}=\left(\lambda_{1}\right)^{-1}$.

A Tabela 14 apresentada os dados de tensão na ruptura do material quando submetido a este tipo de esforço, com média e desvio padrão para cada condição. A Tabela 15 apresenta o percentual de alongamento do material na ruptura, comparando com o comprimento inicial, fornecendo a média e desvio padrão para cada condição.

Da mesma forma como citado nos ensaios equibiaxiais, considerou-se uma deformação específica para se verificar a tensão medida nesta condição, tratando tal tensão com uma forma de módulo em tal deformação. A Tabela 16 apresenta o módulo do material em esforço de cisalhamento puro a $20 \%$ de deformação, permitindo comparar a resistência oferecida por cada condição específica.

Tabela 14 - Tensões na ruptura em ensaio de cisalhamento puro do segundo método.

\begin{tabular}{cccccc}
\hline Condição & \multicolumn{3}{c}{ Tensão na Ruptura (MPa) } & Média (MPa) & Desvio (MPa) \\
\hline 0 kGy & 1,05 & 1,05 & 1,00 & 1,03 & 0,03 \\
$100 \mathrm{kGy}$ & 1,13 & 1,22 & 1,24 & 1,20 & 0,06 \\
$250 \mathrm{kGy}$ & 1,09 & 1,21 & 1,29 & 1,20 & 0,10 \\
\hline
\end{tabular}

Tabela 15 - Alongamento na ruptura em ensaio de cisalhamento puro do segundo método.

\begin{tabular}{cccccc}
\hline Condição & \multicolumn{3}{c}{ Alongamento na Ruptura (\%) } & Média (\%) & Desvio (\%) \\
\hline 0 kGy & 53,58 & 71,19 & 58,47 & 61,17 & 9,05 \\
100 kGy & 55,39 & 62,51 & 71,48 & 63,13 & 8,06 \\
250 kGy & 47,44 & 43,71 & 56,71 & 49,29 & 6,69 \\
\hline
\end{tabular}

Tabela 16 - Tensão a 20\% de alongamento.

\begin{tabular}{|c|c|c|c|c|c|}
\hline Condição & \multicolumn{3}{|c|}{ Tensão a $20 \%$ de Alongamento (MPa) } & Média (MPa) & Desvio (MPa) \\
\hline 0 kGy & 0,56 & 0,51 & 0,48 & 0,52 & 0,04 \\
\hline 100 kGy & 0,66 & 0,66 & 0,56 & 0,63 & 0,06 \\
\hline 250 kGy & 0,61 & 0,67 & 0,58 & 0,62 & 0,05 \\
\hline
\end{tabular}




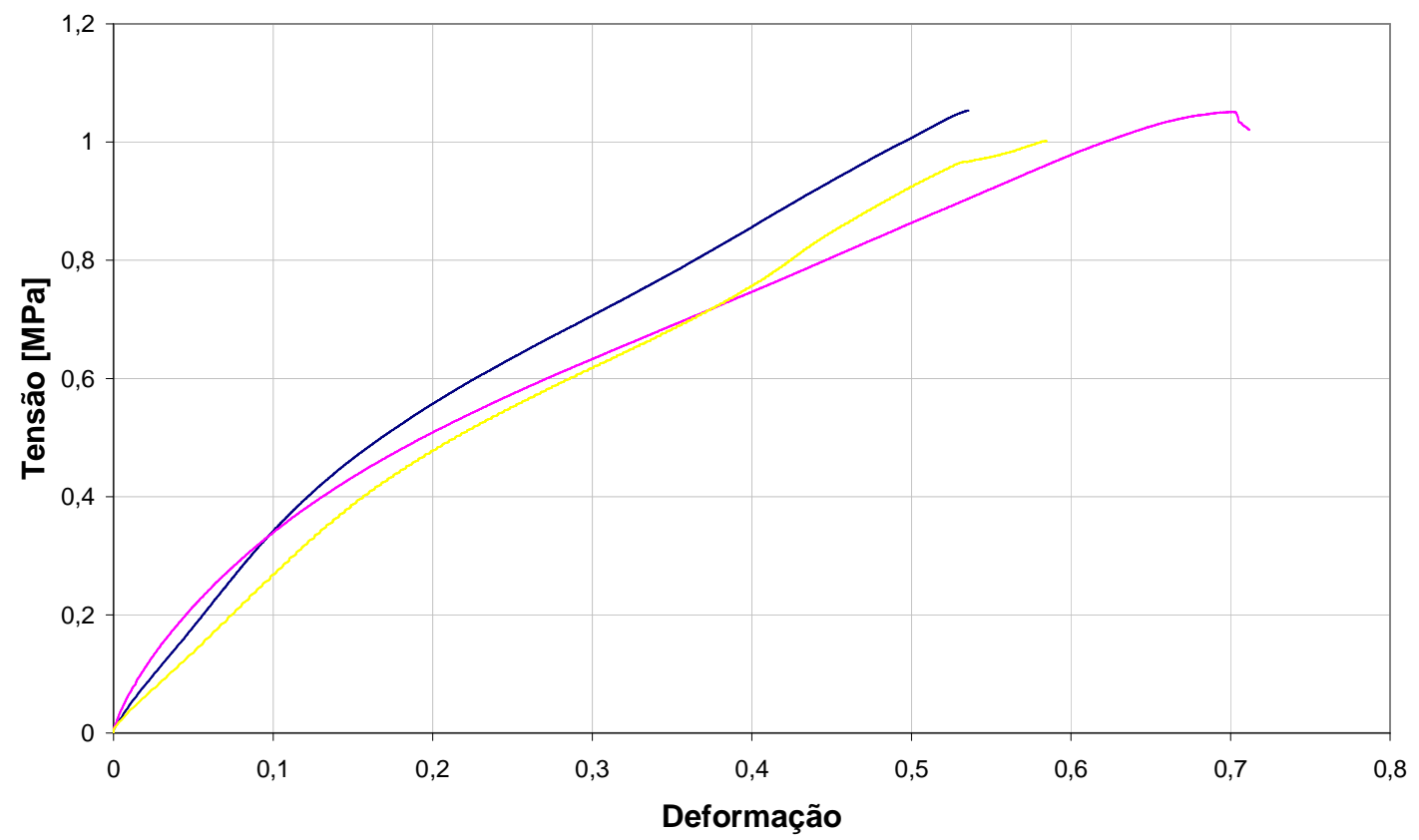

Figura 44 - Curva tensão / deformação das réplicas ensaiadas sem pós cura - ensaio em condição de cisalhamento puro do segundo método.

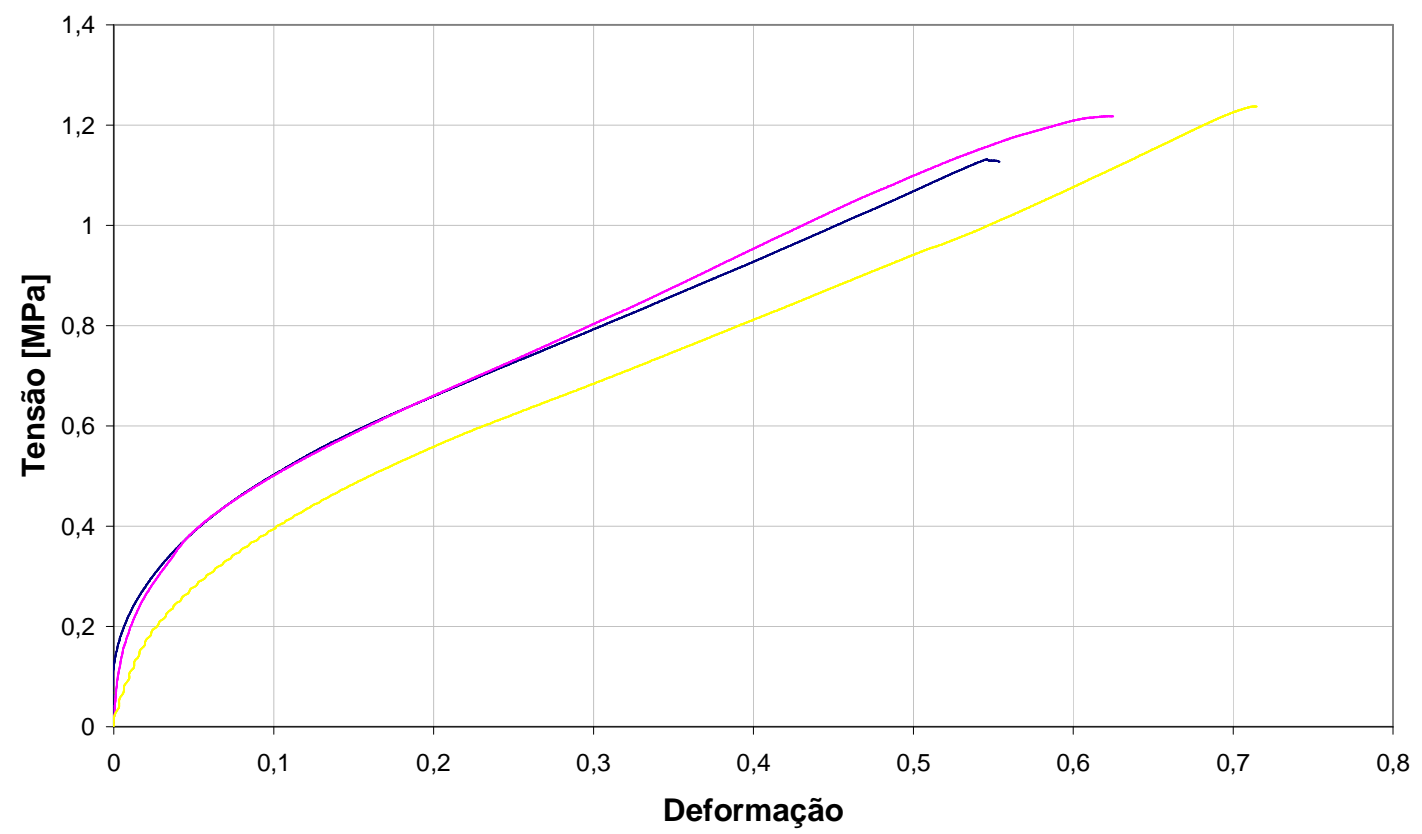

Figura 45 - Curva tensão / deformação das réplicas ensaiadas após 100 kGy de pós cura - ensaio em condição de cisalhamento puro do segundo método. 


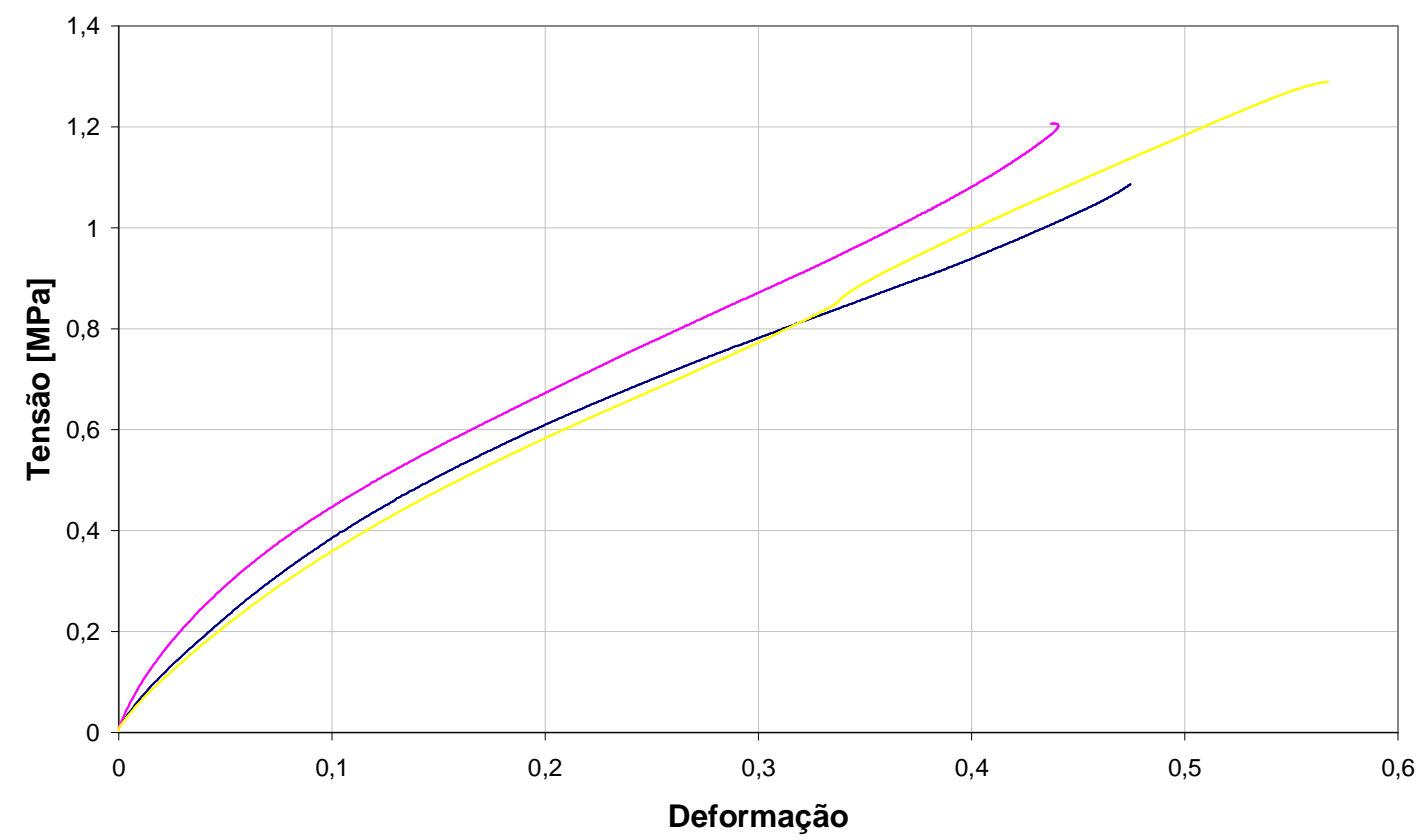

Figura 46 - Curva tensão / deformação das réplicas ensaiadas após 250 kGy de pós cura - ensaio em condição de cisalhamento puro do segundo método.

\subsubsection{Discussão dos Resultados}

Os resultados apresentados mostraram mais uma vez que a irradiação por feixe de elétrons causou alterações no comportamento do ACM, inclusive em condições de cisalhamento puro. A dose de 100 kGy aumentou a média da tensão na ruptura de 1,03 MPa para 1,20 MPa, equivalente a um aumento de 16,5 \%. A aplicação da dose de 250 kGy, por sua vez, não causou nenhuma alteração na média da tensão na ruptura. Embora as médias foram idênticas, os valores medidos individualmente nas condições irradiadas variaram com maior amplitude na condição de 250 kGy, com desvio padrão de $0,10 \mathrm{MPa}$, enquanto na condição de 100 kGy o desvio padrão de 0,06 MPa.

Ao se comparar os valores de alongamento na ruptura, pode-se verificar que não houve variação significativa nos valores apresentados nas condições não irradiada e irradiada com $100 \mathrm{kGy}$, diferente do ocorrido nos outros ensaios, tal variação na média foi positiva, aumento a capacidade de alongamento com a aplicação da dose de 100 kGy em 1,03 \%. Vale salientar que o desvio padrão do alongamento na 
condição de 100 kGy foi de 8,06 \%, ou seja, superior a variação percentual apresentada pelo comportamento, reduzindo a possibilidade de uma medição real de variação no comportamento, causada pela radiação, e aumentando a possibilidade de uma influência exclusiva da variação, ou amplitude, dos resultados no hipotético aumento da capacidade de alongamento em função da aplicação desta dose de radiação. A dose de 250 kGy seguiu a tendência de influência verificada nos ensaios uni e equibiaxiais, ou seja, reduziu a capacidade de alongamento do ACM na ruptura com aumento da dose em 19,42 \% em relação a condição não irradiada e 21,92 \% em relação a condição irradiada com 100 kGy.

Os propostos módulos a 20 \% de deformação apresentaram comportamento similar ao apresentado pela média da tensão na ruptura nesta condição de ensaio. Houve um aumento de 21,15 \% na média da tensão medida nesta condição de deformação, após a irradiação com 100 kGy. Por sua vez a diferença entre as duas condições irradiadas foi de 1,59 \%, representando uma redução do módulo com o aumento da dose para o patamar de 250 kGy.

As curvas e resultados obtidos mostram uma grande variação no alongamento na ruptura dentro de uma mesma condição de radiação. Também indicam que neste caso o módulo segue o mesmo padrão de comportamento e aumento da média da tensão na ruptura, aumentando com a aplicação de 100 kGy e se mantendo com o aumento da dose para 250 kGy.

O perfil das curvas em cada condição respeitaram um padrão de comportamento, porém com um deslocamento relativo entre si, diferente das curvas obtidas nas condições uni e equibiaxiais, onde além do perfil parecido, as curvas quase se sobrepunham.

Os três tipos de ensaios mecânicos realizados mostraram que a radiação aumentou o módulo material, reduzindo de maneira geral e com variações quantitativas a capacidade de alongamento do material e aumentaram, também com variações quantitativas, a tensão do ACM na ruptura. Desta forma, os efeitos e alterações causados pela radiação na estrutura molecular do adesivo, geram variações diferenciadas quantativamente no comportamento do material, de acordo com o esforço aplicado.

Os dados experimentais gerados nestes testes permitiu determinar os parâmetros do Modelo de Ogden e simular o comportamento do ACM através da utilização do métodos de elementos finitos. 


\subsubsection{Resultados da análise termodinâmico-mecânica - Segunda fase}

Os ensaios de DMTA permitiram identificar as temperaturas de transição vítrea para cada condição de material, bem como gerar as curvas que representam a variação do módulo de armazenamento de energia elástica e módulo de dissipação de energia viscosa em função do aumento de temperatura. As curvas referente a estes módulos, parcela elástica e viscosa, são apresentadas nas Figuras 48 e 49 respectivamente.

A Figura 46 mostra a variação da tan $\delta$, relação entre a parcela viscosa e elástica do material, em função do aumento da temperatura ao longo de uma determinada faixa. Permitindo identificar o ponto onde ocorre a alteração da parcela de contribuição predominante e consequentemente determinar as $T_{g} s$ para cada condição, apresentadas na Tabela 17.

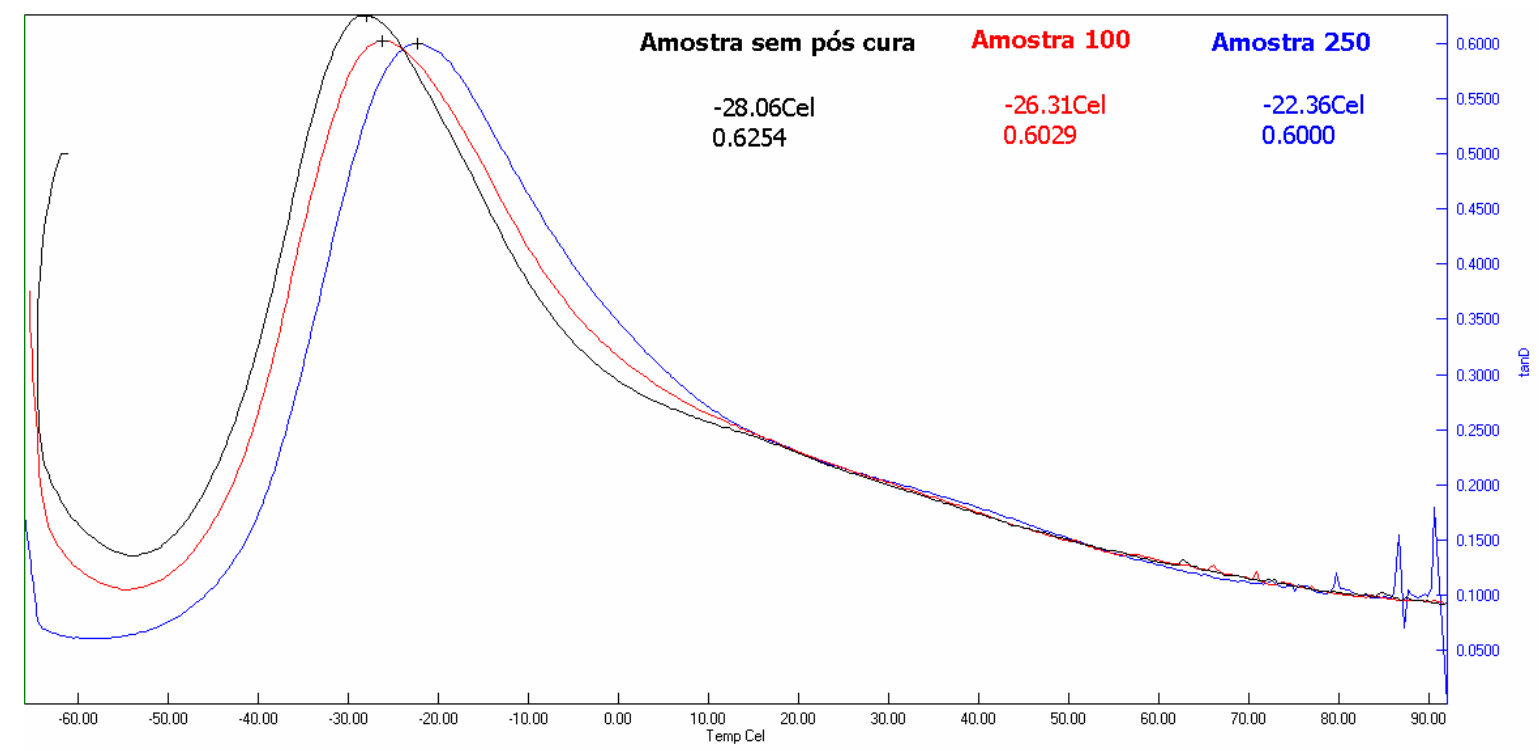

Figura 47 - Curva de variação da Tan $\delta$ em função da temperatura.

Tabela 17 - Valores e intensidades dos picos de $\tan \delta-T_{g}$.

\begin{tabular}{ccc}
\hline Condição & Pico de $\tan \delta\left({ }^{\circ} \mathbf{C}\right)-\mathbf{T}_{\mathbf{g}}$ & Intensidade do Pico \\
\hline 0 kGy & $-28,06$ & 0,6254 \\
100 kGy & $-26,31$ & 0,6029 \\
250 kGy & $-22,36$ & 0,6000 \\
\hline
\end{tabular}




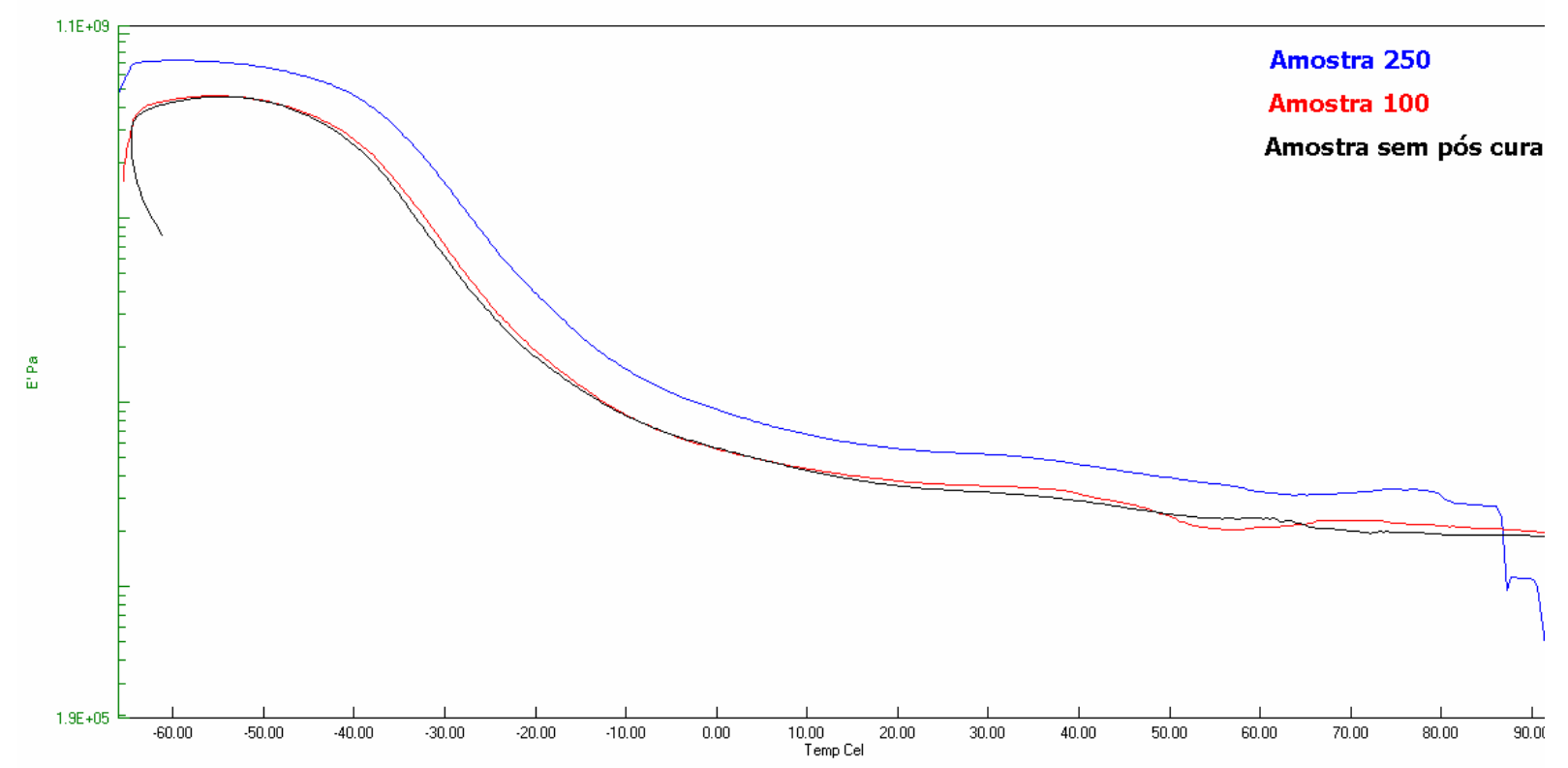

Figura 48 - Variação do módulo de armazenamento de energia elástica (E’) em função da temperatura.

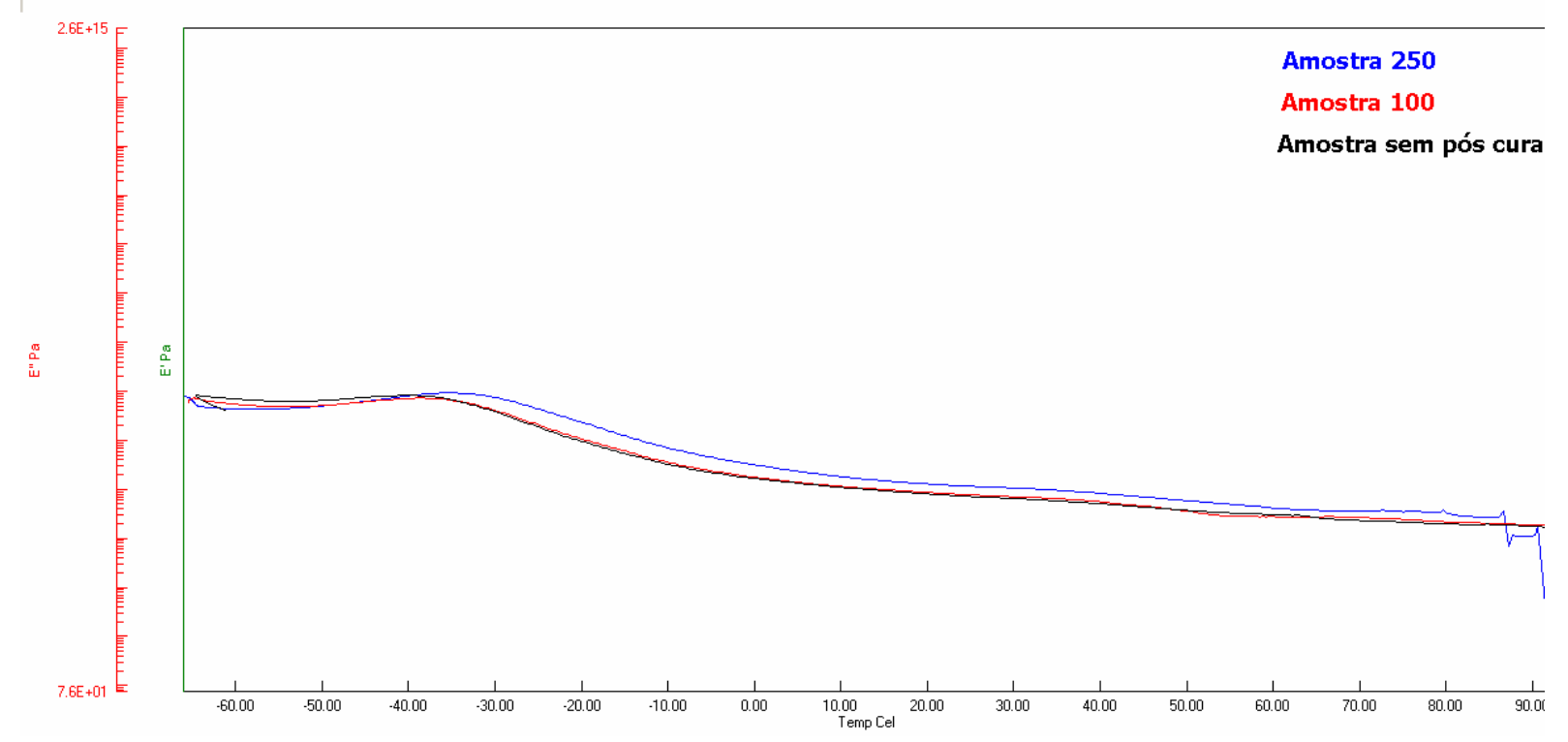

Figura 49 - Variação do módulo de dissipação de energia viscosa (E”) em função da temperatura.

\subsubsection{Discussão dos Resultados}

A Figura 47 mostra uma pequena variação na temperatura de transição vítrea do material em função da aplicação e aumento da dose de radiação EB, a aplicação de 
EB aumentou a $T_{g}$ devido ao aumento do nível de reticulação do ACM causado pela radiação.

Os picos identificados na Figura 47 e apresentados de maneira quantitativa na Tabela 17 , mostram que a partir de $-22,36^{\circ} \mathrm{C}$ o $\mathrm{ACM}$ irradiado com 250 kGy passa a ter a predominância da parcela viscosa na determinação de seu comportamento, caracterizando esta temperatura como a $T_{g}$ do material para esta condição. $O$ material irradiado com $100 \mathrm{kGy}$ apresenta este pico na temperatura de $-26,21^{\circ} \mathrm{C}$, enquanto o material não irradiado é o primeiro a sofrer esta mudança de comportamento, fenômeno que ocorre já a temperatura de $-28,06^{\circ} \mathrm{C}$.

A partir da $T_{g}$ a participação da parcela viscosa no comportamento continua aumentando em relação a participação elástica, causando uma redução contínua da curva da tan $\delta$. $O$ aumento da participação viscosa em altas temperaturas pode ser um fator facilitador para a relaxação por compressão do material, fenômeno que deve ser acentuado em tal faixa de temperatura.

A Figura 48 mostra que a maior variação identificada no comportamento é apresentada pela parcela elástica do mesmo, a qual se mantém constante até a região próxima a $T_{g}$ e reduz-se drasticamente após a mesma. O módulo de dissipação por energia viscosa, Figura 49, também apresenta uma redução em função do aumento da temperatura, porém muito inferior a perda apresentada na parcela elástica, o que gera a redução na relação entre os módulos ao longo da faixa de temperatura estudada.

A amostra irradiada com 250 kGy apresenta uma maior capacidade de armazenamento de energia elástica, em comparação as outras condições, mesma em elevadas temperaturas. Tal característica pode favorecer o comportamento do material sob esforço de compressão, no que diz respeito a relaxação. A maior capacidade comparativa de armazenamento de energia elástica, apresentada pelo ACM irradiado com $250 \mathrm{kGy}$, pode compensar a predominância do comportamento viscoso do material em altas temperaturas, apresentada em todas as condições, reduzindo a relaxação do material por esforços de compressão.

Tal indicativo poderá ser confirmado por ensaios de relaxação da tensão por compressão (CSR), onde se verificará a perda da tensão por compressão do material quando submetido a uma deformação pré-determinada e constante. Como a energia elástica armazenada é maior no material irradiado com 250 kGy, a tendência é que a tensão oposta a deformação seja mais elevada, além de ser capaz de se 
manter por mais tempo, e consequentemente a relaxação por compressão será menor.

\subsubsection{Resultado da análise de decomposição térmica - Segunda fase}

A Figura 50 apresenta as curvas de percentual de perda de massa em função do aumento da temperatura, resultando em uma curva de estágio único. A Figura 51 apresenta as curvas da derivada das curvas anteriores, permitindo identificar o ponto de inflexão da curva da derivada, ponto de maior taxa de perda de massa, tais valores são apresentados na Tabela 18.

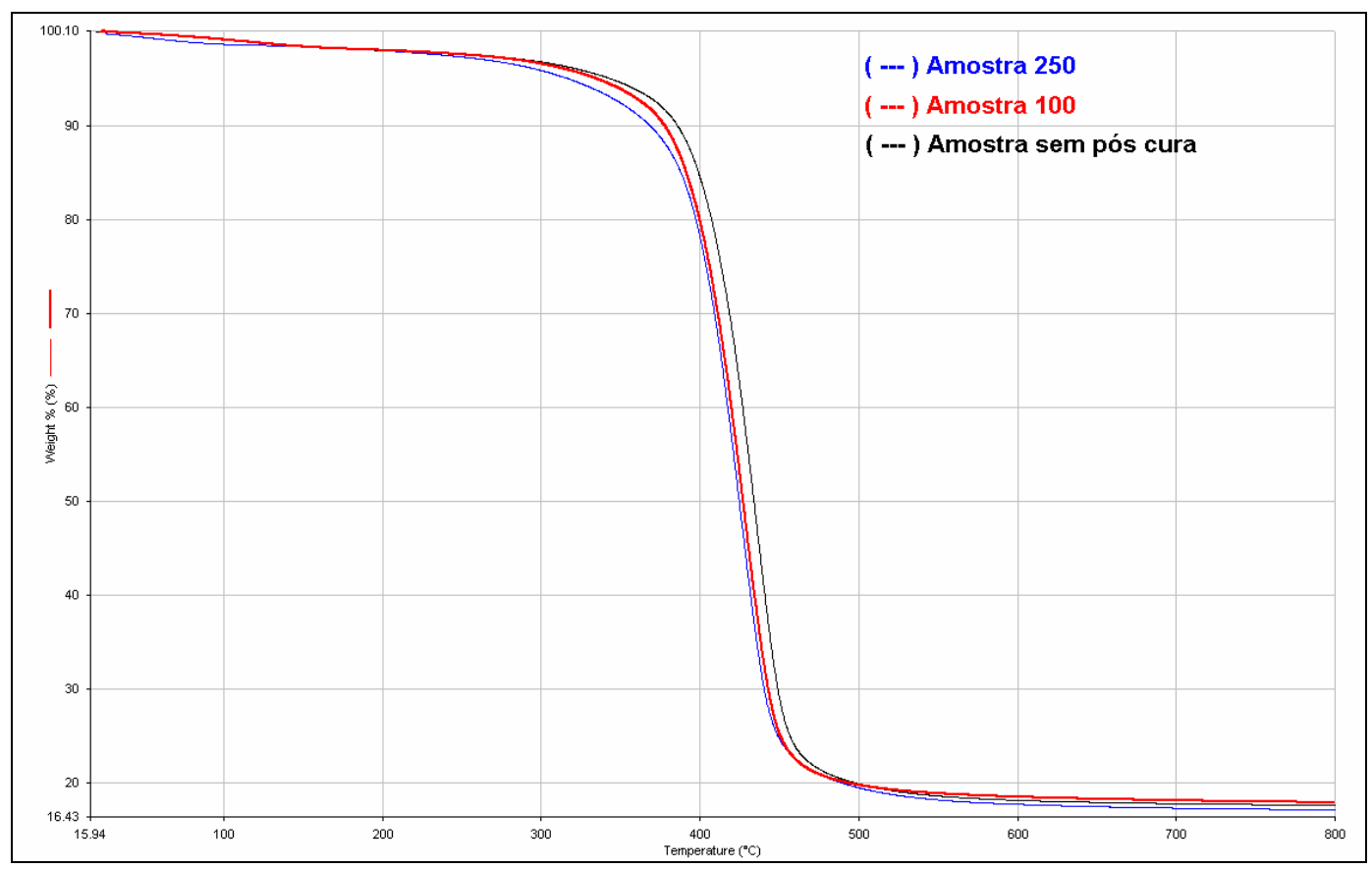

Figura 50 - Curvas de perda de massa em função do aumento de temperatura por TGA. 


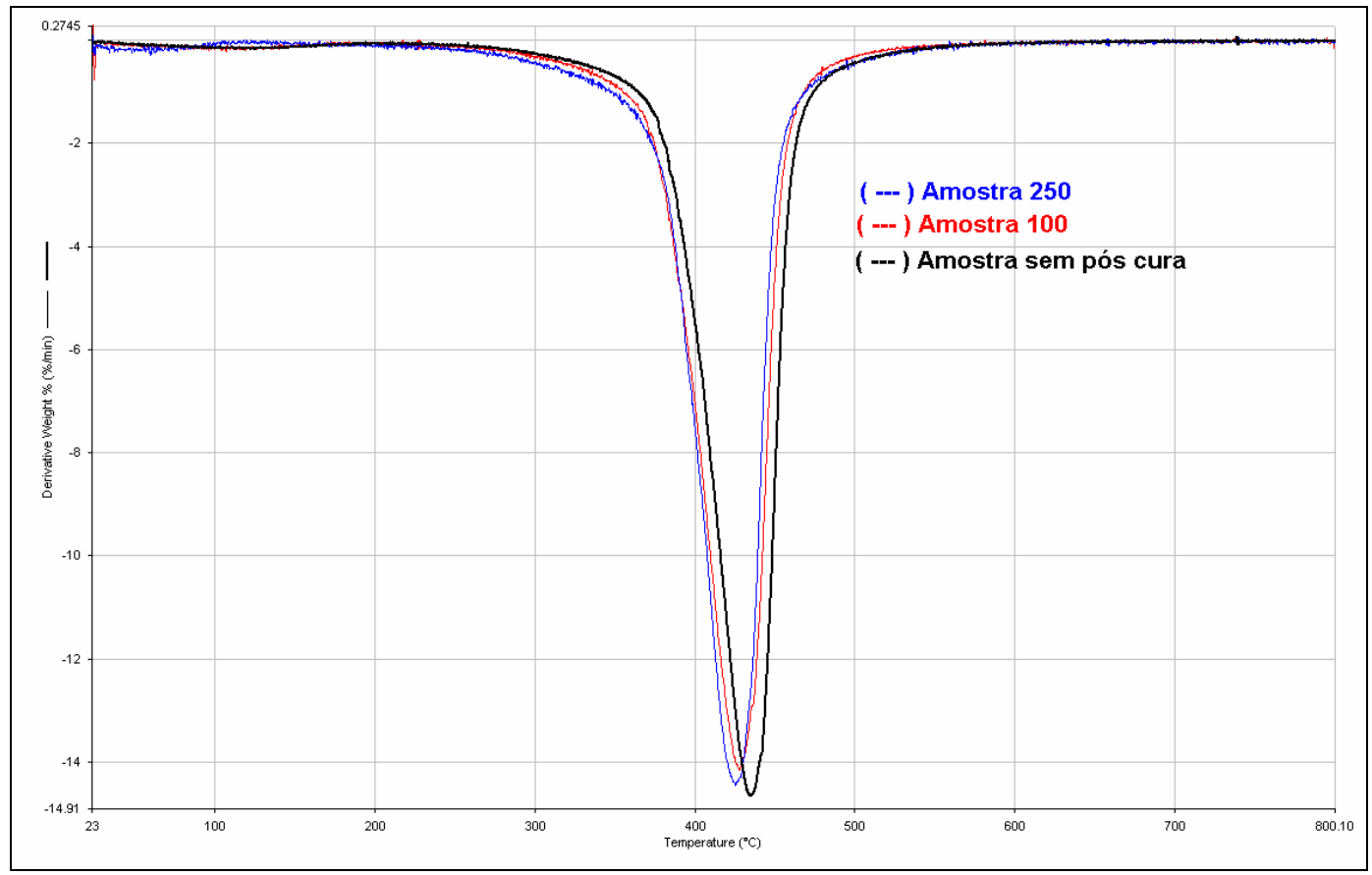

Figura 51 - Curvas da derivada das curvas de perda de massa em função da temperatura.

Tabela 18 - Pontos de inflexão das curvas.

\begin{tabular}{cc}
\hline Condição & Pico de Perda de Massa $\left({ }^{\circ} \mathbf{C}\right)$ - Inflexão da Curva da Figura 56 \\
\hline 0 kGy & 435 \\
100 kGy & 426 \\
250 kGy & 425 \\
\hline
\end{tabular}

\subsubsection{Discussão dos Resultados}

Todas as condições testadas apresentaram curva de degradação com perfil idêntico, mesmo em temperaturas abaixo de $100^{\circ} \mathrm{C}$ pode-se verificar uma pequena perda de massa, menos acentuada na condição de 100 kGy e mais acentuada na condição de 250 kGy. Tal perda pode ser conseqüência de aditivos presentes no ACM, sem interação química com a estrutura molecular.

De acordo com o software utilizado, o aumento do nível de degradação aconteceu a partir de uma temperatura média de $242,29{ }^{\circ} \mathrm{C}$ e um percentual médio massa de $97,655 \%$, o processo por sua vez, foi finalizado a uma temperatura média de 600,63 ${ }^{\circ} \mathrm{C}$ e percentual médio de massa de $18,543 \%$. 
Analisando a Figura 50 é possível verificar um leve deslocamento da curva referente ao material sem pós cura, em relação as duas condições de material pós curado, no sentido crescente do eixo de temperatura. Este deslocamento indica que a perda de massa do material sem pós cura, obedeceu ao mesmo padrão ou perfil das outras duas condições, porém ocorreu a uma temperatura levemente superior, devido a diferentes tipos de ligações químicas presentes no material sem pós cura. Estes dados não tornam possível identificar os tipos de ligações presentes, apenas indicam a diferença entre as estruturas, ou diferença da concentração de determinados tipos de ligações. Como o perfil da curva é definido pelo tipo de fenômeno causa da degradação, a similaridade entre as curvas mostra que nas três condições o mesmo tipo de fenômeno se fez presente.

A Figura 51 apresenta os picos da taxa de perda de massa, ou seja, a temperatura onde a taxa de perda de massa é maior para cada condição. Os resultados apresentados na Tabela 18 reforçam o deslocamento apresentado pelo material sem pós cura, que apresenta o pico na temperatura de $435^{\circ} \mathrm{C}$, enquanto os materiais pós curados com 100 kGy e 250 kGy, apresentaram seus picos nas temperaturas de $425^{\circ} \mathrm{C}$ e $426^{\circ} \mathrm{C}$.

De maneira geral esta análise mostrou uma maior resistência do material sem pós cura a perda de massa em função do aumento da temperatura, mesmo com menor nível de reticulação em relação aos materiais pós curados. Evidenciando que para este material o aumento do nível de reticulação não aumentou a resistência a degradação térmica.

\subsubsection{Resultados da espectroscopia por IR - Segunda fase}

A espectroscopia por IR permite verificar os grupos químicos presentes no material e as possíveis alterações causadas pela radiação EB. A Figura 52 mostra o espectro de absorbância na faixa de $800 \mathrm{~cm}^{-1}$ até $4000 \mathrm{~cm}^{-1}$ na superfície dos corpos de prova ensaiados, os picos representam quantidades específicas de determinados grupos químicos. A Figura 53 apresenta o espectro referente a região central do corpo de prova. 


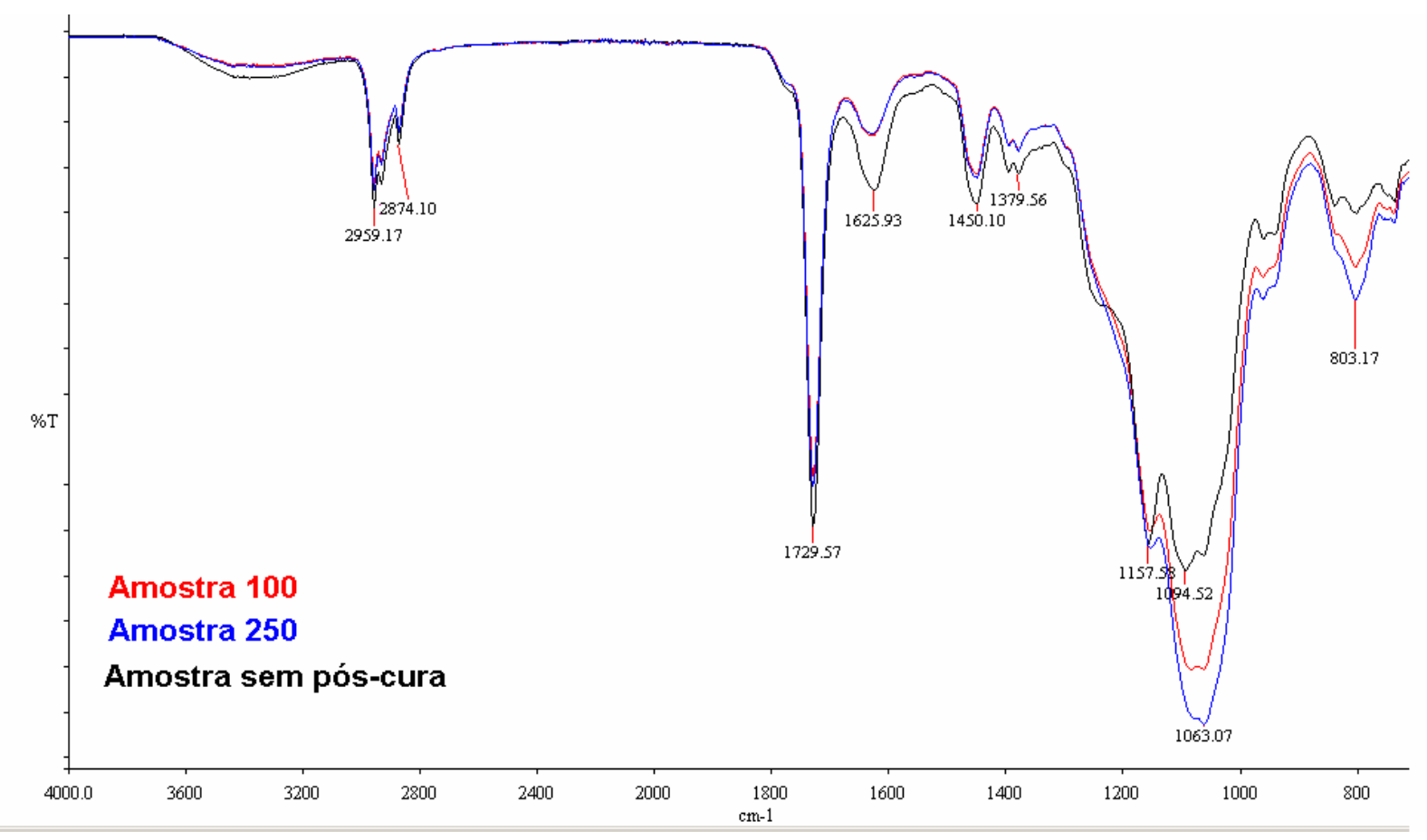

Figura 52 - Espectro de absorbância de $800 \mathrm{~cm}-1$ até $4000 \mathrm{~cm}-1$ na região superficial do ACM..

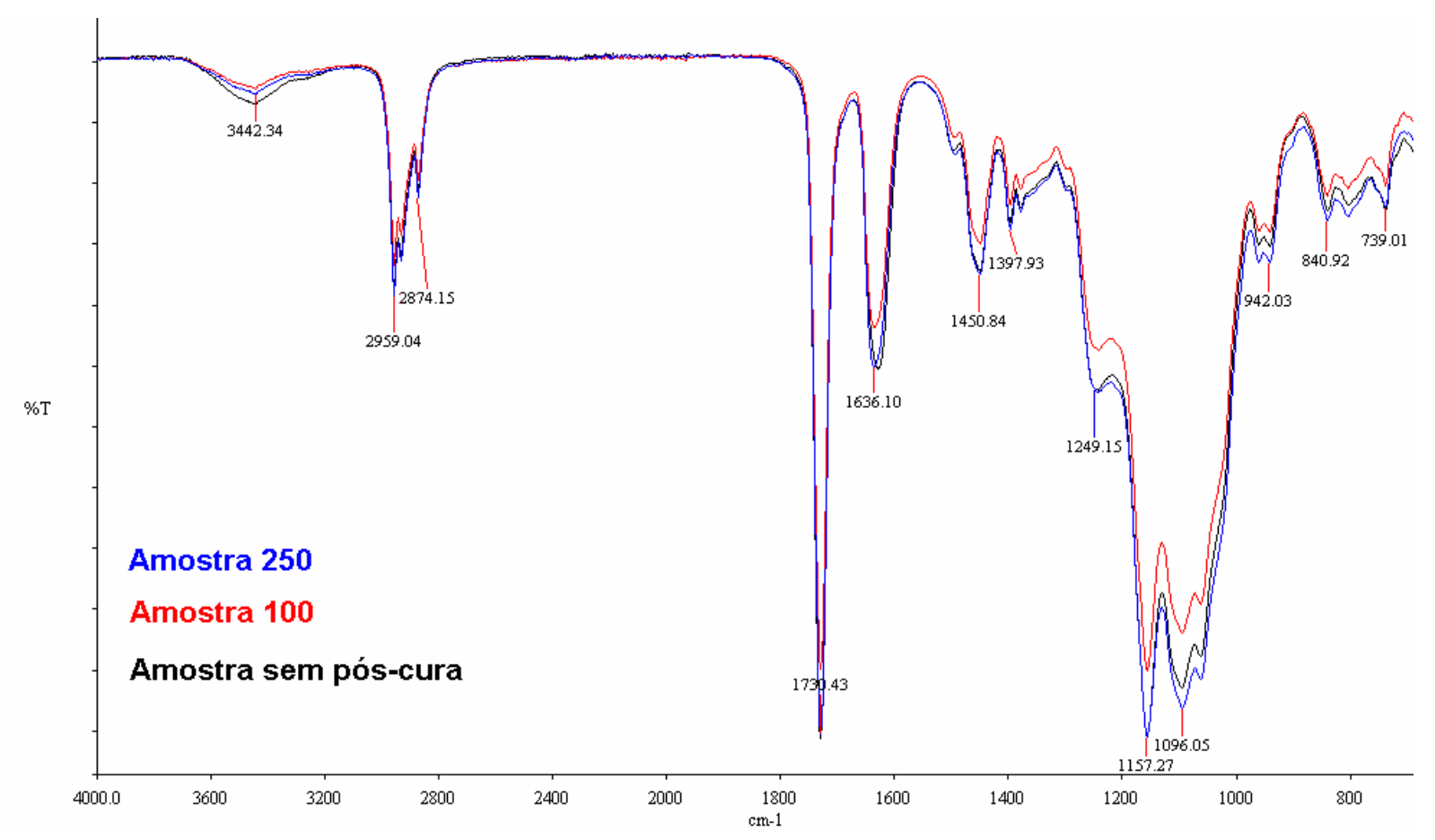

Figura 53 - Espectro de absorbância de $800 \mathrm{~cm}-1$ até $4000 \mathrm{~cm}-1$ na região central do ACM.. 


\subsubsection{Discussão dos Resultados}

Nas Figuras 52 e 53 pode-se verificar que os picos referentes ao comprimento de onda de $1160 \mathrm{~cm}^{-1}$ apresentam alturas semelhantes para as condições não irradiada e irradiada com 250 kGy, tanto na superfície como na região central, ou seja, ambas as condições apresentaram quantidades similares de ligações do tipo $>\mathrm{C}-\mathrm{O}-\mathrm{C}<$, indicando que a dose de 250 kGy não causou grande alteração deste grupo químico do ACM. A dose de 100 kGy, por sua vez, causou uma redução na quantidade deste grupo químico em comparação as outras condições, nas duas regiões analisadas. Tal redução na superfície, repete o padrão de comportamento apresentado na análise IR do primeiro método, onde a quantidade de $>\mathrm{C}-\mathrm{O}-\mathrm{C}<$ também foi reduzida na superfície quando aplicada uma dose de $100 \mathrm{kGy}$. No primeiro método porém, a região central apresentou aumento da quantidade de $>\mathrm{C}-\mathrm{O}-\mathrm{C}<$ para a dose de 100 kGy, contrariando o comportamento apresentado para esta dose na região central no segundo método. Tal contradição pode ser explicada pela diferença nos métodos de obtenção dos corpos de prova para os dois métodos, ou seja, preparação manual no primeiro método, permitindo a presença de bolhas de ar no material, alterando o tipo de reação causada pelo radiação EB, em comparação com os corpos de prova do segundo método que foram obtidos por processo automático e não apresentaram bolhas de ar.

O comprimento de onda de $1630 \mathrm{~cm}^{-1}$ do espectro se relaciona diretamente com a quantidade de ligações do tipo $>\mathrm{C}=\mathrm{C}<$, a Figura 52 mostra que a radiação $\mathrm{EB}$ causou uma redução na quantidade deste grupo químico na superfície para as doses de 100 kGy e 250 kGy, reforçando o comportamento apresentado na mesma região no primeiro método, para a dose de $100 \mathrm{kGy}$. A análise deste comprimento de onda na região central, conforme Figura 53 , mostrou alteração significativa somente para a dose de $100 \mathrm{kGy}$, a qual causou um redução da quantidade do grupo $>\mathrm{C}=\mathrm{C}<$ quando submetido a tal dose na região central.

As duas doses aplicadas causaram redução na quantidade de ligações $>C=O$, identificadas pelo pico na faixa de $1740 \mathrm{~cm}^{-1}$, na região superficial do ACM. Tal redução também foi identificada no corpo de prova irradiado com $100 \mathrm{kGy}$ no primeiro método. Na região central a dose de $250 \mathrm{kGy}$ não causou alteração significativa na quantidade de $>\mathrm{C}=\mathrm{O}$ em comparação com a condição não irradiada. 
A radiação com 100 kGy por sua vez causou uma redução deste grupo na região central.

Comparando os resultados obtidos nas análises por espectroscopia IR do primeiro e do segundo método, pode-se verificar que a dose de 100 kGy causou alterações de comportamentos oposto na região central em ambos os métodos. Sendo assim, quando a dose de $100 \mathrm{kGy}$ causou aumento da quantidade de um determinado grupo no primeiro método, esta mesma dose apresentou redução da quantidade deste mesmo grupo na região central no segundo método. Este comportamento controverso foi identificado nas faixas de $1160 \mathrm{~cm}^{-1}, 1630 \mathrm{~cm}^{-1}$ e $1740 \mathrm{~cm}^{-1}$, quando comparados o primeiro com o segundo método, e pode ter como causa os diferentes métodos de obtenção dos corpos de prova utilizados nos métodos.

A obtenção manual gerou corpos de prova com pequenas bolhas de ar, tais bolhas alteram o mecanismo de reação química causado pela radiação EB. Esta hipótese é reforçada ao constatar que na região superficial, as alterações causadas pela dose de 100 kGy obedecem a mesma dinâmica no primeiro e no segundo método. A manutenção desta dinâmica se dá devido ao fato da presença de ar com material nos dois métodos.

Os resultados apresentados neste segundo método são apenas qualitativos e não devem ser utilizados como determinantes na caracterização do comportamento do material, podem porém gerar indicadores da alteração do comportamento do ACM em função da alteração dos grupos químicos e mostram a influência do método de obtenção, ou da presença de ar, nas reações causadas pela radiação EB em ACM.

\subsubsection{Resultados da simulação por elementos finitos - Segunda fase}

As Figuras 54 e 55 apresentam as curvas obtidas com a simulação do comportamento do ACM, realizadas com a utilização do software ANSYS. Na Figura 58 são apresentadas curvas para os diferentes coeficientes de atrito utilizados nas simulação, enquanto na Figura 55 encontram-se as curvas que simulam o comportamento do ACM sob compressão, com dois níveis de parâmetros possíveis para o modelo de Ogden, ou seja, de $2^{\circ}$ e $3^{\circ}$ ordens. 


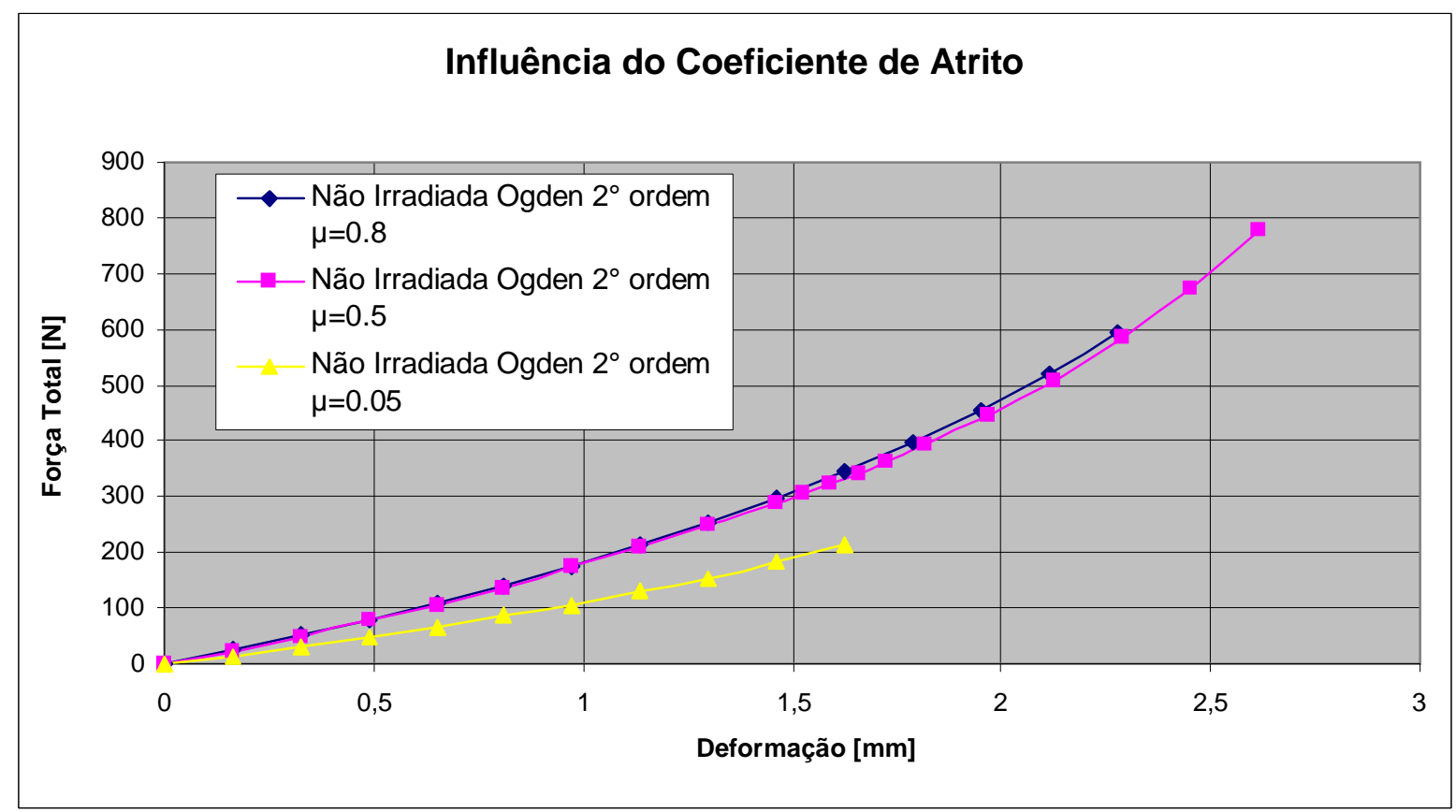

Figura 54 - Simulação em elementos finitos da influência do coeficiente de atrito.

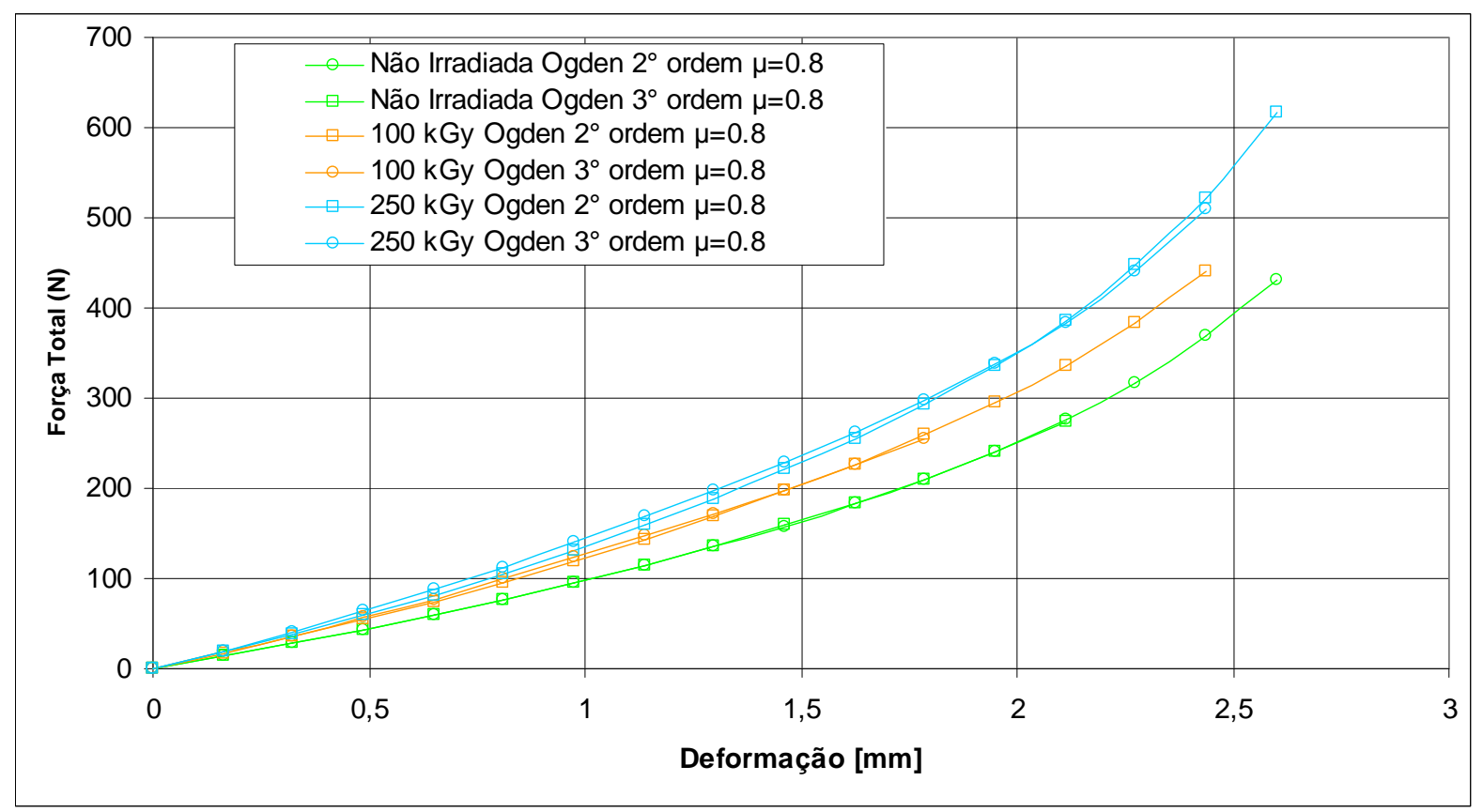

Figura 55 - Simulação em elementos finitos do comportamento do ACM em compressão. 


\subsubsection{Discussão dos Resultados}

A simulação realizada considerando um coeficiente de atrito de $\mu=0,05$, representa o comportamento do material quando submetido a condições de baixo atrito, ou com possível lubrificação da superfície, condição que não representa a realidade dos testes de CSR a serem realizados, desta forma a utilização deste coeficiente na simulação final não é indicada, por não condizer com a condição do ensaio de CSR. A curva obtida com este coeficiente de atrito apresentou tensões por compressão inferiores para uma mesma deformação, em comparação com as curvas obtidas com os outros coeficientes de atrito.

Os outros dois coeficientes simulados, $\mu=0,5$ e $\mu=0,8$, geraram curvas de tensão por compressão em função da deformação idênticas, mostrando que não houveram diferenças de comportamento do material quando simulados com estes coeficientes. Tal comportamento é idêntico para deformações no mínimo até $1,5 \mathrm{~mm}$, que correspondem a 23,07\% de deformação, o valor máximo de deformação considerado nos ensaios é de $15 \%$. A similaridade das curvas não indicam que estes sejam os melhores coeficientes para a simulação final, indicam apenas que a variação entre estes coeficientes não alteram o resultado da simulação. Como fatores abaixo de $\mu=0,5$ indicam situações de baixo atrito, não reais para aplicações com este tipo de elastômero, bem como coeficientes acima de $\mu=0,8$, indicariam um coeficiente extremamente elevado para a simulação, optou-se por realizar as simulações com coeficiente de $\mu=0,8$.

A Figura 55 apresenta curvas de tensão por compressão em função da deformação simuladas, usando os resultados experimentais dos três tipos de ensaios na definição dos parâmetros, para as condições de material não irradiado, irradiado com $100 \mathrm{kGy}$ e $250 \mathrm{kGy}$, considerando o modelo de Ogden de $2^{\circ}$ e $3^{\circ}$ ordens.

Os resultados obtidos na simulação apresentam um aumento da tensão por compressão com o aumento da dose de radiação, mantendo a tendência apresentada nos resultados experimentais e indicam que a dose de $250 \mathrm{kGy}$ gera uma maior força de vedação para uma mesma deformação, em comparação com a força obtida com as outras doses. Este aumento da força obtida pode significar uma maior capacidade de vedação do material quando utilizado em aplicações industriais, tal indicativo é acentuado ao se verificar os resultados obtidos nos 
ensaios de DMA, onde o ACM irradiado com dose de $250 \mathrm{kGy}$ apresentou maior capacidade de armazenar energia elástica mesmo em temperaturas de $90^{\circ} \mathrm{C}$.

No que se referem aos dois níveis do modelo de Ogden simulados, de $2^{\circ}$ e $3^{\circ}$ ordens, os resultados da simulação não apresentaram diferenças significativas no comportamento das curvas.

\subsection{VERIFICAÇÃO DA RELAXAÇÃO DA TENSÃO POR COMPRESSÃO}

\subsubsection{Resultados do ensaio da relaxação da tensão por compressão}

Os ensaios de relaxação da tensão de compressão permitiram a obtenção das Tabelas 19 e 20, onde estão descritas as médias dos valores absolutos de força por compressão medidos durante 5.000 min, sob deformação constante, bem como as médias dos valores de percentual de força retida, em relação a força inicial medida. As Figuras 56, 57, 58 e 59 descrevem todos os valores de força medidos, gerando curvas de força em função do tempo, descrevendo o comportamento do materiais nas oito condições ensaiadas, ao longo de todo o período de 5.000 min. Cada figura apresenta comparativamente as curvas das três réplicas de condições que se distinguem apenas pela aplicação da dose de 250 kGy de EB.

\subsubsection{Discussão dos Resultados}

Os valores referentes as condições $1\left(23^{\circ} \mathrm{C}, 0 \mathrm{kGy}, 10 \%\right)$ e $2\left(23^{\circ} \mathrm{C}, 250 \mathrm{kGy}\right.$, $10 \%$ ), apresentados naTabela 19, associados ao comportamento apresentado na Figura 56 mostram que a aplicação da dose de 250 kGy no material aumentou a força, consequentemente a tensão, de compressão gerada, conforme já indicado pela simulação anterior, aumentando a resposta elástica deste material. As curvas, bem como os valores apresentados na Tabela 19, mostram uma superior força de compressão ao longo de todo a curva do material irradiado, mesmo a réplica que apresentou o menor nível de força na condição irradiada, mostrou comportamento 
superior a réplica com melhor comportamento na condição não irradiada. A condição não irradiada apresentou uma força média de $23,78 \mathrm{~N}$, após $500 \mathrm{~min}$, enquanto a condição irradiada apresentou na mesma condição a força média de 29,02 N, ou seja, um aumento de $22,03 \%$. Ao final do período de teste, ou seja, com $5.000 \mathrm{~min}$ de teste, a condição não irradiada oferecia uma força média mantida de $20,60 \mathrm{~N}$, para 26,32 $\mathrm{N}$ da condição irradiada, um diferença de $27,77 \%$, este aumento da diferença entre as forças finais se deve a maior taxa de relaxação do ACM não irradiado. Os valores de força, referentes ao tempo $0 \mathrm{~s}$, apresentados na Tabela 19 foram calculados relacionando, já que o software não apresentou os valores.

Tabela 19 - Valores absolutos de força por compressão medidos em tempos específicos.

\begin{tabular}{ccccccccc}
\hline $\mathbf{t ~} \mathbf{~ m i n}$ & $\mathbf{1}(\mathbf{N})$ & $\mathbf{2}(\mathbf{N})$ & $\mathbf{3} \mathbf{( N )}$ & $\mathbf{4}(\mathbf{N})$ & $\mathbf{5}(\mathbf{N})$ & $\mathbf{6}(\mathbf{N})$ & $\mathbf{7}(\mathbf{N})$ & $\mathbf{8}(\mathbf{N})$ \\
\hline 0 & 46,63 & 55,81 & 63,27 & 83,61 & 34,50 & 40,07 & 44,38 & 57,74 \\
500 & 23,78 & 29,02 & 32,90 & 42,64 & 26,22 & 30,05 & 34,17 & 44,46 \\
1000 & 23,34 & 28,48 & 32,06 & 41,86 & 25,78 & 29,26 & 33,53 & 43,09 \\
1500 & 22,60 & 28,33 & 31,67 & 40,93 & 25,53 & 28,62 & 33,09 & 42,50 \\
2000 & 22,45 & 27,65 & 30,93 & 40,58 & 25,00 & 28,19 & 32,90 & 41,81 \\
2500 & 22,36 & 27,40 & 30,64 & 39,80 & 24,90 & 28,14 & 32,56 & 41,66 \\
3000 & 21,48 & 27,26 & 30,64 & 39,90 & 24,65 & 27,74 & 32,36 & 41,42 \\
3500 & 21,13 & 26,96 & 30,05 & 39,85 & 24,55 & 27,70 & 32,21 & 41,27 \\
4000 & 21,14 & 27,01 & 29,95 & 39,41 & 24,75 & 27,59 & 32,11 & 41,27 \\
5000 & 20,60 & 26,32 & 29,41 & 39,11 & 24,21 & 27,30 & 31,82 & 40,78 \\
\hline
\end{tabular}

Tabela 20 - Valores relativos de força por compressão medidos em tempos específicos.

\begin{tabular}{ccccccccc}
\hline $\mathbf{t}$ min & $\mathbf{1}(\%)$ & $\mathbf{2 ( \% )}$ & $\mathbf{3 ( \% )}$ & $\mathbf{4}(\%)$ & $\mathbf{5}(\%)$ & $\mathbf{6}(\%)$ & $\mathbf{7}(\%)$ & $\mathbf{8}(\%)$ \\
\hline 500 & 0,51 & 0,52 & 0,52 & 0,51 & 0,76 & 0,75 & 0,77 & 0,77 \\
1000 & 0,50 & 0,51 & 0,50 & 0,50 & 0,74 & 0,73 & 0,76 & 0,75 \\
1500 & 0,48 & 0,51 & 0,50 & 0,49 & 0,73 & 0,71 & 0,75 & 0,74 \\
2000 & 0,48 & 0,50 & 0,49 & 0,49 & 0,72 & 0,70 & 0,74 & 0,73 \\
2500 & 0,48 & 0,49 & 0,48 & 0,47 & 0,72 & 0,70 & 0,74 & 0,72 \\
3000 & 0,46 & 0,49 & 0,48 & 0,48 & 0,71 & 0,69 & 0,73 & 0,72 \\
3500 & 0,45 & 0,48 & 0,47 & 0,48 & 0,71 & 0,69 & 0,73 & 0,72 \\
4000 & 0,45 & 0,48 & 0,47 & 0,47 & 0,71 & 0,69 & 0,73 & 0,72 \\
5000 & 0,44 & 0,47 & 0,46 & 0,47 & 0,70 & 0,68 & 0,72 & 0,71 \\
\hline
\end{tabular}


A irradiação reduziu a relaxação por compressão do material, nestas condições em questão, tanto em valores absolutos, como percentuais. O ACM não irradiado perdeu em média $3,18 \mathrm{~N}$ de força após $5.000 \mathrm{~min}$, enquanto a condição irradiado teve uma redução média de 2,70 N. Percentualmente foram mantidas $44 \%$ e $47 \%$, conforme Tabela 20, das médias das forças iniciais medidas, após 5.000 min de compressão a $10 \%$ de deformação em temperatura de $23^{\circ} \mathrm{C}$, para as condições não irradiadas e irradiadas com $250 \mathrm{kGy}$, respectivamente. Apresentado desta forma a redução da relaxação por compressão proposta, ao menos comparativamente para estas condições nomeadas com 1 e 2 .

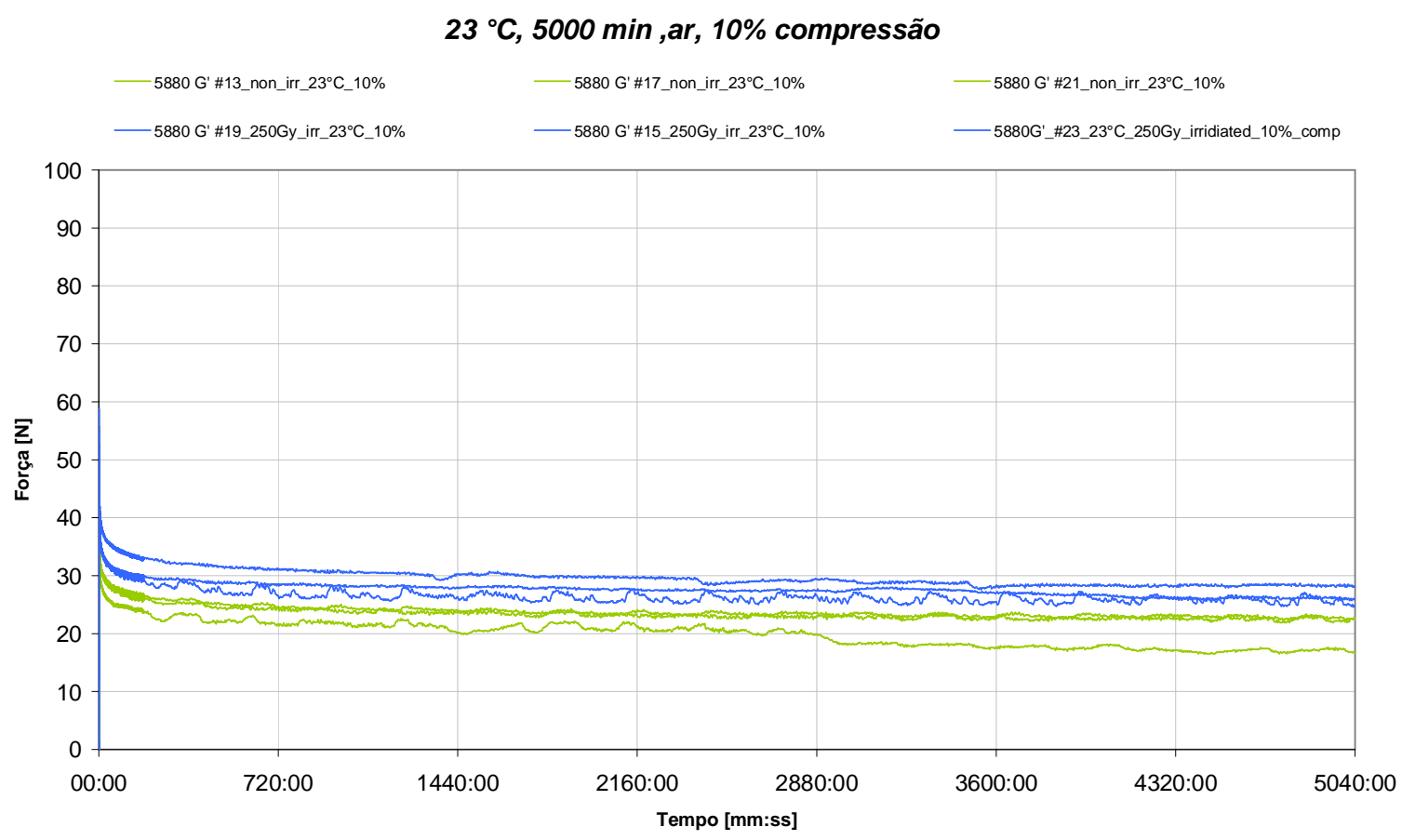

Figura 56 - Curvas de força em função do tempo para condições 1 e 2.

A Figura 57 descreve comparativamente através das curvas apresentadas o comportamento do ACM em igualdade de condições de deformação (15\%) e temperatura $\left(23^{\circ} \mathrm{C}\right)$, divergindo mais uma vez apenas no que se refere a aplicação da dose de $250 \mathrm{kGy}$ de radiação. As médias dos valores de força de compressão medidos após intervalos de tempo determinados são apresentados na Tabela 19, classificados como condição 3 e 4, para corpos de prova não irradiados e irradiados com 250 kGy respectivamente. O ensaio de compressão gera forças e deformações comparáveis aos ensaio equibiaxial de tensões, tanto que são substituíveis na 
definição dos parâmetros do modelo de comportamento não linear de Ogden, desta forma ao gerar um incremento na deformação do sentido de aplicação da força de compressão, de 10\% para 15\%, também é gerado um aumento na tensão de compressão presente nos corpos de prova, basicamente em duas direções, sendo que uma delas é a direção de aplicação da força.

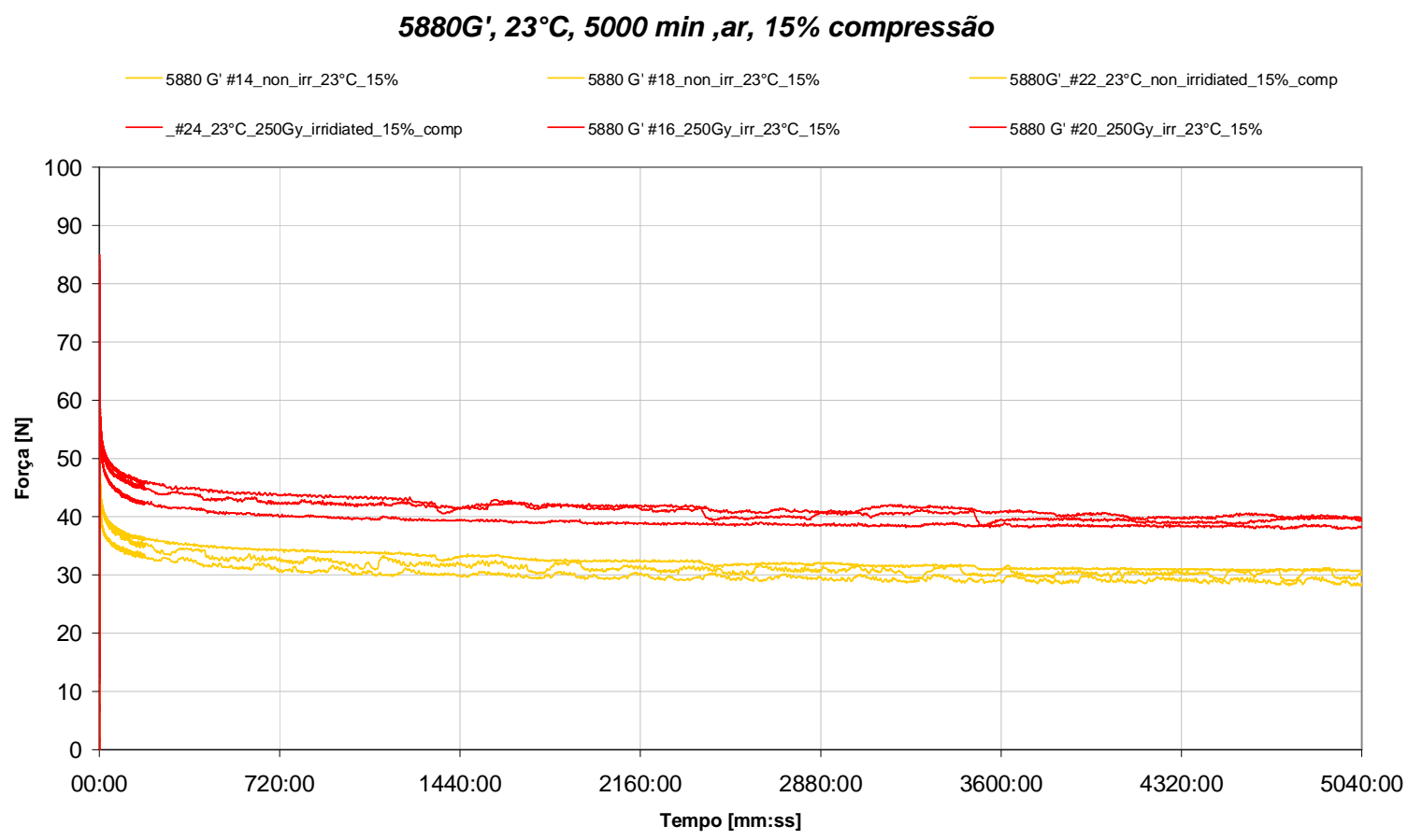

Figura 57 - Curvas de força em função do tempo para condições 3 e 4.

As médias das forças por compressão, para as duas condições após 500 min de ensaio, foram 32,90 N (0 kGy) e 42,64 N (250 kGy), relatando um aumento de $29,60 \%$ da força causado pela aplicação da radiação EB. Este aumento foi superior ao causado pela radiação na mesma condição para uma deformação de $10 \%$. Os valores obtidos ao final do ensaio mostram médias de forças de 29,41 N (0 kGy) e 39,11 N (250 kGy), um acréscimo de 32,98\% em relação a condição sem radiação, resultando em uma perda de força de 3,49 $\mathrm{N}$ para a condição não irradiada e 3,53 N para a condição irradiada. Apesar do valor escalar de perda ser superior na condição irradiada, o percentual de força retida também foi superior nesta condição, devido a superior amplitude da força inicial medida, em suma, o condição irradiada apresentou um percentual de $47 \%$ de capacidade de retenção de força, contra $46 \%$ da condição não irradiada. Desta forma, a aplicação da irradiação EB aumentou a 
força de compressão gerada no material, ao longo de todo período de tempo medido, proporcionado uma maior capacidade de vedação no caso de se utilizar o material para produção de elementos de vedação, já que a vedação depende da força gerada. Além do aumento da força em níveis elevados, onde se pode verificar uma diferença de força de $32,98 \%$ entre as condições após 5.000 min, a radiação gerou um leve aumento na capacidade de manter este valor ao longo do tempo, reduzindo a relaxação por compressão.

Devido as abrangentes aplicações do ACM como juntas sólidas de vedação, optouse por realizar os ensaios em nível de temperatura que condiz com aplicações em motores e transmissões automotivas, ou seja temperatura de trabalho de $90^{\circ} \mathrm{C}$. A Figura 58 apresenta as curvas de força por compressão em função do tempo para as condições $5\left(90^{\circ} \mathrm{C}, 0 \mathrm{kGy}, 10 \%\right)$ e $6\left(23^{\circ} \mathrm{C}, 250 \mathrm{kGy}, 10 \%\right)$, onde é possível identificar uma região de sobreposição de algumas réplicas das duas condições, porém com uma clara predominância do comportamento de maior força de compressão para a condição irradiada. As amostras submetidas ao esforço de compressão em temperatura de $90^{\circ} \mathrm{C}$ apresentaram maior força de compressão quando comparadas com as amostras ensaiadas a $23^{\circ} \mathrm{C}$.

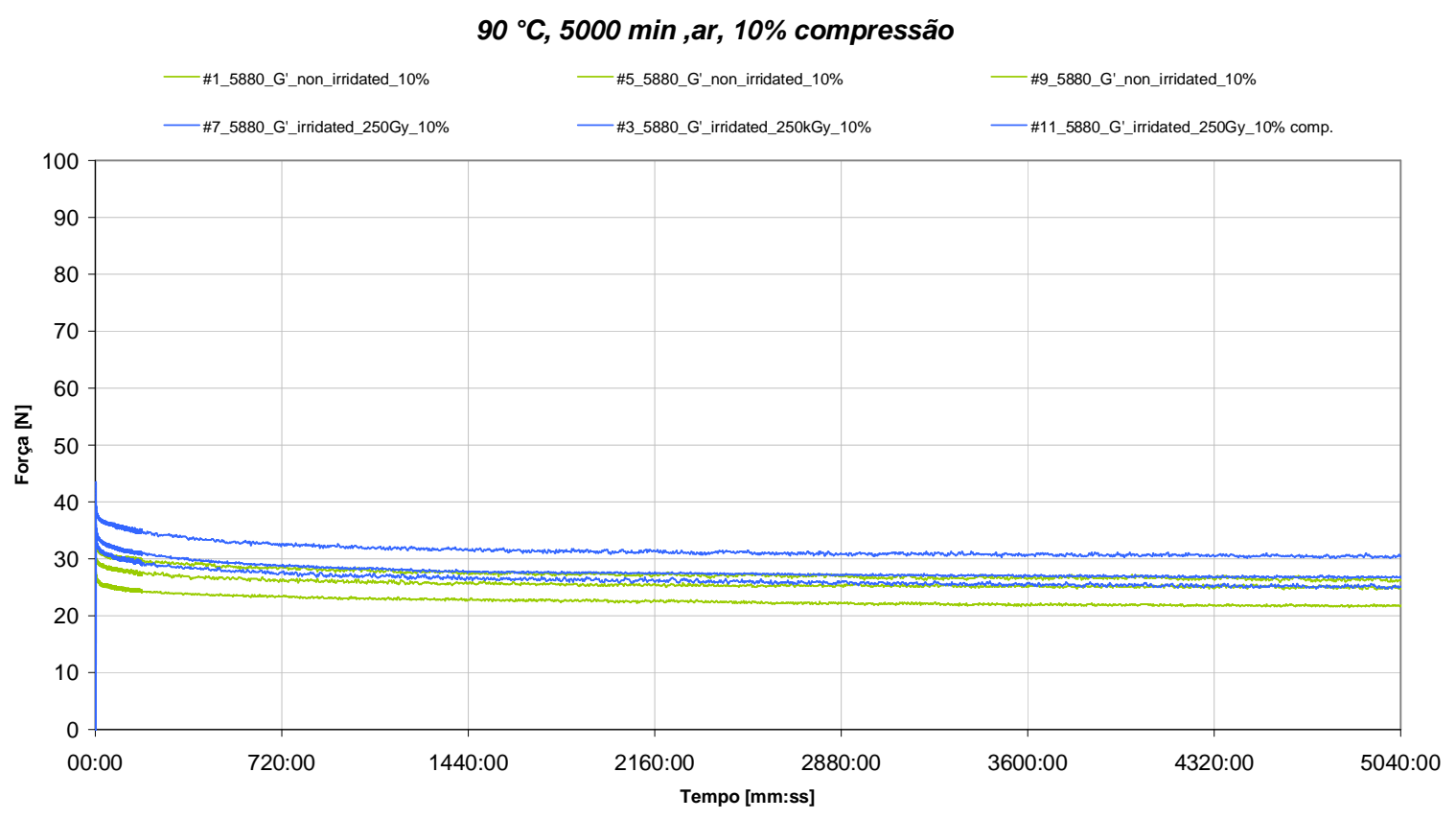

Figura 58 - Curvas de força em função do tempo para condições 5 e 6. 
A estrutura amorfa, associada ao baixo nível de reticulação de elastômeros, pode encontrar uma condição de equilíbrio nesta faixa de temperatura onde as movimentações moleculares podem ter atingido um determinado estado, onde o nível de compactação do material tenha sido aumentado, ou melhor distribuído, e conseqüentemente a resistência mecânica deste. Outra hipótese seria um aumento do nível de reticulação do ACM quando submetido a temperatura de $90^{\circ} \mathrm{C}$.

Ao se analisar as condições 5 e 6, comparativamente com as condições 1 e 2, verifica-se que o aumento da temperatura até $90^{\circ} \mathrm{C}$ aumentou a força de compressão em 10,26\% após 500 min e 17,52\% após 5.000 min, para as condições não irradiadas, 3,55\% após $500 \min$ e 3,72\% após 5.000 min para a condição irradiada. O aumento foi mais elevado nas condições não irradiadas, as quais apresentavam menor nível de reticulação e maior possibilidade de aumento deste nível, enquanto no ACM irradiado, o nível de reticulação é maior, conforme já mostrado devido ao aumento do módulo de elasticidade, sofrendo uma possível menor influência do aumento da temperatura e menor capacidade de aumentar seu nível de reticulação. A condição 6 mostrou um acréscimo da força de compressão, em relação a condição 5, causada pela aplicação da dose de 250 kGy, de 16,51\% e 13,28\%, após 500 min e 5.000 min respectivamente, quando as médias da força de compressão foram 26,22 N (0 kGy) e 30,05 N (250 kGy), 24,21 N (0 kGy) e 27,30 N (250 kGy).

A temperatura de $90^{\circ} \mathrm{C}$ causou alterações significativas também na força de compressão inicial medida, os dados coletados após 500 min de compressão mostram uma força retida em torno de $76 \%$ em relação a força inicial, enquanto este valor se apresentava em torno de $52 \%$ nos ensaios a $23^{\circ} \mathrm{C}$. Ao tomar-se, por exemplo a condição 1, a força de compressão após 500min foi de $23,78 \mathrm{~N}$, equivalente a $51 \%$ da força inicial, equivalente a uma média da força inicial de 46,63 N. A condição 5 , diferenciada somente na temperatura da condição 1 , apresenta uma força média após 500 min de 26,22 N, equivalente a $76 \%$ da força inicial, o que seria equivalente a uma força inicial média de $34,50 \mathrm{~N}$, valor $26,01 \%$ inferior a força média estimada na condição 1. As outras condições ensaiadas apresentam 0 mesmo padrão de comportamento quando comparadas a condições que se diferenciam somente pela temperatura de trabalho. Tal comportamento pode ser verificado nas curvas de DMA, onde o ACM apresenta maior dissipação de energia viscosa a $90^{\circ} \mathrm{C}$, permitindo maior movimento viscoso deste e conseqüente 
movimento com menor resistência, característica que reflete na força inicial menor em comparação com as condições a $23^{\circ} \mathrm{C}$. A elevação do nível de reticulação, causada pela irradiação e com possível incremento por temperatura, se opõe a continuidade do movimento molecular e colabora com o aumento da tensão de compressão, quando comparado com os resultados a temperatura ambiente e não irradiados. Uma análise visual das curvas de força de compressão em função do tempo, mostra picos de força reduzidos nos instantes iniciais dos ensaios, indicando uma menor resistência e maior estabilidade de movimento em alta temperatura. $\mathrm{O}$ software utilizado não forneceu exatos das forças iniciais, somente as forças após determinados períodos de tempo e percentuais.

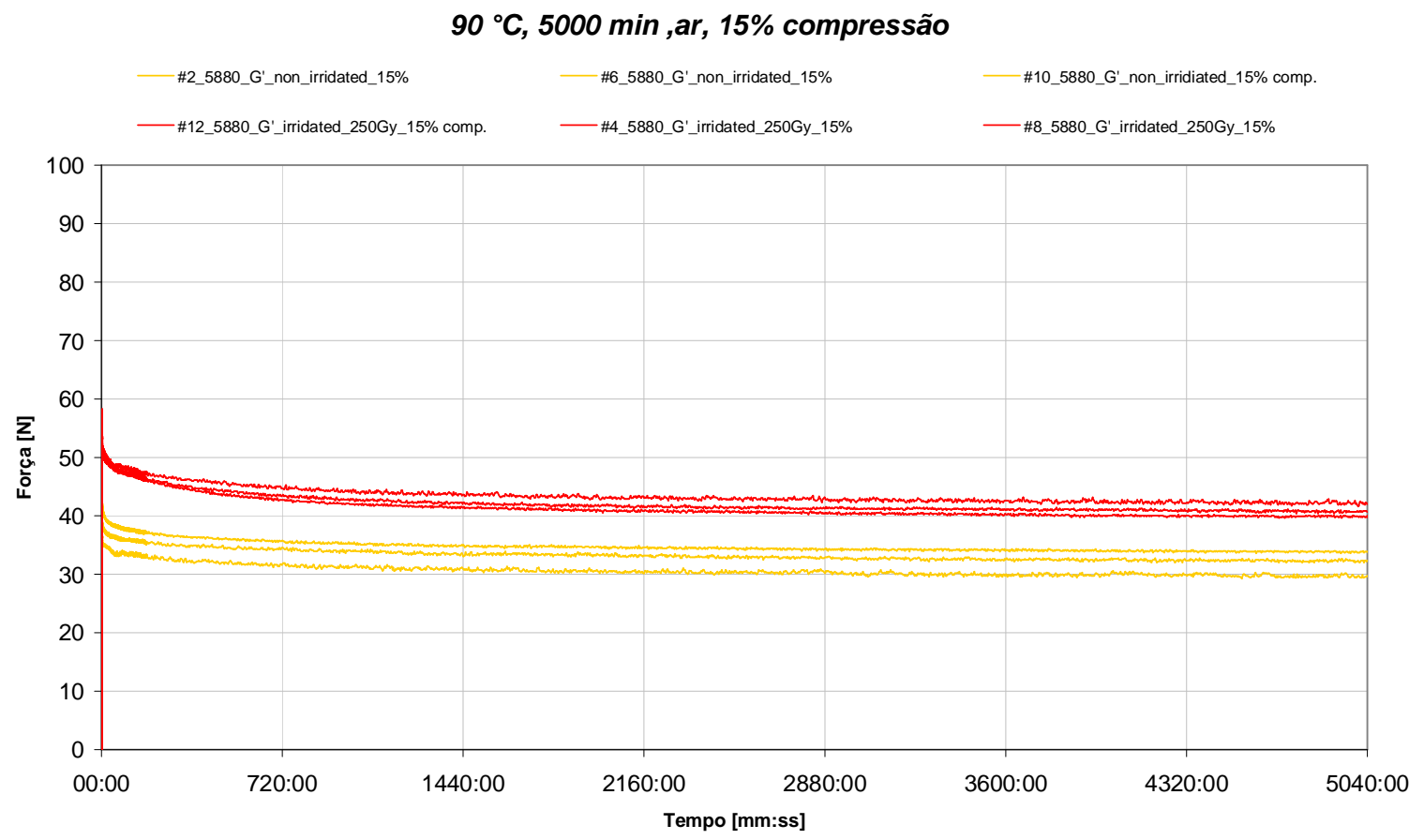

Figura 59 - Curvas de força em função do tempo para condições 7 e 8.

A comparação das médias das forças de compressão das condições $7\left(90^{\circ} \mathrm{C}, 0\right.$ kGy, $15 \%)$ e $8\left(90{ }^{\circ} \mathrm{C}, 0 \mathrm{kGy}, 15 \%\right)$ confirma o aumento da força de compressão causada pela radiação EB em $30,11 \%$ e $28,16 \%$ após os respectivos períodos de 500 min e 5.000 min sob compressão a deformação constante. Também nestas duas condições a temperatura de $90^{\circ} \mathrm{C}$ causou um aumento na força retida em comparação aos corpos de prova ensaiados, os quais se diferenciavam apenas na temperatura de testes em relação as condições 7 e 8 , ou seja, as condições 3 e 4 . 
Ao ensaiar em temperatura de $90^{\circ} \mathrm{C}$, houve um aumento da força retida após 500 min de $3,86 \%$ e $4,27 \%$ para as condições não irradiada e irradiada, sendo este aumento de $8,19 \%$ e 4,27\% após 5.000 min. A Figura 59 mostra curvas com valores superiores de força de compressão, responsáveis por vedação em aplicações específicas, ao longo de todo o período de tempo medido.

Uma análise simples mostra que a irradiação por feixe de elétrons, com dose de 250 kGy, aumentou a força de compressão do ACM em todos as condições ensaiadas ao longo de todo o período de tempo testado. Tal fenômeno é verificado pela comparação direta entre os valores médios de todas as condições que somente se diferenciaram pela aplicação da radiação, tal aumento teve amplitude variada devido a outras condições como temperatura e deformação. A força de compressão é diretamente responsável pela capacidade de vedação de juntas sólidas, desta maneira, o aumento da força de compressão causado pela irradiação aumentaria também a capacidade de vedação de juntas sólidas obtidas com ACM curável por radiação UV, material estudado neste trabalho.

O comportamento da relaxação por compressão não pode ser descrito por um modelo linear, devido ao comportamento viscoelástico do material. Devido a isso, a comparação direta é precisa somente quando utilizada para comparar condições testadas em mesma temperatura e nível de deformação. A variação da temperatura de teste e do nível de deformação coloca os corpos de prova sob condições extremamente diferentes e não predizíveis por modelos lineares, não permitindo uma comparação quantitativa precisa entre as condições, de maneira prática, uma variação de $5 \%$ na relaxação por compressão na condição de $23^{\circ} \mathrm{C}$, não representa o mesmo nível de relaxação na condição de $90^{\circ} \mathrm{C}$, nem em termos quantitativos de força perdida, quanto ao modelo de comportamento que rege 0 material.

\subsubsection{Planejamento Fatorial $2^{k}$}

A análise dos resultados experimentais pela ferramenta de Planejamento Fatorial $2^{k}$ foi realizada utilizando os valores absolutos de força após 5.000 min de ensaio, bem como os resultados percentuais após o mesmo período. Deve-se levar em consideração que os valores de força medidos, mostram a capacidade de vedação 
do material após o tempo específico, porém não mostram de maneira direta a redução ou não da relaxação por compressão. Porém permitem avaliar a eficácia da utilização de EB como método de melhoria de desempenho de juntas sólidas feitas de ACM curável por UV.

Os dados percentuais mostram o aumento ou a redução da relaxação do material em função da constante deformação aplicada, através da relação da força inicial pela força no momento medido. Este método porém, desconsidera o comportamento não linear do material, bem como o fato de que as forças iniciais medidas são diferentes para cada condição. Ou seja, embora em alguns casos a força final percentualmente retida seja de valores próximos a $70 \%$, o método não considera que a força no tempo zero possa ter sido menor que em condições onde 0 percentual retido tenha sido de $44 \%$, por exemplo. Sendo assim, o Planejamento Fatorial desconsidera as alterações não lineares causadas pela alteração estrutural das cadeias poliméricas e conseqüentemente seu comportamento não linear, gerando desta força limitações na análise dos dados percentuais.

\subsubsection{Discussão dos Resultados}

A Figura 60 apresenta as variações causadas pelos fatores analisados na força por compressão do ACM, conseqüentemente na capacidade de vedação deste material. O fator de maior influência foi o nível de deformação, propondo desta forma, que de maneira geral, sendo na condição irradiada ou não irradiada, ao elevar o nível de compressão de $10 \%$ para $15 \%$ da altura inicial, é causada um aumento médio de $43,03 \%$ na força de compressão do material, aumento a capacidade a vedação do material após 5.000 min de ensaio.

O segundo fator de maior influência foi a radiação, ou seja, ao submeter o material a radiação EB de dose 250 kGy, o material apresenta uma força de compressão, ou força de vedação, de 33,30 N equivalente a aumento de 25,61\% na força por compressão, em relação ao valor medido no tempo zero do experimento. Os valores apresentados na Figura 60 não consideram as interações dos fatores de influência, ou seja, quanto a combinação destes interfere na resistência do material. 
O fator temperatura apresentou a menor influência no comportamento do material, no que se refere a força de compressão retida após $5.000 \mathrm{~min}$, apresentando um aumento médio da força de compressão de $28,78 \mathrm{~N}$ para $31,03 \mathrm{~N}$, o que representa um aumento de $7,82 \%$.

Os três fatores analisados causaram aumento da força de compressão no tempo final. Para os fatores deformação e radiação, este aumento foi previsto, devido ao comportamento já verificado nas fases anteriores deste trabalho, onde a simulação realizada previu um aumento da força em função da deformação por compressão e da aplicação da dose de 250 kGy. Bem como a dose de 250 kGy causou aumento da resistência nos três tipos de experimentos realizados na fase inicial deste trabalho.

A influência da temperatura permanecia indeterminada até a realização dos ensaios de relaxação por compressão. O aumento da resistência apresentado propõe um possível aumento do nível de reticulação, mesmo em relação a condição irradiada, pois a radiação $E B$, causa diversos tipos de rearranjos estruturais. A revisão bibliográfica mostrou alguns dos diversos tipos de reações possíveis, onde em alguns deles o surgimento de ligações duplas de carbono eram possíveis, desta forma tais reações tornam possível um aumento do nível de reticulação, já mostrado através da medição do módulo a 100\% de alongamento, bem como o surgimento de novas ligações duplas de carbono. Estas por sua vez, teriam reagido, pela ação da temperatura e aumentado ainda mais o nível de reticulação na condição de alta temperatura, explicando o ganho de força causado na condição a $90^{\circ} \mathrm{C}$. O DMA apresentou um aumento da capacidade de conservação de energia elástica a $90^{\circ} \mathrm{C}$, sendo esta uma segunda explicação possível para o aumento da força verificado a $90^{\circ} \mathrm{C}$.

A Figura 61 apresenta a influência das combinações dos fatores analisados. A influência da variação do nível do fator analisado é verificada pela comparação entre as inclinações das curvas de cada gráfico. Ao se analisar, por exemplo, o quadrante que apresenta a combinação entre os fatores deformação e temperatura, o único quadrante da linha inferior da Figura 61, verifica-se que a inclinação, ou derivada, das duas curvas é similar. Sendo assim as alterações causadas pela variação do nível de deformação, respeitaram um mesmo padrão nas duas condições de temperatura, ou seja, a combinação entre os dois fatores não causa alteração 
significativa no comportamento do material, no que se refere a força por compressão após $5.000 \mathrm{~min}$.

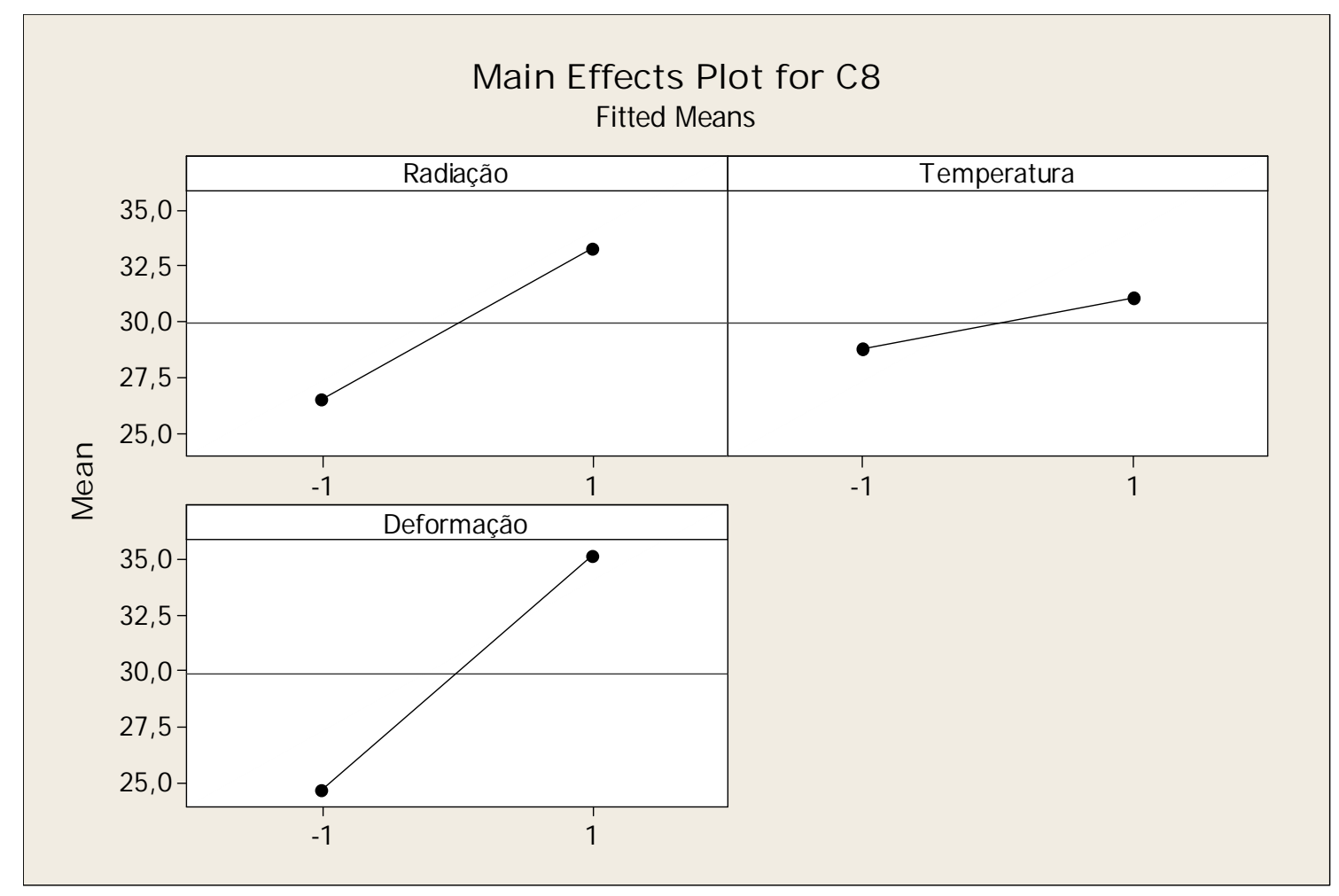

Figura 60 - Aumento da força por compressão, em valores absolutos, em função da alteração de nível das variáveis de influência.

Ao se analisar a interação entre os fatores temperatura e radiação, percebe-se que a temperatura causou maior variação do comportamento do ACM na condição não irradiada, devido a maior inclinação da respectiva curva. A combinação de fatores com maior influência se referiu a interação da radiação com a deformação. Ao elevar-se o nível de deformação do ACM irradiado o aumento da força de compressão foi de 19,29\% para a condição não irradiada e de 29,96\%.

A Figura 62 define, através do gráfico de Pareto, a significância do fatores analisados, bem como das combinações de fatores e confirma a maior influência da interação entre a radiação e a deformação, definindo como não significantes as alterações causadas pelas interações entre temperatura e radiação, bem como entre deformação e temperatura. 


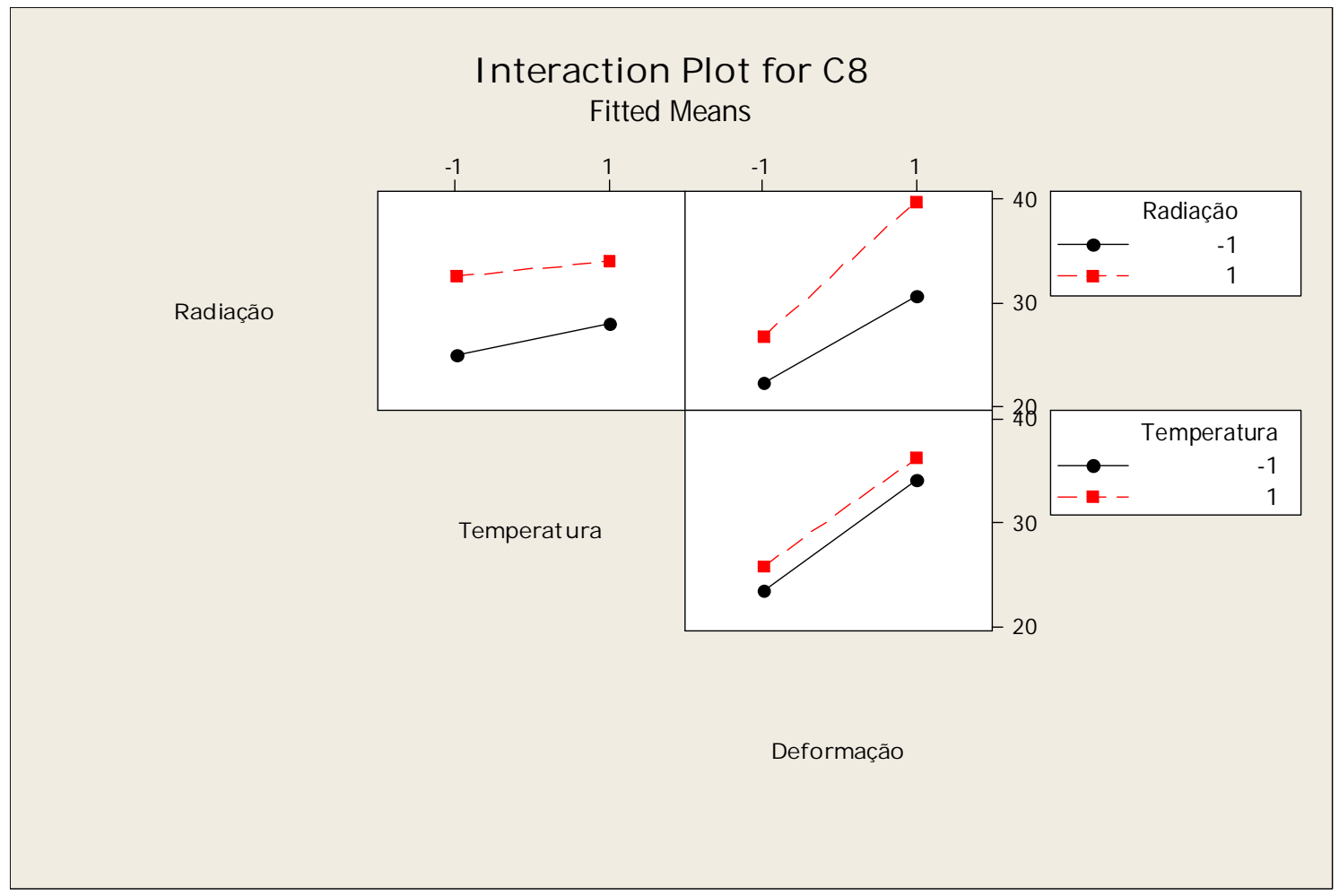

Figura 61 - Alteração da força por compressão, valores absolutos, em função da interação entre as variáveis de influência.

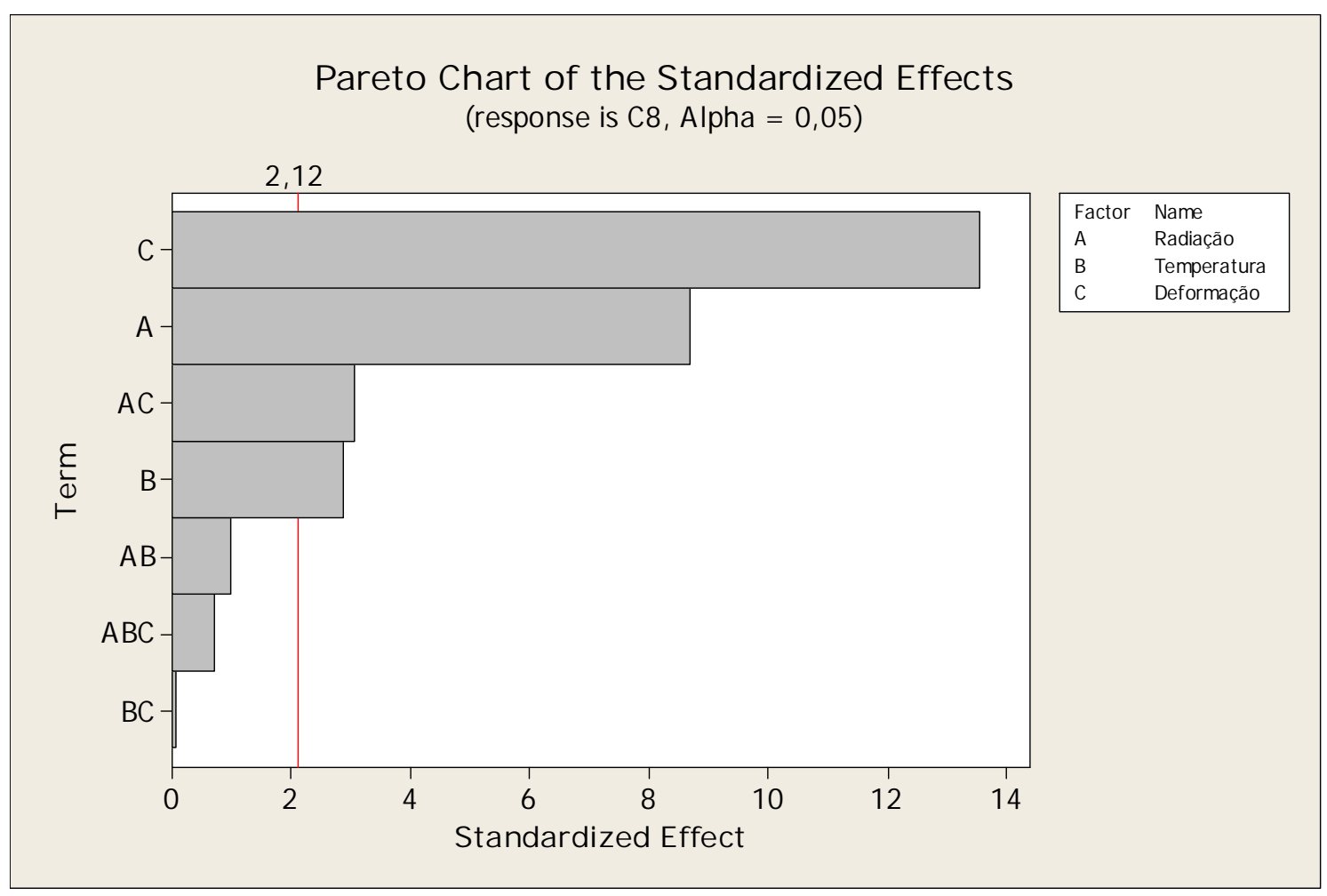

Figura 62 - Gráfico de Pareto referente a influência das variáveis e suas combinações. 
A Figura 63 apresenta as variações da força média por compressão, causada pela alteração dos níveis de cada fator de influência, em valores percentuais, ou seja levando em consideração a relação entre a força inicial medida e a força de vedação após $5.000 \mathrm{~min}$.

Os valores percentuais não oferecem informações diretas sobre a força por compressão, ou força de vedação, do material após os intervalos de tempo estudados. Valores percentuais elevados, representam apenas uma elevada relação entre a força inicial e a força final medidas. Os resultados experimentais porém, nos mostraram que os valores de força inicial medidos são inferiores nas condições ensaiadas a $90^{\circ} \mathrm{C}$ em comparação com os valores medidos a $23^{\circ} \mathrm{C}$. Isso se dá a facilidade de movimentação molecular do elastômero a $90^{\circ} \mathrm{C}$, que oferece menor resistência a uma movimentação inicial, porém apresenta um aumento posterior desta resistência ao movimento, devido ao aumento do seu nível de reticulação. Sendo assim, devido a esta facilidade de movimentação inicial, os valores de força inicial a $90^{\circ} \mathrm{C}$ são reduzidos, desta forma, mesmo apresentando resultados percentuais superiores, eles poderiam ter valor absoluto inferior. Em suma, o aumento do percentual de força retida não implica em um aumento da capacidade de vedação, ou das força por compressão.

A Figura 63 mostra um aumento significativo do percentual de força retida causado pela temperatura a $90^{\circ} \mathrm{C}$, o percentual médio passou de $46,08 \%$ em $23^{\circ} \mathrm{C}$ para $70,17 \%$ em $90^{\circ} \mathrm{C}$. Os outros fatores, radiação e deformação, bem como as interações entre os fatores, não apresentaram variação significativa no percentual de força retida segundo o Planejamento Fatorial $2^{k}$, conforme apresentado no gráfico de Pareto, Figura 65.

Os valores percentuais, analisados par a par no capítulo anterior, para as condições de baixo e alto nível de temperatura, mostraram que a radiação causou um leve aumento do percentual de força retida na condição de baixa temperatura e uma leve redução do mesmo percentual para a condição de alta temperatura. A análise da interação temperatura e radiação, pelo Planejamento Fatorial $2^{k}$, repetiu a tendência da análise anterior, apresentando um aumento médio do percentual de força retido de $45,17 \%$ para $47,00 \%$ na condição de baixo nível de temperatura e uma redução de $70,83 \%$ para $69,50 \%$ para a condição de alto nível de temperatura. Sendo que de maneira geral o aumento da força retida percentual após 5.000 min causado pela radiação não foi significativo, passando de $58,00 \%$ para $58,25 \%$. 
O aumento da força percentual retida causado pelo aumento do nível de deformação de $10 \%$ para $15 \%$ foi considerado como não significativo, de acordo com o gráfico de Pareto, se elevando de uma média geral de força retida de $57,33 \%$ na condição de baixo nível de deformação para $58,92 \%$, para a condição de alto nível de deformação.

A Figura 64 apresenta os resultados das alterações causadas pela interação dos diferentes fatores, conforme citado na análise dos valores absolutos, uma possível diferença entre as derivadas das duas curvas do mesmo gráfico, é diretamente proporcional a variação causada pela interação dos fatores. Visualmente não é possivelmente identificar alterações significativas pela interação dos fatores, condição confirmada pelo gráfico de Pareto da Figura 65.

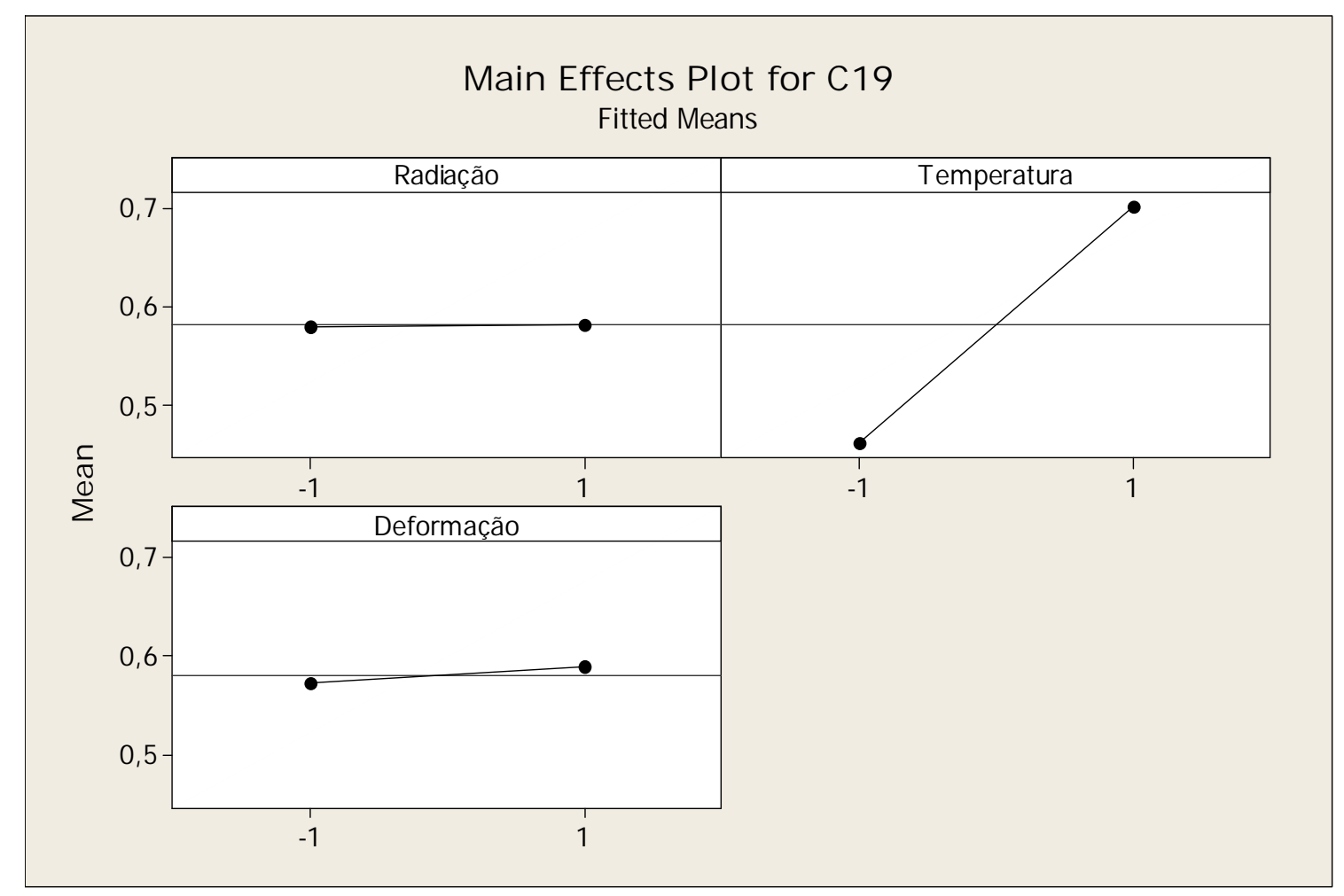

Figura 63 - Aumento da força por compressão, em valores percentuais, em função da alteração de nível das variáveis de influência. 


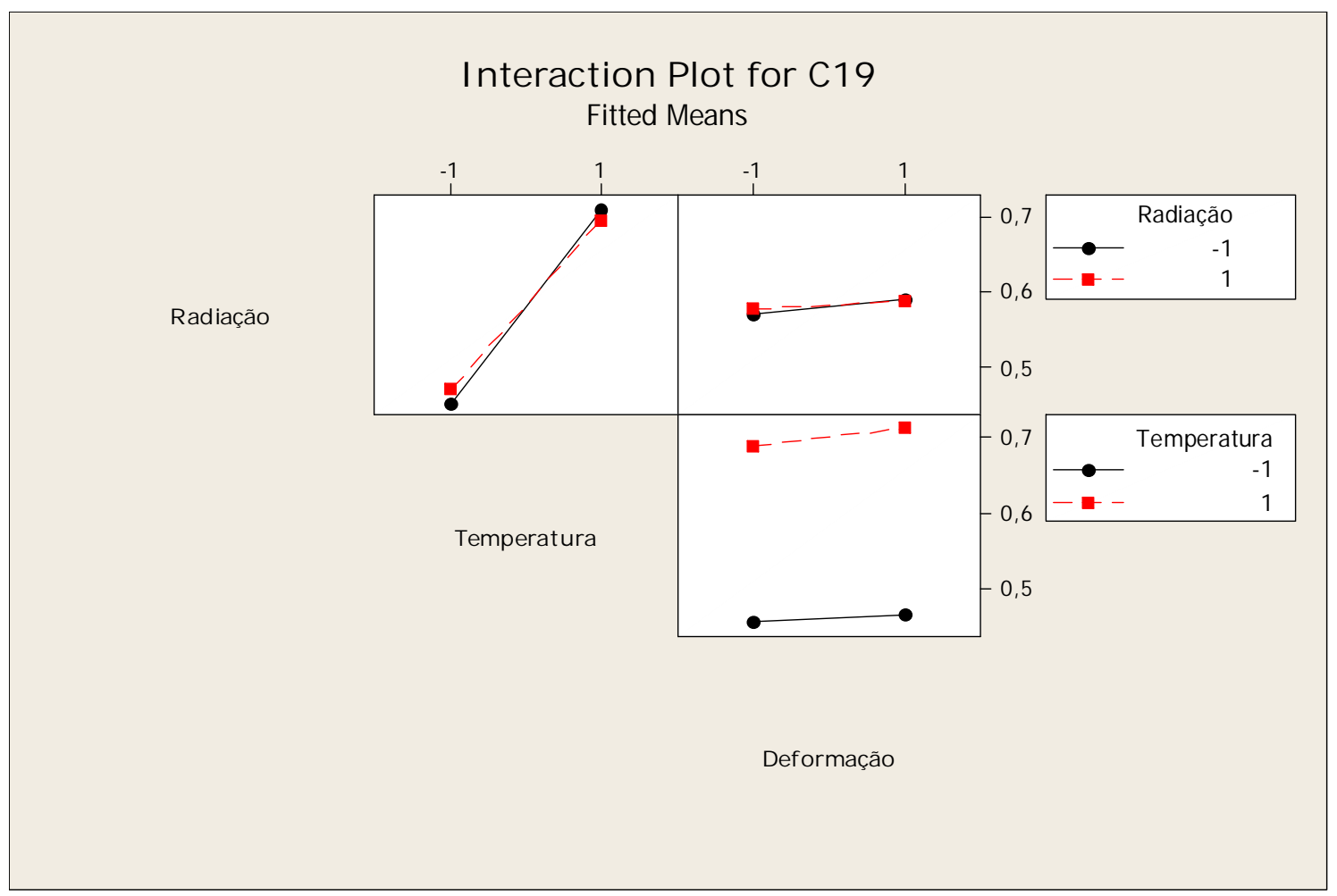

Figura 64 - Alteração do percentual de força por compressão retida em função da interação entre as variáveis de influência.

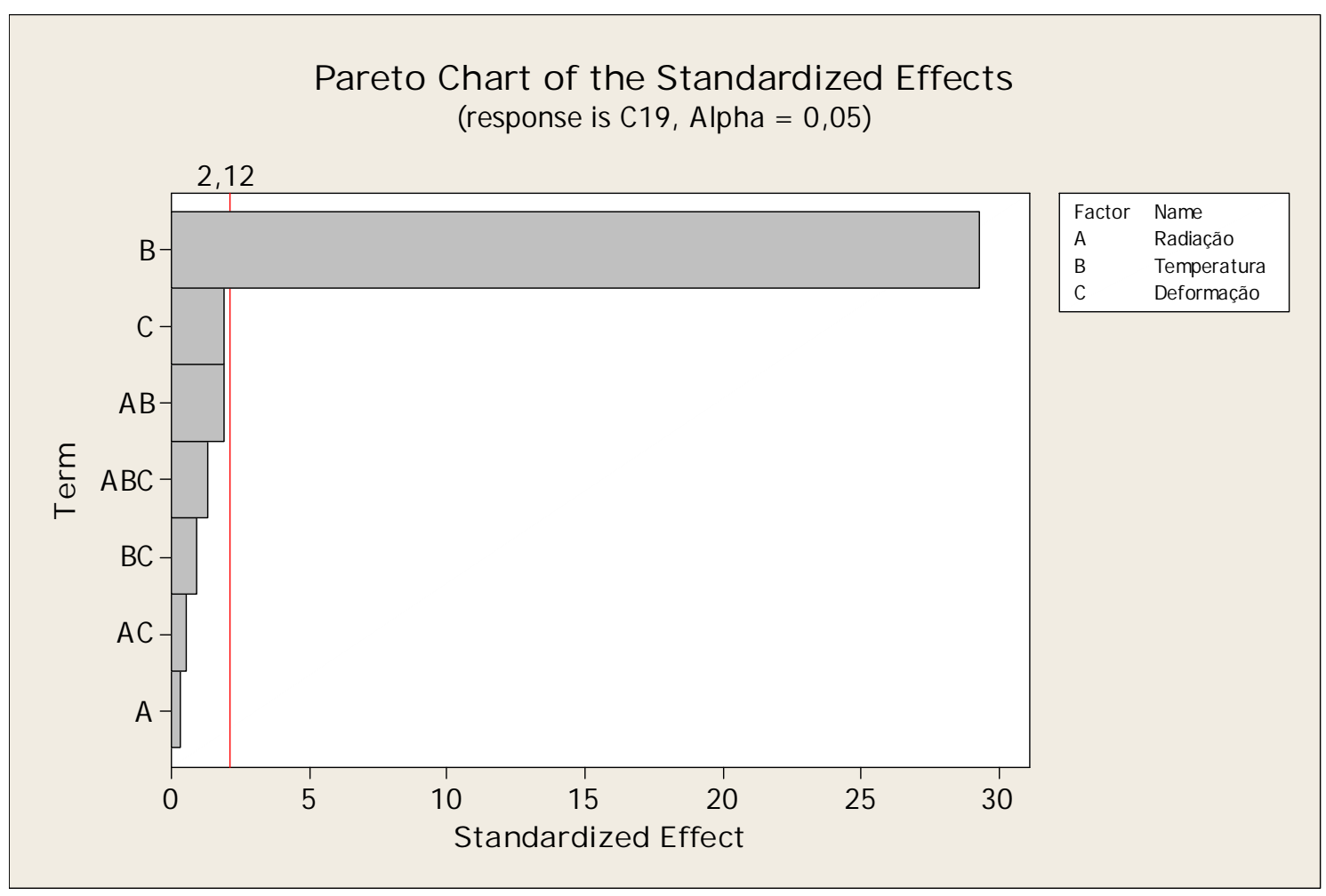

Figura 65 - Gráfico de Pareto referente a influência das variáveis e suas combinações, valores percentuais. 


\section{CONCLUSÕES}

O conteúdo desenvolvido neste trabalho mostrou que:

- A irradiação por feixe de elétrons, por doses de até $100 \mathrm{kGy}$, não fragmenta a estrutura molecular da borracha acrílica modificada, curada por radiação ultravioleta e que o aumento da dose de radiação aumentou a tensão na ruptura do material em até aproximadamente $15 \%$.

- A cura do material ocorreu de maneira diferente na superfície e na região central do mesmo, reagindo também de maneira diferente a pós cura com radiação EB nas duas regiões.

- $\quad$ O processo de obtenção dos corpos de prova influencia diretamente na resistência dos mesmos.

- A radiação EB aumenta o módulo de elasticidade do material a $100 \%$ de deformação, proporcionalmente ao aumento da dose de radiação para doses de até 250 kGy, bem como reduzem de maneira inversamente proporcional o percentual de alongamento na ruptura do material.

- O aumento do módulo mostra um aumento no nível de reticulação e peso molecular deste elastômero com o aumento da dose de radiação. Os ensaios equibiaxial e cisalhamento puro confirmaram, de maneira geral, o aumento da tensão na ruptura e redução do alongamento com o aumento da dose de radiação. - A dose que maior influenciou o comportamento mecânico do ACM foi de 250 kGy.

- O aumento da dose de radiação, causadora do aumento do nível de reticulação, não alterou de maneira significativa a temperatura de degradação do material, sendo que o material não irradiado apresentou maior resistência a degradação.

- O material irradiado com 250 kGy apresenta maior capacidade de armazenar energia elástica ao longo da faixa de temperatura estudada.

- O Modelo de Ogden, usado para simulação do comportamento não linear deste elastômero, não gerou curvas de comportamento similares, quando os resultados da simulação foram comparados com os resultados experimentais, no que se refere ao esforço uniaxial de tensão. As curvas obtidas por simulação, 
referentes aos esforços equibiaxiais e de cisalhamento puro, apresentaram comportamento similar aos resultados experimentais.

- O Modelo de Ogden com seis parâmetros apresentou melhores resultados quando o comportamento do material se apresentou sua não linearidade com maior evidência.

- Diferentes alterações moleculares foram causadas simultaneamente, pela radiação EB na estrutura da borracha poliacrílica. O contato com ar durante a irradiação, condição da superfícies do ACM, proporciona diferentes mecanismos de reações químicas, ao ser comparado com a região isenta de ar durante a irradiação, condição da região central do $\mathrm{ACM}$.

- A radiação $E B$ reduziu a quantidade de ligações $C=C$ na superfície do material. O mesmo comportamento não foi encontrado na região central para a dose de $250 \mathrm{kGy}$, onde as quantidade de ligações $\mathrm{C}=\mathrm{C}$ não aumentaram com o aumento da dose para 250 kGy.

A dose de 250 kGy de radiação por feixe de elétrons aumentou de maneira geral a força por compressão, ou força de vedação do material, em aproximadamente $25 \%$ após $5.000 \mathrm{~min}$.

- $\quad$ O fator de influência que causou maior aumento da força de vedação foi a deformação, causando um aumento próximo a 43\% após 5.000 min.

- A interação dos fatores deformação e radiação causaram alterações significativas no aumento da força de vedação, ao elevar o nível de deformação o aumento da força de compressão foi de aproximadamente 19\% para a condição não irradiada e em torno de $29 \%$ para a condição irradiada.

- O aumento da temperatura apresentou a menor influência na força de vedação, causando um aumento de quase $8 \%$ após 5.000 min.

- $\quad \mathrm{Na}$ análise percentual de força retida, ou relaxação por compressão, o único fator significativo foi o aumento da temperatura, que reduziu a perda percentual de força ao longo do tempo, passando de níveis próximos a $46 \%$ em $23^{\circ} \mathrm{C}$ para níveis próximos a $70 \%$ em $90^{\circ} \mathrm{C}$.

- A radiação EB causou uma leve redução da relaxação por compressão em $23^{\circ} \mathrm{C}$ após $5.000 \mathrm{~min}$, porém também causou um leve aumento na relaxação por compressão a $90^{\circ} \mathrm{C}$, apresentando de maneira geral uma alteração não significativa. 
- $\quad$ A dose de 250 kGy de radiação EB aumentou a força de vedação de borracha poliacrílica, aumentando a capacidade de vedação de juntas sólidas fabricadas deste material.

- O aumento da força retida percentual, ou a redução da relaxação por compressão, causada pela temperatura de $90^{\circ} \mathrm{C}$ tem como principal causa o aumento da capacidade de dissipação viscoso deste material nesta temperatura. Reduzindo a resistência ao movimento no início da deformação.

\subsection{LIMITAÇÕES DO ESTUDO}

- O fabricante da borracha acrílica modificada não forneceu dados sobre a formulação do produto, fator que impossibilitou a caracterização exata da estrutura molecular do material e as alterações causadas pela radiação EB em tais estruturas.

- $\quad$ Os corpos de prova que serão utilizados nos ensaios de relaxação da tensão por compressão foram obtidos por processo manual e tiveram espessura superior a dos corpos de prova utilizados no restante do estudo. Embora o material tenha condições de cura em profundidades de até $26 \mathrm{~mm}$, de acordo com fabricante, não foram realizados ensaios para comprovação das informações.

- $\quad$ A relaxação por tensão de compressão foi analisada por curtos períodos de tempo, não sendo possível desta forma predizer o comportamento em vida do material, ou seja, a relaxação em longos períodos de tempo.

- $\quad$ Os resultados uniaxial, equibiaxial e de cisalhamento puro não apresentaram um comportamento padrão esperado, o que pode ter acontecido por erro nos ensaios ou característica específica do material.

- $\quad A$ análise por planejamento fatorial $2^{k}$ gerou informações específicas sobre os níveis estudados, não representando o comportamento entre os níveis.

- As comparações entre as forças medidas nos ensaios de CSR não consideram o comportamento viscoelástico do material.

- $\quad T$ Tas as condições testadas em temperatura de $90^{\circ} \mathrm{C}$, tiveram os respectivos corpos de prova deformados na mesma temperatura, sendo mantidos por três horas a $90^{\circ} \mathrm{C}$ para garantir uma temperatura homogênea do corpo de prova. Tal condição não condiz com situações reais de aplicação de juntas sólidas e não permite 
comparar a capacidade de redução de relaxação por compressão de juntas em situações reais de aplicações.

- Os corpos de prova utilizados nos ensaios mecânicos nos primeiro e segundo métodos foram obtidos através de corte de folha de ACM e processo automático. Os cilindros utilizados no ensaio CSR foi obtido por processo manual e apresenta geometria diferenciada em relação as folhas de ACM.

\subsection{TRABALHOS FUTUROS}

- A utilização do feixe de elétrons como método de cura para borracha poliacrílica (ACM), pode tornar possível a retirada de componentes da formulação do material que reduzem a capacidade de alongamento do mesmo, dentre a redução de outras propriedades. Sendo assim, ao retirar alguns componentes da formulação e curar o ACM com EB, pode-se melhorar o desempenho do material curado em aplicações de vedação.

- A realização de trabalho comparativo, através de ensaios de relaxação por compressão, do ACM irradiado e ACM não irradiado, com deformação realizada em temperatura ambiente nas duas condições, tornariam possível analisar a relaxação do material em condições reais de aplicação.

- $\quad$ Estudo com maior foco nas alterações estruturais causadas pela radiação EB na borracha poliacrílica. 


\section{REFERÊNCIAS BIBLIOGRÁFICAS}

ABAQUS REGIONAL USERS GROUP MEETING, 2003, Akron. Characterization And Finite Element Analysis of Elastomers. Akron Rubber Development Laboratory.

BANIK, I.; \& BHOWMICK, A. K. Effect of electron beam irradiation on the properties of crosslinked rubbers. Radiation Physics and Chemistry, v. 58, p. $293-298.2000$.

BERNARDI, B. A; LANGLEY, M. W. \& MANLEY, P. E. An Introduction to Polycrylate Elastomers. In: Rubber Division Meeting of the American Chemical Society, April, 1999, Chicago. Paper n PA0910.1.

BIK, J.; GLUSZEWSKI, W.; RZYMSKI, W. M; \& ZAGÓRSKI, Z. K. EB radiation crosslinking of elastomer. Radiation Physics and Chemistry, v. 67, p. $421-423$. 2003.

BOULENOUAR, A. \& MAZARI, M. Characterisation of Elastomer Fracture Behaviour by Energetic Parameters. Computational Materials Science, 2008. No prelo.

CANEVAROLO, J. S. - Ciência dos Polímeros. São Paulo: Artliber, 2001. 280 p.

CARREAU, P. J.; DE KEE, D. C. R.; \& CHHABRA, R.J. Rheology of Polymeric Systems: Principles and Applications. New York: Carl Hanser verlag, 1997. 520 p.

CHEN, J.; CZAYKA, M.; \& URIBE, R. M. Effects of electron beam irradiations on the strutucture and mechanical properties of polycarbonate. Radiation Physics and Chemistry, v. 74, p. $31-35.2005$.

DAY, J.; \& MILLER, K. Equibiaxial Stretching of Elastomeric Sheets, An Analytical Verification of Experimental Technique. Testing and Analysis, Michigan, July, 2000.

ESTADOS UNIDOS. Vanderbilt Company, Inc. The Vanderbilt Rubber Handbook. $3^{\text {rd }}$ ed. Vanderbilt Company, 1990. 832 p. 
GENT, A. L. Engineering with Rubber: How to Design Rubber Components. New York: Oxford Univ. Press, 1992. 323 p.

GENT, A. N. Elastic Instabilities in Rubber. International Journal of Non-Linear Mechanics, v. 40, p. $165-175,2005$.

HAINES, D. W. \& WILSON, W. D. Strain-Energy Density Functions for Rubber-Like Materials. J. Mech. Phys. Solids, v. 27, p. 345 - 360, Feb. 1979.

HARPER, C. A. Handbook of Plastics, Elastomers, and Composites. $4^{\text {th }}$ ed. New York: McGraw Hill, 2002. 884 p.

HOFMANN, W. Rubber Technology Handbook. Muenchen: Hanser, 1996. 611 p.

KOENIG, J. L. Microspectroscopic Imaging of Polymers. Washington, DC: American Chemical Society, 1997. 411 p.

LUCAS, E. F.; SOARES, B. G.; \& MONTEIRO, E. Caracterização de polímeros: determinação de peso molecular e análise térmica. Rio de Janeiro: E-papers, 2001. 366 p.

MANAS, D.; MANAS, M.; STANEK, M.; \& DANEK, M. Improvement of Plastic Properties. Archives of Materials Science and Engineering, v. 32, p. 69 - 76, Aug. 2008.

MATHOT, V. B. F. Calorimetry and Thermal Analysis of Polymers. Passau: Carl Hanser Verlag, 1994. 369 p.

MISHRA, J. K.; CHANG, Y.W.; LEE, B. C \& RYU, S. H. Mechanical properties and heat shrinkability of electron beam crosslinked polyethylene-octene copolymer. Radiation Physics and Chemistry, v. 77, p. 675 - 679. 2008. 
MONTEIRO, E. E. C.; \& FONSECA, J. L. C. Stress relaxation of thermoplastic polyurethanes monitored by FTIR spectroscopy. Polymer Testing, v. 18, p. 281 286. 1999.

MOSTAFA, A.; KASEM, A. A.; BAYOUMI, M. R.; \& SEBAIE, M. G. On the influence of $\mathrm{CB}$ loading on the creep and relaxation behavior of SBR and NBR rubber vulcanizates. Materials and Design, v. 30, p. 2721 - 2725. 2009.

NAVARRO, R. M. Fundamentos da Reologia de Polímeros. Caxias do Sul: EDUCS, 1997. 265 p.

OGDEN, R. W. Non-Linear Elastic Deformations. New York: Dover Publications, INC, 1997. $535 \mathrm{p}$.

PLACEK, V.; KOHOUT, T.; HNAT, V.; \& BARTONICEK, B. Assesment of EPDM seal lifetime on nuclear power plants. Polymer Testing, v. 28, p. 209 -214. 2009.

RIVLIN, R. S. Large Elastic Deformation. In: Rheology: Theory and Applications. New York: Academic Press Inc., 1956. p. 351 - 385.

ROSÁRIO, S. C. Estudo do efeito da radiação ionizante por feixe de elétrons sobre o polietileno de ultra alto peso molecular virgem e reciclado industrial. 2006. 62 p. Dissertação (mestrado). Instituto de Pesquisas Energéticas e Nucleares, São Paulo, 2006.

SALGUEIRO, W.; SOMOZAA, A.; MARZOCCA, A. J.; CONSOLATI, G.; \& QUASSO, $F$. Evolution of crosslinking structure in the elastomer NR and SBR. Radiation Physics and Chemistry, v. 76, p. $142-145.2007$.

SANTOS, D.J.; \& BATALHA, G.F. Mechanical Bevahiour Characterizing and Simulation of Polyacrylate Rubber. Journal of Achievements in Materials and Manufacturing Engineering, v. 38, p. $33-40.2010$. 
SENGUPTA, R.; TIKKU, V.K.; SOMANI, A. W.; CHAKU, T. K.; \& BHOWMICK, A. K. Electron beam irradiated polyamide 6-6 films - I: characterization wide angle X-Ray Scattering and Infrared spectroscopy. Radiation Physics and Chemistry, v. 72, p. $625-633.2005$.

SHAH, V. Handbook of Plastics Testing Technology. USA: John Wiley \& Sons, Inc., 1984. 493 p.

SPERLING, L. H. Introduction to Physical Polymer Science. New Jersey: John Wiley \& Sons, Inc., 2006. 845 p.

VIJAYABASKAR, V.; BHATTACHARYA, S.; TIKKU, V.K \& BHOWMICK, A. K. Electron beam initiated modification of acrylic elastomer in presence of polyfunctional monomers. Radiation Physics and Chemistry, v. 71, p. 1045 - 1058. 2004.

VIJAYABASKAR, V.; TIKKU, V.K \& BHOWMICK, A. K. Electron beam modification and crosslinking: Influence of nitrile and carboxyl contents and level of unsaturation on structure and properties of nitrile rubber. Radiation Physics and Chemistry, v. 75, p. 779 - 792. 2006.

WARD, I. M.; \& SWEENEY, J. The Mechanical Properties of Solid Polymers. UK: John Wiley \& Sons, Ltd., 2004. 382 p.

ZAGÓRSKI, Z. P. EB - crosslinking of elastomers, how does it compare with radiation crosslinking of other polymers. Radiation Physics and Chemistry, v. 71, p. 261 - 265. 2004. 


\section{APÊNDICE A - RESULTADOS EXPERIMENTAIS DE TRAÇÃO}

\begin{tabular}{|c|c|c|c|c|c|c|c|}
\hline $\begin{array}{c}\text { Extensão } \\
(\%)\end{array}$ & $\begin{array}{c}\text { Tensão } \\
\text { MPa }\end{array}$ & $\begin{array}{c}\text { Extensão } \\
\text { (\%) }\end{array}$ & $\begin{array}{c}\text { Tensão } \\
\text { MPa }\end{array}$ & $\begin{array}{c}\text { Extensão } \\
(\%)\end{array}$ & $\begin{array}{c}\text { Tensão } \\
\text { MPa }\end{array}$ & $\begin{array}{c}\text { Extensão } \\
\text { (\%) }\end{array}$ & $\begin{array}{c}\text { Tensão } \\
\text { MPa }\end{array}$ \\
\hline 0,086509 & 0,076579 & 48,31139 & 1,330798 & 92,20637 & 2,392112 & 135,897 & 3,549207 \\
\hline 1,137255 & 0,10917 & 49,68524 & 1,362461 & 93,46709 & 2,428898 & 137,2438 & 3,581567 \\
\hline 2,39307 & 0,173685 & 51,09837 & 1,396053 & 94,7352 & 2,46153 & 138,5165 & 3,614557 \\
\hline 3,66527 & 0,229686 & 52,48063 & 1,427389 & 96,02959 & 2,493392 & 139,8294 & 3,647766 \\
\hline 4,917899 & 0,283424 & 53,80563 & 1,458765 & 97,27255 & 2,527923 & 141,1012 & 3,683288 \\
\hline 6,323781 & 0,336207 & 55,17828 & 1,48953 & 98,59458 & 2,561252 & 145,0122 & 3,77726 \\
\hline 7,787812 & 0,388624 & 56,61223 & 1,51967 & 99,88548 & 2,589806 & 146,2812 & 3,806339 \\
\hline 9,156153 & 0,429276 & 57,97917 & 1,555622 & 101,1802 & 2,622722 & 147,5832 & 3,845884 \\
\hline 10,56747 & 0,469553 & 59,31681 & 1,582914 & 102,4459 & 2,660357 & 148,9378 & 3,880405 \\
\hline 12,03109 & 0,511983 & 60,66685 & 1,613217 & 103,7478 & 2,695566 & 150,2542 & 3,914472 \\
\hline 15,06003 & 0,590624 & 63,29004 & 1,673021 & 106,3535 & 2,763897 & 154,2356 & 4,013377 \\
\hline 16,44437 & 0,628489 & 64,67124 & 1,707901 & 107,6543 & 2,799643 & 155,5708 & 4,045088 \\
\hline 17,91123 & 0,664429 & 65,95072 & 1,738337 & 108,9317 & 2,835304 & 156,9452 & 4,07746 \\
\hline 19,40668 & 0,701694 & 67,28794 & 1,772029 & 110,1887 & 2,865552 & 158,2881 & 4,107738 \\
\hline 20,90457 & 0,73141 & 68,5892 & 1,805144 & 111,5219 & 2,901158 & 159,6207 & 4,129907 \\
\hline 22,40626 & 0,770372 & 69,9049 & 1,840936 & 112,7783 & 2,93452 & 163,6849 & 4,230969 \\
\hline 23,84664 & 0,798137 & 71,26512 & 1,869095 & 114,0576 & 2,968627 & 165,0816 & 4,265442 \\
\hline 25,30259 & 0,835852 & 72,58119 & 1,901938 & 115,3195 & 3,00067 & 166,4055 & 4,293799 \\
\hline 26,80837 & 0,867355 & 73,91017 & 1,936261 & 116,5766 & 3,035813 & 167,7291 & 4,325323 \\
\hline 28,2876 & 0,898357 & 75,20632 & 1,965201 & 117,8509 & 3,071276 & 169,1048 & 4,356444 \\
\hline 31,2835 & 0,963356 & 77,79115 & 2,030612 & 120,4385 & 3,142167 & 173,1916 & 4,444457 \\
\hline 32,71197 & 0,994112 & 79,13119 & 2,064054 & 121,6991 & 3,170745 & 174,5727 & 4,476201 \\
\hline 34,14487 & 1,023274 & 80,46835 & 2,097156 & 122,9717 & 3,206654 & 175,9912 & 4,505344 \\
\hline 35,56478 & 1,057071 & 81,78578 & 2,128813 & 124,2648 & 3,242443 & 177,3357 & 4,529 \\
\hline 37,01267 & 1,089708 & 83,06926 & 2,159972 & 125,5993 & 3,279078 & 178,7657 & 4,563852 \\
\hline 38,48144 & 1,115705 & 84,37246 & 2,193496 & 126,8976 & 3,309703 & 182,9089 & 4,636142 \\
\hline 39,88698 & 1,150351 & 85,69641 & 2,226451 & 128,2097 & 3,337982 & 184,3418 & 4,666118 \\
\hline 41,26198 & 1,178745 & 86,91552 & 2,255186 & 129,5499 & 3,373811 & 185,6841 & 4,698093 \\
\hline 42,68505 & 1,211673 & 88,25795 & 2,290801 & 130,7577 & 3,411518 & 187,1513 & 4,722319 \\
\hline 44,08536 & 1,240341 & 89,54692 & 2,320998 & 132,0349 & 3,445754 & 188,601 & 4,745555 \\
\hline
\end{tabular}

Segundo Método - Pares tensão / deformação obtidos nos ensaios uniaxiais da primeira réplica da condição não irradiada. 


\begin{tabular}{|c|c|c|c|c|c|c|c|}
\hline $\begin{array}{c}\text { Extensão } \\
(\%)\end{array}$ & $\begin{array}{c}\text { Tensão } \\
\text { MPa }\end{array}$ & $\begin{array}{c}\text { Extensão } \\
\text { (\%) }\end{array}$ & $\begin{array}{c}\text { Tensão } \\
\text { MPa }\end{array}$ & $\begin{array}{c}\text { Extensão } \\
\text { (\%) }\end{array}$ & $\begin{array}{c}\text { Tensão } \\
\text { MPa }\end{array}$ & $\begin{array}{c}\text { Extensão } \\
\text { (\%) }\end{array}$ & $\begin{array}{c}\text { Tensão } \\
\text { MPa }\end{array}$ \\
\hline 0,212399 & 0,077966 & 47,88521 & 1,348922 & 92,56396 & 2,441763 & 138,212 & 3,660658 \\
\hline 1,223934 & 0,108595 & 49,25091 & 1,383017 & 93,86875 & 2,477766 & 139,4849 & 3,691568 \\
\hline 2,48213 & 0,170862 & 50,62589 & 1,410555 & 95,0724 & 2,510062 & 140,7735 & 3,727709 \\
\hline 3,729396 & 0,230455 & 52,00066 & 1,443714 & 96,3294 & 2,54561 & 142,0172 & 3,759142 \\
\hline 4,968909 & 0,286995 & 53,35582 & 1,475869 & 97,59519 & 2,579615 & 143,338 & 3,793312 \\
\hline 6,250351 & 0,339985 & 54,68476 & 1,504401 & 98,85826 & 2,608295 & 147,1345 & 3,886006 \\
\hline 7,65856 & 0,391716 & 56,05434 & 1,536698 & 100,1521 & 2,641703 & 148,4296 & 3,922828 \\
\hline 9,080392 & 0,437595 & 57,45829 & 1,569014 & 101,4119 & 2,67643 & 149,7365 & 3,957851 \\
\hline 10,43764 & 0,478656 & 58,81447 & 1,601665 & 102,7009 & 2,713037 & 151,011 & 3,99036 \\
\hline 11,86115 & 0,517711 & 60,16277 & 1,631765 & 103,9671 & 2,746859 & 152,3283 & 4,022122 \\
\hline 13,30339 & 0,562244 & 61,50836 & 1,665437 & 105,2459 & 2,78035 & 156,2916 & 4,120682 \\
\hline 14,80357 & 0,60338 & 62,79223 & 1,690898 & 106,5458 & 2,815383 & 157,6281 & 4,150437 \\
\hline 16,31903 & 0,639007 & 64,11577 & 1,722192 & 107,77 & 2,847574 & 158,9293 & 4,183882 \\
\hline 17,69681 & 0,675092 & 65,44846 & 1,757127 & 109,0414 & 2,882451 & 160,2548 & 4,207716 \\
\hline 19,15167 & 0,708462 & 66,68723 & 1,78813 & 110,327 & 2,91621 & 161,596 & 4,238377 \\
\hline 20,61497 & 0,744782 & 67,99516 & 1,821026 & 111,5675 & 2,949828 & 165,6002 & 4,334192 \\
\hline 22,09423 & 0,780819 & 69,26827 & 1,849754 & 115,3679 & 3,051684 & 166,9851 & 4,365183 \\
\hline 23,59929 & 0,813468 & 70,60559 & 1,883718 & 116,6203 & 3,087449 & 168,2823 & 4,395735 \\
\hline 25,03486 & 0,84752 & 71,89979 & 1,916394 & 117,8619 & 3,122251 & 169,634 & 4,424173 \\
\hline 26,44556 & 0,878147 & 73,21797 & 1,95078 & 119,1062 & 3,156848 & 170,9376 & 4,45573 \\
\hline 27,93228 & 0,9127 & 74,52003 & 1,983491 & 120,3727 & 3,188521 & 172,3087 & 4,484186 \\
\hline 29,39231 & 0,944109 & 75,80482 & 2,011035 & 121,6681 & 3,220135 & 175,0003 & 4,53959 \\
\hline 30,89281 & 0,976499 & 77,09678 & 2,047333 & 122,9128 & 3,255521 & 176,3545 & 4,574191 \\
\hline 32,36103 & 1,009534 & 78,37537 & 2,078819 & 124,1596 & 3,290649 & 177,7206 & 4,592804 \\
\hline 33,76751 & 1,041141 & 79,67124 & 2,114672 & 125,4067 & 3,327216 & 179,0815 & 4,627313 \\
\hline 35,19224 & 1,073111 & 80,94831 & 2,145924 & 126,7382 & 3,355079 & 180,4615 & 4,656147 \\
\hline 36,58003 & 1,100646 & 82,30311 & 2,17895 & 128,0053 & 3,391245 & 183,1869 & 4,714808 \\
\hline 38,03086 & 1,132911 & 83,56839 & 2,212736 & 129,2776 & 3,424712 & 184,5135 & 4,741631 \\
\hline 39,46289 & 1,16211 & 84,85965 & 2,243222 & 130,5829 & 3,460386 & 185,8517 & 4,771931 \\
\hline 40,88736 & 1,19511 & 86,10933 & 2,276325 & 131,8011 & 3,490315 & 187,2114 & 4,799226 \\
\hline 42,25539 & 1,225735 & 87,3748 & 2,309562 & 133,0543 & 3,526051 & 188,6148 & 4,826151 \\
\hline 43,67589 & 1,2559 & 88,62601 & 2,3388 & 134,3203 & 3,560873 & 190,0007 & 4,840768 \\
\hline
\end{tabular}

Segundo Método - Pares tensão / deformação obtidos nos ensaios uniaxiais da segunda réplica da condição não irradiada. 


\begin{tabular}{|c|c|c|c|c|c|c|c|}
\hline $\begin{array}{c}\text { Extensão } \\
(\%)\end{array}$ & $\begin{array}{c}\text { Tensão } \\
\text { MPa }\end{array}$ & $\begin{array}{c}\text { Extensão } \\
\text { (\%) }\end{array}$ & $\begin{array}{c}\text { Tensão } \\
\text { MPa }\end{array}$ & $\begin{array}{c}\text { Extensão } \\
\text { (\%) }\end{array}$ & $\begin{array}{c}\text { Tensão } \\
\text { MPa }\end{array}$ & $\begin{array}{c}\text { Extensão } \\
\text { (\%) }\end{array}$ & $\begin{array}{c}\text { Tensão } \\
\text { MPa }\end{array}$ \\
\hline 0,379312 & 0,112757 & 59,93517 & 1,520929 & 111,0288 & 2,739581 & 155,8369 & 3,904051 \\
\hline 1,533008 & 0,174173 & 61,2965 & 1,554139 & 112,3416 & 2,77279 & 157,0663 & 3,937095 \\
\hline 2,743834 & 0,227968 & 62,61042 & 1,57978 & 113,521 & 2,799458 & 158,3669 & 3,973659 \\
\hline 4,015081 & 0,280188 & 63,98514 & 1,605641 & 114,7891 & 2,83765 & 159,6178 & 4,004227 \\
\hline 5,436597 & 0,337032 & 65,34109 & 1,640614 & 116,0038 & 2,870103 & 160,889 & 4,037136 \\
\hline 9,750623 & 0,469537 & 66,60511 & 1,66741 & 117,2331 & 2,900035 & 162,1772 & 4,070193 \\
\hline 11,18489 & 0,507617 & 67,88415 & 1,693795 & 118,4782 & 2,931881 & 163,4969 & 4,10067 \\
\hline 12,68894 & 0,549016 & 69,14831 & 1,720826 & 119,6683 & 2,964805 & 164,7544 & 4,132754 \\
\hline 14,22662 & 0,584227 & 70,46261 & 1,753548 & 120,9169 & 2,99748 & 166,0771 & 4,163795 \\
\hline 15,72131 & 0,619365 & 71,72202 & 1,783521 & 122,1466 & 3,031909 & 167,3397 & 4,197709 \\
\hline 20,12801 & 0,715483 & 75,62 & 1,873903 & 125,8759 & 3,121695 & 168,593 & 4,22709 \\
\hline 21,62562 & 0,749556 & 76,88449 & 1,906456 & 127,1807 & 3,160321 & 169,8793 & 4,253863 \\
\hline 23,11491 & 0,779113 & 78,17962 & 1,934278 & 128,4168 & 3,19423 & 171,1636 & 4,281698 \\
\hline 24,57749 & 0,810205 & 79,43729 & 1,965875 & 129,6644 & 3,227039 & 172,4766 & 4,315359 \\
\hline 26,02282 & 0,840912 & 80,72677 & 1,992855 & 130,929 & 3,258768 & 173,7107 & 4,34805 \\
\hline 30,4904 & 0,927224 & 84,61633 & 2,083663 & 132,1111 & 3,292893 & 175,0199 & 4,379257 \\
\hline 31,98554 & 0,957145 & 85,86834 & 2,114062 & 133,3534 & 3,324283 & 176,3268 & 4,406868 \\
\hline 33,42267 & 0,983957 & 87,13523 & 2,136888 & 134,5411 & 3,356397 & 177,5923 & 4,439461 \\
\hline 34,85377 & 1,013026 & 88,3377 & 2,170819 & 135,834 & 3,386046 & 178,9399 & 4,469337 \\
\hline 36,25251 & 1,04222 & 89,6495 & 2,205067 & 137,0522 & 3,424965 & 180,2334 & 4,498134 \\
\hline 37,74771 & 1,071168 & 93,51507 & 2,301538 & 140,813 & 3,517236 & 181,5216 & 4,530718 \\
\hline 39,15777 & 1,097522 & 94,74833 & 2,329918 & 142,0319 & 3,550729 & 182,7762 & 4,557088 \\
\hline 40,59124 & 1,125477 & 95,99662 & 2,3606 & 143,3044 & 3,582677 & 184,065 & 4,587148 \\
\hline 41,99307 & 1,150976 & 97,27713 & 2,38929 & 144,4904 & 3,610546 & 185,3512 & 4,614118 \\
\hline 43,4121 & 1,182517 & 98,49089 & 2,421479 & 145,7694 & 3,649172 & 186,6526 & 4,644679 \\
\hline 47,62062 & 1,267142 & 99,78865 & 2,450413 & 146,9662 & 3,681476 & 187,978 & 4,676081 \\
\hline 49,01866 & 1,292152 & 101,039 & 2,480142 & 148,2262 & 3,717234 & 189,3495 & 4,70148 \\
\hline 50,35356 & 1,322898 & 102,2979 & 2,516176 & 149,487 & 3,744501 & 190,715 & 4,728304 \\
\hline 51,71459 & 1,351408 & 103,5213 & 2,549185 & 150,7335 & 3,775482 & 192,1068 & 4,753658 \\
\hline 53,09884 & 1,379607 & 104,7889 & 2,579066 & 152,0277 & 3,809468 & 193,4697 & 4,781462 \\
\hline 54,43494 & 1,408349 & 106,0845 & 2,611033 & 153,2683 & 3,84451 & 194,9034 & 4,805884 \\
\hline 55,79573 & 1,433698 & 107,3326 & 2,64357 & 154,5224 & 3,873971 & 196,2897 & 4,815222 \\
\hline
\end{tabular}




\begin{tabular}{|c|c|c|c|c|c|c|c|}
\hline $\begin{array}{c}\text { Extensão } \\
(\%)\end{array}$ & $\begin{array}{c}\text { Tensão } \\
\text { MPa }\end{array}$ & $\begin{array}{c}\text { Extensão } \\
\text { (\%) }\end{array}$ & $\begin{array}{c}\text { Tensão } \\
\text { MPa }\end{array}$ & $\begin{array}{c}\text { Extensão } \\
(\%)\end{array}$ & $\begin{array}{c}\text { Tensão } \\
\text { MPa }\end{array}$ & $\begin{array}{c}\text { Extensão } \\
(\%)\end{array}$ & $\begin{array}{c}\text { Tensão } \\
\text { MPa }\end{array}$ \\
\hline 0,004036 & 0,000141 & 40,14591 & 1,26503 & 79,29783 & 2,403382 & 115,8105 & 3,632529 \\
\hline 0,00198 & 0,099987 & 41,47641 & 1,297712 & 80,53161 & 2,446909 & 117,0381 & 3,671123 \\
\hline 1,074915 & 0,147519 & 42,78117 & 1,335008 & 81,8036 & 2,485949 & 118,258 & 3,708146 \\
\hline 2,475538 & 0,209647 & 44,10187 & 1,36844 & 83,02692 & 2,52573 & 119,4345 & 3,753952 \\
\hline 3,819323 & 0,272144 & 45,38988 & 1,406838 & 84,22199 & 2,567044 & 120,6842 & 3,799755 \\
\hline 5,178622 & 0,327784 & 46,72996 & 1,439501 & 85,42617 & 2,607916 & 121,9267 & 3,839533 \\
\hline 6,574797 & 0,378177 & 48,04191 & 1,477405 & 86,67463 & 2,647804 & 123,1675 & 3,883463 \\
\hline 7,988741 & 0,422642 & 49,34346 & 1,510567 & 87,81924 & 2,686556 & 124,3801 & 3,92629 \\
\hline 9,445408 & 0,465694 & 50,64017 & 1,547953 & 89,05036 & 2,730314 & 125,6057 & 3,968945 \\
\hline 10,78729 & 0,509493 & 51,92381 & 1,579375 & 90,27845 & 2,770226 & 126,892 & 4,006462 \\
\hline 12,25567 & 0,549434 & 53,21147 & 1,617927 & 91,49904 & 2,806743 & 128,1159 & 4,052062 \\
\hline 13,70968 & 0,590798 & 54,4262 & 1,652431 & 92,77843 & 2,84732 & 129,3649 & 4,088877 \\
\hline 15,1188 & 0,630986 & 55,68662 & 1,688187 & 94,04305 & 2,883318 & 130,6598 & 4,130108 \\
\hline 16,54985 & 0,669076 & 56,96005 & 1,721933 & 95,19973 & 2,929595 & 131,8198 & 4,175354 \\
\hline 17,94953 & 0,707788 & 58,27077 & 1,760564 & 96,37279 & 2,969767 & 133,0465 & 4,212796 \\
\hline 19,3556 & 0,743844 & 59,52812 & 1,796298 & 97,57779 & 3,014606 & 134,2937 & 4,251918 \\
\hline 20,77231 & 0,780366 & 60,74774 & 1,834004 & 98,7931 & 3,056985 & 135,5948 & 4,295509 \\
\hline 22,15481 & 0,81571 & 62,04356 & 1,874936 & 100,0231 & 3,096487 & 136,8131 & 4,336593 \\
\hline 23,63198 & 0,850662 & 63,31967 & 1,906313 & 101,227 & 3,137659 & 138,1278 & 4,374222 \\
\hline 25,00528 & 0,888676 & 64,55458 & 1,946805 & 102,4583 & 3,17768 & 139,3923 & 4,418303 \\
\hline 26,37277 & 0,921155 & 65,85266 & 1,985305 & 103,6445 & 3,217072 & 140,6603 & 4,458038 \\
\hline 27,77723 & 0,953938 & 67,01998 & 2,022751 & 104,8715 & 3,261281 & 141,908 & 4,494013 \\
\hline 29,19977 & 0,990634 & 68,28232 & 2,059533 & 106,1166 & 3,304115 & 143,22 & 4,529593 \\
\hline 30,63086 & 1,023479 & 69,50606 & 2,096791 & 107,3236 & 3,339097 & 144,4425 & 4,57143 \\
\hline 32,03481 & 1,059769 & 70,73866 & 2,13592 & 108,5437 & 3,383943 & 145,7674 & 4,610409 \\
\hline 33,38224 & 1,092314 & 71,98045 & 2,177655 & 109,7604 & 3,423299 & 147,0138 & 4,647772 \\
\hline 34,73318 & 1,126138 & 73,2169 & 2,213547 & 110,9411 & 3,46662 & 148,3318 & 4,684649 \\
\hline 36,07554 & 1,162036 & 74,45356 & 2,250027 & 112,2166 & 3,508027 & 149,6607 & 4,71648 \\
\hline 37,46635 & 1,195447 & 76,87781 & 2,326187 & 113,3706 & 3,552259 & 150,9789 & 4,755163 \\
\hline 38,76013 & 1,228765 & 78,09542 & 2,363727 & 114,6205 & 3,589458 & 152,3745 & 4,785941 \\
\hline
\end{tabular}

Segundo Método - Pares tensão / deformação obtidos nos ensaios uniaxiais da primeira réplica da condição irradiada com 100 kGy. 


\begin{tabular}{|c|c|c|c|c|c|c|c|}
\hline $\begin{array}{c}\text { Extensão } \\
\text { (\%) }\end{array}$ & $\begin{array}{c}\text { Tensão } \\
\text { MPa }\end{array}$ & $\begin{array}{c}\text { Extensão } \\
\text { (\%) }\end{array}$ & $\begin{array}{c}\text { Tensão } \\
\text { MPa }\end{array}$ & $\begin{array}{c}\text { Extensão } \\
\text { (\%) }\end{array}$ & $\begin{array}{c}\text { Tensão } \\
\text { MPa }\end{array}$ & $\begin{array}{c}\text { Extensão } \\
\text { (\%) }\end{array}$ & $\begin{array}{c}\text { Tensão } \\
\text { MPa }\end{array}$ \\
\hline 0,007294 & $-0,00278$ & 43,31712 & 1,302564 & 82,71246 & 2,374355 & 121,3048 & 3,613242 \\
\hline 0,002108 & 0,102006 & 44,70477 & 1,332454 & 83,95003 & 2,413442 & 122,5061 & 3,652643 \\
\hline 1,183227 & 0,150712 & 46,05705 & 1,367732 & 85,19111 & 2,450177 & 123,7542 & 3,695929 \\
\hline 2,61762 & 0,214213 & 47,47203 & 1,40347 & 86,45646 & 2,487429 & 125,0133 & 3,735092 \\
\hline 3,973263 & 0,278846 & 48,87491 & 1,435703 & 87,6675 & 2,52695 & 126,2919 & 3,778289 \\
\hline 5,408021 & 0,333421 & 50,19707 & 1,473653 & 88,91103 & 2,567923 & 127,5983 & 3,822508 \\
\hline 6,873003 & 0,39371 & 51,53581 & 1,507306 & 90,17573 & 2,608202 & 128,8173 & 3,854969 \\
\hline 8,417358 & 0,442442 & 52,90783 & 1,541122 & 91,44061 & 2,64535 & 130,1038 & 3,902473 \\
\hline 9,852005 & 0,481668 & 54,22735 & 1,574198 & 92,7528 & 2,687946 & 131,368 & 3,944755 \\
\hline 11,25229 & 0,52296 & 55,56453 & 1,609973 & 94,03638 & 2,728465 & 132,5684 & 3,984449 \\
\hline 12,74456 & 0,569507 & 56,91537 & 1,647218 & 95,23685 & 2,766587 & 133,839 & 4,024779 \\
\hline 14,30215 & 0,607708 & 58,3122 & 1,679062 & 96,44353 & 2,80585 & 135,0828 & 4,065525 \\
\hline 15,81864 & 0,648674 & 59,63148 & 1,714072 & 97,67228 & 2,843054 & 136,327 & 4,107714 \\
\hline 17,21933 & 0,686628 & 60,85683 & 1,745183 & 98,91465 & 2,882686 & 137,6261 & 4,14826 \\
\hline 18,68362 & 0,717049 & 62,17948 & 1,783337 & 100,1861 & 2,917026 & 138,9354 & 4,187982 \\
\hline 20,17768 & 0,759062 & 63,51519 & 1,81801 & 101,4383 & 2,959797 & 140,1751 & 4,225824 \\
\hline 21,66407 & 0,793396 & 64,77309 & 1,854413 & 102,6928 & 3,001897 & 141,4769 & 4,265968 \\
\hline 23,14286 & 0,828815 & 66,07809 & 1,889136 & 103,9402 & 3,04518 & 142,7221 & 4,306783 \\
\hline 24,59656 & 0,859782 & 67,36092 & 1,931883 & 105,1981 & 3,08693 & 143,9664 & 4,345016 \\
\hline 26,03113 & 0,897513 & 68,61646 & 1,96419 & 106,4703 & 3,12363 & 145,2621 & 4,387346 \\
\hline 27,54775 & 0,930623 & 69,89266 & 2,002057 & 107,6802 & 3,168691 & 146,5276 & 4,42853 \\
\hline 29,0215 & 0,967448 & 71,19906 & 2,036842 & 108,9354 & 3,207061 & 147,7883 & 4,46744 \\
\hline 30,48109 & 0,999179 & 72,51027 & 2,077445 & 110,1771 & 3,247949 & 149,1144 & 4,505798 \\
\hline 31,98889 & 1,033728 & 73,7748 & 2,107481 & 111,3924 & 3,287683 & 150,4334 & 4,544427 \\
\hline 33,41287 & 1,068202 & 75,08715 & 2,151326 & 112,6689 & 3,327337 & 151,779 & 4,581982 \\
\hline 34,8301 & 1,102717 & 76,345 & 2,184843 & 113,8796 & 3,367437 & 153,0554 & 4,623317 \\
\hline 36,22113 & 1,13391 & 77,60467 & 2,227177 & 115,1178 & 3,411742 & 154,4044 & 4,662575 \\
\hline 37,69694 & 1,172606 & 78,84266 & 2,264572 & 116,3379 & 3,454967 & 155,7716 & 4,694319 \\
\hline 39,1024 & 1,200374 & 80,13918 & 2,299258 & 117,5645 & 3,488656 & 157,0902 & 4,733829 \\
\hline 40,52426 & 1,233862 & 81,40086 & 2,337991 & 118,7996 & 3,531344 & 158,4628 & 4,767587 \\
\hline
\end{tabular}

Segundo Método - Pares tensão / deformação obtidos nos ensaios uniaxiais da segunda réplica da condição irradiada com 100 kGy. 


\begin{tabular}{|c|c|c|c|c|c|c|c|}
\hline $\begin{array}{c}\text { Extensão } \\
(\%)\end{array}$ & $\begin{array}{c}\text { Tensão } \\
\text { MPa }\end{array}$ & $\begin{array}{c}\text { Extensão } \\
\text { (\%) }\end{array}$ & $\begin{array}{c}\text { Tensão } \\
\text { MPa }\end{array}$ & $\begin{array}{c}\text { Extensão } \\
(\%)\end{array}$ & $\begin{array}{c}\text { Tensão } \\
\text { MPa }\end{array}$ & $\begin{array}{c}\text { Extensão } \\
(\%)\end{array}$ & $\begin{array}{c}\text { Tensão } \\
\text { MPa }\end{array}$ \\
\hline 0,001355 & 0,000874 & 41,78002 & 1,446448 & 81,44175 & 2,710708 & 120,1455 & 4,05298 \\
\hline 0,051198 & 0,090748 & 43,11788 & 1,488014 & 82,73246 & 2,752428 & 121,4543 & 4,095934 \\
\hline 1,168431 & 0,14157 & 44,43358 & 1,529085 & 83,95154 & 2,8013 & 122,6899 & 4,13703 \\
\hline 2,474074 & 0,218707 & 45,73499 & 1,566795 & 85,17517 & 2,843661 & 123,9539 & 4,183891 \\
\hline 3,7871 & 0,286467 & 47,0867 & 1,604095 & 86,42928 & 2,884442 & 125,2175 & 4,226248 \\
\hline 5,127354 & 0,348337 & 48,41127 & 1,645664 & 87,63705 & 2,927296 & 126,5591 & 4,270573 \\
\hline 6,51582 & 0,410813 & 49,72899 & 1,68474 & 88,86624 & 2,974179 & 127,8522 & 4,311236 \\
\hline 7,942143 & 0,467126 & 50,9739 & 1,71711 & 90,11795 & 3,017498 & 129,1427 & 4,351827 \\
\hline 9,38924 & 0,513967 & 52,25664 & 1,757408 & 91,38967 & 3,061056 & 130,4786 & 4,394799 \\
\hline 10,74879 & 0,561386 & 53,5458 & 1,796009 & 92,67208 & 3,102203 & 131,7148 & 4,430908 \\
\hline 12,20567 & 0,607568 & 54,79778 & 1,837708 & 93,96104 & 3,147607 & 132,9897 & 4,47147 \\
\hline 13,6823 & 0,657038 & 56,11343 & 1,877022 & 95,15513 & 3,186887 & 134,2763 & 4,518693 \\
\hline 15,1221 & 0,701305 & 57,46193 & 1,918165 & 96,36411 & 3,225348 & 135,6424 & 4,554092 \\
\hline 16,5698 & 0,74002 & 58,75617 & 1,963778 & 97,59185 & 3,272169 & 136,9095 & 4,595345 \\
\hline 17,99323 & 0,782366 & 60,0362 & 2,00098 & 98,82388 & 3,314943 & 138,2804 & 4,637026 \\
\hline 19,41675 & 0,825774 & 61,3334 & 2,043744 & 100,0924 & 3,362076 & 139,5723 & 4,672263 \\
\hline 20,8594 & 0,863966 & 62,59344 & 2,085651 & 101,3338 & 3,40784 & 140,9081 & 4,712616 \\
\hline 22,25517 & 0,907985 & 63,91936 & 2,124637 & 102,5979 & 3,453768 & 142,1963 & 4,756212 \\
\hline 23,73604 & 0,944969 & 65,21162 & 2,163327 & 103,8441 & 3,495904 & 143,5377 & 4,791424 \\
\hline 25,14389 & 0,987104 & 66,44722 & 2,203102 & 105,1 & 3,537705 & 144,837 & 4,832654 \\
\hline 26,52884 & 1,025657 & 67,70717 & 2,248602 & 106,3854 & 3,580557 & 146,1913 & 4,873245 \\
\hline 27,97769 & 1,061306 & 68,94527 & 2,289687 & 107,6072 & 3,621882 & 147,4829 & 4,907909 \\
\hline 29,37165 & 1,103074 & 70,22796 & 2,329388 & 108,8673 & 3,666319 & 148,8409 & 4,945281 \\
\hline 30,82771 & 1,143412 & 71,46619 & 2,374708 & 110,1307 & 3,709883 & 150,2343 & 4,983207 \\
\hline 32,24504 & 1,179733 & 72,76959 & 2,413401 & 111,3537 & 3,750373 & 151,6085 & 5,017108 \\
\hline 33,58585 & 1,215874 & 74,00314 & 2,457584 & 112,6484 & 3,799773 & 152,9474 & 5,053605 \\
\hline 34,96486 & 1,257057 & 75,26736 & 2,498512 & 113,8919 & 3,83924 & 154,3501 & 5,088598 \\
\hline 36,30356 & 1,296777 & 76,48164 & 2,539962 & 115,1364 & 3,882323 & 155,77 & 5,121128 \\
\hline 37,72119 & 1,331858 & 77,70487 & 2,583083 & 116,3784 & 3,925457 & 157,1459 & 5,152316 \\
\hline 39,05035 & 1,371076 & 78,91723 & 2,628563 & 117,627 & 3,972096 & 158,5478 & 5,185072 \\
\hline
\end{tabular}
condição irradiada com 100 kGy. 


\begin{tabular}{|c|c|c|c|c|c|c|c|}
\hline $\begin{array}{c}\text { Extensão } \\
(\%)\end{array}$ & $\begin{array}{c}\text { Tensão } \\
\text { MPa }\end{array}$ & $\begin{array}{c}\text { Extensão } \\
\text { (\%) }\end{array}$ & $\begin{array}{c}\text { Tensão } \\
\text { MPa }\end{array}$ & $\begin{array}{c}\text { Extensão } \\
\text { (\%) }\end{array}$ & $\begin{array}{c}\text { Tensão } \\
\text { MPa }\end{array}$ & $\begin{array}{c}\text { Extensão } \\
(\%)\end{array}$ & $\begin{array}{c}\text { Tensão } \\
\text { MPa }\end{array}$ \\
\hline 0,638556 & 0,197285 & 32,40183 & 1,521533 & 61,67258 & 2,744532 & 89,83681 & 4,066045 \\
\hline 1,978769 & 0,269124 & 33,69428 & 1,574223 & 62,90558 & 2,798229 & 91,09628 & 4,123165 \\
\hline 3,303582 & 0,354928 & 35,01492 & 1,625592 & 64,15386 & 2,855826 & 92,35574 & 4,181264 \\
\hline 4,649394 & 0,432743 & 36,2976 & 1,673196 & 65,41153 & 2,910636 & 93,61886 & 4,2361 \\
\hline 6,072714 & 0,505192 & 37,59113 & 1,717997 & 66,60411 & 2,969199 & 94,82463 & 4,290754 \\
\hline 7,462726 & 0,571895 & 38,81542 & 1,765425 & 67,8356 & 3,025173 & 96,05169 & 4,350457 \\
\hline 8,828945 & 0,626336 & 40,13457 & 1,821451 & 69,02164 & 3,082642 & 97,31235 & 4,411032 \\
\hline 10,20088 & 0,682953 & 41,40384 & 1,874079 & 70,25065 & 3,143209 & 98,5179 & 4,467753 \\
\hline 11,64994 & 0,743478 & 42,67771 & 1,92825 & 71,46589 & 3,196335 & 99,80056 & 4,527039 \\
\hline 13,08311 & 0,801412 & 43,97087 & 1,982124 & 72,73997 & 3,256731 & 101,0474 & 4,579243 \\
\hline 14,51531 & 0,853405 & 45,23676 & 2,034883 & 73,94321 & 3,310668 & 102,3067 & 4,63662 \\
\hline 15,90177 & 0,906874 & 46,53152 & 2,08765 & 75,16968 & 3,370217 & 103,5406 & 4,690396 \\
\hline 17,28313 & 0,9615 & 47,83517 & 2,140996 & 76,36783 & 3,428743 & 104,8227 & 4,750895 \\
\hline 18,69577 & 1,01588 & 49,11733 & 2,193967 & 77,5914 & 3,484512 & 106,1366 & 4,80291 \\
\hline 20,04884 & 1,063603 & 50,33839 & 2,249931 & 78,77146 & 3,541506 & 107,426 & 4,857444 \\
\hline 21,4227 & 1,112282 & 51,58812 & 2,297975 & 80,03499 & 3,602858 & 108,7264 & 4,912156 \\
\hline 22,78554 & 1,16734 & 52,86865 & 2,352707 & 81,23837 & 3,65401 & 110,0092 & 4,967071 \\
\hline 24,20978 & 1,220857 & 54,09859 & 2,408102 & 82,53654 & 3,716271 & 111,2658 & 5,020866 \\
\hline 25,53262 & 1,268535 & 55,35373 & 2,461618 & 83,7217 & 3,772728 & 112,6283 & 5,071828 \\
\hline 26,88221 & 1,317829 & 56,57568 & 2,521225 & 84,96097 & 3,833653 & 113,901 & 5,123896 \\
\hline 28,30479 & 1,371339 & 57,91954 & 2,572852 & 86,1644 & 3,89193 & 115,205 & 5,177145 \\
\hline 29,64668 & 1,420423 & 59,14957 & 2,628898 & 87,3683 & 3,951068 & 116,5395 & 5,222335 \\
\hline 31,03035 & 1,468757 & 60,40495 & 2,688297 & 88,58248 & 4,005004 & & \\
\hline
\end{tabular}

Segundo Método - Pares tensão / deformação obtidos nos ensaios uniaxiais da primeira réplica da condição irradiada com 250 kGy. 


\begin{tabular}{|c|c|c|c|c|c|c|c|}
\hline $\begin{array}{c}\text { Extensão } \\
(\%)\end{array}$ & $\begin{array}{c}\text { Tensão } \\
\text { MPa }\end{array}$ & $\begin{array}{c}\text { Extensão } \\
\text { (\%) }\end{array}$ & $\begin{array}{c}\text { Tensão } \\
\text { MPa }\end{array}$ & $\begin{array}{c}\text { Extensão } \\
\text { (\%) }\end{array}$ & $\begin{array}{c}\text { Tensão } \\
\text { MPa }\end{array}$ & $\begin{array}{c}\text { Extensão } \\
(\%)\end{array}$ & $\begin{array}{c}\text { Tensão } \\
\text { MPa }\end{array}$ \\
\hline 0,494955 & 0,181727 & 32,5906 & 1,405157 & 62,02046 & 2,539298 & 89,98137 & 3,799918 \\
\hline 1,829585 & 0,250939 & 33,90827 & 1,452007 & 63,28903 & 2,591354 & 91,21986 & 3,853114 \\
\hline 3,159124 & 0,332952 & 35,25657 & 1,497756 & 64,51796 & 2,643538 & 92,48993 & 3,907963 \\
\hline 4,51941 & 0,402944 & 36,53784 & 1,54045 & 65,76747 & 2,698064 & 93,73137 & 3,968715 \\
\hline 5,935121 & 0,470725 & 37,88233 & 1,595992 & 66,96436 & 2,754086 & 94,89544 & 4,026204 \\
\hline 7,371318 & 0,529978 & 39,19518 & 1,639237 & 68,19427 & 2,80799 & 96,07185 & 4,084754 \\
\hline 8,752591 & 0,579045 & 40,43784 & 1,680981 & 69,3969 & 2,861697 & 97,29526 & 4,141137 \\
\hline 10,14572 & 0,63008 & 41,71067 & 1,72987 & 70,62702 & 2,913526 & 98,51729 & 4,196413 \\
\hline 11,61573 & 0,685905 & 43,00945 & 1,777297 & 71,84811 & 2,967599 & 99,76529 & 4,254038 \\
\hline 13,04398 & 0,739522 & 44,26888 & 1,826705 & 73,07452 & 3,022365 & 100,9776 & 4,307539 \\
\hline 14,49052 & 0,788469 & 45,52645 & 1,878098 & 74,30358 & 3,077024 & 102,2307 & 4,361433 \\
\hline 15,94228 & 0,838157 & 46,8472 & 1,927791 & 75,50997 & 3,132124 & 103,4379 & 4,420606 \\
\hline 17,30845 & 0,885399 & 48,10937 & 1,976162 & 76,68405 & 3,182992 & 104,6755 & 4,472836 \\
\hline 18,73825 & 0,938289 & 49,41509 & 2,025139 & 77,89898 & 3,238123 & 105,9576 & 4,527297 \\
\hline 20,12262 & 0,980577 & 50,66035 & 2,076923 & 79,07209 & 3,297207 & 107,1955 & 4,586409 \\
\hline 21,50325 & 1,027506 & 51,9615 & 2,127315 & 80,28676 & 3,352887 & 108,4528 & 4,642657 \\
\hline 22,9345 & 1,075868 & 53,20069 & 2,17364 & 81,55341 & 3,411316 & 109,6895 & 4,694253 \\
\hline 24,31029 & 1,123094 & 54,44113 & 2,231782 & 82,77214 & 3,463329 & 110,9062 & 4,751122 \\
\hline 25,63947 & 1,169643 & 55,71224 & 2,278647 & 83,95334 & 3,520295 & 112,2338 & 4,803733 \\
\hline 27,05396 & 1,214494 & 57,00227 & 2,328424 & 85,18025 & 3,574098 & 113,4529 & 4,857574 \\
\hline 28,45248 & 1,261646 & 58,3075 & 2,380512 & 86,39634 & 3,632327 & 114,7299 & 4,909444 \\
\hline 29,82861 & 1,311637 & 59,5477 & 2,431791 & 87,55999 & 3,686057 & 116,0116 & 4,957575 \\
\hline 31,22436 & 1,357589 & 60,74678 & 2,487444 & 88,76855 & 3,740908 & 117,3001 & 5,004075 \\
\hline
\end{tabular}

Segundo Método - Pares tensão / deformação obtidos nos ensaios uniaxiais da segunda réplica da condição irradiada com 250 kGy. 


\begin{tabular}{|c|c|c|c|c|c|c|c|}
\hline $\begin{array}{c}\text { Extensão } \\
(\%)\end{array}$ & $\begin{array}{c}\text { Tensão } \\
\text { MPa }\end{array}$ & $\begin{array}{c}\text { Extensão } \\
\text { (\%) }\end{array}$ & $\begin{array}{c}\text { Tensão } \\
\text { MPa }\end{array}$ & $\begin{array}{c}\text { Extensão } \\
(\%)\end{array}$ & $\begin{array}{c}\text { Tensão } \\
\text { MPa }\end{array}$ & $\begin{array}{c}\text { Extensão } \\
\text { (\%) }\end{array}$ & $\begin{array}{c}\text { Tensão } \\
\text { MPa }\end{array}$ \\
\hline 0,354546 & 0,093981 & 35,20921 & 1,397417 & 66,93248 & 2,616177 & 97,26212 & 3,959419 \\
\hline 1,768787 & 0,154701 & 36,56315 & 1,446947 & 68,22393 & 2,667709 & 98,4845 & 4,018008 \\
\hline 3,335611 & 0,220813 & 37,98594 & 1,492227 & 69,469 & 2,722306 & 99,77294 & 4,07764 \\
\hline 4,677974 & 0,305983 & 39,36301 & 1,542559 & 70,75266 & 2,778892 & 101,0299 & 4,139074 \\
\hline 6,066011 & 0,3723 & 40,73006 & 1,588253 & 72,04054 & 2,832573 & 102,3195 & 4,191998 \\
\hline 7,604814 & 0,439216 & 42,03526 & 1,637001 & 73,3008 & 2,888397 & 103,5644 & 4,250202 \\
\hline 9,131451 & 0,502936 & 43,31017 & 1,674639 & 74,60772 & 2,942859 & 104,8507 & 4,303526 \\
\hline 10,53293 & 0,558578 & 44,64916 & 1,730026 & 75,84722 & 2,998341 & 106,1566 & 4,364727 \\
\hline 11,98299 & 0,611467 & 45,95723 & 1,782165 & 77,098 & 3,052873 & 107,4262 & 4,419409 \\
\hline 13,49484 & 0,664483 & 47,31987 & 1,832556 & 78,33789 & 3,110755 & 108,7281 & 4,472629 \\
\hline 15,01777 & 0,716873 & 48,67595 & 1,881868 & 79,59496 & 3,163828 & 110,0124 & 4,528418 \\
\hline 16,50049 & 0,769865 & 49,99701 & 1,934814 & 80,85271 & 3,219279 & 111,2539 & 4,584152 \\
\hline 17,92412 & 0,820296 & 51,27952 & 1,981321 & 82,17143 & 3,275713 & 112,5907 & 4,644643 \\
\hline 19,37696 & 0,87132 & 52,63331 & 2,036227 & 83,40104 & 3,333971 & 113,8518 & 4,69854 \\
\hline 20,88792 & 0,920662 & 53,92799 & 2,087451 & 84,67841 & 3,395405 & 115,1427 & 4,751456 \\
\hline 22,33028 & 0,965205 & 55,24091 & 2,137098 & 85,89938 & 3,450556 & 116,4401 & 4,806892 \\
\hline 23,831 & 1,015154 & 56,51221 & 2,188639 & 87,14195 & 3,505766 & 117,7324 & 4,861064 \\
\hline 25,25021 & 1,063577 & 57,90502 & 2,237267 & 88,35782 & 3,560603 & 119,0534 & 4,911121 \\
\hline 26,67524 & 1,112928 & 59,22461 & 2,293669 & 89,64173 & 3,620081 & 120,3851 & 4,960097 \\
\hline 28,14391 & 1,158302 & 60,50439 & 2,343879 & 90,91514 & 3,67486 & 121,7771 & 5,00835 \\
\hline 29,55981 & 1,207758 & 61,82896 & 2,400523 & 92,19843 & 3,731064 & 123,1973 & 5,047888 \\
\hline 31,03226 & 1,256215 & 63,1246 & 2,451566 & 93,48654 & 3,78892 & & \\
\hline 32,45509 & 1,304157 & 64,3941 & 2,505262 & 94,7222 & 3,845463 & & \\
\hline 33,83385 & 1,34827 & 65,73351 & 2,561531 & 95,98993 & 3,90196 & & \\
\hline
\end{tabular}

Segundo Método - Pares tensão / deformação obtidos nos ensaios uniaxiais da terceira réplica réplica da condição irradiada com 250 kGy. 


\begin{tabular}{|c|c|c|c|c|c|c|c|}
\hline $\begin{array}{c}\text { Extensão } \\
\text { (\%) }\end{array}$ & $\begin{array}{c}\text { Tensão } \\
\text { MPa }\end{array}$ & $\begin{array}{c}\text { Extensão } \\
(\%)\end{array}$ & $\begin{array}{c}\text { Tensão } \\
\text { MPa }\end{array}$ & $\begin{array}{c}\text { Extensão } \\
\text { (\%) }\end{array}$ & $\begin{array}{c}\text { Tensão } \\
\text { MPa }\end{array}$ & $\begin{array}{c}\text { Extensão } \\
\text { (\%) }\end{array}$ & $\begin{array}{c}\text { Tensão } \\
\text { MPa }\end{array}$ \\
\hline 0,1162 & 0,011244 & 12,5446 & 0,458905 & 26,3936 & 0,699013 & 40,1533 & 0,916633 \\
\hline 0,2323 & 0,022096 & 12,8216 & 0,464854 & 26,6885 & 0,702477 & 40,4392 & 0,920424 \\
\hline 0,3753 & 0,03347 & 13,0985 & 0,470083 & 26,9654 & 0,706661 & 40,6715 & 0,924608 \\
\hline 0,9471 & 0,069947 & 13,9295 & 0,487015 & 27,8232 & 0,720651 & 41,4667 & 0,939121 \\
\hline 1,1616 & 0,081583 & 14,1886 & 0,492636 & 28,0912 & 0,724573 & 41,7258 & 0,943958 \\
\hline 1,376 & 0,093219 & 14,4388 & 0,498258 & 28,3682 & 0,72928 & 41,9849 & 0,948665 \\
\hline 2,0908 & 0,128977 & 15,2786 & 0,51434 & 29,2528 & 0,74523 & 42,7801 & 0,961543 \\
\hline 2,341 & 0,13996 & 15,5646 & 0,519831 & 29,5119 & 0,750133 & 43,0482 & 0,965465 \\
\hline 2,5554 & 0,151465 & 15,8505 & 0,524799 & 29,8067 & 0,754513 & 43,2805 & 0,969584 \\
\hline 3,2702 & 0,18487 & 16,6903 & 0,539442 & 30,6109 & 0,767456 & 43,5485 & 0,97344 \\
\hline 3,5025 & 0,195787 & 16,9227 & 0,54428 & 30,8968 & 0,772555 & 43,8076 & 0,97697 \\
\hline 3,7348 & 0,206573 & 17,1907 & 0,549444 & 31,1916 & 0,776216 & 44,0489 & 0,981416 \\
\hline 4,4585 & 0,237101 & 18,0127 & 0,563499 & 31,9868 & 0,788506 & 44,3348 & 0,98573 \\
\hline 4,7087 & 0,246841 & 18,2808 & 0,568598 & 32,2727 & 0,793082 & 44,5671 & 0,99011 \\
\hline 4,9946 & 0,256647 & 18,5309 & 0,572912 & 32,5229 & 0,797135 & 44,8351 & 0,993182 \\
\hline 5,7898 & 0,284037 & 19,3619 & 0,588667 & 33,3449 & 0,809359 & 45,0853 & 0,997039 \\
\hline 6,0489 & 0,291424 & 19,6657 & 0,593308 & 33,6308 & 0,812889 & 45,3623 & 1,000962 \\
\hline 6,3259 & 0,300772 & 19,9158 & 0,598276 & 33,9078 & 0,817596 & 45,5678 & 1,004884 \\
\hline 7,1122 & 0,325025 & 20,7646 & 0,612462 & 34,7388 & 0,82982 & 45,809 & 1,008283 \\
\hline 7,416 & 0,332739 & 21,0238 & 0,617626 & 35,0336 & 0,834723 & 46,0503 & 1,012271 \\
\hline 7,6661 & 0,340257 & 21,2829 & 0,622006 & 35,2927 & 0,839038 & 46,3094 & 1,015866 \\
\hline 8,4524 & 0,362287 & 22,1406 & 0,635145 & 36,0969 & 0,852243 & 46,5417 & 1,020181 \\
\hline 8,7115 & 0,369216 & 22,4444 & 0,639983 & 36,3649 & 0,856361 & 46,7561 & 1,024364 \\
\hline 9,0064 & 0,375884 & 22,7303 & 0,644297 & 36,6508 & 0,862898 & 47,0331 & 1,02881 \\
\hline 9,8284 & 0,397064 & 23,5881 & 0,65711 & 37,446 & 0,875449 & 47,2565 & 1,028483 \\
\hline 10,0964 & 0,403732 & 23,8561 & 0,661686 & 37,723 & 0,879437 & 47,4888 & 1,032601 \\
\hline 10,3555 & 0,409877 & 24,142 & 0,666262 & 37,991 & 0,883294 & 47,7568 & 1,034758 \\
\hline 11,1597 & 0,428311 & 24,9998 & 0,679009 & 38,7684 & 0,895061 & 47,9892 & 1,038485 \\
\hline 11,4545 & 0,434848 & 25,2767 & 0,682997 & 39,0454 & 0,899244 & 48,2304 & 1,040315 \\
\hline 11,7226 & 0,440601 & 25,5448 & 0,687704 & 39,3581 & 0,903755 & 48,4448 & 1,040446 \\
\hline
\end{tabular}

Segundo Método - Pares tensão / deformação obtidos nos ensaios equibiaxiais da primeira réplica da condição não irradiada. 


\begin{tabular}{|c|c|c|c|c|c|c|c|}
\hline $\begin{array}{c}\text { Extensão } \\
\text { (\%) }\end{array}$ & $\begin{array}{c}\text { Tensão } \\
\text { MPa }\end{array}$ & $\begin{array}{c}\text { Extensão } \\
\text { (\%) }\end{array}$ & $\begin{array}{c}\text { Tensão } \\
\text { MPa }\end{array}$ & $\begin{array}{c}\text { Extensão } \\
\text { (\%) }\end{array}$ & $\begin{array}{c}\text { Tensão } \\
\text { MPa }\end{array}$ & $\begin{array}{c}\text { Extensão } \\
\text { (\%) }\end{array}$ & $\begin{array}{c}\text { Tensão } \\
\text { MPa }\end{array}$ \\
\hline 0,2641 & 0,010971 & 12,3264 & 0,443503 & 25,4675 & 0,679347 & 38,1183 & 0,878138 \\
\hline 0,5356 & 0,022007 & 12,5452 & 0,448759 & 25,7089 & 0,683814 & 38,3823 & 0,882211 \\
\hline 0,7846 & 0,032781 & 12,8167 & 0,454868 & 25,9956 & 0,687361 & 39,6949 & 0,903365 \\
\hline 1,5088 & 0,064315 & 13,5787 & 0,471621 & 26,7726 & 0,699778 & 39,9514 & 0,907832 \\
\hline 1,7351 & 0,075023 & 13,8427 & 0,476876 & 27,0592 & 0,703916 & 40,223 & 0,911511 \\
\hline 1,9614 & 0,085928 & 14,0841 & 0,482132 & 27,3233 & 0,707858 & 40,4644 & 0,91519 \\
\hline 2,6252 & 0,117527 & 14,8686 & 0,49803 & 28,1304 & 0,720209 & 40,7359 & 0,918606 \\
\hline 2,8214 & 0,127776 & 15,1251 & 0,502628 & 28,402 & 0,723887 & 41,0075 & 0,922153 \\
\hline 3,0628 & 0,138155 & 15,3967 & 0,507424 & 28,666 & 0,727698 & 41,2564 & 0,926424 \\
\hline 3,7266 & 0,169163 & 16,1586 & 0,523191 & 29,4581 & 0,740377 & 41,5205 & 0,930431 \\
\hline 3,9529 & 0,179411 & 16,4453 & 0,527855 & 29,7221 & 0,745172 & 42,0259 & 0,938577 \\
\hline 4,1717 & 0,189923 & 16,6867 & 0,532585 & 29,9937 & 0,74964 & 42,2899 & 0,943241 \\
\hline 4,8355 & 0,219945 & 17,4863 & 0,545921 & 30,8009 & 0,763173 & 42,554 & 0,94784 \\
\hline 5,0467 & 0,230456 & 17,7503 & 0,550848 & 31,0347 & 0,766786 & 42,8029 & 0,951847 \\
\hline 5,2881 & 0,240967 & 18,0143 & 0,55571 & 31,3214 & 0,77145 & 43,0896 & 0,956183 \\
\hline 6,035 & 0,269807 & 18,814 & 0,56944 & 32,1286 & 0,783341 & 43,331 & 0,960585 \\
\hline 6,2613 & 0,278413 & 19,0629 & 0,573316 & 32,37 & 0,786954 & 43,5874 & 0,963344 \\
\hline 6,5329 & 0,286625 & 19,3194 & 0,578571 & 32,6642 & 0,790764 & 43,8515 & 0,968928 \\
\hline 7,2797 & 0,31126 & 20,1341 & 0,592498 & 33,4336 & 0,802721 & 44,0929 & 0,973264 \\
\hline 7,5437 & 0,319012 & 20,3981 & 0,596703 & 33,675 & 0,806203 & 44,3871 & 0,977731 \\
\hline 7,77 & 0,326896 & 20,6697 & 0,601367 & 33,9466 & 0,810079 & 44,6285 & 0,982198 \\
\hline 8,5093 & 0,348772 & 21,4392 & 0,614112 & 34,7236 & 0,822298 & 44,9 & 0,986534 \\
\hline 8,7507 & 0,355998 & 21,6881 & 0,619039 & 34,9876 & 0,826896 & 45,1657 & 0,990607 \\
\hline 8,9996 & 0,363422 & 21,9597 & 0,623375 & 35,2517 & 0,830838 & 45,4222 & 0,993957 \\
\hline 9,7766 & 0,38313 & 22,7669 & 0,636251 & 36,0136 & 0,844108 & 45,6636 & 0,998359 \\
\hline 10,018 & 0,389043 & 23,0309 & 0,640061 & 36,3002 & 0,847853 & 45,9201 & 1,002366 \\
\hline 10,2594 & 0,395481 & 23,2949 & 0,6442 & 36,5718 & 0,852386 & 46,1766 & 1,005914 \\
\hline 11,0213 & 0,415189 & 24,1398 & 0,657602 & 37,3488 & 0,865788 & 46,3878 & 1,009921 \\
\hline 11,2552 & 0,421167 & 24,3812 & 0,662397 & 37,6128 & 0,869992 & 46,6594 & 1,013994 \\
\hline 11,5494 & 0,426423 & 24,6603 & 0,666799 & 37,8769 & 0,874328 & 46,9008 & 1,017016 \\
\hline
\end{tabular}

Segundo Método - Pares tensão / deformação obtidos nos ensaios equibiaxiais da segunda réplica da condição não irradiada. 


\begin{tabular}{|c|c|c|c|c|c|c|c|}
\hline $\begin{array}{c}\text { Extensão } \\
\text { (\%) }\end{array}$ & $\begin{array}{c}\text { Tensão } \\
\text { MPa }\end{array}$ & $\begin{array}{c}\text { Extensão } \\
(\%)\end{array}$ & $\begin{array}{c}\text { Tensão } \\
\text { MPa }\end{array}$ & $\begin{array}{c}\text { Extensão } \\
\text { (\%) }\end{array}$ & $\begin{array}{c}\text { Tensão } \\
\text { MPa }\end{array}$ & $\begin{array}{c}\text { Extensão } \\
(\%)\end{array}$ & $\begin{array}{c}\text { Tensão } \\
\text { MPa }\end{array}$ \\
\hline 0,1808 & 0,011505 & 11,9463 & 0,457597 & 25,388 & 0,695744 & 38,4928 & 0,906108 \\
\hline 0,3287 & 0,022357 & 12,2257 & 0,463219 & 25,6427 & 0,700974 & 38,7146 & 0,909442 \\
\hline 0,4683 & 0,033012 & 12,505 & 0,468841 & 25,9303 & 0,705419 & 38,9775 & 0,913887 \\
\hline 1,027 & 0,065502 & 13,2773 & 0,485184 & 26,6944 & 0,717578 & 39,717 & 0,925981 \\
\hline 1,1996 & 0,076680 & 13,5567 & 0,490937 & 26,9491 & 0,721762 & 39,9963 & 0,930164 \\
\hline 1,3721 & 0,087793 & 13,8278 & 0,496297 & 27,2448 & 0,726272 & 40,251 & 0,933760 \\
\hline 1,9965 & 0,121263 & 14,6412 & 0,512247 & 28,05 & 0,740785 & 40,9987 & 0,945461 \\
\hline 2,202 & 0,132638 & 14,9124 & 0,517346 & 28,3047 & 0,744576 & 41,2534 & 0,950103 \\
\hline 2,4156 & 0,144274 & 15,1671 & 0,522445 & 28,5594 & 0,749087 & 41,4999 & 0,954221 \\
\hline 3,1386 & 0,177548 & 15,9065 & 0,538657 & 29,3482 & 0,760788 & 42,2229 & 0,967230 \\
\hline 3,3522 & 0,188399 & 16,1859 & 0,543756 & 29,6193 & 0,764972 & 42,4941 & 0,971675 \\
\hline 3,5658 & 0,199512 & 16,4652 & 0,548202 & 29,874 & 0,768371 & 42,7241 & 0,977166 \\
\hline 4,2724 & 0,232525 & 17,2868 & 0,563237 & 30,6463 & 0,781903 & 43,4471 & 0,989325 \\
\hline 4,4943 & 0,242723 & 17,5662 & 0,568205 & 30,9257 & 0,785760 & 43,71 & 0,994228 \\
\hline 4,7572 & 0,252528 & 17,8291 & 0,572650 & 31,1968 & 0,789944 & 43,9319 & 0,998020 \\
\hline 5,4884 & 0,280769 & 18,6672 & 0,585463 & 31,9938 & 0,802626 & 44,6796 & 1,00959 \\
\hline 5,7431 & 0,290117 & 18,9219 & 0,589778 & 32,2156 & 0,806875 & 44,9178 & 1,013578 \\
\hline 5,9978 & 0,298942 & 19,1766 & 0,593896 & 32,4868 & 0,811516 & 45,1561 & 1,018481 \\
\hline 6,7784 & 0,323587 & 19,9982 & 0,607558 & 33,2919 & 0,823479 & 45,8873 & 1,029267 \\
\hline 7,0413 & 0,331170 & 20,2529 & 0,612657 & 33,5713 & 0,827597 & 46,1338 & 1,033712 \\
\hline 7,2713 & 0,338883 & 20,5076 & 0,616906 & 33,8342 & 0,831912 & 46,3474 & 1,037765 \\
\hline 8,019 & 0,361633 & 21,3128 & 0,630111 & 34,623 & 0,842763 & 47,0622 & 1,051559 \\
\hline 8,2984 & 0,368104 & 21,5839 & 0,634426 & 34,8612 & 0,847078 & 47,2923 & 1,0562 \\
\hline 8,5531 & 0,375622 & 21,8468 & 0,639721 & 35,1324 & 0,851262 & 47,5059 & 1,060841 \\
\hline 9,3336 & 0,396410 & 22,652 & 0,653253 & 35,9375 & 0,863682 & 48,2207 & 1,073131 \\
\hline 9,6129 & 0,403993 & 22,9149 & 0,657371 & 36,184 & 0,867212 & 48,4261 & 1,077315 \\
\hline 9,8594 & 0,410269 & 23,2025 & 0,661882 & 36,447 & 0,872050 & 48,6726 & 1,081237 \\
\hline 10,6482 & 0,428965 & 23,9666 & 0,674564 & 37,2193 & 0,885124 & 49,1327 & 1,088036 \\
\hline 10,9111 & 0,435502 & 24,2624 & 0,679205 & 37,4822 & 0,889177 & 49,3546 & 1,091762 \\
\hline 11,1658 & 0,440993 & 24,5499 & 0,682997 & 37,7287 & 0,891007 & 49,5435 & 1,094834 \\
\hline
\end{tabular}

Segundo Método - Pares tensão / deformação obtidos nos ensaios equibiaxiais da terceira réplica da condição não irradiada. 


\begin{tabular}{|c|c|c|c|c|c|c|c|}
\hline $\begin{array}{c}\text { Extensão } \\
\text { (\%) }\end{array}$ & $\begin{array}{c}\text { Tensão } \\
\text { MPa }\end{array}$ & $\begin{array}{c}\text { Extensão } \\
\text { (\%) }\end{array}$ & $\begin{array}{c}\text { Tensão } \\
\text { MPa }\end{array}$ & $\begin{array}{c}\text { Extensão } \\
\text { (\%) }\end{array}$ & $\begin{array}{c}\text { Tensão } \\
\text { MPa }\end{array}$ & $\begin{array}{c}\text { Extensão } \\
\text { (\%) }\end{array}$ & $\begin{array}{c}\text { Tensão } \\
\text { MPa }\end{array}$ \\
\hline 0,1676 & 0,015383 & 9,0756 & 0,449736 & 18,1893 & 0,690581 & 27,5011 & 0,890559 \\
\hline 0,3658 & 0,029907 & 9,3347 & 0,457923 & 18,4788 & 0,696391 & 27,7678 & 0,896633 \\
\hline 0,5258 & 0,044564 & 9,609 & 0,466637 & 18,7227 & 0,702069 & 28,0345 & 0,902047 \\
\hline 0,6858 & 0,058891 & 9,8986 & 0,47423 & 18,9894 & 0,707747 & 28,3317 & 0,908187 \\
\hline 0,8839 & 0,073679 & 10,1805 & 0,482416 & 19,2637 & 0,714349 & 28,5755 & 0,913667 \\
\hline 1,1125 & 0,088864 & 10,4548 & 0,490801 & 19,5533 & 0,720159 & 28,8651 & 0,919873 \\
\hline 1,3411 & 0,102729 & 10,7139 & 0,498856 & 19,8124 & 0,726233 & 29,1394 & 0,926343 \\
\hline 1,5621 & 0,116989 & 10,973 & 0,506316 & 20,1019 & 0,732307 & 29,429 & 0,932219 \\
\hline 1,7831 & 0,131514 & 11,2626 & 0,513842 & 20,3763 & 0,73838 & 29,6881 & 0,937368 \\
\hline 2,0117 & 0,14518 & 11,514 & 0,521699 & 20,6506 & 0,744785 & 29,9319 & 0,943376 \\
\hline 2,7509 & 0,186444 & 12,3294 & 0,542892 & 20,9401 & 0,750858 & 30,7244 & 0,960014 \\
\hline 3,0176 & 0,20011 & 12,5961 & 0,550682 & 21,2145 & 0,756998 & 31,0292 & 0,965097 \\
\hline 3,269 & 0,213842 & 12,8628 & 0,558011 & 21,504 & 0,762742 & 31,2731 & 0,969983 \\
\hline 3,5129 & 0,227245 & 13,1066 & 0,565537 & 21,7784 & 0,768816 & 31,5474 & 0,976057 \\
\hline 3,7644 & 0,240581 & 13,3734 & 0,572469 & 22,0298 & 0,774824 & 31,8217 & 0,982131 \\
\hline 4,0234 & 0,253389 & 13,6401 & 0,579203 & 22,8528 & 0,792386 & 32,0884 & 0,987478 \\
\hline 4,2825 & 0,266461 & 13,9449 & 0,58607 & 23,1195 & 0,798328 & 32,3323 & 0,993024 \\
\hline 4,5416 & 0,278807 & 14,2116 & 0,593002 & 23,3938 & 0,803873 & 32,6142 & 0,998768 \\
\hline 4,7931 & 0,291285 & 14,5088 & 0,599868 & 23,6682 & 0,809089 & 32,919 & 1,004314 \\
\hline 5,0522 & 0,302707 & 14,7678 & 0,606866 & 23,9272 & 0,815493 & 33,1629 & 1,010388 \\
\hline 5,8599 & 0,336708 & 15,0193 & 0,613138 & 24,2016 & 0,821765 & 34,1458 & 1,031646 \\
\hline 6,1418 & 0,347601 & 15,2784 & 0,619806 & 24,4911 & 0,827377 & 34,3897 & 1,036928 \\
\hline 6,4085 & 0,357967 & 15,5298 & 0,626144 & 24,7502 & 0,832263 & 34,6412 & 1,042342 \\
\hline 6,6752 & 0,368068 & 15,7966 & 0,632483 & 25,0245 & 0,837544 & 34,8926 & 1,048284 \\
\hline 6,9267 & 0,378169 & 16,0709 & 0,638821 & 25,3217 & 0,84342 & 35,1288 & 1,054754 \\
\hline 7,1934 & 0,387676 & 16,33 & 0,645687 & 25,6037 & 0,84956 & 35,3879 & 1,06063 \\
\hline 7,4373 & 0,396655 & 16,6119 & 0,652289 & 25,8475 & 0,855568 & 35,6318 & 1,066638 \\
\hline 7,7116 & 0,405436 & 16,8786 & 0,658363 & 26,1371 & 0,861576 & 35,9061 & 1,072448 \\
\hline 7,9707 & 0,414415 & 17,1453 & 0,665097 & 26,4266 & 0,86765 & 36,1499 & 1,077069 \\
\hline 8,245 & 0,423129 & 17,3968 & 0,671171 & 26,6705 & 0,873064 & 36,4014 & 1,079842 \\
\hline
\end{tabular}

Segundo Método - Pares tensão / deformação obtidos nos ensaios equibiaxiais da primeira réplica da condição irradiada com 100 kGy. 


\begin{tabular}{|c|c|c|c|c|c|c|c|}
\hline $\begin{array}{c}\text { Extensão } \\
(\%)\end{array}$ & $\begin{array}{c}\text { Tensão } \\
\text { MPa }\end{array}$ & $\begin{array}{c}\text { Extensão } \\
\text { (\%) }\end{array}$ & $\begin{array}{c}\text { Tensão } \\
\text { MPa }\end{array}$ & $\begin{array}{c}\text { Extensão } \\
\text { (\%) }\end{array}$ & $\begin{array}{c}\text { Tensão } \\
\text { MPa }\end{array}$ & $\begin{array}{c}\text { Extensão } \\
\text { (\%) }\end{array}$ & $\begin{array}{c}\text { Tensão } \\
\text { MPa }\end{array}$ \\
\hline 0,1664 & 0,012482 & 9,6825 & 0,49665 & 20,616 & 0,785443 & 31,6796 & 1,031666 \\
\hline 0,3399 & 0,025226 & 9,9428 & 0,504402 & 20,8763 & 0,791947 & 31,9399 & 1,038038 \\
\hline 0,499 & 0,039022 & 10,2176 & 0,512154 & 21,1438 & 0,798451 & 32,7425 & 1,054922 \\
\hline 0,7087 & 0,051898 & 10,4779 & 0,520366 & 21,4114 & 0,804823 & 32,9956 & 1,060309 \\
\hline 0,9039 & 0,0653 & 10,7382 & 0,528446 & 21,7151 & 0,811327 & 33,7766 & 1,077849 \\
\hline 1,1353 & 0,078899 & 10,9986 & 0,536789 & 22,5033 & 0,829196 & 34,8106 & 1,100185 \\
\hline 1,3523 & 0,092563 & 11,2589 & 0,54441 & 22,7564 & 0,835765 & 35,0782 & 1,105638 \\
\hline 2,1332 & 0,145447 & 12,3436 & 0,575549 & 23,0311 & 0,841875 & 35,3168 & 1,111156 \\
\hline 2,314 & 0,158521 & 12,6111 & 0,58271 & 23,3059 & 0,848247 & 35,5627 & 1,116675 \\
\hline 2,5092 & 0,171791 & 12,8787 & 0,589871 & 23,5446 & 0,853437 & 35,8375 & 1,122587 \\
\hline 2,7262 & 0,185258 & 13,1679 & 0,597425 & 24,3183 & 0,870189 & 36,0833 & 1,128237 \\
\hline 2,9142 & 0,198069 & 13,4427 & 0,604783 & 24,5931 & 0,875379 & 36,3364 & 1,133492 \\
\hline 3,1239 & 0,210945 & 13,703 & 0,611418 & 24,8751 & 0,879912 & 36,5678 & 1,138617 \\
\hline 3,3191 & 0,224149 & 13,9923 & 0,618776 & 25,1209 & 0,885956 & 36,8137 & 1,144923 \\
\hline 4,2302 & 0,276639 & 14,7877 & 0,63901 & 25,3813 & 0,892197 & 37,0451 & 1,15031 \\
\hline 4,4616 & 0,288661 & 15,0263 & 0,646302 & 26,1695 & 0,910657 & 37,2837 & 1,156288 \\
\hline 4,693 & 0,300092 & 15,2939 & 0,653397 & 26,4153 & 0,915978 & 37,5223 & 1,161938 \\
\hline 4,9172 & 0,311129 & 15,5614 & 0,660229 & 26,6756 & 0,921234 & 37,7826 & 1,167522 \\
\hline 5,1341 & 0,32256 & 15,829 & 0,667062 & 26,9432 & 0,926883 & 38,043 & 1,173566 \\
\hline 5,3583 & 0,333793 & 16,082 & 0,673631 & 27,2107 & 0,932073 & 38,2743 & 1,179216 \\
\hline 5,5752 & 0,34437 & 16,3568 & 0,679806 & 27,9989 & 0,948891 & 38,513 & 1,184734 \\
\hline 6,537 & 0,386678 & 17,1522 & 0,700434 & 28,252 & 0,955198 & 38,7516 & 1,190515 \\
\hline 6,7973 & 0,396992 & 17,4343 & 0,706544 & 28,5051 & 0,961636 & 38,9685 & 1,196559 \\
\hline 7,0648 & 0,406714 & 17,6801 & 0,713048 & 28,7727 & 0,967483 & 39,2072 & 1,201618 \\
\hline 7,3252 & 0,415977 & 17,9332 & 0,719946 & 29,033 & 0,973198 & 39,4386 & 1,207333 \\
\hline 7,5855 & 0,425569 & 18,2008 & 0,726975 & 29,7922 & 0,99133 & 39,7149 & 1,21226 \\
\hline 7,853 & 0,435357 & 18,9962 & 0,746946 & 30,0598 & 0,997176 & 39,9463 & 1,21653 \\
\hline 8,1206 & 0,444751 & 19,271 & 0,753253 & 30,3273 & 1,003155 & 40,1777 & 1,221523 \\
\hline 8,3809 & 0,453292 & 19,5168 & 0,759691 & 30,5877 & 1,008213 & 40,4091 & 1,226139 \\
\hline 8,6412 & 0,462358 & 19,7916 & 0,766326 & 30,8697 & 1,014651 & 40,655 & 1,229818 \\
\hline
\end{tabular}

Segundo Método - Pares tensão / deformação obtidos nos ensaios equibiaxiais da segunda réplica da condição irradiada com 100 kGy. 


\begin{tabular}{|c|c|c|c|c|c|c|c|}
\hline $\begin{array}{c}\text { Extensão } \\
(\%)\end{array}$ & $\begin{array}{c}\text { Tensão } \\
\text { MPa }\end{array}$ & $\begin{array}{c}\text { Extensão } \\
\text { (\%) }\end{array}$ & $\begin{array}{c}\text { Tensão } \\
\text { MPa }\end{array}$ & $\begin{array}{c}\text { Extensão } \\
\text { (\%) }\end{array}$ & $\begin{array}{c}\text { Tensão } \\
\text { MPa }\end{array}$ & $\begin{array}{c}\text { Extensão } \\
\text { (\%) }\end{array}$ & $\begin{array}{c}\text { Tensão } \\
\text { MPa }\end{array}$ \\
\hline 0,1742 & 0,014261 & 8,7479 & 0,447029 & 18,6622 & 0,712369 & 28,2963 & 0,931295 \\
\hline 0,3559 & 0,028191 & 9,013 & 0,456338 & 18,95 & 0,718905 & 28,5917 & 0,936576 \\
\hline 0,4847 & 0,042584 & 9,2629 & 0,464921 & 19,2227 & 0,72478 & 28,8492 & 0,942386 \\
\hline 0,6513 & 0,056646 & 9,5583 & 0,47324 & 19,4954 & 0,731581 & 29,084 & 0,948592 \\
\hline 0,7952 & 0,070907 & 9,8158 & 0,482087 & 19,768 & 0,738513 & 29,3339 & 0,953874 \\
\hline 0,9921 & 0,08563 & 10,0809 & 0,490273 & 20,0331 & 0,744719 & 29,5839 & 0,958627 \\
\hline 1,1815 & 0,100418 & 10,3536 & 0,497272 & 20,2982 & 0,751387 & 29,849 & 0,964041 \\
\hline 1,3936 & 0,115933 & 10,6187 & 0,505458 & 20,5709 & 0,757791 & 30,1141 & 0,969191 \\
\hline 1,6132 & 0,130854 & 10,8762 & 0,512919 & 20,8132 & 0,764129 & 30,3564 & 0,975859 \\
\hline 1,8632 & 0,145775 & 11,1791 & 0,520643 & 21,0859 & 0,769807 & 30,6291 & 0,981339 \\
\hline 2,5903 & 0,18816 & 11,982 & 0,544015 & 21,8812 & 0,787501 & 31,4319 & 0,998504 \\
\hline 2,8553 & 0,201827 & 12,2395 & 0,551739 & 22,1462 & 0,793641 & 31,6819 & 1,004908 \\
\hline 3,128 & 0,214965 & 12,4894 & 0,559199 & 22,4265 & 0,799715 & 31,9318 & 1,010124 \\
\hline 3,3931 & 0,228235 & 12,7545 & 0,566198 & 22,6916 & 0,806383 & 32,1893 & 1,014745 \\
\hline 3,6506 & 0,240581 & 13,0348 & 0,574186 & 22,9718 & 0,812655 & 32,462 & 1,020423 \\
\hline 3,8854 & 0,252597 & 13,3074 & 0,581118 & 23,2445 & 0,817606 & 32,7346 & 1,025441 \\
\hline 4,1353 & 0,264943 & 13,5725 & 0,587853 & 23,5096 & 0,824869 & 32,9997 & 1,031515 \\
\hline 4,3853 & 0,276365 & 13,8527 & 0,595313 & 23,7822 & 0,830348 & 33,28 & 1,037853 \\
\hline 4,6428 & 0,288315 & 14,1254 & 0,602443 & 24,0397 & 0,836488 & 33,5526 & 1,043729 \\
\hline 4,9079 & 0,300198 & 14,3905 & 0,608847 & 24,267 & 0,84243 & 33,848 & 1,049076 \\
\hline 5,6653 & 0,333011 & 15,1933 & 0,629248 & 25,0849 & 0,85953 & 34,3782 & 1,060828 \\
\hline 5,9228 & 0,344036 & 15,4584 & 0,636246 & 25,3349 & 0,86567 & 34,6206 & 1,066044 \\
\hline 6,1803 & 0,353742 & 15,7008 & 0,642782 & 25,6303 & 0,871612 & 34,8629 & 1,072316 \\
\hline 6,453 & 0,364041 & 15,9507 & 0,649384 & 25,9029 & 0,877355 & 35,1204 & 1,078456 \\
\hline 6,7256 & 0,37401 & 16,1855 & 0,656118 & 26,1604 & 0,883627 & 35,3704 & 1,083275 \\
\hline 6,968 & 0,383253 & 16,4961 & 0,662985 & 26,4255 & 0,889371 & 35,6279 & 1,088161 \\
\hline 7,2255 & 0,39276 & 16,746 & 0,669389 & 26,683 & 0,894983 & 35,8551 & 1,093443 \\
\hline 7,4679 & 0,402861 & 17,0338 & 0,676057 & 26,9406 & 0,901057 & 36,1126 & 1,098922 \\
\hline 7,7254 & 0,41184 & 17,314 & 0,682263 & 27,2056 & 0,907593 & 36,355 & 1,10427 \\
\hline 7,9981 & 0,420291 & 17,5867 & 0,688271 & 27,4707 & 0,914459 & 36,5746 & 1,108628 \\
\hline
\end{tabular}

Segundo Método - Pares tensão / deformação obtidos nos ensaios equibiaxiais da terceira réplica da condição irradiada com 100 kGy. 


\begin{tabular}{|c|c|c|c|c|c|c|c|}
\hline $\begin{array}{c}\text { Extensão } \\
(\%)\end{array}$ & $\begin{array}{c}\text { Tensão } \\
\text { MPa }\end{array}$ & $\begin{array}{c}\text { Extensão } \\
\text { (\%) }\end{array}$ & $\begin{array}{c}\text { Tensão } \\
\text { MPa }\end{array}$ & $\begin{array}{c}\text { Extensão } \\
\text { (\%) }\end{array}$ & $\begin{array}{c}\text { Tensão } \\
\text { MPa }\end{array}$ & $\begin{array}{c}\text { Extensão } \\
\text { (\%) }\end{array}$ & $\begin{array}{c}\text { Tensão } \\
\text { MPa }\end{array}$ \\
\hline 0,1225 & 0,017338 & 7,5981 & 0,487545 & 15,4655 & 0,783166 & & \\
\hline 0,2857 & 0,037211 & 7,8593 & 0,497681 & 15,694 & 0,791502 & 23,4226 & 1,036508 \\
\hline 0,4734 & 0,05635 & 8,1531 & 0,509084 & 16,0286 & 0,801038 & 23,6675 & 1,045244 \\
\hline 0,6856 & 0,075155 & 8,4142 & 0,520621 & 16,2898 & 0,810241 & 23,9286 & 1,053713 \\
\hline 0,9059 & 0,093561 & 8,6754 & 0,532025 & 16,5509 & 0,81891 & 24,198 & 1,063116 \\
\hline 1,1344 & 0,113033 & 8,9039 & 0,542961 & 16,8202 & 0,827579 & 24,4591 & 1,071385 \\
\hline 1,3711 & 0,131372 & 9,1487 & 0,553231 & 17,0569 & 0,836715 & 24,7284 & 1,079254 \\
\hline 1,6078 & 0,150511 & 9,4181 & 0,563834 & 17,2936 & 0,845051 & 24,9978 & 1,086856 \\
\hline 1,8526 & 0,16925 & 9,6792 & 0,57417 & 17,5629 & 0,853987 & 25,2589 & 1,095259 \\
\hline 2,0893 & 0,187122 & 9,9485 & 0,58444 & 17,8486 & 0,86359 & 25,5364 & 1,102327 \\
\hline 2,326 & 0,205794 & 10,2342 & 0,594977 & 18,1179 & 0,872192 & 25,8302 & 1,110063 \\
\hline 2,5627 & 0,223933 & 10,5035 & 0,605113 & 18,3872 & 0,880528 & 26,075 & 1,117265 \\
\hline 2,832 & 0,240471 & 10,7565 & 0,615249 & 18,6728 & 0,888931 & 26,3199 & 1,125001 \\
\hline 3,0686 & 0,25781 & 11,0176 & 0,624385 & 18,9585 & 0,895332 & 26,5973 & 1,13367 \\
\hline 3,3543 & 0,274281 & 11,2951 & 0,633988 & 19,236 & 0,907003 & 26,8259 & 1,141539 \\
\hline 3,6481 & 0,289886 & 11,5808 & 0,643858 & 19,5053 & 0,915472 & 27,2992 & 1,15541 \\
\hline 3,8848 & 0,305024 & 11,8174 & 0,653727 & 19,7746 & 0,923341 & 27,5359 & 1,163412 \\
\hline 4,1378 & 0,319828 & 12,1112 & 0,663397 & 20,0684 & 0,93141 & 27,8215 & 1,170881 \\
\hline 4,3989 & 0,333566 & 12,3724 & 0,673533 & 20,3296 & 0,939146 & 28,0827 & 1,17755 \\
\hline 4,6274 & 0,348237 & 12,6091 & 0,683136 & 20,5907 & 0,946281 & 28,3112 & 1,185819 \\
\hline 4,8886 & 0,362107 & 12,8457 & 0,692739 & 20,8519 & 0,955084 & 28,556 & 1,192221 \\
\hline 5,1579 & 0,375778 & 13,0906 & 0,701942 & 21,113 & 0,963219 & 28,8172 & 1,200356 \\
\hline 5,4272 & 0,389982 & 13,3273 & 0,711411 & 21,3579 & 0,971689 & 29,0783 & 1,208092 \\
\hline 5,721 & 0,402653 & 13,5884 & 0,720214 & 21,5945 & 0,979224 & 29,3232 & 1,214361 \\
\hline 5,9904 & 0,415657 & 13,8741 & 0,729483 & 21,8802 & 0,98776 & 29,5762 & 1,221213 \\
\hline 6,2515 & 0,42826 & 14,1352 & 0,738486 & 22,1577 & 0,996229 & 29,8455 & 1,229615 \\
\hline 6,5127 & 0,440664 & 14,3719 & 0,747088 & 22,4025 & 1,003565 & 30,0822 & 1,235617 \\
\hline 6,7493 & 0,452801 & 14,6657 & 0,756891 & 22,6881 & 1,011234 & 30,3025 & 1,242019 \\
\hline 7,035 & 0,464271 & 14,9513 & 0,765027 & 22,9411 & 1,019636 & 30,5474 & 1,24722 \\
\hline 7,2961 & 0,476341 & 15,2125 & 0,774363 & 23,2023 & 1,027905 & 30,8167 & 1,252422 \\
\hline
\end{tabular}

Segundo Método - Pares tensão / deformação obtidos nos ensaios equibiaxiais da primeira réplica da condição irradiada com 250 kGy. 


\begin{tabular}{|c|c|c|c|c|c|c|c|}
\hline $\begin{array}{c}\text { Extensão } \\
(\%)\end{array}$ & $\begin{array}{c}\text { Tensão } \\
\text { MPa }\end{array}$ & $\begin{array}{c}\text { Extensão } \\
(\%)\end{array}$ & $\begin{array}{c}\text { Tensão } \\
\text { MPa }\end{array}$ & $\begin{array}{c}\text { Extensão } \\
(\%)\end{array}$ & $\begin{array}{c}\text { Tensão } \\
\text { MPa }\end{array}$ & $\begin{array}{c}\text { Extensão } \\
(\%)\end{array}$ & $\begin{array}{c}\text { Tensão } \\
\text { MPa }\end{array}$ \\
\hline 0,1181 & 0,015647 & 6,7479 & 0,467166 & 14,7321 & 0,760894 & 22,2517 & 1,006229 \\
\hline 0,2598 & 0,032483 & 7,0314 & 0,478654 & 14,9841 & 0,769147 & 22,5116 & 1,014481 \\
\hline 0,4094 & 0,04912 & 7,2676 & 0,490405 & 15,2439 & 0,777862 & 22,7872 & 1,022008 \\
\hline 0,5905 & 0,065757 & 7,5196 & 0,501365 & 15,5038 & 0,786114 & 23,0627 & 1,029402 \\
\hline 0,7874 & 0,081206 & 7,7401 & 0,512192 & 15,74 & 0,795489 & 23,299 & 1,037325 \\
\hline 0,9448 & 0,09824 & 8,0078 & 0,523482 & 16,0077 & 0,80427 & 23,5352 & 1,044719 \\
\hline 1,1417 & 0,114349 & 8,307 & 0,533451 & 16,2439 & 0,813051 & 23,7242 & 1,05284 \\
\hline 1,3149 & 0,131052 & 8,5826 & 0,544807 & 16,5116 & 0,821369 & 23,9368 & 1,059244 \\
\hline 1,5039 & 0,147888 & 8,8424 & 0,555634 & 16,7636 & 0,829028 & 24,1179 & 1,067298 \\
\hline 1,7244 & 0,163997 & 9,1259 & 0,565141 & 17,0077 & 0,837545 & 24,3856 & 1,075221 \\
\hline 1,9291 & 0,180898 & 9,3936 & 0,575705 & 17,2911 & 0,845665 & 24,6769 & 1,081889 \\
\hline 2,0866 & 0,197536 & 9,6456 & 0,58574 & 17,5431 & 0,853258 & 24,9682 & 1,090472 \\
\hline 2,2755 & 0,213116 & 9,9448 & 0,595643 & 17,8187 & 0,861642 & 25,2517 & 1,098592 \\
\hline 2,4645 & 0,23015 & 10,2597 & 0,605282 & 18,0549 & 0,869037 & 25,5037 & 1,100771 \\
\hline 2,7007 & 0,245995 & 10,5668 & 0,615119 & 18,2911 & 0,877289 & 25,8108 & 1,114041 \\
\hline 2,9212 & 0,261774 & 10,8896 & 0,624692 & 18,5352 & 0,885938 & 26,0706 & 1,122888 \\
\hline 3,1102 & 0,277817 & 11,1573 & 0,634926 & 18,74 & 0,894983 & 26,3068 & 1,130811 \\
\hline 3,3621 & 0,29419 & 11,4408 & 0,645027 & 18,9211 & 0,903368 & 26,543 & 1,138469 \\
\hline 3,6456 & 0,309705 & 11,7007 & 0,65493 & 19,173 & 0,912413 & 26,8029 & 1,146128 \\
\hline 3,8976 & 0,324824 & 11,9605 & 0,663381 & 19,4092 & 0,920467 & 27,047 & 1,153984 \\
\hline 4,1338 & 0,339151 & 12,1888 & 0,673152 & 19,6612 & 0,928126 & 27,3383 & 1,160982 \\
\hline 4,3779 & 0,353411 & 12,4408 & 0,681933 & 19,9132 & 0,935586 & 27,6296 & 1,168839 \\
\hline 4,6613 & 0,367342 & 12,7164 & 0,690714 & 20,1573 & 0,943971 & 27,8973 & 1,176167 \\
\hline 4,9212 & 0,38048 & 12,9684 & 0,699692 & 20,4329 & 0,952223 & 28,1493 & 1,183231 \\
\hline 5,1732 & 0,39375 & 13,2046 & 0,708935 & 20,7006 & 0,959486 & 28,3777 & 1,189702 \\
\hline 5,433 & 0,407087 & 13,4408 & 0,717716 & 20,9525 & 0,96721 & 28,6218 & 1,195775 \\
\hline 5,7243 & 0,419433 & 13,7085 & 0,726629 & 21,2281 & 0,974605 & 28,8737 & 1,200529 \\
\hline 5,9842 & 0,432307 & 13,9447 & 0,735608 & 21,5116 & 0,982659 & & \\
\hline 6,244 & 0,444059 & 14,1967 & 0,744191 & 21,7635 & 0,990582 & & \\
\hline 6,5275 & 0,456338 & 14,4802 & 0,752641 & 22,0234 & 0,998636 & & \\
\hline
\end{tabular}

Segundo Método - Pares tensão / deformação obtidos nos ensaios equibiaxiais da segunda réplica da condição irradiada com 250 kGy. 


\begin{tabular}{|c|c|c|c|c|c|c|c|}
\hline $\begin{array}{c}\text { Extensão } \\
\text { (\%) }\end{array}$ & $\begin{array}{c}\text { Tensão } \\
\text { MPa }\end{array}$ & $\begin{array}{c}\text { Extensão } \\
(\%)\end{array}$ & $\begin{array}{c}\text { Tensão } \\
\text { MPa }\end{array}$ & $\begin{array}{c}\text { Extensão } \\
(\%)\end{array}$ & $\begin{array}{c}\text { Tensão } \\
\text { MPa }\end{array}$ & $\begin{array}{c}\text { Extensão } \\
(\%)\end{array}$ & $\begin{array}{c}\text { Tensão } \\
\text { MPa }\end{array}$ \\
\hline 0,1748 & 0,02494 & 7,3091 & 0,594243 & 14,777 & 0,947548 & 22,1417 & 1,238434 \\
\hline 0,3575 & 0,049948 & 7,5633 & 0,607514 & 15,0313 & 0,958018 & 22,4039 & 1,247637 \\
\hline 0,5721 & 0,074755 & 7,8334 & 0,620651 & 15,2855 & 0,968354 & 22,6581 & 1,256306 \\
\hline 0,7786 & 0,097762 & 8,0559 & 0,634855 & 15,5477 & 0,978624 & 22,9123 & 1,264575 \\
\hline 1,0328 & 0,121502 & 8,3181 & 0,647259 & 15,8019 & 0,988894 & 23,1984 & 1,273645 \\
\hline 1,2712 & 0,143709 & 8,5643 & 0,659596 & 16,08 & 0,99903 & 23,4367 & 1,284048 \\
\hline 1,5254 & 0,166182 & 8,8345 & 0,672266 & 16,3421 & 1,0091 & 23,6909 & 1,293918 \\
\hline 1,7637 & 0,187722 & 9,0887 & 0,68507 & 16,6043 & 1,019236 & 23,9452 & 1,300853 \\
\hline 2,0021 & 0,209462 & 9,3111 & 0,697674 & 16,8585 & 1,028905 & 24,1835 & 1,309656 \\
\hline 2,2484 & 0,231068 & 9,5733 & 0,709344 & 17,081 & 1,037775 & 24,3901 & 1,318725 \\
\hline 2,4947 & 0,252341 & 9,8355 & 0,721081 & 17,3193 & 1,048111 & 24,5887 & 1,326327 \\
\hline 2,733 & 0,273214 & 10,0897 & 0,732951 & 17,5736 & 1,057581 & 24,8032 & 1,334463 \\
\hline 2,9793 & 0,294354 & 10,3439 & 0,744754 & 17,8119 & 1,066783 & 25,0415 & 1,342732 \\
\hline 3,2176 & 0,315693 & 10,63 & 0,757091 & 18,0661 & 1,07672 & 25,256 & 1,350068 \\
\hline 3,4798 & 0,3363 & 10,8921 & 0,769095 & 18,2965 & 1,086789 & 25,4626 & 1,35927 \\
\hline 3,7022 & 0,354572 & 11,1305 & 0,780832 & 18,5269 & 1,096526 & 25,693 & 1,367806 \\
\hline 3,9406 & 0,373244 & 11,3529 & 0,792635 & 18,7653 & 1,106262 & 25,9154 & 1,375542 \\
\hline 4,1789 & 0,390782 & 11,6151 & 0,803772 & 19,0036 & 1,116531 & 26,1379 & 1,384344 \\
\hline 4,4093 & 0,408521 & 11,8455 & 0,815109 & 19,2658 & 1,126068 & 26,3444 & 1,393414 \\
\hline 4,6476 & 0,425659 & 12,0838 & 0,826979 & 19,5279 & 1,13487 & 26,5828 & 1,401283 \\
\hline 4,878 & 0,442665 & 12,346 & 0,838516 & 19,7504 & 1,145207 & 26,7973 & 1,410219 \\
\hline 5,0846 & 0,459536 & 12,5684 & 0,849852 & 19,9967 & 1,153542 & 27,0118 & 1,417421 \\
\hline 5,2912 & 0,475674 & 12,8306 & 0,860589 & 20,243 & 1,163479 & 27,2501 & 1,425557 \\
\hline 5,5613 & 0,491146 & 13,0848 & 0,872259 & 20,4654 & 1,174082 & 27,4408 & 1,433959 \\
\hline 5,7837 & 0,507217 & 13,2993 & 0,883262 & 20,6879 & 1,182618 & 27,6473 & 1,440361 \\
\hline 6,0538 & 0,522622 & 13,5536 & 0,892465 & 20,9262 & 1,192287 & 27,8539 & 1,44783 \\
\hline 6,3081 & 0,536759 & 13,7919 & 0,904335 & 21,1566 & 1,201557 & 28,0605 & 1,454232 \\
\hline 6,5305 & 0,552497 & 14,0303 & 0,914005 & 21,3949 & 1,205958 & & \\
\hline 6,8006 & 0,566901 & 14,2845 & 0,925675 & 21,6571 & 1,219762 & & \\
\hline 7,0549 & 0,580639 & 14,5149 & 0,936611 & 21,8875 & 1,229098 & & \\
\hline
\end{tabular}

Segundo Método - Pares tensão / deformação obtidos nos ensaios equibiaxiais da terceira réplica da condição irradiada com 250 kGy. 


\begin{tabular}{|c|c|c|c|c|c|c|c|}
\hline $\begin{array}{c}\text { Extensão } \\
(\%)\end{array}$ & $\begin{array}{c}\text { Tensão } \\
\text { MPa }\end{array}$ & $\begin{array}{c}\text { Extensão } \\
(\%)\end{array}$ & $\begin{array}{c}\text { Tensão } \\
\text { MPa }\end{array}$ & $\begin{array}{c}\text { Extensão } \\
(\%)\end{array}$ & $\begin{array}{c}\text { Tensão } \\
\text { MPa }\end{array}$ & $\begin{array}{c}\text { Extensão } \\
(\%)\end{array}$ & $\begin{array}{c}\text { Tensão } \\
\text { MPa }\end{array}$ \\
\hline 0,908992 & 0,043375 & 14,24675 & 0,448515 & 29,74967 & 0,702731 & 43,94795 & 0,917976 \\
\hline 1,083051 & 0,050433 & 14,61083 & 0,45674 & 30,04582 & 0,707335 & 44,10703 & 0,920371 \\
\hline 1,305822 & 0,057921 & 15,21196 & 0,468768 & 30,22699 & 0,70979 & 44,2318 & 0,922335 \\
\hline 1,514621 & 0,065961 & 15,70519 & 0,478648 & 30,9105 & 0,719426 & 44,37029 & 0,924604 \\
\hline 2,053585 & 0,083576 & 16,12688 & 0,487241 & 31,1854 & 0,723232 & 45,11857 & 0,936204 \\
\hline 2,353402 & 0,093519 & 16,38599 & 0,492213 & 32,25603 & 0,738144 & 45,25378 & 0,938354 \\
\hline 3,308789 & 0,124943 & 18,38032 & 0,529041 & 32,62734 & 0,743669 & 45,49286 & 0,941485 \\
\hline 3,614249 & 0,134579 & 18,52451 & 0,531495 & 33,05416 & 0,750361 & 45,89252 & 0,947742 \\
\hline 4,603728 & 0,16631 & 19,16394 & 0,54291 & 33,39353 & 0,755147 & 45,91789 & 0,948235 \\
\hline 4,816542 & 0,173491 & 19,29664 & 0,545182 & 34,11345 & 0,765459 & 45,92714 & 0,948235 \\
\hline 5,175609 & 0,185643 & 20,29889 & 0,561999 & 34,53788 & 0,771779 & 45,9346 & 0,948358 \\
\hline 5,499366 & 0,196138 & 20,49857 & 0,565434 & 35,2787 & 0,782581 & 45,9543 & 0,948417 \\
\hline 6,059307 & 0,215042 & 21,0407 & 0,57458 & 35,80551 & 0,79056 & 45,96057 & 0,948417 \\
\hline 6,623726 & 0,234191 & 21,25142 & 0,577647 & 35,96759 & 0,793137 & 45,97281 & 0,948603 \\
\hline 6,635844 & 0,234498 & 21,26017 & 0,577773 & 36,26934 & 0,797801 & 45,97818 & 0,948725 \\
\hline 7,357022 & 0,258925 & 22,6302 & 0,599681 & 36,73945 & 0,8048 & 45,98833 & 0,948971 \\
\hline 7,538048 & 0,264633 & 22,76532 & 0,601891 & 36,9248 & 0,807868 & 45,99728 & 0,949034 \\
\hline 8,769293 & 0,305264 & 23,76014 & 0,616194 & 37,25372 & 0,813085 & 46,00415 & 0,949093 \\
\hline 8,93826 & 0,310174 & 23,89846 & 0,618526 & 37,46623 & 0,816401 & 46,01997 & 0,949461 \\
\hline 9,269211 & 0,320669 & 24,08701 & 0,621103 & 38,10766 & 0,826527 & 46,0331 & 0,949524 \\
\hline 9,426239 & 0,324843 & 24,2606 & 0,623925 & 39,26545 & 0,844202 & 46,04773 & 0,950077 \\
\hline 10,14034 & 0,346324 & 25,19289 & 0,638102 & 39,3726 & 0,846106 & 46,05638 & 0,9502 \\
\hline 10,99527 & 0,369524 & 25,49495 & 0,642031 & 39,7054 & 0,851078 & 46,33068 & 0,954065 \\
\hline 11,12451 & 0,373085 & 25,87598 & 0,647433 & 40,2931 & 0,860592 & 46,69632 & 0,959464 \\
\hline 11,6886 & 0,387507 & 26,4264 & 0,655473 & 40,48473 & 0,863782 & 50,53502 & 1,014643 \\
\hline 12,28663 & 0,402546 & 26,69026 & 0,659587 & 41,11003 & 0,874093 & 51,7328 & 1,03195 \\
\hline 12,78648 & 0,415494 & 27,07836 & 0,665172 & 41,35538 & 0,877777 & 52,13336 & 1,037535 \\
\hline 13,03682 & 0,421019 & 28,01119 & 0,678183 & 41,71385 & 0,883666 & 52,92522 & 1,047724 \\
\hline 13,5342 & 0,432433 & 28,19682 & 0,680697 & 42,34393 & 0,893365 & 53,2807 & 1,051099 \\
\hline 13,60652 & 0,434275 & 29,63222 & 0,700952 & 43,91273 & 0,917913 & 53,57679 & 1,053064 \\
\hline
\end{tabular}

Segundo Método - Pares tensão / deformação obtidos nos ensaios de cisalhamento puro da primeira réplica da condição não irradiada. 


\begin{tabular}{|c|c|c|c|c|c|c|c|}
\hline $\begin{array}{c}\text { Extensão } \\
(\%)\end{array}$ & $\begin{array}{c}\text { Tensão } \\
\text { MPa }\end{array}$ & $\begin{array}{c}\text { Extensão } \\
(\%)\end{array}$ & $\begin{array}{c}\text { Tensão } \\
\text { MPa }\end{array}$ & $\begin{array}{c}\text { Extensão } \\
(\%)\end{array}$ & $\begin{array}{c}\text { Tensão } \\
\text { MPa }\end{array}$ & $\begin{array}{c}\text { Extensão } \\
(\%)\end{array}$ & $\begin{array}{c}\text { Tensão } \\
\text { MPa }\end{array}$ \\
\hline 0,010298 & 0,00117 & 19,51014 & 0,501537 & 36,18472 & 0,703432 & 55,52734 & 0,926794 \\
\hline 0,008209 & 0,005722 & 19,74318 & 0,504983 & 36,52038 & 0,706815 & 56,91101 & 0,942913 \\
\hline 1,227497 & 0,078064 & 20,01351 & 0,508735 & 37,10822 & 0,713213 & 57,14798 & 0,945987 \\
\hline 2,553911 & 0,133674 & 20,48665 & 0,515441 & 37,50785 & 0,717824 & 57,9966 & 0,955645 \\
\hline 3,234443 & 0,157973 & 20,84933 & 0,520053 & 38,47467 & 0,7289 & 58,29267 & 0,958719 \\
\hline 3,481626 & 0,166093 & 21,31998 & 0,526391 & 39,46071 & 0,740032 & 59,1235 & 0,968503 \\
\hline 4,182611 & 0,188915 & 21,6124 & 0,530202 & 39,74473 & 0,743478 & 59,99363 & 0,978284 \\
\hline 4,467663 & 0,197404 & 22,16154 & 0,537894 & 40,75917 & 0,75535 & 61,17188 & 0,990402 \\
\hline 6,123844 & 0,245387 & 23,14074 & 0,550567 & 41,67262 & 0,765562 & 61,56894 & 0,994276 \\
\hline 6,310265 & 0,251169 & 23,51425 & 0,555055 & 41,88606 & 0,7679 & 62,02308 & 0,999137 \\
\hline 7,163874 & 273315 & 24,57806 & 0,568528 & 42,82907 & 0,779035 & 63,15802 & 1,009963 \\
\hline 7,547129 & 0,28328 & 24,96246 & 0,573511 & 43,47686 & 0,786601 & 65,46747 & 1,030325 \\
\hline 8,195813 & 0,298167 & 25,5153 & 0,580032 & 44,70848 & 0,801302 & 65,7337 & 1,032357 \\
\hline 9,168969 & 0,321174 & 25,89187 & 0,58452 & 45,02033 & 0,804685 & 66,23404 & 1,035554 \\
\hline 9,582835 & 0,330524 & 25,9048 & 0,584829 & 45,24266 & 0,807391 & 66,48593 & 1,036908 \\
\hline 10,89125 & 0,357715 & 26,33342 & 0,589935 & 46,18854 & 0,818466 & 66,74068 & 1,038937 \\
\hline 11,59723 & 0,371862 & 27,28207 & 0,601376 & 46,35981 & 0,820618 & 67,08552 & 1,040719 \\
\hline 12,13072 & 0,381765 & 27,86839 & 0,608328 & 47,15134 & 0,829784 & 67,32249 & 1,041951 \\
\hline 12,4144 & 0,387735 & 28,2585 & 0,613002 & 47,47351 & 0,833781 & 67,6266 & 1,043552 \\
\hline 13,98885 & 0,415968 & 28,60888 & 0,616508 & 48,53586 & 0,846208 & 67,79357 & 1,044534 \\
\hline 14,18034 & 0,419351 & 28,89717 & 0,620018 & 49,88424 & 0,861958 & 68,30939 & 1,045948 \\
\hline 14,80912 & 0,429809 & 29,26381 & 0,624569 & 50,69642 & 0,871062 & 68,47321 & 1,046871 \\
\hline 15,2 & 0,436578 & 30,10153 & 0,633673 & 51,04643 & 0,875304 & 68,68292 & 1,047612 \\
\hline 15,81977 & 0,446541 & 30,62883 & 0,639761 & 51,22028 & 0,877459 & 69,06448 & 1,049026 \\
\hline 16,06913 & 0,450665 & 32,1109 & 0,65674 & 52,00177 & 0,88564 & 69,34449 & 1,050132 \\
\hline 16,29408 & 0,453739 & 32,61927 & 0,662155 & 52,95137 & 0,896589 & 69,57859 & 1,050195 \\
\hline 17,03756 & 0,465366 & 33,87986 & 0,676919 & 53,11174 & 0,898926 & 70,48372 & 1,039 \\
\hline 18,50683 & 0,487082 & 34,3865 & 0,682516 & 53,63904 & 0,905078 & 71,02107 & 1,024359 \\
\hline 18,72389 & 0,490402 & 35,91419 & 0,699863 & 54,4079 & 0,91369 & 71,12119 & 1,021899 \\
\hline 19,35358 & 0,499754 & 36,17267 & 0,703309 & 55,36554 & 0,924889 & 71,18861 & 1,020421 \\
\hline
\end{tabular}

Segundo Método - Pares tensão / deformação obtidos nos ensaios de cisalhamento puro da segunda réplica da condição não irradiada. 


\begin{tabular}{|c|c|c|c|c|c|c|c|}
\hline $\begin{array}{c}\text { Extensão } \\
(\%)\end{array}$ & $\begin{array}{c}\text { Tensão } \\
\text { MPa }\end{array}$ & $\begin{array}{c}\text { Extensão } \\
(\%)\end{array}$ & $\begin{array}{c}\text { Tensão } \\
\text { MPa }\end{array}$ & $\begin{array}{c}\text { Extensão } \\
(\%)\end{array}$ & $\begin{array}{c}\text { Tensão } \\
\text { MPa }\end{array}$ & $\begin{array}{c}\text { Extensão } \\
\text { (\%) }\end{array}$ & $\begin{array}{c}\text { Tensão } \\
\text { MPa }\end{array}$ \\
\hline 0,303766 & 0,017018 & 14,37683 & 0,372101 & 27,86244 & 0,590353 & 41,05049 & 0,773588 \\
\hline 1,132541 & 0,040829 & 14,65322 & 0,379129 & 28,0732 & 0,59314 & 42,10388 & 0,794378 \\
\hline 1,644342 & 0,053954 & 15,62305 & 0,399919 & 28,2504 & 0,596221 & 43,62915 & 0,823011 \\
\hline 3,678139 & 0,104423 & 16,26067 & 0,411187 & 28,50895 & 0,598428 & 44,08301 & 0,832013 \\
\hline 3,93763 & 0,109534 & 16,39221 & 0,415077 & 28,67489 & 0,60133 & 45,74301 & 0,858959 \\
\hline 4,172921 & 0,117491 & 16,76892 & 0,420653 & 29,38703 & 0,610796 & 46,88239 & 0,876732 \\
\hline 4,55678 & 0,126144 & 17,20139 & 0,430583 & 29,67716 & 0,612655 & 47,04845 & 0,880217 \\
\hline 5,051709 & 0,136888 & 17,64638 & 0,438309 & 30,06926 & 0,617823 & 49,11149 & 0,911404 \\
\hline 5,52956 & 0,149491 & 18,33175 & 0,448531 & 30,0929 & 0,619682 & 49,27016 & 0,913899 \\
\hline 6,435857 & 0,174232 & 18,38387 & 0,451665 & 30,84165 & 0,628336 & 49,54614 & 0,918024 \\
\hline 6,631879 & 179807 & 19,02465 & 0,460551 & 31,52952 & 0,63699 & 49,68531 & 0,920231 \\
\hline 6,922779 & 0,18637 & 19,49095 & 0,468334 & 32,56902 & 0,650346 & 49,86408 & 0,922497 \\
\hline 7,145217 & 0,193223 & 20,24572 & 0,480762 & 32,92626 & 0,654762 & 50,44588 & 0,929988 \\
\hline 7,544795 & 0,202806 & 20,58635 & 0,486514 & 32,95935 & 0,656909 & 51,10332 & 0,939862 \\
\hline 8,072523 & 0,219184 & 21,44641 & 0,500856 & 33,7211 & 0,666319 & 52,04354 & 0,952462 \\
\hline 8,445596 & 0,225862 & 22,17476 & 0,512529 & 34,27779 & 0,672707 & 52,23029 & 0,954321 \\
\hline 8,591652 & 0,23289 & 22,37776 & 0,514099 & 34,54461 & 0,67648 & 52,62387 & 0,959317 \\
\hline 9,318829 & 0,249267 & 22,92032 & 0,521359 & 34,9633 & 0,682464 & 52,70483 & 0,961871 \\
\hline 9,822446 & 0,263496 & 23,75083 & 0,53547 & 35,60568 & 0,69193 & 53,07359 & 0,965241 \\
\hline 10,55754 & 0,280571 & 24,34383 & 0,542033 & 36,14345 & 0,698493 & 53,67459 & 0,967971 \\
\hline 10,69792 & 0,286611 & 24,45085 & 0,543544 & 36,28469 & 0,701048 & 53,86193 & 0,968491 \\
\hline 11,01255 & 0,294335 & 24,8428 & 0,550571 & 36,53585 & 0,703718 & 54,78058 & 0,973488 \\
\hline 11,48491 & 0,306299 & 25,23107 & 0,554809 & 36,78937 & 0,707032 & 55,46639 & 0,977729 \\
\hline 11,79094 & 0,312862 & 25,40886 & 0,557599 & 37,13479 & 0,712664 & 56,49052 & 0,984988 \\
\hline 12,31763 & 0,326684 & 25,61268 & 0,560849 & 37,67345 & 0,71998 & 57,38789 & 0,99335 \\
\hline 12,6023 & 0,33168 & 25,68619 & 0,561604 & 38,57969 & 0,734618 & 57,74838 & 0,996544 \\
\hline 12,91355 & 0,338823 & 26,0749 & 0,567065 & 39,40792 & 0,747685 & 57,94872 & 0,998635 \\
\hline 13,31771 & 0,349277 & 26,39269 & 0,571362 & 39,84316 & 0,753665 & 58,42444 & 1,001769 \\
\hline 13,74879 & 0,358683 & 26,90709 & 0,577634 & 40,14809 & 0,759301 & 58,46758 & 1,001945 \\
\hline 14,35766 & 0,371985 & 27,20142 & 0,582455 & 41,04695 & 0,773704 & 58,47231 & 1,002177 \\
\hline
\end{tabular}

Segundo Método - Pares tensão / deformação obtidos nos ensaios de cisalhamento puro da terceira réplica da condição não irradiada. 


\begin{tabular}{|c|c|c|c|c|c|c|c|}
\hline $\begin{array}{c}\text { Extensão } \\
(\%)\end{array}$ & $\begin{array}{c}\text { Tensão } \\
\text { MPa }\end{array}$ & $\begin{array}{c}\text { Extensão } \\
\text { (\%) }\end{array}$ & $\begin{array}{c}\text { Tensão } \\
\text { MPa }\end{array}$ & $\begin{array}{c}\text { Extensão } \\
(\%)\end{array}$ & $\begin{array}{c}\text { Tensão } \\
\text { MPa }\end{array}$ & $\begin{array}{c}\text { Extensão } \\
\text { (\%) }\end{array}$ & $\begin{array}{c}\text { Tensão } \\
\text { MPa }\end{array}$ \\
\hline 0,0816 & 0,137776 & 14,7068 & 0,583688 & 27,8736 & 0,764681 & 40,5871 & 0,935405 \\
\hline 0,4317 & 0,181142 & 15,0113 & 0,588356 & 28,1007 & 0,767482 & 41,0012 & 0,941130 \\
\hline 1,5695 & 0,259163 & 15,2109 & 0,591778 & 29,0751 & 0,780235 & 41,3307 & 0,946231 \\
\hline 1,7070 & 0,266691 & 15,5915 & 0,596879 & 29,3493 & 0,783721 & 42,0598 & 0,955999 \\
\hline 2,2835 & 0,294067 & 15,9728 & 0,602792 & 29,9032 & 0,791310 & 42,4666 & 0,961849 \\
\hline 2,4841 & 0,301906 & 16,7305 & 0,613867 & 30,4860 & 0,799087 & 42,8505 & 0,967138 \\
\hline 2,6604 & 0,309434 & 17,0061 & 0,617597 & 30,7735 & 0,803006 & 43,1651 & 0,971429 \\
\hline 3,1246 & 0,327664 & 17,2387 & 0,620959 & 31,2648 & 0,809416 & 43,6225 & 0,977776 \\
\hline 3,8517 & 0,353485 & 17,4659 & 0,624192 & 31,8067 & 0,817069 & 44,9917 & 0,997125 \\
\hline 3,9882 & 0,357715 & 18,0630 & 0,632843 & 32,1170 & 0,820615 & 45,4578 & 1,003660 \\
\hline 4,2366 & 0,366114 & 18,2076 & 0,634894 & 32,6239 & 0,827459 & 45,6913 & 1,007390 \\
\hline 4,5199 & 0,374764 & 18,4396 & 0,637755 & 33,0499 & 0,832872 & 46,1241 & 1,013364 \\
\hline 5,0144 & 0,389693 & 18,9942 & 0,645845 & 33,5138 & 0,839467 & 46,7798 & 1,022387 \\
\hline 5,7026 & 0,407988 & 19,1642 & 0,647897 & 33,7620 & 0,842949 & 47,9607 & 1,038499 \\
\hline 6,7584 & 0,434056 & 19,6514 & 0,654431 & 34,4264 & 0,851908 & 48,1092 & 1,041115 \\
\hline 7,3073 & 0,446874 & 20,5053 & 0,666251 & 34,6651 & 0,855330 & 48,8820 & 1,051629 \\
\hline 7,4158 & 0,450047 & 21,1250 & 0,674714 & 35,1469 & 0,861741 & 49,1532 & 1,055920 \\
\hline 8,6143 & 0,475494 & 21,4326 & 0,678696 & 35,5230 & 0,866905 & 49,3846 & 1,059093 \\
\hline 8,9541 & 0,482089 & 21,6660 & 0,681681 & 35,5943 & 0,867963 & 49,5892 & 1,062267 \\
\hline 9,1713 & 0,486256 & 22,3859 & 0,691450 & 35,8585 & 0,871633 & 50,7072 & 1,078133 \\
\hline 10,3413 & 0,508966 & 22,5644 & 0,694126 & 36,1712 & 0,875925 & 50,9573 & 1,081803 \\
\hline 10,5206 & 0,511579 & 23,3876 & 0,704888 & 36,3459 & 0,878413 & 51,1478 & 1,084664 \\
\hline 11,2288 & 0,525390 & 23,9771 & 0,713038 & 36,8491 & 0,885445 & 51,3426 & 1,087653 \\
\hline 11,8141 & 0,535907 & 24,2432 & 0,716464 & 37,2773 & 0,891170 & 51,5627 & 1,090514 \\
\hline 12,4034 & 0,546173 & 24,4882 & 0,719761 & 38,0652 & 0,901311 & 52,8698 & 1,109430 \\
\hline 12,5648 & 0,549222 & 25,3434 & 0,731209 & 38,6394 & 0,909213 & 53,1668 & 1,113285 \\
\hline 13,1404 & 0,558990 & 25,6073 & 0,734506 & 39,2117 & 0,916493 & 54,6704 & 1,130085 \\
\hline 13,2891 & 0,561106 & 25,9206 & 0,738112 & 39,7748 & 0,924454 & 54,8606 & 1,129400 \\
\hline 13,8780 & 0,570874 & 26,4431 & 0,745393 & 40,0119 & 0,927692 & 55,3646 & 1,127224 \\
\hline 14,6990 & 0,583379 & 26,8818 & 0,750870 & 40,5812 & 0,935220 & 55,3901 & 1,127160 \\
\hline
\end{tabular}

Segundo Método - Pares tensão / deformação obtidos nos ensaios de cisalhamento puro da primeira réplica da condição irradiada com 100 kGy. 


\begin{tabular}{|c|c|c|c|c|c|c|c|}
\hline $\begin{array}{c}\text { Extensão } \\
\text { (\%) }\end{array}$ & $\begin{array}{c}\text { Tensão } \\
\text { MPa }\end{array}$ & $\begin{array}{c}\text { Extensão } \\
\text { (\%) }\end{array}$ & $\begin{array}{c}\text { Tensão } \\
\text { MPa }\end{array}$ & $\begin{array}{c}\text { Extensão } \\
(\%)\end{array}$ & $\begin{array}{c}\text { Tensão } \\
\text { MPa }\end{array}$ & $\begin{array}{c}\text { Extensão } \\
\text { (\%) }\end{array}$ & $\begin{array}{c}\text { Tensão } \\
\text { MPa }\end{array}$ \\
\hline 0,3552 & 0,116953 & 17,1372 & 0,618723 & 34,0348 & 0,861994 & 53,4083 & 1,143464 \\
\hline 0,4098 & 0,127288 & 17,8605 & 0,629061 & 34,6244 & 0,871001 & 53,6840 & 1,146064 \\
\hline 1,0897 & 0,202475 & 18,9281 & 0,645198 & 34,8882 & 0,874991 & 54,3975 & 1,154405 \\
\hline 1,7281 & 0,247624 & 19,0834 & 0,647071 & 35,0872 & 0,877711 & 54,9497 & 1,161053 \\
\hline 2,7299 & 0,297849 & 19,7955 & 0,657405 & 35,9723 & 0,891369 & 55,4757 & 1,166553 \\
\hline 2,8649 & 0,304014 & 20,0038 & 0,660608 & 36,9843 & 0,906841 & 55,6739 & 1,169153 \\
\hline 3,7608 & 0,342635 & 20,8716 & 0,672697 & 37,5750 & 0,916030 & 56,3952 & 1,177128 \\
\hline 3,8964 & 0,349647 & 21,0511 & 0,675356 & 37,8095 & 0,919654 & 57,0529 & 1,182994 \\
\hline 5,3458 & 0,399328 & 21,2677 & 0,678439 & 38,5486 & 0,931078 & 57,2984 & 1,185107 \\
\hline 5,4706 & 0,403134 & 21,5639 & 0,682308 & 39,2191 & 0,941474 & 57,9810 & 1,191211 \\
\hline 6,0594 & 0,418427 & 22,3253 & 0,693249 & 39,8951 & 0,951750 & 58,2273 & 1,193386 \\
\hline 6,8727 & 0,436861 & 22,5843 & 0,696935 & 40,3812 & 0,959063 & 58,4246 & 1,194959 \\
\hline 7,3219 & 0,446954 & 23,5705 & 0,710472 & 41,0378 & 0,969277 & 58,6545 & 1,197076 \\
\hline 8,1767 & 0,465267 & 23,8240 & 0,714158 & 41,2298 & 0,972177 & 58,9068 & 1,199855 \\
\hline 8,3980 & 0,469922 & 24,6127 & 0,725220 & 41,6919 & 0,979128 & 59,1361 & 1,201607 \\
\hline 9,2036 & 0,485635 & 25,1092 & 0,732292 & 42,4497 & 0,990369 & 59,3349 & 1,203300 \\
\hline 9,4610 & 0,490473 & 25,7873 & 0,742264 & 43,4088 & 1,005358 & 59,5732 & 1,205417 \\
\hline 10,7961 & 0,515251 & 26,6953 & 0,754957 & 44,0267 & 1,014427 & 59,7833 & 1,207348 \\
\hline 10,9470 & 0,517910 & 26,9489 & 0,759005 & 44,8343 & 1,026513 & 60,0149 & 1,209162 \\
\hline 11,3388 & 0,525344 & 27,7105 & 0,769825 & 45,4778 & 1,036364 & 60,1956 & 1,210189 \\
\hline 11,5486 & 0,528609 & 28,0110 & 0,774601 & 46,3160 & 1,048271 & 60,3630 & 1,211279 \\
\hline 12,0404 & 0,537313 & 28,3274 & 0,778587 & 46,9166 & 1,056733 & 60,4897 & 1,212065 \\
\hline 12,3319 & 0,542450 & 28,5590 & 0,782214 & 47,3362 & 1,062656 & 60,6676 & 1,213031 \\
\hline 13,1076 & 0,555143 & 29,5051 & 0,796238 & 48,1087 & 1,072629 & 60,7487 & 1,213755 \\
\hline 13,4337 & 0,560160 & 30,1592 & 0,805665 & 48,8736 & 1,083449 & 60,8745 & 1,214541 \\
\hline 14,4423 & 0,576356 & 30,5929 & 0,811769 & 49,7083 & 1,094690 & 61,0258 & 1,215086 \\
\hline 15,1271 & 0,587538 & 31,2272 & 0,820717 & 50,5357 & 1,106172 & 61,1319 & 1,215027 \\
\hline 15,3905 & 0,591769 & 31,4760 & 0,824403 & 51,1434 & 1,114513 & 61,2314 & 1,214906 \\
\hline 16,1185 & 0,603072 & 32,1527 & 0,833830 & 51,7064 & 1,121465 & 61,5611 & 1,216234 \\
\hline 16,3979 & 0,607120 & 32,7459 & 0,842533 & 52,5284 & 1,132526 & 62,5078 & 1,217503 \\
\hline
\end{tabular}

Segundo Método - Pares tensão / deformação obtidos nos ensaios de cisalhamento puro da segunda réplica da condição irradiada com 100 kGy. 


\begin{tabular}{|c|c|c|c|c|c|c|c|}
\hline $\begin{array}{c}\text { Extensão } \\
(\%)\end{array}$ & $\begin{array}{c}\text { Tensão } \\
\text { MPa }\end{array}$ & $\begin{array}{c}\text { Extensão } \\
\text { (\%) }\end{array}$ & $\begin{array}{c}\text { Tensão } \\
\text { MPa }\end{array}$ & $\begin{array}{c}\text { Extensão } \\
\text { (\%) }\end{array}$ & $\begin{array}{c}\text { Tensão } \\
\text { MPa }\end{array}$ & $\begin{array}{c}\text { Extensão } \\
\text { (\%) }\end{array}$ & $\begin{array}{c}\text { Tensão } \\
\text { MPa }\end{array}$ \\
\hline 0,7151 & 0,084956 & 24,3105 & 0,614505 & 37,1503 & 0,775016 & 55,5748 & 1,012341 \\
\hline 1,0135 & 0,109024 & 24,7596 & 0,619834 & 37,4030 & 0,778606 & 57,1695 & 1,034850 \\
\hline 1,2785 & 0,126446 & 25,0262 & 0,623663 & 37,8157 & 0,783518 & 57,6597 & 1,041975 \\
\hline 1,9724 & 0,170151 & 25,5159 & 0,629473 & 38,0835 & 0,786749 & 58,4950 & 1,054308 \\
\hline 2,4051 & 0,192183 & 25,6794 & 0,631567 & 38,4087 & 0,791360 & 59,0505 & 1,062151 \\
\hline 3,2015 & 0,218526 & 26,0104 & 0,635279 & 38,7628 & 0,795732 & 59,7948 & 1,072746 \\
\hline 3,7713 & 0,242055 & 26,2425 & 0,638452 & 39,5264 & 0,805849 & 61,0495 & 1,092085 \\
\hline 4,5246 & 0,263727 & 26,9555 & 0,646773 & 39,8001 & 0,809142 & 61,3698 & 1,096874 \\
\hline 5,8810 & 0,303720 & 27,8367 & 0,657730 & 40,0708 & 0,812673 & 62,2522 & 1,110465 \\
\hline 6,7108 & 0,321801 & 28,1048 & 0,660965 & 40,3955 & 0,816564 & 62,5941 & 1,115195 \\
\hline 7,4161 & 0,340840 & 28,3998 & 0,664497 & 40,6406 & 0,819798 & 63,4334 & 1,127529 \\
\hline 8,2358 & 0,357961 & 28,7739 & 0,669166 & 41,4485 & 0,829495 & 64,5397 & 1,144891 \\
\hline 9,0413 & 0,374964 & 29,0550 & 0,672698 & 42,0264 & 0,837580 & 65,3176 & 1,156866 \\
\hline 10,0436 & 0,394843 & 29,9290 & 0,683235 & 42,2621 & 0,840272 & 66,0471 & 1,167642 \\
\hline 10,1561 & 0,398016 & 30,1497 & 0,686049 & 42,7404 & 0,846618 & 67,5072 & 1,189793 \\
\hline 10,8553 & 0,411966 & 30,5244 & 0,690479 & 42,9651 & 0,849432 & 68,1918 & 1,200391 \\
\hline 11,6135 & 0,425854 & 30,8337 & 0,694728 & 43,6459 & 0,858713 & 68,6910 & 1,207393 \\
\hline 12,2843 & 0,437948 & 31,9266 & 0,708319 & 44,2926 & 0,867156 & 69,1270 & 1,214221 \\
\hline 12,7760 & 0,446030 & 32,6482 & 0,717183 & 45,0282 & 0,876494 & 69,5041 & 1,219307 \\
\hline 13,4826 & 0,458903 & 33,3811 & 0,726521 & 45,8993 & 0,888111 & 70,0605 & 1,225715 \\
\hline 14,5924 & 0,477464 & 33,5266 & 0,728437 & 46,7987 & 0,899543 & 70,4076 & 1,230326 \\
\hline 16,2277 & 0,503327 & 34,4691 & 0,740651 & 47,5095 & 0,908885 & 70,9604 & 1,235354 \\
\hline 17,8570 & 0,527813 & 34,7287 & 0,744241 & 48,2052 & 0,918104 & 71,1341 & 1,236611 \\
\hline 18,5712 & 0,537992 & 34,9205 & 0,746397 & 48,8443 & 0,926427 & 71,2857 & 1,236792 \\
\hline 19,2910 & 0,548410 & 35,6943 & 0,756155 & 49,1652 & 0,930495 & 71,3961 & 1,236969 \\
\hline 20,0706 & 0,559186 & 36,0632 & 0,761005 & 50,1068 & 0,942050 & 71,4436 & 1,237390 \\
\hline 20,8245 & 0,570259 & 36,3349 & 0,764598 & 50,7398 & 0,950494 & 71,4705 & 1,237328 \\
\hline 21,5586 & 0,579601 & 36,5683 & 0,767413 & 51,7526 & 0,961209 & 71,4774 & 1,237328 \\
\hline 22,3746 & 0,589957 & 36,8498 & 0,771242 & 53,0515 & 0,978212 & 71,4821 & 1,237328 \\
\hline 23,1312 & 0,600016 & 37,1413 & 0,775016 & 54,0762 & 0,991147 & 71,4827 & 1,237328 \\
\hline
\end{tabular}

Segundo Método - Pares tensão / deformação obtidos nos ensaios de cisalhamento puro da terceira réplica da condição irradiada com 100 kGy. 


\begin{tabular}{|c|c|c|c|c|c|c|c|}
\hline $\begin{array}{c}\text { Extensão } \\
(\%)\end{array}$ & $\begin{array}{c}\text { Tensão } \\
\text { MPa }\end{array}$ & $\begin{array}{c}\text { Extensão } \\
\text { (\%) }\end{array}$ & $\begin{array}{c}\text { Tensão } \\
\text { MPa }\end{array}$ & $\begin{array}{c}\text { Extensão } \\
\text { (\%) }\end{array}$ & $\begin{array}{c}\text { Tensão } \\
\text { MPa }\end{array}$ & $\begin{array}{c}\text { Extensão } \\
\text { (\%) }\end{array}$ & $\begin{array}{c}\text { Tensão } \\
\text { MPa }\end{array}$ \\
\hline 0,0023 & 0,003221 & 13,3017 & 0,470239 & 24,0012 & 0,682665 & 37,7120 & 0,901471 \\
\hline 0,0046 & 0,003344 & 14,0265 & 0,485717 & 24,5233 & 0,691150 & 38,0853 & 0,907723 \\
\hline 1,8400 & 0,105441 & 14,3028 & 0,492033 & 25,2542 & 0,704149 & 38,2886 & 0,910821 \\
\hline 1,9769 & 0,111756 & 14,7166 & 0,501259 & 25,6438 & 0,710281 & 38,5589 & 0,914844 \\
\hline 2,3128 & 0,125934 & 15,0992 & 0,510298 & 26,0046 & 0,716533 & 38,9590 & 0,921842 \\
\hline 2,7204 & 0,142403 & 15,3843 & 0,516303 & 26,3269 & 0,721983 & 39,2212 & 0,926112 \\
\hline 3,1023 & 0,157201 & 15,9005 & 0,526953 & 27,3555 & 0,739379 & 39,4531 & 0,930012 \\
\hline 3,4639 & 0,170451 & 16,1743 & 0,532958 & 27,7289 & 0,745942 & 39,7323 & 0,934840 \\
\hline 4,0170 & 0,191254 & 16,5338 & 0,540262 & 28,0665 & 0,751018 & 39,9844 & 0,938867 \\
\hline 4,7205 & 0,217320 & 16,7759 & 0,545218 & 28,3624 & 0,756034 & 40,3660 & 0,945243 \\
\hline 5,1211 & 0,232365 & 17,2016 & 0,554505 & 29,3832 & 0,771823 & 40,6705 & 0,950446 \\
\hline 5,4303 & 0,244129 & 17,5370 & 0,560880 & 29,6972 & 0,776652 & 40,9149 & 0,954904 \\
\hline 5,7615 & 0,254902 & 17,7024 & 0,564409 & 30,5905 & 0,791017 & 41,2468 & 0,961343 \\
\hline 6,2698 & 0,272795 & 17,9821 & 0,570290 & 30,8926 & 0,796093 & 41,5078 & 0,966048 \\
\hline 6,6126 & 0,283815 & 18,1902 & 0,574999 & 31,2123 & 0,801416 & 41,9002 & 0,972547 \\
\hline 6,9899 & 0,295455 & 18,4264 & 0,579022 & 31,5674 & 0,806121 & 42,1567 & 0,976758 \\
\hline 7,3213 & 0,306290 & 18,7171 & 0,584592 & 32,0065 & 0,813366 & 42,8562 & 0,989947 \\
\hline 7,9748 & 0,326846 & 19,0374 & 0,591155 & 32,3142 & 0,817824 & 43,1289 & 0,994836 \\
\hline 8,7451 & 0,349444 & 19,3287 & 0,596605 & 32,6723 & 0,823334 & 43,3697 & 0,999046 \\
\hline 9,4961 & 0,371484 & 20,3169 & 0,616047 & 33,0054 & 0,828661 & 44,0451 & 1,011865 \\
\hline 9,7584 & 0,379223 & 20,5540 & 0,620194 & 33,3561 & 0,834107 & 44,4481 & 1,020035 \\
\hline 10,8463 & 0,407580 & 21,0001 & 0,628738 & 33,6796 & 0,839183 & 44,6532 & 1,023998 \\
\hline 11,4136 & 0,422504 & 21,2290 & 0,632949 & 34,1443 & 0,845933 & 45,2387 & 1,035266 \\
\hline 11,5985 & 0,427333 & 21,5922 & 0,639448 & 34,6783 & 0,854789 & 45,6340 & 1,042574 \\
\hline 11,9613 & 0,436308 & 21,9585 & 0,646322 & 35,4695 & 0,867233 & 46,4193 & 1,060282 \\
\hline 12,2710 & 0,444051 & 22,2936 & 0,652080 & 36,2714 & 0,879677 & 46,6294 & 1,064986 \\
\hline 12,4900 & 0,449685 & 22,5922 & 0,657283 & 36,7762 & 0,887353 & 46,9092 & 1,070680 \\
\hline 12,7305 & 0,455502 & 22,9925 & 0,664400 & 37,1149 & 0,892679 & 47,2736 & 1,081270 \\
\hline 13,0017 & 0,462811 & 23,3575 & 0,670839 & 37,4346 & 0,897508 & 47,3444 & 1,083870 \\
\hline 13,0126 & 0,463182 & 23,7041 & 0,677155 & 37,6930 & 0,901224 & 47,4441 & 1,086282 \\
\hline
\end{tabular}

Segundo Método - Pares tensão / deformação obtidos nos ensaios de cisalhamento puro da primeira réplica da condição irradiada com 250 kGy. 


\begin{tabular}{|c|c|c|c|c|c|c|c|}
\hline $\begin{array}{c}\text { Extensão } \\
(\%)\end{array}$ & $\begin{array}{c}\text { Tensão } \\
\text { MPa }\end{array}$ & $\begin{array}{c}\text { Extensão } \\
\text { (\%) }\end{array}$ & $\begin{array}{c}\text { Tensão } \\
\text { MPa }\end{array}$ & $\begin{array}{c}\text { Extensão } \\
(\%)\end{array}$ & $\begin{array}{c}\text { Tensão } \\
\text { MPa }\end{array}$ & $\begin{array}{c}\text { Extensão } \\
\text { (\%) }\end{array}$ & $\begin{array}{c}\text { Tensão } \\
\text { MPa }\end{array}$ \\
\hline 0,0057 & 0,003627 & 15,5103 & 0,578224 & 24,0590 & 0,756106 & 32,8245 & 0,925984 \\
\hline 0,1639 & 0,025386 & 15,7584 & 0,583599 & 24,2510 & 0,759420 & 33,1100 & 0,931734 \\
\hline 1,0007 & 0,094475 & 16,0899 & 0,590416 & 24,4520 & 0,763796 & 33,3487 & 0,936738 \\
\hline 1,7452 & 0,140368 & 16,3731 & 0,596605 & 25,0021 & 0,774362 & 33,6667 & 0,942863 \\
\hline 1,9837 & 0,154248 & 16,7163 & 0,603482 & 25,2882 & 0,779677 & 34,6874 & 0,964561 \\
\hline 2,2811 & 0,170504 & 16,9110 & 0,608423 & 25,5530 & 0,784742 & 34,9685 & 0,970311 \\
\hline 2,6238 & 0,187823 & 17,1733 & 0,614051 & 25,7954 & 0,789993 & 35,2167 & 0,975566 \\
\hline 3,0414 & 0,208269 & 17,3620 & 0,617365 & 26,0293 & 0,794933 & 35,4451 & 0,980442 \\
\hline 3,2756 & 0,218835 & 17,6217 & 0,622805 & 26,2587 & 0,798936 & 35,6992 & 0,985318 \\
\hline 3,6721 & 0,236780 & 18,4649 & 0,640747 & 26,5106 & 0,803748 & 35,8970 & 0,989634 \\
\hline 4,6778 & 0,278108 & 18,6509 & 0,644814 & 26,8010 & 0,809562 & 36,0586 & 0,992820 \\
\hline 5,2271 & 0,299179 & 18,8187 & 0,647814 & 28,4355 & 0,841762 & 36,4313 & 1,000639 \\
\hline 5,9499 & 0,325877 & 19,2064 & 0,656442 & 28,5750 & 0,844202 & 36,5812 & 1,004512 \\
\hline 6,2090 & 0,334442 & 19,4769 & 0,662631 & 28,6731 & 0,846388 & 37,2606 & 1,018770 \\
\hline 6,5208 & 0,345009 & 19,6540 & 0,665132 & 28,8810 & 0,849766 & 37,5968 & 1,026022 \\
\hline 6,8421 & 0,355138 & 19,8319 & 0,669073 & 29,0340 & 0,853394 & 38,1827 & 1,039338 \\
\hline 7,6633 & 0,381461 & 20,1867 & 0,676700 & 29,2304 & 0,857143 & 38,3494 & 1,042905 \\
\hline 8,4205 & 0,404469 & 20,3450 & 0,679700 & 29,5282 & 0,862458 & 38,5167 & 1,046279 \\
\hline 8,6496 & 0,410158 & 20,5827 & 0,685079 & 29,7832 & 0,867024 & 39,2210 & 1,063162 \\
\hline 8,8410 & 0,415912 & 20,8268 & 0,690204 & 30,1429 & 0,874151 & 39,4132 & 1,067100 \\
\hline 9,1625 & 0,424291 & 21,0538 & 0,694581 & 30,3687 & 0,879091 & 39,6612 & 1,073039 \\
\hline 9,4761 & 0,433045 & 21,2468 & 0,698270 & 30,7092 & 0,884905 & 40,7514 & 1,099300 \\
\hline 9,8516 & 0,443920 & 21,4574 & 0,702771 & 30,8705 & 0,888843 & 41,3947 & 1,116493 \\
\hline 10,1450 & 0,451112 & 21,6939 & 0,707901 & 31,1471 & 0,893719 & 41,8786 & 1,129060 \\
\hline 10,4026 & 0,457864 & 22,5499 & 0,725155 & 31,3174 & 0,896973 & 42,8317 & 1,156448 \\
\hline 12,0683 & 0,498882 & 22,7347 & 0,729282 & 31,5576 & 0,901036 & 43,0346 & 1,163075 \\
\hline 12,2418 & 0,503758 & 23,0723 & 0,736098 & 31,7890 & 0,905726 & 43,1834 & 1,167762 \\
\hline 13,0114 & 0,521704 & 23,2966 & 0,740974 & 32,0381 & 0,910602 & 43,3302 & 1,172264 \\
\hline 13,2112 & 0,526205 & 23,5476 & 0,745975 & 32,2331 & 0,914915 & 44,0600 & 1,202466 \\
\hline 14,2071 & 0,549587 & 23,8944 & 0,753042 & 32,3888 & 0,917041 & 43,7135 & 1,206215 \\
\hline
\end{tabular}

Segundo Método - Pares tensão / deformação obtidos nos ensaios de cisalhamento puro da segunda réplica da condição irradiada com 250 kGy. 


\begin{tabular}{|c|c|c|c|c|c|c|c|}
\hline $\begin{array}{c}\text { Extensão } \\
(\%)\end{array}$ & $\begin{array}{c}\text { Tensão } \\
\text { MPa }\end{array}$ & $\begin{array}{c}\text { Extensão } \\
(\%)\end{array}$ & $\begin{array}{c}\text { Tensão } \\
\text { MPa }\end{array}$ & $\begin{array}{c}\text { Extensão } \\
(\%)\end{array}$ & $\begin{array}{c}\text { Tensão } \\
\text { MPa }\end{array}$ & $\begin{array}{c}\text { Extensão } \\
\text { (\%) }\end{array}$ & $\begin{array}{c}\text { Tensão } \\
\text { MPa }\end{array}$ \\
\hline 0,1360 & 0,017523 & 14,5526 & 0,469681 & 26,8883 & 0,713004 & 44,8554 & 1,089193 \\
\hline 0,6689 & 0,045074 & 14,9395 & 0,477978 & 27,2022 & 0,718762 & 45,2164 & 1,095943 \\
\hline 1,1530 & 0,067921 & 15,2805 & 0,485905 & 27,3974 & 0,722848 & 45,4059 & 1,099843 \\
\hline 1,5983 & 0,086495 & 15,6530 & 0,493891 & 27,7022 & 0,728359 & 45,8437 & 1,108324 \\
\hline 2,3998 & 0,118009 & 16,1467 & 0,504106 & 28,5279 & 0,744455 & 46,6625 & 1,122813 \\
\hline 2,7441 & 0,131507 & 16,6521 & 0,515187 & 28,8783 & 0,751205 & 47,2054 & 1,133216 \\
\hline 3,2599 & 0,150576 & 16,9818 & 0,521813 & 29,4727 & 0,762410 & 47,7645 & 1,143618 \\
\hline 3,5410 & 0,161164 & 17,3140 & 0,528934 & 30,2095 & 0,776963 & 48,5309 & 1,157051 \\
\hline 4,2113 & 0,184443 & 17,6327 & 0,535310 & 30,6179 & 0,785631 & 48,8410 & 1,162378 \\
\hline 4,5285 & 0,195092 & 18,1058 & 0,545465 & 31,1886 & 0,797146 & 49,5672 & 1,175317 \\
\hline 5,0030 & 0,211624 & 18,3707 & 0,551036 & 31,7614 & 0,808601 & 50,2362 & 1,187824 \\
\hline 5,4177 & 0,224564 & 18,9641 & 0,562738 & 32,4567 & 0,822963 & 50,4743 & 1,192529 \\
\hline 5,9841 & 0,243324 & 19,4345 & 0,572025 & 33,1675 & 0,838629 & 51,3610 & 1,208008 \\
\hline 6,3990 & 0,256140 & 19,7667 & 0,578464 & 33,6496 & 0,850515 & 51,5552 & 1,211971 \\
\hline 6,9015 & 0,271928 & 20,2007 & 0,587503 & 33,9686 & 0,862775 & 51,8899 & 1,218594 \\
\hline 7,2285 & 0,281401 & 20,6269 & 0,595306 & 34,3944 & 0,875901 & 52,5290 & 1,229184 \\
\hline 7,5575 & 0,291864 & 21,1858 & 0,605832 & 35,0676 & 0,893050 & 52,7650 & 1,234012 \\
\hline 7,9538 & 0,303195 & 21,5652 & 0,613260 & 35,3478 & 0,898748 & 53,1500 & 1,240141 \\
\hline 8,3074 & 0,313348 & 21,8799 & 0,619389 & 35,6943 & 0,906982 & 53,3393 & 1,243609 \\
\hline 8,5781 & 0,320840 & 22,1713 & 0,624652 & 37,4217 & 0,944130 & 53,9745 & 1,254630 \\
\hline 9,2149 & 0,338176 & 22,4825 & 0,630533 & 38,0614 & 0,956698 & 54,3799 & 1,261253 \\
\hline 9,6861 & 0,350497 & 22,7343 & 0,634991 & 38,6866 & 0,970011 & 54,9574 & 1,270356 \\
\hline 10,1013 & 0,361703 & 23,6131 & 0,651649 & 39,3707 & 0,983879 & 55,7076 & 1,280013 \\
\hline 10,5185 & 0,372600 & 23,9243 & 0,657406 & 39,9876 & 0,996386 & 55,9623 & 1,283111 \\
\hline 11,3261 & 0,393154 & 24,1555 & 0,661740 & 40,6536 & 1,009202 & 56,1722 & 1,285276 \\
\hline 11,5681 & 0,399223 & 24,3702 & 0,665951 & 41,2649 & 1,021582 & 56,4518 & 1,288246 \\
\hline 11,8899 & 0,407644 & 25,1339 & 0,680560 & 41,9182 & 1,033655 & 56,6588 & 1,289175 \\
\hline 12,3853 & 0,419406 & 25,3853 & 0,684647 & 42,5703 & 1,046163 & 56,6849 & 1,289052 \\
\hline 13,5035 & 0,445905 & 26,1669 & 0,698949 & 43,8485 & 1,070002 & 56,6961 & 1,288928 \\
\hline 13,7237 & 0,451232 & 26,8711 & 0,712757 & 44,5593 & 1,083312 & 56,7106 & 1,288744 \\
\hline
\end{tabular}

Segundo Método - Pares tensão / deformação obtidos nos ensaios de cisalhamento puro da terceira réplica da condição irradiada com 250 kGy. 


\section{APÊNDICE B - RESULTADOS EXPERIMENTAIS DE CSR}

\begin{tabular}{ccccccccccc}
\hline $\mathbf{t}$ min & $\mathbf{F}_{\mathbf{1}}(\mathbf{N})$ & $\mathbf{F}_{\mathbf{1}}(\mathbf{N})$ & $\mathbf{F}_{\mathbf{1}}(\mathbf{N})$ & $\mathbf{F}_{1 \text { média }}$ & $\mathbf{S}$ & $\mathbf{F}_{\mathbf{0}} / \mathbf{F}_{\mathbf{1}}$ & $\mathbf{F}_{\mathbf{0}} / \mathbf{F}_{\mathbf{1}}$ & $\mathbf{F}_{\mathbf{0}} / \mathbf{F}_{\mathbf{1}}$ & $\mathbf{F}_{\mathbf{0}} / \mathbf{F}_{1 \text { média }}$ & $\mathbf{S}$ \\
\hline 500 & 24,99 & 24,38 & 21,96 & 23,78 & 1,1332 & 0,53 & 0,50 & 0,49 & 0,51 & 0,0147 \\
1000 & 24,4 & 23,8 & 21,81 & 23,34 & 0,9587 & 0,52 & 0,49 & 0,49 & 0,50 & 0,0122 \\
1500 & 23,95 & 23,5 & 20,35 & 22,60 & 1,3870 & 0,51 & 0,48 & 0,45 & 0,48 & 0,0212 \\
2000 & 23,51 & 23,21 & 20,64 & 22,45 & 1,1155 & 0,50 & 0,47 & 0,46 & 0,48 & 0,0147 \\
2500 & 23,66 & 22,77 & 20,64 & 22,36 & 1,0973 & 0,51 & 0,46 & 0,46 & 0,48 & 0,0204 \\
3000 & 23,22 & 22,92 & 18,3 & 21,48 & 1,9502 & 0,50 & 0,47 & 0,41 & 0,46 & 0,0324 \\
3500 & 22,77 & 22,62 & 18,01 & 21,13 & 1,9134 & 0,49 & 0,46 & 0,40 & 0,45 & 0,0324 \\
4000 & 23,22 & 22,48 & 17,71 & 21,14 & 2,1146 & 0,50 & 0,46 & 0,40 & 0,45 & 0,0356 \\
5000 & 22,48 & 22,03 & 17,28 & 20,60 & 2,0373 & 0,48 & 0,45 & 0,39 & 0,44 & 0,0324 \\
\hline
\end{tabular}

Resultados experimentais de relaxação por compressão na condição $1,23^{\circ} \mathrm{C}, 10 \%$ e 0 kGy.

\begin{tabular}{ccccccccccc}
\hline $\mathbf{t ~ m i n}$ & $\mathbf{F}_{\mathbf{1}} \mathbf{( N )}$ & $\mathbf{F}_{\mathbf{1}} \mathbf{( N )}$ & $\mathbf{F}_{\mathbf{1}}(\mathbf{N})$ & $\mathbf{F}_{1 \text { média }}$ & $\mathbf{S}$ & $\mathbf{F}_{\mathbf{0}} / \mathbf{F}_{\mathbf{1}}$ & $\mathbf{F}_{\mathbf{0}} / \mathbf{F}_{\mathbf{1}}$ & $\mathbf{F}_{\mathbf{0}} / \mathbf{F}_{\mathbf{1}}$ & $\mathbf{F}_{\mathbf{0}} / \mathbf{F}_{1 \text { média }}$ & $\mathbf{S}$ \\
\hline 500 & 26,79 & 28,69 & 31,58 & 29,02 & 1,7055 & 0,51 & 0,52 & 0,54 & 0,52 & 0,0108 \\
1000 & 26,79 & 28,1 & 30,55 & 28,48 & 1,3496 & 0,51 & 0,51 & 0,52 & 0,51 & 0,0041 \\
1500 & 26,79 & 28,1 & 30,11 & 28,33 & 1,1825 & 0,51 & 0,51 & 0,51 & 0,51 & 0,0000 \\
2000 & 25,47 & 27,65 & 29,82 & 27,65 & 1,5380 & 0,48 & 0,50 & 0,51 & 0,50 & 0,0108 \\
2500 & 26,21 & 27,36 & 28,64 & 27,40 & 0,8595 & 0,50 & 0,49 & 0,49 & 0,49 & 0,0041 \\
3000 & 25,47 & 27,36 & 28,94 & 27,26 & 1,2285 & 0,48 & 0,49 & 0,49 & 0,49 & 0,0041 \\
3500 & 25,18 & 27,36 & 28,35 & 26,96 & 1,1468 & 0,48 & 0,49 & 0,48 & 0,48 & 0,0041 \\
4000 & 26,06 & 26,76 & 28,2 & 27,01 & 0,7715 & 0,49 & 0,48 & 0,48 & 0,48 & 0,0041 \\
5000 & 25,03 & 25,88 & 28,06 & 26,32 & 1,1051 & 0,47 & 0,47 & 0,48 & 0,47 & 0,0041
\end{tabular}

Resultados experimentais de relaxação por compressão na condição $2,23^{\circ} \mathrm{C}, 10 \%$ e 250 kGy. 


\begin{tabular}{ccccccccccc}
\hline $\mathbf{t} \mathbf{m i n}$ & $\mathbf{F}_{\mathbf{1}}(\mathbf{N})$ & $\mathbf{F}_{\mathbf{1}}(\mathbf{N})$ & $\mathbf{F}_{\mathbf{1}}(\mathbf{N})$ & $\mathbf{F}_{1 \text { média }}$ & $\mathbf{S}$ & $\mathbf{F}_{\mathbf{0}} / \mathbf{F}_{\mathbf{1}}$ & $\mathbf{F}_{\mathbf{0}} / \mathbf{F}_{\mathbf{1}}$ & $\mathbf{F}_{\mathbf{0}} / \mathbf{F}_{\mathbf{1}}$ & $\mathbf{F}_{\mathbf{0}} / \mathbf{F}_{1 \text { média }}$ & $\mathbf{S}$ \\
\hline 500 & 31,44 & 32,5 & 34,75 & 32,90 & 1,1952 & 0,50 & 0,51 & 0,55 & 0,52 & 0,0187 \\
1000 & 30,55 & 31,77 & 33,86 & 32,06 & 1,1837 & 0,48 & 0,50 & 0,53 & 0,50 & 0,0178 \\
1500 & 30,11 & 31,62 & 33,27 & 31,67 & 1,1176 & 0,48 & 0,49 & 0,52 & 0,50 & 0,0147 \\
2000 & 29,53 & 30,74 & 32,53 & 30,93 & 1,0672 & 0,47 & 0,48 & 0,51 & 0,49 & 0,0147 \\
2500 & 29,82 & 30,3 & 31,79 & 30,64 & 0,7264 & 0,47 & 0,47 & 0,50 & 0,48 & 0,0122 \\
3000 & 28,94 & 31,18 & 31,79 & 30,64 & 1,0611 & 0,46 & 0,49 & 0,50 & 0,48 & 0,0147 \\
3500 & 28,79 & 30,01 & 31,35 & 30,05 & 0,9054 & 0,45 & 0,47 & 0,49 & 0,47 & 0,0141 \\
4000 & 29,09 & 29,72 & 31,05 & 29,95 & 0,7075 & 0,46 & 0,46 & 0,49 & 0,47 & 0,0122 \\
5000 & 28,35 & 29,28 & 30,61 & 29,41 & 0,8032 & 0,45 & 0,46 & 0,48 & 0,46 & 0,0108 \\
\hline
\end{tabular}

Resultados experimentais de relaxação por compressão na condição $3,23^{\circ} \mathrm{C}, 15 \%$ e 0 kGy.

\begin{tabular}{ccccccccccc}
\hline $\mathbf{t} \mathbf{m i n}$ & $\mathbf{F}_{\mathbf{1}}(\mathbf{N})$ & $\mathbf{F}_{\mathbf{1}}(\mathbf{N})$ & $\mathbf{F}_{\mathbf{1}}(\mathbf{N})$ & $\mathbf{F}_{1 \text { média }}$ & $\mathbf{S}$ & $\mathbf{F}_{0} / \mathbf{F}_{\mathbf{1}}$ & $\mathbf{F}_{\mathbf{0}} / \mathbf{F}_{1}$ & $\mathbf{F}_{\mathbf{0}} / \mathbf{F}_{\mathbf{1}}$ & $\mathbf{F}_{0} / \mathbf{F}_{1 \text { média }}$ & $\mathbf{S}$ \\
\hline 500 & 40,66 & 43,04 & 44,21 & 42,64 & 1,2792 & 0,48 & 0,51 & 0,54 & 0,51 & 0,0212 \\
1000 & 39,78 & 42,31 & 43,48 & 41,86 & 1,3373 & 0,47 & 0,50 & 0,53 & 0,50 & 0,0212 \\
1500 & 39,33 & 41,87 & 41,58 & 40,93 & 0,9831 & 0,47 & 0,49 & 0,51 & 0,49 & 0,0141 \\
2000 & 38,89 & 41,28 & 41,58 & 40,58 & 1,0424 & 0,46 & 0,49 & 0,51 & 0,49 & 0,0178 \\
2500 & 38,59 & 40,98 & 39,82 & 39,80 & 0,8451 & 0,46 & 0,48 & 0,48 & 0,47 & 0,0082 \\
3000 & 38,45 & 40,54 & 40,7 & 39,90 & 0,8877 & 0,46 & 0,48 & 0,49 & 0,48 & 0,0108 \\
3500 & 38,45 & 41,13 & 39,97 & 39,85 & 0,9504 & 0,46 & 0,48 & 0,49 & 0,48 & 0,0108 \\
4000 & 38,3 & 40,4 & 39,53 & 39,41 & 0,7461 & 0,46 & 0,48 & 0,48 & 0,47 & 0,0082 \\
5000 & 38 & 39,52 & 39,82 & 39,11 & 0,6900 & 0,45 & 0,47 & 0,48 & 0,47 & 0,0108
\end{tabular}

Resultados experimentais de relaxação por compressão na condição $4,23{ }^{\circ} \mathrm{C}, 15 \%$ e 250 kGy.

\begin{tabular}{ccccccccccc}
\hline $\mathbf{t}$ min & $\mathbf{F}_{\mathbf{1}}(\mathbf{N})$ & $\mathbf{F}_{\mathbf{1}}(\mathbf{N})$ & $\mathbf{F}_{\mathbf{1}}(\mathbf{N})$ & $\mathbf{F}_{1 \text { média }}$ & $\mathbf{S}$ & $\mathbf{F}_{\mathbf{0}} / \mathbf{F}_{\mathbf{1}}$ & $\mathbf{F}_{\mathbf{0}} / \mathbf{F}_{\mathbf{1}}$ & $\mathbf{F}_{\mathbf{0}} / \mathbf{F}_{\mathbf{1}}$ & $\mathbf{F}_{\mathbf{0}} / \mathbf{F}_{1 \text { média }}$ & $\mathbf{S}$ \\
\hline 500 & 23,51 & 28,64 & 26,5 & 26,22 & 1,8220 & 0,74 & 0,77 & 0,76 & 0,76 & 0,0108 \\
1000 & 23,22 & 28,2 & 25,91 & 25,78 & 1,7626 & 0,73 & 0,76 & 0,74 & 0,74 & 0,0108 \\
1500 & 22,92 & 27,62 & 26,06 & 25,53 & 1,6927 & 0,72 & 0,74 & 0,74 & 0,73 & 0,0082 \\
2000 & 22,48 & 27,18 & 25,33 & 25,00 & 1,6742 & 0,71 & 0,73 & 0,72 & 0,72 & 0,0071 \\
2500 & 22,33 & 27,03 & 25,33 & 24,90 & 1,6828 & 0,71 & 0,72 & 0,72 & 0,72 & 0,0041 \\
3000 & 22,03 & 26,88 & 25,03 & 24,65 & 1,7307 & 0,70 & 0,72 & 0,72 & 0,71 & 0,0082 \\
3500 & 22,03 & 26,59 & 25,03 & 24,55 & 1,6388 & 0,70 & 0,71 & 0,72 & 0,71 & 0,0071 \\
4000 & 22,03 & 27,03 & 25,18 & 24,75 & 1,7876 & 0,70 & 0,72 & 0,72 & 0,71 & 0,0082 \\
5000 & 21,74 & 26 & 24,89 & 24,21 & 1,5626 & 0,69 & 0,70 & 0,71 & 0,70 & 0,0071
\end{tabular}

Resultados experimentais de relaxação por compressão na condição $5,90^{\circ} \mathrm{C}, 10 \%$ e 0 kGy. 


\begin{tabular}{ccccccccccc}
\hline $\mathbf{t}$ min & $\mathbf{F}_{\mathbf{1}}(\mathbf{N})$ & $\mathbf{F}_{\mathbf{1}}(\mathbf{N})$ & $\mathbf{F}_{\mathbf{1}}(\mathbf{N})$ & $\mathbf{F}_{1 \text { média }}$ & $\mathbf{S}$ & $\mathbf{F}_{\mathbf{0}} / \mathbf{F}_{\mathbf{1}}$ & $\mathbf{F}_{\mathbf{0}} / \mathbf{F}_{\mathbf{1}}$ & $\mathbf{F}_{\mathbf{0}} / \mathbf{F}_{\mathbf{1}}$ & $\mathbf{F}_{\mathbf{0}} / \mathbf{F}_{1 \text { média }}$ & $\mathbf{S}$ \\
\hline 500 & 27,96 & 29,28 & 32,9 & 30,05 & 1,8086 & 0,74 & 0,76 & 0,76 & 0,75 & 0,0082 \\
1000 & 27,23 & 28,24 & 32,32 & 29,26 & 1,9056 & 0,72 & 0,73 & 0,74 & 0,73 & 0,0071 \\
1500 & 26,64 & 27,65 & 31,58 & 28,62 & 1,8455 & 0,70 & 0,71 & 0,73 & 0,71 & 0,0108 \\
2000 & 26,06 & 27,5 & 31 & 28,19 & 1,7965 & 0,69 & 0,71 & 0,71 & 0,70 & 0,0082 \\
2500 & 25,91 & 27,36 & 31,14 & 28,14 & 1,9093 & 0,68 & 0,71 & 0,72 & 0,70 & 0,0147 \\
3000 & 25,62 & 27,06 & 30,55 & 27,74 & 1,7925 & 0,68 & 0,70 & 0,70 & 0,69 & 0,0082 \\
3500 & 25,18 & 27,06 & 30,85 & 27,70 & 2,0422 & 0,66 & 0,70 & 0,71 & 0,69 & 0,0187 \\
4000 & 25,47 & 26,76 & 30,55 & 27,59 & 1,8671 & 0,67 & 0,69 & 0,70 & 0,69 & 0,0108 \\
5000 & 25,03 & 26,76 & 30,11 & 27,30 & 1,8262 & 0,66 & 0,69 & 0,69 & 0,68 & 0,0122 \\
\hline
\end{tabular}

Resultados experimentais de relaxação por compressão na condição $6,90^{\circ} \mathrm{C}, 10 \%$ e 250 kGy.

\begin{tabular}{ccccccccccc}
\hline $\mathbf{t ~ m i n}$ & $\mathbf{F}_{\mathbf{1}} \mathbf{( N )}$ & $\mathbf{F}_{\mathbf{1}} \mathbf{( N )}$ & $\mathbf{F}_{\mathbf{1}}(\mathbf{N})$ & $\mathbf{F}_{1 \text { média }}$ & $\mathbf{S}$ & $\mathbf{F}_{\mathbf{0}} / \mathbf{F}_{\mathbf{1}}$ & $\mathbf{F}_{\mathbf{0}} / \mathbf{F}_{\mathbf{1}}$ & $\mathbf{F}_{\mathbf{0}} / \mathbf{F}_{\mathbf{1}}$ & $\mathbf{F}_{\mathbf{0}} / \mathbf{F}_{\mathbf{1 m e ́ d i a ~}}$ & $\mathbf{S}$ \\
\hline 500 & 34,52 & 31,92 & 36,08 & 34,17 & 1,4860 & 0,79 & 0,77 & 0,76 & 0,77 & 0,0108 \\
1000 & 33,93 & 31,33 & 35,34 & 33,53 & 1,4384 & 0,77 & 0,75 & 0,75 & 0,76 & 0,0082 \\
1500 & 33,49 & 30,89 & 34,9 & 33,09 & 1,4384 & 0,76 & 0,74 & 0,74 & 0,75 & 0,0082 \\
2000 & 33,49 & 30,6 & 34,6 & 32,90 & 1,4601 & 0,76 & 0,73 & 0,73 & 0,74 & 0,0122 \\
2500 & 32,76 & 30,6 & 34,31 & 32,56 & 1,3176 & 0,75 & 0,73 & 0,73 & 0,74 & 0,0082 \\
3000 & 32,61 & 30,16 & 34,31 & 32,36 & 1,4752 & 0,74 & 0,72 & 0,73 & 0,73 & 0,0071 \\
3500 & 32,46 & 30,01 & 34,16 & 32,21 & 1,4752 & 0,74 & 0,72 & 0,72 & 0,73 & 0,0082 \\
4000 & 32,46 & 29,87 & 34,01 & 32,11 & 1,4790 & 0,74 & 0,72 & 0,72 & 0,73 & 0,0082 \\
5000 & 32,17 & 29,57 & 33,71 & 31,82 & 1,4796 & 0,73 & 0,71 & 0,71 & 0,72 & 0,0082
\end{tabular}

Resultados experimentais de relaxação por compressão na condição $7,90^{\circ} \mathrm{C}, 15 \%$ e 0 kGy.

\begin{tabular}{ccccccccccc}
\hline $\mathbf{t}$ min & $\mathbf{F}_{\mathbf{1}}(\mathbf{N})$ & $\mathbf{F}_{\mathbf{1}}(\mathbf{N})$ & $\mathbf{F}_{\mathbf{1}}(\mathbf{N})$ & $\mathbf{F}_{1 \text { média }}$ & $\mathbf{S}$ & $\mathbf{F}_{\mathbf{0}} / \mathbf{F}_{\mathbf{1}}$ & $\mathbf{F}_{\mathbf{0}} / \mathbf{F}_{1}$ & $\mathbf{F}_{\mathbf{0}} / \mathbf{F}_{\mathbf{1}}$ & $\mathbf{F}_{\mathbf{0}} / \mathbf{F}_{1 \text { média }}$ & $\mathbf{S}$ \\
\hline 500 & 43,77 & 44,22 & 45,38 & 44,46 & 0,5874 & 0,76 & 0,77 & 0,78 & 0,77 & 0,0071 \\
1000 & 42 & 42,75 & 44,51 & 43,09 & 0,9111 & 0,73 & 0,75 & 0,77 & 0,75 & 0,0141 \\
1500 & 41,55 & 42,31 & 43,63 & 42,50 & 0,7442 & 0,73 & 0,74 & 0,75 & 0,74 & 0,0071 \\
2000 & 40,81 & 41,72 & 42,9 & 41,81 & 0,7410 & 0,71 & 0,73 & 0,74 & 0,73 & 0,0108 \\
2500 & 40,81 & 41,42 & 42,75 & 41,66 & 0,7015 & 0,71 & 0,72 & 0,74 & 0,72 & 0,0108 \\
3000 & 40,66 & 41,13 & 42,46 & 41,42 & 0,6602 & 0,71 & 0,72 & 0,73 & 0,72 & 0,0071 \\
3500 & 40,07 & 41,13 & 42,6 & 41,27 & 0,8984 & 0,70 & 0,72 & 0,73 & 0,72 & 0,0108 \\
4000 & 40,07 & 41,13 & 42,6 & 41,27 & 0,8984 & 0,70 & 0,72 & 0,73 & 0,72 & 0,0108 \\
5000 & 39,93 & 40,84 & 41,58 & 40,78 & 0,5844 & 0,70 & 0,71 & 0,72 & 0,71 & 0,0071
\end{tabular}

Resultados experimentais de relaxação por compressão na condição $8,90{ }^{\circ} \mathrm{C}, 15 \%$ e 250 kGy. 